\title{
Production and function of endothelial nitric oxide in the arterial and venous system : emphasis on antithromboembolic activity in vivo
}

Citation for published version (APA):

Broeders, M. A. W. (2002). Production and function of endothelial nitric oxide in the arterial and venous system : emphasis on antithromboembolic activity in vivo. [Doctoral Thesis, Maastricht University]. Universiteit Maastricht. https://doi.org/10.26481/dis.20021205mb

Document status and date:

Published: 01/01/2002

DOI:

10.26481/dis.20021205mb

Document Version:

Publisher's PDF, also known as Version of record

Please check the document version of this publication:

- A submitted manuscript is the version of the article upon submission and before peer-review. There can be important differences between the submitted version and the official published version of record.

People interested in the research are advised to contact the author for the final version of the publication, or visit the DOI to the publisher's website.

- The final author version and the galley proof are versions of the publication after peer review.

- The final published version features the final layout of the paper including the volume, issue and page numbers.

Link to publication

\footnotetext{
General rights rights.

- You may freely distribute the URL identifying the publication in the public portal. please follow below link for the End User Agreement:

www.umlib.nl/taverne-license

Take down policy

If you believe that this document breaches copyright please contact us at:

repository@maastrichtuniversity.nl

providing details and we will investigate your claim.
}

Copyright and moral rights for the publications made accessible in the public portal are retained by the authors and/or other copyright owners and it is a condition of accessing publications that users recognise and abide by the legal requirements associated with these

- Users may download and print one copy of any publication from the public portal for the purpose of private study or research.

- You may not further distribute the material or use it for any profit-making activity or commercial gain

If the publication is distributed under the terms of Article 25fa of the Dutch Copyright Act, indicated by the "Taverne" license above, 
Cover: example of typical changes in cytosolic free $\mathrm{Ca}^{2+}$ concentration $\left(\left[\mathrm{Ca}^{2+}\right]_{\mathrm{i}}\right)$ in mouse thoracic aorta endothelium as depicted by digital fluorescent microscopy using fluorescent $\mathrm{Ca}^{2+}$-probe fura $2-A M ; 340 / 380 \mathrm{~nm}$ fura 2 ratio images are presented. The images represent an area of $\sim 200 \times 200 \mu \mathrm{m}$, in which individual endothelial cells can be identified. Every color corresponds with a certain $\left[\mathrm{Ca}^{2+}\right]_{i}$; blue indicates low $\left[\mathrm{Ca}^{2+}\right]_{i}$, red indicates high $\left[\mathrm{Ca}^{2+}\right]_{i}$. The image on the inside of the cover illustrates $\left[\mathrm{Ca}^{2+}\right]_{i}$ at baseline. All colours of the spectrum can be identified in the image at the front of the cover, illustrating the typical heterogeneity in response between single endothelial cells within the same vascular segment and shows the effect of metabolized nebivolol on $\left[\mathrm{Ca}^{2+}\right]_{i}$ (from Chapter 7 ).

Ontwerp en vormgeving: Ad Broeders Grafische Vormgeving BV, Middelbeers 


\title{
Production and Function of Endothelial Nitric Oxide in the Arterial and Venous System
}

\author{
Emphasis on Antithromboembolic Activity in Vivo
}

\section{PROEFSCIIRIFT}

ter verkrijging van de graad van doetor

aan de Universiteit Maastricht,

op gezag van de Rector Magnificus, Prof. dr. A.C. Nieuwenhuijzen Kruseman,

volgens het besluit van het College van Decanen,

in het openbaar te verdedigen

op donderdag 5 december 2002 om 14.00 uur

door

Martinus Arnoldus Wilhelmus Broeders

geboren op 14 september 1970 te Nieuw-Ginneken 


\section{Promotores:}

Prof. dr. R.S. Reneman

Prof. dr. G.J. Tangelder (Vrije Universiteit, Amsterdam)

\section{Co-promotor:}

Dr. Mirjam G.A. oude Egbrink

\section{Beoordelingscommissie:}

Prof. dr. M.J.A.P. Daemen (voorzitter)

Dr. P.A. Doevendans

Prof. dr. H.C. Hemker

Prof. dr. G. Hornstra

Prof. dr. V.W.M. van Hinsbergh (Vrije Universiteit, Amsterdam)

Financial support by the Netherlands Heart Foundation for the publication of this thesis is gratefully acknowledged.

Additionally, gratitude is expressed to Astra Zeneca BV, Menarini Farma Nederland, Pfizer BV, Roche Nederland BV, Servier Nederland BV and Tramedico Nederland BV for their financial support. 


\section{Contents}

\section{Chapter 1}

General introduction 1

This thesis , 3

- Function of nitric oxide 3

- Production of nitric oxide 4

\section{Chapter 2}

Survey of the literature 11

Part I: Interaction between blood platelets and the vessel wall $\quad 12$

Factors influencing platelet-vessel wall interactions $\quad 14$

- Prothrombotic factors 14

- Antithrombotic factors 16

Part II: Endothelium-derived antithrombotic factors: nitric oxide and eicosanoids $\quad 18$

$\begin{array}{ll}\text { 1. Nitric oxide: production and function } & 18\end{array}$

- Nitric oxide synthesis $\quad 18$

- Biochemistry 18

- Nitric oxide synthase isoforms $\quad 18$

- Biological functions of nitric oxide in the cardiovascular system 20

- Role of nitric oxide in platelet function 21

- Mechanisms of nitric oxide synthase activation $\quad 23$

- Shear stress-induced nitric oxide production 24

- Agonist-induced nitric oxide production 25

2. Eicosanoids: production and function $\quad 26$

- Eicosanoid synthesis $\quad 26$

- Biological functions of thromboxane $A_{2}$ and prostaglandin $I_{2}$ in the cardiovascular system focusing on platelet function

3. Nitric oxide/eicosanoid synergistic interactions 29

4. Heterogeneity in anti- and prothrombotic properties of the vessel wall 31

- Heterogeneity in the L-arginine/nitric oxide pathway 31

- Heterogeneity in the arachidonic acid/prostaglandin pathway 32

- Heterogeneity in nitric oxide/eicosanoid synergistic interactions? 33

- Heterogeneity in prothrombotic properties of the vessel wall 33 
Part III: Endothelial dysfunction and the role of nitric oxide and eicosanoids in hypercholesterolemia, atherosclerosis and thrombosis

\section{Chapter 3}

Endogenous nitric oxide protects against thromboembolism in venules

but not in arterioles

\section{Chapter 4}

Endogenous nitric oxide and prostaglandins synergistically counteract

thrombeembolism in arterioles but not in venules

\section{Chapter 5}

Hypercholesterolemia enhances thromboembolism in arterioles but not in venules; complete reversal by $\mathrm{L}$-arginine

\section{Chapter 6}

The human internal mammary artery releases more nitric oxide in response to vascular endothelial growth factor than the human saphenous vein

\section{Chapter 7}

Nebivolol: a third-generation $\beta$-blocker that augments vascular nitric oxide release. Endothelial $\beta_{2}$-adrenergic receptor-mediated nitric oxide production

\section{Chapter 8}

General discussion

- Function of nitric oxide

- Production of nitric oxide

- Heterogeneity in production and function of nitric oxide

Summary 


Chapter 1

General Introduction 
In the second half of the 19th century nitrate therapy (amylnitrite) was found to be beneficial in cases of angina pectoris. ${ }^{1}$ Since then, the efficacy of organic nitrates (eg, nitroglycerine, nitroprusside, isosorbide-5-mononitrate and isosorbidedinitrate) for the chronic treatment of ischemic heart disease and congestive heart failure has been well established. ${ }^{2}$ The biochemical mechanism of this therapeutic effect was discovered only by the end of the 20th century. Research groups of Schultz and Murad showed that the bioactivity of this group of drugs is based on the release of a potent small molecule: nitric oxide. ${ }^{3,4}$ Nitric oxide is an inorganic free radical gas, of formula - $\mathrm{N}=\mathrm{O}$ (abbreviated as $\mathrm{NO}$ ). Important in this respect was the finding by Furchgott and Zawadzki in 1980 that vascular endothelium is mandatory for the vasodilator action of acetylcholine in isolated arterial strips or rings. ${ }^{5}$ Removal of the endothelium prevented the relaxant effect of acetylcholine and even led to a contraction. Thus, stimulation of the endothelial cells caused the release of a substance, which Furchgott named "endothelium-derived relaxing factor" (EDRF). This factor was highly unstable with a half-life of seconds in buffer solution. Its action was destroyed by oxyhemoglobin and preserved by superoxide dismutase, showing that superoxide anions (ie, $\mathrm{O}_{2}{ }^{-}$) could inactivate it. In 1987 EDRF was shown to be NO, as independently pointed out by Moncada and Ignarro. ${ }^{6,7}$ These fundamental discoveries in NO research have led to the awarding of the Nobel Price for Physiology and Medicine to Robert F. Furchgott, Louis J. Ignarro and Ferid Murad in $1998 .^{8}$ Shortly after 1987, the amino acid L-arginine was found to be the substrate for endogenous NO synthesis. NO synthase (NOS) was identified as the enzyme system responsible for the conversion of L-arginine to NO. ${ }^{9}$ The detailed mechanism of NO synthesis is still under investigation and will be discussed in the next Chapter (Chapter 2: part II, section 1: "Nitric oxide: production and function"). Ever since, NO is more and more recognized as a major factor in cell signaling and intercellular communication in several biological systems. This is reflected by the exponential increase in the number of publications on this molecule: from 129 papers in 1987 to 5,975 papers in 2000 . This increasing interest in NO led to its nomination as molecule of the year by Science in $1992 .{ }^{10}$

The simple molecule NO seems present in biological systems from the early occurrence of life onwards, ${ }^{11-13}$ which may be an explanation for the great number of phenomena that are mediated by this free radical gas. The biological importance of NOS in platelets can be emphasized by its presence and function in hemocytes which are multicompetent cells in the hemolymph of an arthropod, the American horseshoe crab. The formation of $\mathrm{NO}$ in hemocytes downregulates the hemostatic function of these cells in a manner similar to that in mammalian platelets. ${ }^{13}$ Since the horseshoe crab is a "phylogenetic relic" whose existence spans over 500 million years of evolution it is likely that NOS ranks among the oldest regulatory systems which have contributed to the development of human life. ${ }^{14}$ In mammals, $\mathrm{NO}$ is involved in intercellular communication in, for example, the cardiovascular system, the immuno-inflammatory system and the central 
nervous system. A well known vascular phenomenon in which $\mathrm{NO}$ is involved is endotheliumdependent vascular relaxation. ${ }^{6,7}$ Other eardiovascular related phenomena in which NO is involved include: platelet adhesion, aggregation and disaggregation, ${ }^{15-17}$ regulation of basal blood pressure, ${ }^{18-20}$ cardiac contractility, ${ }^{21-23}$ leukocyte adhesion, ${ }^{24}$ endothelial permeability, ${ }^{25}$ vascular smooth muscle cell mitogenesis ${ }^{26}$ and macrophage-mediated cytotoxicity. ${ }^{27}$

In many cardiovascular diseases, the bioavailability of NO is decreased, which may result in the onset of thrombotic processes. For example, if a coronary artery is involved in an atherosclerotic process, the reduced NO bioavailability in the diseased area may contribute to thrombus formation and/or vasospasm; as a result, (unstable) angina pectoris occurs and ultimately myocardial infaretion may develop. In case of thrombus formation in carotid arteries and brain vessels, transient ischemic attacks develop and finally stroke may occur. Cardiovascular disease, which is often due to thrombosis, has become an ubiquitous cause of morbidity and a leading contributor to mortality in most countries. ${ }^{28}$ The rise and recent decline of the cardiovaseular disease epidemic in the developed countries is well documented. However, the prevalence of such diseases will probably show a continued rise in the next decades. Prevention of identified predisposing conditions is crucial to improve the quality of patient treatment and to control the profound economic impact on health care systems. ${ }^{29}$

\section{This thesis}

The studies described in this thesis were performed to obtain more knowledge on the vasclular production and function of NO, with special emphasis on the antithromboembolic activity of this molecule. Both aspects were investigated in the arterial as well as the venous part of the circulation, because many studies indicate significant functional differences between the walls of arteries and veins, ${ }^{30-32}$ and of arterioles and venules. ${ }^{33-38}$

\section{Function of nitric oxide}

The functional studies were primarily aimed at the role of endogenous NO in platelet-vessel wall interactions in vivo. Our knowledge of the processes involved in thrombosis and hemostasis is still growing. In vitro studies rapidly accumulate knowledge of the role of $\mathrm{NO}$ in the functioning of blood platelets. For a more detailed review on the relevant literature, the reader is referred to Chapter 2 (part I and II). However, in contrast to the experimental in vitro situations, where the reaction of one type of cell is tested to changes in one mediator, in vivo a variety of mediators simultaneously determines the outcome of a thrombotic reaction. The interaction between blood platelets and the vessel wall at a site of injury is a complex phenomenon, which may be differently influenced by the type of injury and the size and type of vessel, the local fluid dynamic conditions, the intravascular milieu and the balance between activating and inhibiting agents. Such 
agents may originate from the platelets themselves, the injured vessel wall, other blood cells or the plasma. Studies performed in vitro lack the contribution of natural microenvironmental factors and therefore may easily introduce artifacts. Hence, in addition to in vitro studies the processes of thrombosis and hemostasis are investigated in vivo to be able to assess in physiological conditions or under pathophysiological circumstances, the role of mediators such as NO.

In the three functional studies of the present thesis a thromboembolic reaction, ie the formation of an intravascular thrombus and subsequent embolization, was induced by wall puncture and directly observed and investigated in microvessels of the rabbit mesentery by means of intravital videomicroscopy. ${ }^{33}$ In Chapter 3 of this thesis differences in the involvement of NO in the thromboembolic reaction in mesenteric arterioles and venules are described. Because fluid dynamic effects of NO could influence the platelet-vessel wall interactions studied, their role was investigated as well.

Using our model, we provided evidence that thromboembolism is predominantly inhibited by endogenous $\mathrm{NO}$ in venules (Chapter 3 ), ${ }^{39}$ whereas vascular prostaglandins are more important inhibitors in arterioles. ${ }^{34}$ However, at a site of wall injury these antithrombotic, endotheliumderived mediators are probably produced simultaneously and activated platelets are likely to be exposed to a combination of both. This combination may exert a more pronounced antithrombotic effect than expected on the basis of their individual antithrombotic effects, because in vitro studies have shown that prostacyclin (ie, $\mathrm{PGI}_{2}$ ) and $\mathrm{NO}$ released by cultured endothelial cells can act synergistically in the inhibition of platelet aggregation. ${ }^{16}$ It is unknown, however, whether such a synergistic interaction is also effective in vivo and whether this interaction, if any, differs between vessel types. Hence, this question was dealt with in Chapter 4 of this thesis.

Platelets isolated from hypercholesterolemic patients and from rabbits fed a high cholesterol diet show an increased tendency to aggregate; this can be reversed by L-arginine. ${ }^{40,41}$ Excess L-arginine is known to stimulate endogenous NO synthesis. Since it is unknown whether in hypercholesterolemia the thromboembolic reaction is enhanced in vivo and whether this reaction differs between vessel types, the first aim of the study described in Chapter $\mathbf{5}$ was to investigate in vivo the effect of diet-induced hypercholesterolemia on thromboembolism in arterioles and venules. The second aim of this study was to investigate whether changes in endogenous $\mathrm{NO}$ are involved in the effect of hypercholesterolemia on thromboembolism. For this purpose NO synthesis was stimulated by local administration of L-arginine.

\section{Production of nitric oxide}

In the second part of this thesis we focused on mechanisms of NOS activation and production of vascular NO (discussion of the literature in Chapter 2: part II, section 1). Two studies were performed to obtain more insight into the mechanisms involved in receptor-mediated NO production 
(ie, agonist-induced) in arteries and veins of mice and men. Graft failure is one of the major eauses of recurrent angina after coronary artery bypass grafting. The internal mammary artery has been shown to have a much better long-term patency rate than saphenous vein when used as a conduit for coronary artery bypass. ${ }^{42}$ Intimal thickening is an important cause of late coronary vein graft occlusion. ${ }^{43}$ Because $\mathrm{NO}$ has been reported to reduce vascular smooth muscle cell mitogenesis, ${ }^{26}$ a process known to contribute to intimal thickening, it is conceivable that a difference in NO production between arteries and veins may add to this phenomenon. ${ }^{4,45}$ Vascular endothelial growth factor (VEGF) is an endothelial cell mitogen. This feature is considered central to the documented role of VEGF in promoting angiogenesis. More recent evidence suggests that VEGF may also serve a "maintenance" function, modulating various aspects of endothelial cell biology. A greater stimulating effect on NO production of VEGF in arteries than in veins could contribute to the difference in long-term patency rate. ${ }^{32}$ Therefore, in Chapter 6 we investigated the basal NO release from freshly isolated segments of human internal mammary artery and saphenous vein, using the Griess method. ${ }^{32}$ In addition, we studied to which extent VEGF influences NO production in these vascular segments. Possible differences in VEGF-mediated NO production between arteries and veins can be caused by differences in expression of constitutive NO synthase present in endothelial cells (ec-NOS) or inducible NO synthase (i-NOS). Therefore, vascular expression of ec-NOS and i-NOS protein was studied as well.

Because in many cardiovascular diseases the capacity of the endogenous L-arginine/NO system is decreased, an obvious therapeutic measure would be the pharmacological substitution of NO. Nitrate therapy would therefore seem to be the logical approach. Indeed, organic nitrates represent a suitable drug class for chronic treatment of patients with ischemic heart disease and congestive heart failure. ${ }^{2}$ Unfortunately, systemic administration of exogenous NO only in part mimics the effects of the primarily locally activated endogenous nitrovasodilator system. Furthermore, the clinical value of long-term nitrate therapy is limited by the development of tolerance to the hemodynamic and clinical effects. ${ }^{46}$ The biochemical mechanism of "nitrate tolerance", which is still not completely understood, seems to be complex, involving several processes such as reflex neurohormonal activation and increased production of endothelin- 1 and superoxide anions. ${ }^{46}$ This limitation of chronic nitrate therapy is only partly overcome by potential therapeutic strategies including the use of antioxidants and nitrate free-intervals. ${ }^{46}$

A potential advantageous therapeutic approach in many cardiovascular diseases could be to stimulate the endogenous L-arginine/NO system. Such effects have been attributed to $s t a t i n s{ }^{47}$ and angiotensin-converting enzyme (ACE) inhibitors. ${ }^{48.49}$ The use of $\beta$-blockers, especially the so-called third-generation blockers with vasodilating properties in the treatment of hypertension, congestive heart failure and ischemic syndromes, is increasing. ${ }^{50}$ One of these third-generation blockers, nebivolol, has been shown to cause vasodilation in animals ${ }^{51}$ and humans. ${ }^{51-53}$ It has 
been suggested that this effeet is also mediated by increased NO production, since it can be abrogated by inhibitors of NO synthase. ${ }^{52,53}$ However, no direct evidence is available on the NO production stimulating properties of nebivolol and the mechanisms involved. Therefore, in Chapter 7 we investigated whether nebivolol indeed induces NO production in vascular endothelium and which mechanism underlies the enhanced NO production, if any.

The outcomes of the studies on vasular production and antithromboembolic function of NO are discussed in Chapter 8 ("General Discussion"). The large heterogeneity in function between vessels and the possible biochemical mechanisms underlying this heterogeneity are discussed. Interpretation of these data with regard to human cardiovascular disease states conclude this thesis. 


\section{References}

1. Brunton TL. Use of nitrite of amyl in angina pectoris. Lancet. 1867;97:97-98.

2. Abrams J. Beneficial actions of nitrates in cardiovascular disease. Am J Cardiel. 1996:77:31C-37C.

3. Schultz KD, Schultz K. Schultz G. Sodium nitroprusside and other smooth muscle-relaxants increase eyclie GMP levels in rat duetus deferens. Nature. 1977:265:750-751.

4. Katsuki S, Arnold W, Mittal C, Murad F. Stimulation of guanylate eyclase by sodium nitroprusside, nitroglycerin and nitric oxide in various tissue preparations and comparison to the effects of sodium azide and hydroxylamine. J Cyclic Nucleotide Res. 1977;3:23-35.

5. Furchgott RF, Zawadzki JV. The obligatory role of endothelial cells in the relaxation of arterial smooth musele by acetyleholine. Nature. 1980:288:373-377.

6. Palmer RM. Ferrige AG, Moneada S. Nitrie oxide release accounts for the biological activity of endothelium-derived relaxing factor. Nature. 1987;327:524-526.

7. Ignarro LJ, Buga GM, Wood KS, Byrns RE, Chaudhuri G. Endothelium-derived relaxing factor produced and released from artery and vein is nitric oxide. Proc Natl Acad Sci U S A. 1987:84:92659269.

8. SoRelle R. Nobel prize awarded to scientists for nitric oxide discoveries. Circulation. 1998;98:23652366.

9. Palmer RM, Ashton DS, Moncada S. Vascular endothelial cells synthesize nitric oxide from L-arginine. Nature. 1988;333:664-666.

10. Koshland DE. The molecule of the year. Science. 1992;258:1861

11. Golderer G, Werner ER, Leitner S, Grobner P, Werner-Felmayer G. Nitric oxide synthase is induced in sporulation of Physarum polycephalum. Genes Dev. 2001;15:1299-1309.

12. Montfort WR, Weichsel A, Andersen JF. Nitrophorins and related antihemostatic lipocalins from Rhodnius prolixus and other blood-sucking arthropods. Biochim Biophys Acta. 2000;1482:110-118.

13. Radomski MW, Martin JF, Moncada S. Synthesis of nitric oxide by the haemocytes of the American horseshoe crab (Limulus polyphemus). Phil Trans R Soc Lond. 1991;B 334:129.

14. Radomski MW, Moncada S. The biological and pharmacological role of nitric oxide in platelet function. Adv Exp Med Biol. 1993;344:251-264.

15. Radomski MW, Palmer RM, Moncada S. Endogenous nitric oxide inhibits human platelet adhesion to vascular endothelium. Lancet. 1987;2:1057-1058.

16. Radomski MW, Palmer RM, Moncada S. The anti-aggregating properties of vascular endothelium: interactions between prostacyclin and nitric oxide. Br J Pharmacol. 1987;92:639-646.

17. Radomski MW, Palmer RM, Moncada S. An L-arginine/nitric oxide pathway present in human platelets regulates aggregation. Proc Natl Acad Sci U S A. 1990;87:5193-5197. 
18. Johnson RA, Freeman RH. Sustained hypertension in the rat induced by ehronic blockade of nitric oxide production. Am J Hypertens. 1992;5:919-922.

19. Huang PL, Huang Z, Mashimo H, Bloch KD, Moskowitz MA, Bevan JA, Fishman MC. Hypertension in mice lacking the gene for endothelial nitrie oxide synthase. Nature. 1995;377:239-242.

20. Sander M, Vietor RG. Neural mechanisms in nitric oxide-defieient hypertension. Curr Opin Nephrol Hypertens. 1999;8:61-73.

21. Kelly RA, Han X. Nitrovasodilators have (small) direct effects on cardiac contractility: is this important? Circulation. 1997;96:2493-2495.

22. Balligand JL. Regulation of cardiac beta-adrenergie response by nitrie oxide. Cardiovasc Res. $1999 ; 43: 607-620$.

23. Petroff MG, Kim SH, Pepe S, Dessy C, Marban E, Balligand JL, Sollott SJ. Endogenous nitric oxide mechanisms mediate the streteh dependence of $\mathrm{Ca}^{2+}$ release in cardiomyocytes. Nat Cell Biol. $2001 ; 3: 867-873$.

24. Kubes P, Suzuki M, Granger DN. Nitric oxide: an endogenous modulator of leukocyte adhesion. Proe Natl Acad Sci U S A. 1991;88:4651-4655.

25. Kubes P, Granger DN. Nitrie oxide modulates mierovascular permeability. Am J Physiol. $1992 ; 262: H 611-H 615$.

26. Garg UC, Hassid A. Nitric oxide-generating vasodilators and 8-bromo cyclic guanosine monophosphate inhibit mitogenesis and proliferation of eultured rat vascular smooth muscle cells. J Clin Invest. 1989;83:1774-1777.

27. Mulligan MS, Moncada S, Ward PA. Protective effects of inhibitors of nitric oxide synthase in immune complex-induced vasculitis. Br J Pharmacol. 1992;107:1159-1162.

28. Reddy KS, Yusuf S. Emerging epidemic of eardiovascular disease in developing countries. Circulation. 1998;97:596-601.

29. O'Connell JB, Bristow MR. Economic impact of heart failure in the United States: time for a different approach. J Heart Lung Transplant. 1994;13(4):S107-S112.

30. Lischer TF, Diederich D, Siebenmann R, Lehmann K, Stulz P, von Segesser L, Yang ZH, Turina M, Gradel E, Weber E. Difference between endothelium-dependent relaxation in arterial and in venous coronary bypass grafts. $N$ Engl $J$ Med. 1988;319:462-467.

31. Yang ZH, Stulz P, von Segesser L, Bauer E, Turina M, Läscher TF. Different interactions of platelets with arterial and venous coronary bypass vessels. Lancet. 1991;337:939-943.

32. Van der Zee R, Murohara T, Luo Z, Zollmann F, Passeri J, Lekutat C, Isner JM. Vascular endothelial growth factor/vascular permeability factor augments nitric oxide release from quiescent rabbit and human vascular endothelium. Circulation. 1997;95:1030-1037.

33. oude Egbrink MGA, Tangelder GJ, Slaaf DW, Reneman RS. Thromboembolie reaction following wall puncture in arterioles and venules of the rabbit mesentery. Thromb Haemost. 1988;59:23-28.

Chapter 1 
34. oude Egbrink MGA, Tangelder GJ, Slaaf DW, Reneman RS. Different roles of prostaglandins in thromboembolie processes in arterioles and venules in vivo. Thromb Haemost. 1993; 70:826-833.

35. Faleone JC, Bohlen HG. EDRF from rat intestine and skeletal muscle venules causes dilation of arterioles. Am J Physiol. 1990;258:H1515-H1523.

36. Persson MG, Gustafsson LE, Wiklund NP, Hedqvist P, Moneada S. Endogenous nitrie oxide as a modulator of rabbit skeletal muscle microcirculation in vivo. Br J Pharmacol, 1990;100:463-466.

37. Mitehell D, Tyml K. Nitrie oxide release in rat skeletal muscle capillary. Am J Physiol. 1996;270:H1696-H1703.

38. Boegehold MA. Shear-dependent release of venular nitrie oxide: effeet on arteriolar tone in rat striated muscle. Am J Physiol. 1996;271:H387-H395.

39. Broeders MAW, Tangelder GJ, Slaaf DW, Reneman RS, oude Egbrink MGA. Endogenous nitrie oxide protects against thromboembolism in venules but not in arterioles. Arterioscler Thromb Vase Biol. 1998:18:139-145.

40. Wolf A, Zalpour C, Theilmeier G, Wang BY, Ma A, Anderson B, Tsao PS, Cooke JP. Dietary L-arginine supplementation normalizes platelet aggregation in hypercholesterolemic humans. J Am Coll Cardiol. 1997;29:479-485.

41. Tsao PS, Theilmeier G, Singer AH, Leung LLK, Cooke JP. L-Arginine attenuates platelet reactivity in hypercholesterolemic rabbits. Arterioscler Thromb. 1994;14:1529-1533.

42. Fitzgibbon GM, Kafka HP, Leach AJ, Keon WJ, Hooper GD, Burton JR. Coronary bypass graft fate and patient outcome: angiographic follow-up of 5,065 grafts related to survival and reoperation in 1,388 patients during 25 years. J Am Coll Cardiol. 1996;28:616-626.

43. Lawrie GM, Lie JT, Morris GC, Jr., Beazley HL. Vein graft patency and intimal proliferation after aortocoronary bypass: early and long-term angiopathologic correlations. Am J Cardiol. 1976;38:856862.

44. Ku DD, Caulfield JB, Kirklin JK. Endothelium-dependent responses in long-term human coronary artery bypass grafts. Circulation. 1991;83:402-411.

45. Buttery LD, Chester AH, Springall DR, Borland JA, Michel T, Yacoub MH, Polak JM. Explanted vein grafts with an intact endothelium demonstrate reduced focal expression of endothelial nitric oxide synthase specific to atherosclerotic sites. J Pathol. 1996;179:197-203.

46. Glasser SP. Prospects for therapy of nitrate tolerance. Lancet. 1999;353:1545-1546.

47. Hernandez-Perera O, Perez-Sala D, Navarro-Antolin J, Sanchez-Pascuala R, Hernandez G, Diaz C, Lamas S. Effects of the 3-hydroxy-3-methylglutaryl-CoA reductase inhibitors, atorvastatin and simvastatin, on the expression of endothelin-1 and endothelial nitric oxide synthase in vascular endothelial cells. J Clin Invest. 1998;101:2711-2719. 
48. Maneini GB, Henry GC, Macaya C, O'Neill BJ, Pueillo AL, Carere RG, Wargovich TJ, Mudra H, Luscher TF, Klibaner MI, Haber HE, Uprichard AC, Pepine CJ, Pitt B. Angiotensin-converting enzyme inhibition with quinapril improves endothelial vasomotor dysfunction in patients with coronary artery disease. The TREND (Trial on Reversing ENdothelial Dysfunction) Study. Circulation. 1996;94:258-265.

49. Yusuf S, Sleight P, Pogue J, Bosch J, Davies R, Dagenais G. Effects of an angiotensinconverting enzyme inhibitor, ramipril, on cardiovascular events in high-risk patients. The Heart Outcomes Prevention Evaluation Study Investigators. N Engl J Med. 2000;342:145-153.

50. Braunwald E. Expanding indications for beta-blockers in heart failure. $N$ Engl $J$ Med. 2001:344:1711-1712.

51. Van de Water A, Janssens W, Van Nueten J, Xhonneux R, De Cree J, Verhaegen H, Reneman RS, Janssen PA. Pharmacological and hemodynamic profile of nebivolol, a chemically novel, potent, and selective beta 1-adrenergic antagonist. J Cardiovase Pharmacol. 1988;11:552-563.

52. Bowman AJ, Chen CP, Ford GA. Nitric oxide mediated venodilator effects of nebivolol. Br J Clin Pharmacol. 1994:38:199-204.

53. Cockeroft JR, Chowienczyk PJ, Brett SE, Chen CP, Dupont AG, Van Nueten L, Wooding SJ, Ritter JM. Nebivolol vasodilates human forearm vasculature: evidence for an L-arginine/NO-dependent mechanism. J Pharmacol Exp Ther. 1995;274:1067-1071. 
Chapter 2

Survey of the Literature 


\section{Interaction between blood platelets and the vessel wall}

Normal blood vessels are lined by a continuous layer of endothelium (see for extensive review on functions of endothelium: Cines, et al 1998). ${ }^{1}$ When this lining is disrupted, subendothelial elements, such as extracellular collagen, are exposed to the circulating blood. ${ }^{2}$ Blood platelets draw a sharp distinction between endothelium and subendothelium, avoiding firm adhesion to the former and adhering avidly to the latter. This distinction governs platelet function, keeping the surface of normal vessels free of platelets while encouraging platelet deposition on exposed subendothelium. Depending on the vascular insult, attached platelets initiate either normal (ie, hemostatic) or abnormal (ie, thrombotic) events. For example, platelet plugs at sites of vascular injury limit blood loss (hemostasis), while platelet masses on diseased/atherosclerotic vessels impair blood flow (thrombosis) and contribute to myocardial infaretion and stroke. Activation of the platelet is an extremely complicated event, which at this moment has been only partly elucidated.

Following activation of a platelet a sequence of events follows. An activated platelet changes its shape from a smooth disc to a spiny sphere with extended pseudopodia (shape change); then, it interacts with other platelets to form aggregates (aggregation). In the presence of a prothrombotic surface, such as the subendothelium, it sticks to that surface (adhesion) and spreads out (spreading). If stimulation of platelets is strong a wide variety of factors, including serotonin (5-HT), adenosine diphosphate (ADP), thromboxane $\mathrm{A}_{2}\left(\mathrm{TXA}_{2}\right)$, platelet-derived growth factor (PDGF), platelet factor 4 (PF4), factor V (fV), fibrinogen (Fng), von Willebrand factor (vWf) and thrombospondin (Tsp) are released (ie, secreted) by the platelets. In the final stage of the process the cell membrane becomes procoagulant and sheds procoagulant microvesicles (procoagulant activity). ${ }^{3}$ If the level of platelet activation is not too strong, inter-platelet connections can loosen. In vivo, shear forces created by the flowing blood will then permit breaking up of platelet aggregates (disaggregation). ${ }^{4}$ Subsequently, these dislodged platelet aggregates may flow downstream and potentially hamper blood flow if they get trapped in smaller sized blood vessels. The formation of an intravascular thrombus and the subsequent embolization of platelet aggregates is referred to as the thromboembolic reaction. A distinction can be made between reversible aggregation (aggregation and disaggregation; ie, platelet aggregate embolization) and irreversible aggregation (no disaggregation; ie, formation of a hemostatic plug or thrombus) depending on the nature and intensity of the platelet stimulus.

Platelet aggregation and adhesion results from formation of bridges between adjacent platelets or between a platelet and a surface. Platelets express receptors (eg, GPIb-V-IX, GPIb $\alpha$ and integrins GPIIb-IIIa and GPIa-IIa) that recognize multiple adhesive substrates (eg, $v$ Wf and collagen) and establish attachment to other platelets or surfaces. ${ }^{5}$ Based on studies by the group of Jackson (2000) platelet aggregation under flow appears to be a multistep process involving: (a)

Chapter 2 
exposure of $\mathrm{VWf}$ on the surface of immobilized platelets; (b) a reversible phase of platelet aggregation mediated by the binding of GPIb $\alpha$ on the surface of free-flowing platelets to vWf on the surface of immobilized platelets; and (c) an irreversible phase of aggregation dependent on integrin GPIIb-IIla (Figure 1). ${ }^{6}$ Studies of platelet thrombus formation in vivo demonstrate that this multistep adhesion mechanism is indispensable for platelet aggregation in arterioles and also appears to promote platelet aggregate formation in venules. ${ }^{6}$

Platelets possess a complex set of enzymes, substrates and cofactors whose functions are coordinated in a temporal and spatial manner to affect platelet functional responses, including actin polymerization and cytoskeletal reorganization, adhesion, aggregation, granule secretion and procoagulant activity. As in other cells, these responses result from the action of several diffusable second messengers; they involve numerous specific protein-protein and protein-lipid interactions, the details of which remain incompletely understood. Some of the platelet signalling reactions - involving phospholipase $A_{2}$ and phospholipase $C$ - are reviewed in a comprehensive manner elesewhere. ${ }^{7}$

After injury of a vessel wall platelets are activated and adhere to the subendothelium. In the first moments of its existence a hemostatic plug or thrombus is quite unstable. In some blood vessels, such as arterioles and arteries in which shear is high, it can be swept away by the flowing blood. Formation of a supporting fibrin network helps to consolidate the aggregate. The formation of fibrin requires the generation of thrombin by the plasmatic coagulation system. Apart from being the fibrin-forming enzyme, thrombin is known to be a platelet-activator. It renders the platelet procoagulant and in this way enhances its own formation. Traditionally, the platelet reactions are pooled under primary hemostasis while the coagulation reactions are viewed as secondary hemostasis. However, there are many interactions between the platelets and coagulation proteins that tend to blur this distinction, ${ }^{8}$ which will be discussed in more detail in the next section ("Factors influencing platelet-vessel wall interactions").

The first layer of platelets is in contact with the thrombogenic surface, whereas subsequent growth of the hemostatic plug/thrombus depends primarily on platelet-to-platelet interactions; these two stages represent adhesion and aggregation, respectively. This distinction is useful for the purpose of in vitro experimental evaluation of platelet function, but it does not provide a satisfactory representation of the process of thrombus formation as visualized in real time in vivo (this thesis; Figure 2 ). ${ }^{9}$ In vivo thrombi more likely develop by progressive transfer of platelets from the mobile phase of circulating blood to the immobile vessel wall. In other words, as a result of continued adhesion on a dynamic substrate rather than as cohesion of multiple platelets in suspension induced to interact with one another by certain stimuli (ie, as in some in vitro aggregation studies). 


\section{Factors influencing platelet-vessel wall interactions}

Substances produced and released by the vessel wall either counteract thrombus formation or promote it (ie, antithrombotic and prothrombotic properties, respectively). Under normal conditions, the vessel wall is thromboresistant through some active antithrombotic mechanisms. Injury of the wall, however, induces an inereased expression of prothrombotic factors, while the antithrombotic factors may be depressed.

Antithrombotic and prothrombotic factors involved in hemostasis and thrombosis can be subdivided into three groups: factors inhibiting or stimulating platelet activity, anti- or procoagulant factors and pro- or antifibrinolytic factors. These anti- and prothrombotic factors not only come from the vessel wall (Table 1) but can also be derived from the platelets themselves, other blood cells or the blood plasma.

In this section the most important pro- and antithrombotic factors playing a role in hemostasis and thrombosis will be described. The focus will be on specific factors derived from the vessel wall, which are thought to be major players in hemostasis and thromboembolism, particularly after vessel wall injury.

\section{Prothrombotic factors}

The number of physiological and nonphysiological mediators that can activate platelets through action on corresponding receptors is astounding (eg, collagen, Fng, vWF, Tsp, 5-HT, ADP, thrombin, platelet-activating factor [PAF], tissue factor [thromboplastin; TF], TXA 2 , PDGF, PF4 and $\mathrm{fV})$ considering the tiny dimensions of platelets $(\sim 2 \mu \mathrm{m})$. These agonists are easily diffusable in the fluid phase of blood and rapidly degraded to less active or inactive molecules. Nevertheless, these agonists are potent platelet-activators that evoke a rise in intraplatelet calcium ultimately leading to platelet adhesion and aggregation. The most important substances thought to initiate platelet responses in vivo following vessel wall injury are matrix proteins (eg, collagen, Fng, vWf, Tsp and TF), thrombin and ADP.

Depending on the depth of the vascular wall injury and tissue injury, circulating blood elements are exposed to extracellular matrices of variable composition. This structural variability of the extracellular matrix probably partly accounts for its specific effects on platelet thrombus formation and subsequent embolization. The difference in thromboembolism between various vessel types (eg, arterioles versus venules, microvessels versus macrovessels or blood vessels in different organs/tissues) may also be partly caused by this structural variability. Moreover, circulating plasma proteins may become immobilized at sites of injury by interacting with subendothelial components, thereby adding to the diversity of thrombogenic substrates in tissues that surround injured vessels. ${ }^{5} \mathrm{vWf}$ is one of the matrix components which may become exposed to platelets when deeper injuries of the vessel wall occur. ${ }^{10}$ Moreover, synthesis of vWf and its 
secretion by the endothelium into the blood and the subendothelial matrix, where it acts as a cofactor for platelet adhesion following vessel wall injury, can be stimulated by thrombin.

As already mentioned in the previous section there are many interactions between the platelets and coagulation proteins. Several reaction steps in thrombin generation proceed to a significant extent only when the reactants are adsorbed onte a phospholipid membrane that contains phosphatidylserine (PS). ${ }^{8,11}$ Such membranes oceur at sites where endothelial cells are damaged and expose their intracellular PS to the outside, ${ }^{12}$ so that thrombin generation is confined to the site of lesion. TF meets factor VII and the coagulation cascade starts. Moreover, collagen is exposed which can cause platelet adhesion. ${ }^{2}$ As soon as traces of thrombin are formed. the simultaneous action of thrombin and collagen induces transbilayer movement of PS in the platelet membrane itself (so-called "flip-flop") 11 and the platelet surface becomes procoagulant. 12 Consequently, in plasma the bulk of thrombin generation takes place after a thrombus has formed. The forming thrombus withdraws thrombin from free solution. Kumar, et al (1994) demonstrated in vitro that three known thrombin-dependent feedback activations in the elotting system (factor V, factor VIII and platelets) are efficiently supported by thrombin bound to fibrin in the thrombus and that there is an additional activating effect of fibrin on the procoagulant action of platelets. ${ }^{13}$ The complex roles of fibrinogen and fibrin in hemostasis and thrombosis have been extensively reviewed by Blombäck (1996). ${ }^{14}$

Vascular cells, as well as activated platelets themselves, are a potential source of the platelet agonist ADP and its precursor ATP (adenosine triphosphate). Following vessel wall injury these substances are released into the blood. The amount of ADP, present at a site of injury, both released and generated enzymatically from ATP, is probably high enough to induce platelet activation. TXA $A_{2}$, like ADP, is also synthesized and released by activated platelets. TX $A_{2}$ as well as ADP will amplify the thrombotic reaction by activating other platelets that are not yet in contact with collagen. Moreover, TXA $\mathrm{A}_{2}$ and ADP may synergize each other and other platelet agonists, even if they are present at subthreshold concentrations. For a more extended review of the role of $\mathrm{ADP}$ and $\mathrm{TXA}_{2}$ in platelet activation the reader is referred to more specific publications. ${ }^{15-17}$

More recently, the group of Radomski reported a new pathway of aggregation which is mediated by the release of a metalloproteinase enzyme, gelatinase $A{ }^{18,19}$ Independent of TX $\mathrm{A}_{2}$ and ADP, platelet aggregation could be stimulated by matrix metalloproteinase-2 (MMP-2), which was found to be expressed by human platelets ${ }^{18}$ and vascular cells. ${ }^{20} \mathrm{As}$ yet not much is known about the mediators and signal transduction pathways involved in MMP-2-mediated platelet activating actions.

Another prothrombotic property of injured endothelial cells is an increased secretion of inhibitors of fibrinolysis, which was reviewed by Kohler, et al (2000). ${ }^{21}$ The two principal 
inhibitors of fibrinolysis in the circulation are plasminogen activator inhibitor type 1 (PAI-1), a fast acting inhibitor of both urokinase-type plasminogen activator (u-PA) and tissue-type plasminogen activator (t-PA), and $\alpha_{2}$-antiplasmin, a specific plasmin inhibitor that is covalently bound to polymerizing fibrin by activated factor XIII. In platelet-rich thrombi, PAI-1 provides an important mechanism for controlling the activity of t-PA. Secretion of PAI-1 is stimulated by thrombin. An additional antifibrinolytic pathway has been identified recently. This pathway is analogous to the protein $\mathrm{C}$ pathway and also consists of thrombin, thrombomodulin and a zymogen that is activated to an enzyme. The particular enzyme proteolytically inactivates a cofactor to attenuate fibrinolysis. However, unlike activated protein $\mathrm{C}$, which is a serine protease, the antifibrinolytic enzyme is a metalloproteinase that exhibits carboxypeptidase B-like activity, referred to as thrombin activatable fibrinolysis inhibitor (TAFI), which is reviewed elsewhere by Bajzar (2000). ${ }^{22}$

\section{Antithrombotic factors}

Healthy, noninjured endothelium is thromboresistant due to several antithrombotic properties (Table 1). At least five antiplatelet regulatory systems have been described: the production of cyclooxygenase metabolites (particularly prostaglandin $\mathrm{I}_{2}$ ) and lipoxygenase metabolites (particularly 12-hydroperoxy and 13-hydroxy derivatives), the expression of ectonucleotidase ATPdiphosphohydrolase and matrix metalloproteinase-9 (MMP-9) and the production of endogenous nitric oxide (NO). Because of the central role of NO and cyclooxygenase/lipoxygenase metabolites in this thesis, their production, antiplatelet function and putative synergistic interaction will be discussed more extensively in part II of this chapter. In this section we will briefly review the remaining two antiplatelet systems. Furthermore, some anticoagulant and fibrinolytic properties of the vessel wall will be discussed.

On the luminal surface of endothelial cells the enzymes present are capable of degrading the platelet stimulator ADP. ${ }^{23}$ These so-called ectonucleotidases (ectonucleotidase ATP-diphosphohydrolase) convert ADP into the platelet inhibitors AMP (adenosine 3',5'-monophosphate) and adenosine. It appears that adenosine inhibits platelet function via cyclic (c)AMP-dependent mechanisms.

A biological counterpart for MMP-2 has recently been identified in the vessel wall of human resistance arterioles and in human platelets. ${ }^{19}$ This MMP-9 is released by both resting and activated platelets and inihibits thrombin- and collagen-induced aggregation. The MMP-2/MMP9 system may play an important role in the regulation of platelet-platelet and platelet-vessel wall interactions. However, the in vivo role of this system in hemostasis/thrombosis has not been studied yet.

Vascular thromboresistance is maintained not only by antiplatelet mechanisms, but also 
by several anticoagulant properties, such as the heparin-like molecules (particularly heparan sulphate), which are synthesized and expressed by endothelial cells, ${ }^{24}$ and the protein $\mathrm{C}$ anticoagulant pathway. ${ }^{25}$ Like protein C, t-PA, which is synthesized and secreted by endothelial cells in response to various stimuli, also enhances fibrinolytic activity. ${ }^{26}$ Other antithrombotic factors are tissue factor pathway inhibitor (TFPI), ${ }^{27.28}$ and annexin V. ${ }^{29,30}$ TFPI is a factor that inhibits the start of the extrinsic coagulation pathway by forming a stable quaternary complex, TF-VIIaXa-TFPI. TFPI circulates in plasma, is associated with vascular cell surface and is released from endothelial cells and platelets following stimulation by thrombin. The annexins are a family of highly homologous phospholipid-binding proteins. Annexin $\mathrm{V}$ is a protein that exerts its antithrombotic effect by binding to negatively charged phospholipids. The antithrombotic properties of exogenously administered annexin $\mathbf{V}$ have been established in laboratory animals in vivo, ${ }^{31}, 32$ and in a human ex vivo thrombosis model. ${ }^{33}$ Although the in vivo biological functions of the endogenous annexins have not been definitively established, human diseases involving annexin abnormalities ("annexinopathies") have been identified. ${ }^{30}$ In one of these diseases annexin $V$ was found to be underexpressed on placental trophoblasts from patients diagnosed with antiphospholipid syndrome. Antiphospholipid syndrome is associated with arterial and venous thrombosis, recurrent pregnaney loss and thrombocytopenia. ${ }^{34}$ 


\section{Endothelium-derived antithrombotic factors: nitric oxide and eicosanoids}

In the light of the studies presented in this thesis, section II of this chapter will focus on the two main endothelium-derived mediators involved in the inhibition of platelet activity: nitric oxide (NO) and eicosanoids (in particular prostaglandins, such as $\mathbf{P G I}_{2}$ ).

\section{Nitric oxide: production and function}

\section{Nitric oxide synthesis}

\section{- Biochemistry}

Endothelium-derived relaxing factor (EDRF), ${ }^{35}$ which was later identified as $N O{ }^{36,37}$ is synthesized from L-arginine, but not D-arginine, by NO synthase (NOS) ${ }^{38}$ NOS exists in three established isoforms. The first reports on the properties of these NO synthases demonstrated that the synthesis of NO not only requires L-arginine but also NADPH (nicotinamide adenine dinucleotide phosphate) and results in the formation of L-citrulline. Beside these substrates, the presence of calmodulin is essential and also that of four other coenzymes/cofactors: protoporphyrin IX haem, flavin mononucleotide (FMN), flavin adenine dinuleotide (FAD) and tetrahydrobiopterin $\left(\mathrm{BH}_{4}\right)$. More recently, NOS has been found to contain zine, which seems to be a cofactor too ${ }^{39}$ Molecular oxygen is also a substrate for this reaction, being incorporated into both NO and L-citrulline. For literature references and further details of the present knowledge of the biochemical NO synthesis reaction the reader is referred to more extensive reviews elsewhere. ${ }^{40}$

\section{- Nitric oxide synthase isoforms}

The three distinct NO synthases are classified as: n-NOS (originally identified as constitutive in neuronal tissue, also known as type I NOS), i-NOS (originally identified as being inducible by cytokines or bacterial lipopolysaccharide [LPS] in macrophages and hepatocytes, also known as type II NOS) and ec-NOS (originally identified as constitutive in vascular endothelial cells, also known as type III NOS). The genes encoding each of the three human NOS isoforms is localized to a single position on a separate chromosome (ec-NOS gene on chomosome $7, n-N O S$ gene on chromosome 12 and $\mathrm{i}-\mathrm{NOS}$ gene on chromosome 17). ${ }^{41-43}$ The ec-NOS, n-NOS and i-NOS proteins show an inter-species (ie, human, cow, rat and mouse) amino acid homology of $94 \%, 93 \%$ and $81 \%$, respectively, indicating that these enzymes are well preserved during evolution. ${ }^{4}$ All three NOS isoforms share similar, if not identical, cofactor and prosthetic group requirements and they all utilize L-arginine as the substrate for $\mathrm{NO}$ generation. However, for the most part, the various NOS isoforms are distributed in different cells and tissues. Along with these differences in tissue or cellular origin, the three NOS isoforms do differ significantly with regard to their biophysical 
properties and mechanisms of physiological regulation, which will be discussed below in the section on "Mechanisms of nitric oxide synthase activation".

The constitutive enzyme ec-NOS was originally described as being $\mathrm{Ca}^{2+}$ - and calmodulindependent. Compared with the other two NOS isoforms, ec-NOS has the shortest $N$-terminal part which has a consensus $N$-myristoylation site. The finding that ec-NOS is myristoylated ${ }^{45}$ may explain why it is partially (and in some cells predominantly) membrane-associated. ${ }^{46}$ The association of ec-NOS with a region of the plasma membrane in which several key signal transducing complexes are concentrated (eg, G proteins, sre-family tyrosine kinsases) is likely to have profound repercussions on enzyme activity as well as on its accessibility to signal transduction cascades other than those associated with an increase in intracellular $\mathrm{Ca}^{2+}\left(\left[\mathrm{Ca}^{2 *}\right]_{i}\right){ }^{47}$ ec-NOS is responsible for the NOS activity of vascular endothelium in blood vessels of all sizes and types (ie, arteries, arterioles, capillaries, venules and veins), in different tissues and organs (eg, heart. brain. lung, liver and kidney) and in various species. ${ }^{48}$ However, ee-NOS is not uniquely expressed by endothelial cells, but is also constitutively expressed in megakaryocytes, platelets, T cells, erythrocytes, cardiomyocytes, ${ }^{49}$ some epithelial cells and rat hippocampus (for review, see Förstermann, et al 1998). ${ }^{50}$ The functions of ec-NOS in the cardiovascular system will be discussed more extensively in the section on "Biological functions of nitric oxide in the cardiovascular system".

n-NOS is the other constitutive NOS enzyme which is clearly $\mathrm{Ca}^{2+}$ - and calmodulindependent. The n-NOS protein has a widespread distribution in the central and peripheral (eg, myenteric plexi in the gut) nervous system. ${ }^{51}$ In addition, n-NOS transcripts and/or protein have been detected in nonneuronal cell types, such as rhabdomyocytes, epithelial cells, mast cells and neutrophils (for review, see Förstermann, et al 1998). ${ }^{50}$ Because of this wide expression in different tissues and the high activity of n-NOS in brain and skeletal muscle, it is likely that this isoenzyme is responsible for the largest proportion of constitutive NOS activity in humans. nNOS is likely to play an important role in physiological neuronal functions, but also in a variety of neurological disorders in which excessive production of NO leads to neural injury. ${ }^{52}$

Exposure of many cell types and tissues to cytokines (eg, tumor necrosis factor- $\alpha$ [TNF$\alpha$ ], interleukin-1 [IL-1] or bacterial products [eg, endotoxin or LPS] induces an NO synthase (i-NOS) which is clearly different from n-NOS and ec-NOS. There are also some reports describing constitutive expression of i-NOS in certain cells/tissues, such as the mouse ileal mucosa, ${ }^{53}$ human airway epithelium ${ }^{54}$ and human $B$ lymphocytes. ${ }^{55}$ In contrast to the constitutive NOS isoenzymes, i-NOS is fully active in the absence of either $\mathrm{Ca}^{2+}$ or added calmodulin. Calmodulin appears to be a "constitutive subunit" of i-NOS being extremely tightly bound to the i-NOS protein in a Ca ${ }^{2+}$ independent manner. ${ }^{56}$ The main characteristic of $\mathrm{i}$-NOS is that it releases continuously large amounts of NO; the amount released per unit of time from fully activated macrophages is a 
thousand times higher than that released from NOS in endothelial cells. These high concentrations of NO are cytostatic and cytotoxic on parasitic microorganisms and tumor cells and, consequently, $\mathrm{NO}$ is an essential component of the nonspecific immune defense system. For a review on biological functions of $\mathrm{i}-\mathrm{NOS}$ and its role in inflammatory and cardiovaseular disease the reader is referred elsewhere. ${ }^{57.58}$

The early identification of competitive inhibitors of NOS greatly facilitated and accelerated the study of $\mathrm{NO}$ synthesis in mammalian systems in vitro and in vivo. Analogs of arginine represent the largest and most useful class of NOS inhibitors. Although these arginine analogs all inhibit NO synthesis by competition with its substrate L-arginine, they differ in potency and reversibility of NOS inhibition and also in specificity for NOS and specific NOS isoform (see for extensive review on this subject: Fukuto, et al 1995). ${ }^{59}$

\section{Biological functions of nitric oxide in the cardiovascular system}

$\mathrm{NO}$ is an unusual messenger. This small molecule is uncharged, carrying an unpaired electron. These characteristics of NO make it an ideal messenger molecule. Being uncharged, NO is soluble both in water and lipid and can diffuse freely across membranes, whereas the unpaired electron makes it a radical molecule, which is highly reactive. Released into the bloodstream, most $\mathrm{NO}$ is probably quickly bound to hemoglobin and converted to $\mathrm{NO}_{3}^{-}$(nitrate). ${ }^{60}$ The group of Loscalzo, however, described that $S$-nitrosothiols may serve as carriers in the mechanism of action of EDRF by stabilizing the labile NO radical from inactivation by reactive oxygen species in the physiological milieu, thereby prolonging the biological half-life of NO. ${ }^{61} \mathrm{NO}$ has a half-life of 2 to 30 seconds in solutions in vitro and its biological half-life has been estimated to be 1 to 4 minutes. ${ }^{62}$ After conversion to $\mathrm{NO}_{3}{ }^{-}$it is eliminated in the urine with a half-life of 5 to 8 hours. ${ }^{60}$

Most molecules that transmit signals between cells, such as sex hormones, neurotransmitters and growth factors, act through specific protein receptors that are often associated with the plasma membrane. In contrast, NO diffuses out of the cell that generates it into target cells, where it interacts with specific molecular targets. The best characterized receptor of NO is iron, contained in certain proteins in a heme group or as an iron-sulphur complex. When NO binds to the iron in the heme group of soluble guanylate cyclase (sGC), the enzyme is activated. ${ }^{63}$ The binding of NO to sGC results in the conversion of magnesium guanosine 5'-triphosphate (GTP) to cyclic guanosine $3^{\prime}, 5^{\prime}$-monophosphate (cGMP). Subsequently, the increase in cGMP activates other cellular processes, thereby acting as a second messenger, activating cGMP-dependent protein kinase, which decreases cytosolic $\mathrm{Ca}^{2+}$ concentration and modulates ion channel function leading to, for example, inhibition of platelet activity or relaxation of vascular smooth muscle cells. NO may also act independent of the sGC/eGMP system. For example, direct activation by $\mathrm{NO}$ of $\mathrm{Ca}^{2+}$-dependent potassium channels in vascular smooth muscle cells was shown to produce hyperpolarization and relaxation. ${ }^{64}$ 
Thus, by both sGC-dependent and sGC-independent mechanisms, NO not only dilates blood vessels, but also inhibits platelet function (see: "Role of nitric oxide in platelet function"), inhibits the adhesion and ehemotaxis of stimulated neutrophils ${ }^{65}$ and has antimitogenie effects in vascular smooth muscle cells. ${ }^{66}$ Therefore, it is clear that $\mathrm{NO}$ plays a eritical role in the regulation of vascular homeostasis. In general, endothelial release of $\mathrm{NO}$ acts to limit changes in shear stress and opposes vasoconstrictor, prothrombotic and proinflammatory stimuli in the vasculature. A more detailed description of these and several other cardiovascular actions of NO is presented elsewhere. ${ }^{67-69}$

\section{- Role of nitrie oxide in platelet function}

Although, the antiplatelet effect of nitroglycerin was already described by Hampton, et al in $1967,{ }^{70}$ their findings remained controversial for many years because of the suprapharmacological doses required to inhibit platelet aggregation in vitro and the lack of evidence for a direct antiplatelet effect in vivo. The early observation that $\mathrm{NO}$ inhibits platelet aggregation ${ }^{71}$ coupled with early observations suggesting that EDRF might be acting as an inhibitor of platelet aggregation $^{72}$ added new impetus to the search for the molecular identity of EDRF. Work of the group of Radomski, Palmer and Moneada resulted in the recognition of NO as the primary EDRF having potent inhibiting activities on both platelet adhesion and aggregation. ${ }^{62,73,74}$ In this section the role of $\mathrm{NO}$ in platelet function will be discussed. For literature references and a more detailed review on this subject the reader is referred to Jurasz and colleagues $(2000) .{ }^{75}$

In vitro platelet aggregation induced by a variety of agonists, as well as by shear stress, is inhibited by NO released from fresh or cultured endothelial cells. ${ }^{62,74}$ In addition to inhibition of adhesion and aggregation, $\mathrm{NO}$ disaggregates platelet aggregates ${ }^{74}$ and inhibits platelet recruitment to the aggregate. ${ }^{76.77}$

Under normal conditions of blood flow and shear stress, NO is released into the blood stream as a result of activation of endothelial cells by biochemical agonists and/or shear, ${ }^{62,78,79}$ However, under conditions of endothelial dysfunction or denudation, like in the setting of an acute coronary syndrome, other sources of NO may become important in downregulating the extent of platelet activation. Such a potential nonendothelial source of NO could be the platelets themselves. Indeed, the release of small amounts of NO by resting platelets was shown in vitro, ${ }^{80,81}$ and NOS was identified in these cells. ${ }^{82}$ Using in vitro platelet aggregometry and in vivo bleeding time assays Freedman, et al (1997, 1999) showed that this platelet-derived NO not only modestly modulates platelet activation to strong and weak agonists but also, more importantly, markedly inhibits platelet recruitment to the growing platelet thrombus, which was also confirmed in a ec-NOS gene knockout mouse model. ${ }^{76,77}$ These studies suggest that both endothelialand platelet-derived NO pools contribute to normal hemostatic function and that a deficiency of either pool enhances hemostatic response to vascular injury. 
It has been shown that neutrophils, in addition to platelets, are the main constituents of an intracoronary thrombus in acute myocardial ischemia. ${ }^{83}$ Furthermore, an important consequence of postischemic reperfusion is impairment to flow at the microvascular level (so-called, "no-reflow" phenomenon) secondary to neutrophil plugging and vasoconstriction. ${ }^{84}$ LopezFarre, et al $(1995,1996)$ showed that one of the non-cyclooxygenase-mediated effects of aspirin ${ }^{85}$ is its inhibitory effect on platelet activation through an increase in NO production by peripheral neutrophils.$^{86,87}$ Although clinical and experimental models of myocardial ischemia described the detrimental role of neutrophils in the progression of this pathology mainly through oxygen-derived free radicals, ${ }^{84}$ neutrophils would potentially provide defense properties against thrombosis in the presence of aspirin. Therefore, leukocytes could be another nonendothelial source of NO which is potentially relevant in hemostasis and thrombosis.

The studies reviewed thus far clearly show that NO impairs platelet function in vitro. Most of these in vitro studies were performed in erythrocyte-free systems. Some investigators have suggested that the affinity of hemoglobin for $\mathrm{NO}$ should render these in vitro observations irrelevant for the in vivo situation. ${ }^{88}$ However, the hydrodynamic effects of the flowing intravascular red cell mass leads to a partitioning of platelets close to the low-shear boundary of the endethelial surface, ${ }^{89}$ which facilitates direet diffusional access of circulating platelets to endothelial NO, limiting kinetic competition of erythrocytic hemoglobin for the free radical. Furthermore, it can be argued that because the responsiveness of the endothelium is strongly influenced by its ambience and neighboring tissues, it seems inevitable that extrapolations from function in vitro to function in vivo require considerable prudence. Therefore, in vivo studies on the role of $\mathrm{NO}$ in thrombotic processes are of vital importance. Most of the in vivo studies performed have focused on the antithrombogenic properties of NO in either arterioles, ${ }^{90-92}$ arteries, ${ }^{93-97}$ or veins, ${ }^{98-100}$ but not in venules (only one study involved data on NO and thrombus formation in venules). ${ }^{101}$ We, however, provided strong evidence for the protective role of endogenous NO against thromboembolism in rabbit mesenteric venules but not in arterioles (Chapter 3). ${ }^{102}$ This antihrombogenic function of NO in venules was later confirmed by other investigators. ${ }^{103}$ Thus, evidence is increasing that $\mathrm{NO}$ is an important regulator of platelet function in various species, organs and tissues in vivo; several animal studies have shown that basal or stimulated release of NO results in inhibition of platelet aggregation induced by some aggregating agents or endothelial injury. In addition, results from animal studies showing that there is basal luminal release of $\mathrm{NO}$ from the vasculature, eausing increases in the intraplatelet eGMP levels, have been confirmed in humans. ${ }^{104}$ In healthy volunteers inhibition of NOS with L-NMMA increased platelet aggregation and granule release ex vivo ${ }^{105}$ and shortened bleeding time. ${ }^{106}$ In contrast to L-NMMA, L-arginine administration in vivo leads to the inhibition of platelet activation ex vivo. ${ }^{107}$ In many blood vessel types both the vasodilator ${ }^{108}$ and the 
platelet-inhibitory ${ }^{94,105,107}$ effect contributes to this antithrombotic action of NO. The importance of NO-mediated inhibition of platelet function in vivo is best illustrated by the finding that inactivation of $\mathrm{NO}$ by increased concentrations of reactive oxygen species in plasma is associated with thrombotic events in childhood. ${ }^{109.110}$

The inhibition of platelet aggregation and adhesion by NO is largely dependent on the stimulation of sGC and the resultant inerease in intraplatelet eGMP levels. ${ }^{111}$ However, some actions of $\mathrm{NO}$ on platelets may also be independent of sGC activation, such as direct actions of $\mathrm{NO}$ on $\mathrm{Ca}^{2+}$ flux, ${ }^{112}$ metabolism via inhibition of ADP ribosylation ${ }^{113}$ and inhibition of 12 -lipoxygenase. ${ }^{114}$ In addition to NO, the activity of sGC can be increased by hydrogen peroxide, ${ }^{115}$ arachidonic acid hydroperoxide, ${ }^{116}$ and carbon monoxide. ${ }^{117}$ The significance of these stimuli for the regulation of sGC in vivo remains to be determined.

Three proteins mediate the actions of eGMP in platelets: eGMP-dependent protein kinase, eGMP binding eAMP phosphodiesterase and eGMP regulated ion channels. ${ }^{75,118}$ Stimulation of eGMP-dependent protein kinase results in phosphorylation of proteins 118 such as the 46- to 50-kDa vasodilator-stimulated phosphoprotein (VASP). ${ }^{119.120}$ During platelet adhesion VASP is associated with actin filaments and focal contact areas, ie, transmembrane junctions between microfilaments and the extracellular matrix. ${ }^{121}$ The binding of VASP with the platelet cytoskeleton may mediate its inhibitory effect on the fibrinogen receptor, ${ }^{122}$ and the thromboxane receptor. ${ }^{123}$ Cyclic GMP, by inhibiting cGMP binding cAMP phosphodiesterase, may delay the hydrolysis of cAMP and enhance the biological effects of the latter nucleotide. ${ }^{124}$ This putative "eross talk" between cAMP and eGMP pathways will be further discussed in section 2.II.3 ("Nitric oxide/eicosanoid synergistic interactions").

Cyclic GMP downregulates the function of platelet receptors, including the fibrinogen receptor $\mathrm{Ilb}-\mathrm{III}$, the function of protein kinase $\mathrm{C}$ induced expression of $\mathrm{P}$-selectin and the release of lysosomal protein CD63. ${ }^{125-127}$ Interestingly, von Willebrand factor and fibronectin receptors appear not to be regulated by eGMP. ${ }^{127,128}$ The biological actions of cGMP are terminated by cGMP phosphodiesterase and by its efflux from platelets. These actions may also depend on the activity of protein phosphatases. ${ }^{118}$

\section{Mechanisms of nitric oxide synthase activation}

The number of NO molecules produced by the two constitutively expressed isoforms of NOS, ie ec-NOS and n-NOS, is primarily dependent on the activity of the NOS enzyme. As indicated before, both constitutive $N O S$ isoforms are regulated by $\mathrm{Ca}^{2+}$ via the $\mathrm{Ca}^{2+}$-binding protein calmodulin. Apparently, a $\mathrm{Ca}^{2+}$-calmodulin complex forms as a result of $\mathrm{Ca}^{2+}$-influx into the cell, which then binds constitutive NOS and most likely displaces the enzyme from its location to caveolae in the plasma membrane; this leads to activation of NOS. ${ }^{129,130}$ Thus, any event which 
results in the influx of $\mathrm{Ca}^{2+}$ into a cell containing constitutive NOS can cause activation of constitutive NOS and increased NO levels.

Phosphorylation may also play a regulatory role in the activity of constitutive NOS. Indeed, constitutive NOS from rat cerebellum contains sites for phosphorylation ${ }^{131}$ and can be phosphorylated by $\mathrm{Ca}^{2+}$ - and calmodulin-dependent protein kinase II and protein kinase $\mathrm{C} .{ }^{132}$

Unlike constitutive NOS, i-NOS activity appears to be regulated primarily via the induction of de novo enzyme protein synthesis. Recent studies, however, indicate that the expression of the constitutive ee-NOS is dynamically regulated as well (see for extensive review on this subject Kleinert, et al 2000). ${ }^{133}$ Hemodynamic shear stress, hypoxia, inflammation/cytokines, cell growth, high glucose, estrogens and other sex hormones and injury are among the stimuli that are associated with an increased abundance of ec-NOS expression.

As in constitutive NOS, the availability of substrate and cofactors (most notably $\mathrm{BH}_{4}$ ) may also play a role in $\mathrm{i}-\mathrm{NOS}$ regulation in macrophages and smooth muscle. ${ }^{40}$ The lack of finely tuned regulatory mechanisms for $\mathrm{i}-\mathrm{NOS}$ may be due to its different function, as compared with constitutive NOS. Because NO derived from the constitutive NOS subtypes is involved in the maintenance of vascular tone and neurotransmission, its physiological concentrations may be under stricter regulation than that of NO derived from i-NOS, which is made in large quantities as a cytotoxic agent.

Calcium-dependent processes play a central role in different cells of the cardiovascular system, including vascular smooth muscle cells, endothelial cells and platelets. ${ }^{134}$ There are major differences in the pathways that lead to NO synthesis in response to agonists and to mechanical stimuli. ${ }^{135}$ Until recently, regulation of ec-NOS was attributed solely to changes in endothelial $\left[\mathrm{Ca}^{2+}\right]_{i}$. However, more recent thorough biochemical studies have reinforced the original observation that ec-NOS may also produce $\mathrm{NO}$ in an apparently $\mathrm{Ca}^{2+}$-independent manner when activated by certain physical stimuli (eg, shear stress and isometric stress), growth factors (eg, vascular endothelial growth factor; VEGF) or hormones (eg, estrogen). ${ }^{135}$

\section{- Shear stress-induced nitric oxide production}

In vivo, endothelial cells are continuously exposed to shear stress and other mechanical stimuli such as cyclic stretch, which seem to be the physiologically most relevant determinants of ec-NOS activation and NO production. The ability of endothelial cells to act as mediators of flow-dependent dilation was demonstrated in vivo for the first time by Pohl, et al (1986). ${ }^{136}$ In response to shear stress the continuous production of $\mathrm{NO}$ by native and cultured endothelial cells is associated with only a transient and minimal increase in $\left[\mathrm{Ca}^{2+}\right]_{\mathrm{i}}$. In the absence of extracellular $\mathrm{Ca}^{2+}$ and in the presence of a calmodulin antagonist, shear stress stimulates a continuous production of NO. ${ }^{135}$ The ability of the endothelial cell to sense shear stress involves an array of signalling 
pathways and cellular components, including $\mathrm{G}$ proteins, caveolae, integrins and the cytoskeleton, which may all participate in the mechanotransduction mechanisms that lead to the activation of ee-NOS.

\section{- Agonist-induced nitric oxide production}

Several agonists can induce the production of nitric oxide. For example, simultaneous measurements of $\left[\mathrm{Ca}^{2+}\right]_{i}$ and $[\mathrm{NO}]$ in bradykinin-stimulated endothelial cells in vitro revealed that a transient increase in $\left[\mathrm{Ca}^{2+}\right]_{\mathrm{i}}$ was rapidly followed by an increase in $[\mathrm{NO}]$ that outlasted the $\left[\mathrm{Ca}^{2+}\right]_{\mathrm{i}}$ transient. ${ }^{137}$

VEGF is a potent vascular endothelial cell-specifie mitogen that stimulates endothelial cell proliferation, microvascular permeability, vasodilation and angiogenesis. ${ }^{138}$ Recent studies have demonstrated that ec-NOS/NO plays an important role in many VEGF-induced actions. VEGF has been shown to induce the release of NO from rabbit, pig, bovine and human vascular endothelial cells. ${ }^{139-141}$ The phosphorylation of one of its endothelial receptors, KDR (Flk-1), induces NO release, followed by activation of ERK-1/2 kinase in endothelial cells. ${ }^{142}$ The VEGFdependent release of NO is blocked by tyrosine kinase inhibitors as well as by NO synthase inhibitors. ${ }^{139,141}$ Reciprocally, endogenous NO was found to enhance VEGF expression by vascular smooth muscle cells. ${ }^{143}$ Other studies indicate that prolonged exposure of endothelial cells to VEGF upregulates ec-NOS expression. ${ }^{144,145}$ In a study by Shen, et al (1995) it was demonstrated that two days of exposing cultured endothelial cells to VEGF induces a 5-fold increase in ec-NOS protein and activity via activation of the KDR-receptor tyrosine kinase and a downstream protein kinase $\mathrm{C}$ pathway. ${ }^{145}$ VEGF-mediated arterial protection may prove to be useful in the treatment of occlusive cardiovascular disease, as reviewed by Zachary, et al (2000). ${ }^{146}$

Stimulation of $\beta$-adrenoceptors on vascular smooth muscle results in vasorelaxation, through adenylate cyclase activation and a consequent increase in cyclic adenosine $33^{\prime}, 5^{\prime}$ monophosphate (cAMP) intracellularly. ${ }^{147}$ Vascular endothelial cells may also express $\beta$-adrenoceptors. In vitro as well as in vivo evidence is accumulating that the vascular endothelium may facilitate or mediate $\beta$-adrenergic vasorelaxation through induction of NO production. ${ }^{148}$ Interestingly, Dawes, et al (1997) showed vasodilator responses in the human forearm that were mediated predominantly through $\beta 2$-adrenergic receptors and that were dependent on NO synthesis. ${ }^{149}$ Indeed, $\beta 2$-adrenergic receptors on endothelium of human internal mammary artery and saphenous vein have been demonstrated by autoradiography. ${ }^{150}$

$\beta$-adrenergic receptor-induced endothelial NO production could well be mediated by a mechanism not involving $\mathrm{Ca}^{2+}$ influx. ${ }^{151}$ Sobrevia, et al (1997) have demonstrated that activation of A2-purinoceptors by adenosine in cultured endothelial cells stimulates both L-arginine influx and NO synthesis. ${ }^{152}$ This also occurs without a change in $\left[\mathrm{Ca}^{2+}\right]_{i}$, but is attenuated by inhibition 
of tyrosine kinase activity. Since A2-purinoceptors activate adenylate cyclase and increase cAMP, it is possible that tyrosine kinase may also play a role in the signal transduction pathway coupling $\beta$-adrenoceptor stimulation and NO biosynthesis, possibly through direct phosphorylation of NOS. ${ }^{153}$ Further studies are required to elucidate the mechanisms of $\beta$-adrenoceptor- and cAMP-mediated activation of $\mathrm{L}$-arginine accumulation and $\mathrm{NO}$ generation in these cells.

The physiological consequences of vaseular endothelial NO production in response to $\beta$-adrenergic activation are at present unknown, but it is possible that this process is important in the normal control of vessel tone by the sympathoadrenal system. Furthermore, certain disease states, including atherosclerosis, hypertension and heart failure are associated with both endothelial dysfunction and impaired $\beta$-adrenergic vasodilation. ${ }^{154-157}$

\section{Eicosanoids: production and function}

\section{Eicosanoid synthesis}

The collective term "eicosanoids" refers to a group of biologically highly active lipid mediators of which there are now more than 150 members, derived from peroxidation of $\mathrm{C}$ - 20 carbon polyunsaturated fatty acids (from the Greek word "eikos": "twenty"). The major natural source is arachidonie acid, a C-20 carbon polyunsaturated fatty acid with four double-bonds, which is a constituent of cell membrane phospholipids. Following stimulation of the cell, either mechanically (ie, by injury or shear stress) or chemically (ie, by binding of an agonist/antagonist to its specific receptor on the cell surface), phospholipase $A_{2}$ sets arachidonic acic free from membrane phospholipids. Subsequently, arachidonic acid is converted into many different metabolites via enzymatic activity of either lipoxygenase or cyclooxygenase (COX); ie, the arachidonic acid cascade. Leukotrienes, such as 12-hydroperoxy and 13-hydroxy derivatives of arachidonic acid, are the major products of the lipoxygenase pathway, ${ }^{158}$ whereas the biologically active products of the COX pathway are the prostaglandins ( $\mathrm{PGs}$ ) which include $\mathrm{PGD}_{2}, \mathrm{PGE}_{2}, \mathrm{PGF}_{2 \alpha}, \mathrm{PGI}_{2}$ (also known as prostacyclin) and the thromboxanes (TXs) including TXA 2 (Figure 3). ${ }^{159,160}$ Metabolites of arachidonic acid all carry two double-bonds (suffix number "2"); metabolites from dihomo- $\gamma$-linolenic acid, such as $\mathrm{PGE}_{1}$, have one double-bond (suffix number " 1 ") and those from eicosapentaenoic acid three (suffix number "3"). These one and three double-bond PGs have similar functional properties as the two double-bond PGs. Because up to $40 \%$ of the fatty acid fraction in membrane phospholipids consists of arachidonic acid and the concentrations of other fatty acid precursors of eicosanoids are more than one order of magnitude lower, arachidonic acid is the most important precursor of natural eicosanoids in mammals and the two double-bond PGs are the dominating and most important PGs. The enzymatic formation of COX products has been demonstrated in most cells and tissues of the body. In the (micro)vascular system vascular cells (eg. endothelial cells, pericytes, smooth muscle cells), blood cells (eg, 
leukoeytes, platelets) as well as interstitial cells (eg, fibroblasts, mast cells) possess the ability to produce PGs. ${ }^{161}$ The biological functions of eicosanoids, which were extensively reviewed by others, ${ }^{158-160}$ exert a broad range of physiologic activities, including modulation of inflammation, ovulation, thrombosis and arterial blood pressure.

Biologieal funetions of thromboxane $A_{2}$ and prostaglandin $I_{2}$ in the cardiovascular system foeusing on platelet function

The biological actions of eicosanoids are mediated via specifie seven-transmembrane-domain receptors at the plasma membrane which are selective for each type of eicosanoid; the action is dependent on the local concentration of the respective mediator and the number of available receptor sites. Since eicosanoids are not stored but synthesized when they are needed, the local concentration of an eicosanoid is mainly determined by the de novo biosynthesis potential of a certain cell type. Because of cell- and tissue-specifie isoenzyme variants of COX and PGH synthase, ${ }^{162.163}$ it is likely that $\mathrm{TXA}_{2}$ is the main product in blood platelets, whereas $\mathrm{PGI}_{2}$ is the main product in endothelial cells. Specific eicosanoid receptors have been identified in numerous cells and tissues, including the platelet. For more detailed information on selective eicosanoid receptors, the reader is referred to specifie review articles. ${ }^{159,160} \mathrm{It}$ has been proposed that $\mathrm{PCI}_{2}$ and $\mathrm{TXA}_{2}$ form a balanced control mechanism, regulating the interaction between platelets and the vessel wall at the site of wall injury (Figure 3 ). ${ }^{164}$

$\mathrm{TXA}_{2}$, which is released by activated platelets, reduces blood loss after vessel wall injury by inducing vasoconstriction and further activation of platelets. The main platelet stimulating effect of $\mathrm{TXA}_{2}$ is in the second phase of platelet aggregation, which is characterized by the release of platelet agonists, potentiating adhesion and aggregation of platelets by further activating platelets in an autocatalytic manner. TXA $_{2}$ probably acts via enhanced calcium entry mediated by activation of receptor-operated calcium channels, involving activation of the phosphatidyl inositol cycle. TXA 2 has a serum half-life of approximately 30 seconds. Its effect will therefore mainly be of a local nature. ${ }^{164}$

Albeit labile, $\mathrm{PGI}_{2}$ is a potent vasodilator and inhibitor of platelet activation. Acting at very low concentrations (nanomolar-range) and in a paracrine way, $\mathrm{PGI}_{2}$ inhibits aggregation and stimulates disaggregation of platelet aggregates in vitro ${ }^{165}$ and in the circulation of humans. ${ }^{166}$ In contrast to $\mathrm{NO}$, much lower concentrations of $\mathrm{PGI}_{2}$ are needed to inhibit platelet aggregation (about 20 times lower) than to inhibit adhesion of platelets to the subendothelial components of the vessel wall. ${ }^{167}$ Thus, at low concentrations PGI $_{2}$ may permit platelets to stick to and interact with damaged vascular tissue, thereby allowing platelets to participate in the repair of a vessel wall, while at the same time preventing or limiting thrombus formation. ${ }^{168}$ This specific action of $\mathrm{PGI}_{2}$ may be very important for normal hemostasis. The platelet-inhibitory effects 
of $\mathrm{PGI}_{2}$ are mediated by stimulation of specific receptors present on the cell surface of platelets, which in turn activate the intracellular enzyme adenylate cyclase, leading to an increase in cAMP levels in the platelets. $\mathrm{AAMP}$-mediated responses result in the phosphorylation of specific platelet proteins, including VASP, which also plays a role in the mechanism of platelet inhibition by NO (see section 2.II.1: "Role of nitric oxide in platelet function"). This is followed by down-regulation of several stages of the platelet transduction mechanism including enhancement of $\mathrm{Ca}^{2+}$ sequestration in platelet membranes ${ }^{169}$ and inactivation of platelet receptors. ${ }^{170}$ Moreover, inhibitory effects on platelet phospholipase ${ }^{171,172}$ and platelet $\operatorname{COX}^{173}$ have been described, which may result in reduced formation of all platelet-derived arachidonic acid metabolites. Platelets themselves lack the capacity to synthesize $\mathrm{PGI}_{2}$, but they do produce $\mathrm{PGD}_{1}, \mathrm{PGD}_{2}$. $\mathrm{PGE}_{1}$ and $\mathrm{PGE}_{2}$ which all have inhibitory effects on platelet aggregation too, ${ }^{174}$ albeit much less effective and shorter lasting than $\mathrm{PGI}_{2} .{ }^{168}$ Furthermore platelets may contribute to the endothelial synthesis of $\mathrm{PGI}_{2}$ by generating and releasing arachidonic acid cyclic endoperoxides, which may be taken up by the endothelial cells for $\mathrm{PGI}_{2}$ synthesis. ${ }^{170}$

The molecular basis of aspirin (acetylsalicylic acid) action involves the irreversible acetylation of Ser ${ }^{529}$ elose to the active site of COX ${ }^{175}$ The efficacy of a low dose of about 38 to 100 $\mathrm{mg}$ aspirin daily in reducing the incidence of vascular events (stroke, myocardial infaretion and vascular death) by about 25 per cent in patients who had previously experienced an acute manifestation of coronary ${ }^{176}$ or cerebral thrombotic vascular occlusion is conclusively demonstrated. ${ }^{177}$ However, as already mentioned in section 2.II. ("Role of nitric oxide in platelet function"), inhibition of COX activity by aspirin does not fully explain the antithrombotic effects of this drug and other non-COX-mediated activities of aspirin may play a role. ${ }^{85}$

Initially, it was thought that COX was a single constitutive enzyme that produced PGs in most tissues and cell types. However, several studies have illustrated that COX activity is increased in certain inflammatory states and is induced in cells by proinflammatory cytokines and growth factors in vitro. Following these observations, extensive research in this field led to the discovery that two forms of COX exist. COX-1 is usually expressed constitutively, although its expression may be regulated by hormones and cytokines in a limited repertoire of cells (for an extensive review and specific references on this subject the reader is referred to Smith, et al 2000). ${ }^{178} \mathrm{COX}-2$, like $\mathrm{i}-\mathrm{NOS}$, is a distinct gene product of a family of primary response genes, that is expressed by many cell types mainly during inflammation and cell growth and accounts for the release of large quantities of proinflammatory PGs at the site of inflammation. Both COX enzymes have been crystallized. The COX-2 enzyme is expressed in vascular cells, although its contribution to inflammatory syndromes in the vessel wall is presently unknown. It is up-regulated by laminar shear stress in endothelial cells in vitro and is likely to be a major contributor to vascular $\mathrm{PGI}_{2}$ formation in vivo. In platelets only COX-1 is expressed. The target Ser residue 
for acetylation by aspirin is conserved among eyelooxygenase subtypes. Therefore, aspirin is a relatively nonspecifie COX inhibitor. The antiinflammatory and nociception-inhibitory actions of selective COX-2 inhibitors and their clinical efficacy in patients with arthritis and musculoskeletal pain has recently stimulated the use of this type of drugs. However, as pointed out in a review article on possible risk of cardiovaseular events associated with selective COX-2 inhibitors, the available data raise a cautionary flag about the risk of cardiovascular events with this type of drugs. ${ }^{179}$ Initial characterization of the phenotypes of COX-1-and COX-2-deficient mice were reported in 1995. ${ }^{180,181}$ The COX-1 knockout mouse had few phenotypie abnormalities. Platelets from COX-1 knockout mice did not show the normal aggregatory response to arachidonic acid. In contrast, the COX-2 knoekout mouse was not healthy; progressive nephropathy was observed as early as six weeks after birth and led to death eight to sixteen weeks after birth. The availability of these and other genetic models now in development heralds a new era of eicosanoid biology, in which molecular biology and physiology will synergize to test the molecular insights and hypotheses in integrated in vivo systems.

\section{Nitric oxide/eicosanoid synergistic interactions}

Early studies reviewed by Radomski and Moneada $(1991)^{182}$ showed that platelet activation and thrombus formation occur as a result of synergistic interactions between proaggregating agents. In 1987 Radomski, Palmer and Moncada for the first time described that in vitro synergistic interactions also take place between agents that inhibit platelet aggregation. ${ }^{74}$ Evidence was provided that endothelial cells generate and release $\mathrm{NO}$ and $\mathrm{PGI}_{2}$, which act in concert to maximize the extent of platelet inhibition and vessel wall protection. Similar synergistic interactions were described between NO and other platelet-inhibiting prostaglandins, like PGE ${ }_{1}{ }^{183}$ Other publications confirmed that the release of $\mathrm{PGI}_{2}$ (and/or $\mathrm{PGE}_{2}$ ) and of $\mathrm{NO}$ are coupled in cultured microvascular ${ }^{184}$ and macrovascular endothelial cells ${ }^{185}$ and in blood perfused microvessels in situ. ${ }^{186}$ In this respect, the synergistic effects of combined administration of exogenous $\mathrm{PGI}_{2}$ (or $\mathrm{PGE}_{1}$ ) and $\mathrm{NO}$ to increase thromboresistance in rats in vivo ${ }^{187}$ and in patients suffering from peripheral arteriosclerotic disease $\mathrm{e}^{188,189}$ are interesting and promising. Interactions between endogenous $\mathrm{NO}$ and prostaglandins may well have biological significance to ensure a multilevel control of platelet function in vivo (Chapter 4).

Most agonists that stimulate the L-arginine/NO pathway in endothelium also activate phospholipase $A_{2}$, potentially leading to the formation of $\mathrm{NO}$ as well as $\mathrm{PGI}_{2}$ and $\mathrm{TXA}_{2}$. Depending on the balance between NO, $\mathrm{PGI}_{2}$ and $\mathrm{TXA}_{2}$ this may in one vascular bed lead to vasodilation and/or platelet inactivation and in another vascular bed to vasoconstriction and/or platelet activation. An even greater synergistic disaggregatory effect on platelet clots is obtained when a third important antithrombotic endothelial cell product, such as t-PA, is present together with $\mathrm{PGI}_{2}$ and NO. ${ }^{183}$ 
It is of interest to consider the mechanism underlying the putative synergistic interaction between the L-arginine/NO pathway on the one hand and the arachidonic acid/prostaglandin pathway on the other (see for a review article on this subject: Gerritsen 1996). ${ }^{161}$ Possible mechanisms are illustrated in Figure 3. As stated earlier in section 2.II.1 ("Biological functions of nitric oxide in the cardiovascular system"), iron is the best characterized receptor for NO. Because the COX enzyme contains an iron-heme center at its active site, $\mathrm{COX}$ is a potential target for NO. ${ }^{190}$ Indeed, such a possible mechanism was deseribed by Salvemini and coworkers (1997), who showed in an in vitro study that in endothelial cells NO-mediated activation of COX leads to $\mathrm{PGI}_{2}$ release and $\mathrm{AMM}$ elevation, contributing to the antiplatelet effect of endogenously released NO. ${ }^{190}$ The exact molecular mechanism by which NO potentially activates the COX enzyme remains to be identified. Three possible mechanisms have been proposed by Salvemini and coworkers (Figure 4): (1) antioxidant effect of NO preventing the $\mathrm{O}_{2}{ }^{-}$-induced autoinactivation of COX, (2) formation of nitrosothiols increasing COX enzyme activity by changing COX structure and (3) generation of $\mathrm{ONOO}^{-}$which was shown to increase $\mathrm{COX}$ activity (see for a more detailed discussion of this subject the review by Salvemini 1997). ${ }^{190}$ In an in vivo study it was shown that intravenous infusion of nitroglycerin or sodium nitroprusside in rat elevated both plasma levels and urinary excretion of 6-keto-PGF $1 \alpha$, suggesting that the NO donors induced an increased $\mathrm{PGI}_{2}$ synthesis due to COX-1 activation by NO. ${ }^{191}$ Another possible way in which NO may influence the arachidonic acid/PG pathway is the simultaneous activation of $\mathrm{PGI}_{2}$ synthase and inactivation of $\mathrm{TXA}_{2}$ synthase. Wade, et al (1997) showed that at moderate concentrations, exogenous $\mathrm{NO}$ donors increased $\mathrm{PGI}_{2}$ synthase activity irreversibly, whereas $\mathrm{TXA}_{2}$ synthase activity was irreversibly inhibited. ${ }^{192}$ Moreover, the amounts (small or large) of NO generated in various biological systems appear to be critical for the action (stimulant, no effect or inhibitory) of NO on COX enzymes. ${ }^{193}$

Another possible mechanism underlying synergism includes the inhibition of cAMP-phosphodiesterase (PDE type III) by NO-activated eGMP, thus reducing cAMP degradation resulting in an antiaggregatory effect in platelets ${ }^{124}$ as well as a relaxing effect on vascular smooth muscle cells. ${ }^{194}$ Alternatively, activation of certain target proteins which can be phosphorylated by protein kinases dependent on both CGMP and cAMP may occur; this has been demonstrated for VASP in platelets. ${ }^{119,195}$

Vice versa, contrasting data have been reported concerning the action of eicosanoids on the L-arginine/NO pathway. ${ }^{190}$ These data were mostly obtained from a limited number of in vitro studies. At present, credible conjecture on the effects of PGs on NO production can be given. However, the significance of possible effects of PGs on the L-arginine/NO pathway in both physiology and pathology needs further evaluation. ${ }^{190}$ 
Most in vivo evidence so far suggests that $\mathrm{NO}$ activates $\mathrm{COX}$ enzymes leading to increased PG biosynthesis. The modulation of PG production by NO may have physiological, pathological and therapeutic relevance. In physiological conditions NO produced by constitutive NOS of endothelial cells may represent a permanent stimulus for COX-1 activation. Thus, inhibition of platelet aggregation and smooth muscle relaxation may be achieved by NO, not only via eGMP elevation through direct activation of sGC, but also by concomitant elevation of eAMP via an increased production of $\mathrm{PGI}_{2}$ and $\mathrm{PGE}_{2}$ due to $\mathrm{COX}-1$ activation. In this light it should be investigated whether the elevation of systemic blood pressure by NOS inhibitors and their prothrombogenic effect in venules, ${ }^{102}$ veins, ${ }^{98-100}$ arterioles ${ }^{90-92}$ or arteries ${ }^{93-97}$ is solely due to suppression of endogenous NO production or may also depend on a concomitant reduction in the biosynthesis of vasodilator and antiplatelet PGs (Chapter 4).

\section{Heterogeneity in anti- and prothrombotic properties of the vessel wall}

In vitro studies show marked variety in biochemical properties of different types of vascular cells (ie endothelial cells, smooth muscle cells and fibroblasts). ${ }^{196}$ The vascular endothelial lining exhibits regional variation, which may have important implications for the local hemostatic balance. ${ }^{196}$ Even in the same organ of the same species, the endothelium of large and small vessels and in different organ areas exhibits significant heterogeneity. ${ }^{197-199}$ For example, coronary vessels at various anatomic sites in the heart (ie, right, circumflex and anterior descending coronary vascular beds) respond differently to neural, myogenic, metabolic or humoral factors, which is partly caused by differences in endothelial cell function. ${ }^{200}$ Even more striking is the finding that individual endothelial cells within the same vessel are functionally different. In Chapter 7 of this thesis it was indeed shown that neighbouring endothelial cells in the isolated mouse thoracic aorta respond differently to agonists (compare images on inside and front of cover of this thesis). ${ }^{201}$ A possible role of shear forces in heterogeneity of endothelium is nicely illustrated in a study by Huang, et al (2000), who showed that functional properties differ markedly between endothelial cells located at non-branch sites compared to cells at branch sites. ${ }^{202}$ Phenotypic heterogeneity of the endothelium can also arise from cell type-specific differences in gene expression ${ }^{203}$ or from microenvironmental influences.

\section{Heterogeneity in the L-arginine/nitric oxide pathacay}

Concerning the L-arginine/NO pathway several studies suggest marked heterogeneity along the vascular tree. In a normal blood vessel endogenous NO production and release mainly occurs in the endothelium. A mathematical model for the effective diffusion distance in the microcirculation suggests that the optimal range of vessel diameters within which the effective NO diffusion distance is maximal is 30 to $100 \mu \mathrm{m} .^{204}$ This is qualitatively supported by in vivo experimental 
results showing that 60 to $100 \mu \mathrm{m}$ vessels exhibit the lowest threshold for shear-induced dilation in comparison to their downstream and upstream vessels. The existence of an optimal vessel diameter for NO diffusion is a result of the competition between increased NO production surface and increased NO scavenging blood volume (hemoglobin) in the lumen as the diameter increases.

The group of Lüscher repetitively demonstrated the role of endothelial NO in agonistinduced endothelium-dependent relaxation of both isolated human internal mammary artery and saphenous vein. ${ }^{205-207}$ However, the endogenous NO-dependent component was more important in internal mammary artery than in saphenous vein. Furthermore, incubation with aggregating platelets induced endothelial NO-dependent relaxation in precontracted rings of internal mammary artery and induced only a further increase in tension in precontracted saphenous vein rings. A higher potency of the endogenous NO/cGMP system in arteries than in veins was also found by other investigators, studying not only human internal mammary artery and saphenous vein, ${ }^{208}$ but also arteries and veins from other species. ${ }^{140,209-211}$ Although, no direct measurement of [NO] was performed in these studies, the data suggest that the internal mammary artery releases more NO than saphenous vein upon stimulation with agonists. This was indeed demonstrated in our study presented in Chapter 6. ${ }^{212}$ Unfortunately, no studies are available in the literature in which the relative antithrombotic role of $\mathrm{NO}$ in arteries and veins was compared.

The relatively more important vasodilatory role of the endogenous $\mathrm{NO} / \mathrm{cGMP}$ pathway in the arterial system than in the venous system may also be true in the microcirculation. Although limited data are available, it may be concluded from the findings of a study in anesthesized rats that NO release appears to modulate basal tone of tracheal arterioles more than venules. ${ }^{213}$ The findings of a study in cremaster muscle of anesthetized rats suggest that NO release is more important as an antithrombotic agent in arterioles than in venules. ${ }^{101} \mathrm{We}$, however, provided strong evidence for a more important role of endogenous NO in inhibiting thromboembolic processes in mesenteric venules than arterioles of anesthetized rabbits (Chapter 3). ${ }^{102}$ As a possible explanation for our results we hypothesized that the less pronounced role of NO in arterioles as antithrombotic mediator may be caused by its inactivation by reactive oxygen species. This is supported by the findings of a study by Suzuki and colleagues (1995) in which it was shown that in rat mesentery more superoxide is generated in arterioles than in venules. ${ }^{214}$ Furthermore, the findings of a more recent study directly showed the involvement of both superoxide and NO in ADP-induced thrombus formation in mesenteric venules of anesthetized rats. ${ }^{103}$

\section{Heterogeneity in the arachidonic acid/prostaglandin patheay}

Since 1977 it is known that arachidonic acid metabolism is not the same in arterial and venous vessel walls. ${ }^{215}$ For example, differences have been found for the synthesis of $\mathrm{PGI}_{2}$. Endothelial 
cells derived from saphenous vein have been reported to synthesize less $\mathrm{PGI}_{2}$ than those from the internal mammary artery, a finding that may contribute to the rapidity with which pathogenic changes may develop in venous bypass grafts after coronary bypass surgery. ${ }^{216}$ In addition, the production of $\mathrm{PGI}_{2}{ }^{217-219}$ and $\mathrm{PGE}_{2}{ }^{219}$ differs between macro- and microvascular cells. $\mathrm{PGI}_{2}$ is the major metabolite of arachidonie acid in the heart, kidney and lung vasculature endothelium, albeit mainly in large vessels. $\mathrm{PGE}_{2}$ was found to dominate in mierovessels isolated from bovine brain, ${ }^{220}$ bovine heart, ${ }^{221}$ rabbit brain, ${ }^{222}$ rabbit heart ${ }^{222}$ and human skin. ${ }^{223}$ In addition, a number of laboratories have reported that $\mathrm{PGD}_{2}$ is the major eicosanoid generated by endothelial cells derived from the human cerebral microcirculation. ${ }^{224}$ Unfortunately, no direct data could be found in the literature on the heterogeneity in production of eicosanoids between different types of microvessels, ie, arterioles, capillaries and venules. An in vivo study from our group suggests a higher level of prostaglandin production in arterioles than in venules. ${ }^{225}$

\section{Heterogeneity in nitric oxide/eicosanoid synergistic interactions?}

Combined action of nitrie oxide and eicosanoids has been studied before with regard to vascular reactivity, using either isolated human gastroepiploic arteries, ${ }^{210}$ internal mammary arteries, ${ }^{226}$ saphenous veins ${ }^{226}$ and isolated pig coronary arteries ${ }^{227}$ or hamster arterioles ${ }^{228}$ and rat arterioles ${ }^{229}$ and venules in vivo. ${ }^{230}$ Moreover, several reports describe the combined effects of exogenously added $\mathrm{NO}$ and $\mathrm{PGI}_{2}$ on platelet function in vivo (or ex vivo) in both animal ${ }^{231}$ and human studies. 189 However, combined action of endogenous NO/eicosanoids with regard to their antithromboembolic function in vivo was not studied before. Therefore, this was the aim of the study presented in Chapter 4. ${ }^{232}$

\section{Heterogeneity in prothrombotic properties of the vessel wall}

Not only antithrombotic properties of endothelial cells are heterogenously distributed along the vascular tree but also prothrombotic properties of vascular cells, as demonstrated for example for vWf expression, ${ }^{233,234}$ synthesis of platelet activating factor (PAF), ${ }^{235}$ expression of tissue factor $^{196.236}$ and levels of cholesterol. ${ }^{237}$ 

hypercholesterolemia, atheroselerosis and thrombosis

The vascular endothelium actively regulates vascular tone, lipid breakdown, thrombogenesis, inflammation and vessel growth, all of which are important factors in the development of atherosclerosis. The importance of the endothelium in the development of atherosclerosis was first highlighted by the observation that endothelial removal facilitated lesion development, which led to the concept that the atherogenic process is initially a "response to injury". ${ }^{238}$ However, physical disruption of the endothelium during lesion genesis has been difficult to document. Examination of preadolescent humans has demonstrated the presence of early atherosclerotic lesions in the absence of any evidence of physical endothelial disruption. ${ }^{239}$ Therefore, the most recent version of this hypothesis emphasizes "endothelial dysfunction" rather than denudation. In a dysfunctional endothelium an imbalance exists between proatherogenic factors (eg, endothelin-1, angiotensin- $\mathrm{II}$ and $\mathrm{TXA}_{2}$ ) and antiatherogenie factors (mainly $\mathrm{NO}$ and $\mathrm{PGI}_{2}$ ). ${ }^{240}$

Considerable experimental, epidemiological and clinical trial data support a strong assoeiation between cholesterol and atherosclerosis. ${ }^{241-243}$ The pathophysiology of atherosclerosis has traditionally been thought to involve deposition, modification and cellular uptake of cholesterol, followed by the release of mediators resulting in smooth muscle cell proliferation and collagen matrix production. ${ }^{240}$ Abnormalities in the endothelium may explain much of the relation between hypercholesterolemia and atherosclerosis. Indeed, considerable experimental and clinical data suggest that elevated serum levels of total and low-density lipoprotein (LDL) cholesterol are associated with impaired endothelial function, independent of the presence of coronary artery disease. ${ }^{24}$ Other lipid factors (eg, low levels of high-density lipoprotein (HDL) and elevated triglycerides) as well as free radicals caused by cigarette smoking, hypertension, diabetes mellitus or elevated homocysteine levels ${ }^{245}$ may play a role.

A consensus has emerged that inflammation plays a decisive role in this process (see for an extensive review on this subject: Ross 1999). ${ }^{240}$ Hypercholesterolemia stimulates vascular inflammation and the breakdown of plaque collagen through increases in metalloproteinases, which may lead to plaque instability (see for an extensive review on the pathogenesis of plaque instability: Libby 2001). ${ }^{246}$ Infections by for example Chlamydia pneumoniae or cytomegalovirus may initiate or aggravate atherosclerosis. Large randomized trials now in progress will reveal as to whether antibiotic treatment can forestall recurrent coronary events.

The current understanding of the pathophysiology of atherosclerosis offers insight into the early and substantial reductions in major cardiovascular events associated with cholesterol lowering. Effective lipid-lowering by 3-hydroxy-3-methylglutaryl coenzyme A (HMG-CoA) reductase inhibitors (statins) leads to consistent and significant reductions in the risk for subsequent 
acute ischemic events, ranging from $20 \%$ to $60 \% .^{241-243}$ These results occurred across a wide range of lipid levels in both primary- and secondary-prevention trials with an equal effeet in men and women and in diabetic and nondiabetic subjects. There is a lag period of up to two years before elinical event benefits are noted, although tests of endothelial function improve much ear lier. ${ }^{247}$ The logic of such results is that thrombotic episodes precipitating these major cardiovascular events (stable and unstable angina pectoris, myocardial infarction, transient ischemic attacks and stroke) have been reduced. In most patients myocardial infarctions occur as a result of erosion or uneven thinning and rupture of the fibrous cap, often at the shoulders of the lesion where macrophages enter, accumulate and are activated and where apoptosis may occur, ${ }^{240.248}$ It seems unlikely that statins have sufficient antithrombotic potency for this to be their mode of action, which leads to the view that the number of triggering events has been reduced. A reduction in events caused by both disruption and erosion seems likely. ${ }^{248}$ The beneficial effect of statins may be regarded as an alteration in plaque characteristics leading to increased plaque stability. The mechanism by which plaque behavior might be modified has been studied in animal models in which atheroselerosis was induced by high-fat diets or gene manipulation (apolipoprotein $\mathrm{E}-1-)^{248}$ Lipid-lowering produces a rapid reduction in the number of plaque macrophages, a reduction in the expression of monocyte chemoattractant protein, tissue factor (TF) and macrophage metalloproteinases as well as an increase in smooth muscle cells and connective tissue with only modest decreases in plaque size. The plaque becomes more solid and fibrous and far less inflammatory ${ }^{248}$ and it is much less vulnerable to episodes of disruption or erosion. It is plausible that similar changes occur in atherosclerotic plaques in humans, although there are limited observational studies to confirm this assumption. Thus, plaques are not immutable and lipid-lowering therapy with statins may lead to favorable changes in their composition and structure, which renders the plaque less vulnerable to rupture.

Endothelial function in atherosclerotic vessels improves rapidly following risk factor modification such as reducing serum cholesterol and homocysteine levels, smoking cessation, exercise, estrogen replacement and angiotensin-converting enzyme (ACE)-inhibition. ${ }^{249}$ The beneficial effect of statins on endothelial function is not only a result of their cholesterol lowering effect but may also be explained by direct effects of this type of drug on the vascular wall and plaque. Statins have a multitude of properties that could supplement their lipid-lowering effects, such as improvement of endothelial function via increasing NO release, reducing endothelin-1, antioxidant effects, inhibition of smooth muscle cell proliferation, macrophage activation and lipid uptake, reduction in expression of TF by macrophages, antithrombotic effects on platelets and alteration of fibrinolytic potential (reduction in plasminogen activator inhibitor type 1; PAI-1). ${ }^{246,248}$ Results of recent clinical trials support the idea of early treatment of high-risk patients with unstable coronary disease; early and aggressive statin treatment resulted in fewer 
recurrent ischemic events in patients with an acute coronary syndrome. ${ }^{250}$ Additional studies are needed to confirm the benefit of early statin treatment in patients with unstable coronary disease and to elucidate the reasons for the occurrence of events in treated patients.

Atherogenesis is associated with profound changes in the oxidative status of the vascular wall. There are high concentrations of lipid peroxides in atheroselerotic lesions, ${ }^{251}$ which could predispose to the development and expression of endothelial dysfunction and ultimately to thrombus formation. A reduced bioactivity of endothelial-derived $\mathrm{NO}$ and/or $\mathrm{PGI}_{2}$ may be a key detrimental effect of hypercholesterolemia. Concurrently, endothelium-mediated vasoconstrictors, adhesion molecules, cytokines, growth factors and prothrombogenic factors (eg, TXA $\mathrm{A}_{2}$ are increased by LDL. Modified (mostly oxidized; ox-) LDL impairs endothelial function more than does native LDL. ${ }^{252} \mathrm{HDL}$ reduces the inhibitory effect of LDL on endothelium-mediated vasodilation $^{253}$ and a positive correlation was observed between HDL levels and acetylcholine-induced coronary vasodilation in humans. ${ }^{254}$ In experimental models, reduction in dietary cholesterol is associated with reduced production of $\mathrm{O}_{2}^{-}$(superoxide anion). ${ }^{255}$ Decreases in lipid peroxidation and slowing of the progression of atherosclerosis with cholesterol lowering have also been reported. ${ }^{256}$ However, in human subjects there is only indirect evidence that lipid peroxidation is relevant to endothelial function. For example, the susceptibility of LDL to oxidation correlates better with impairment in endothelial function than does the cholesterol level, ${ }^{257}$ and there is an inverse correlation between endothelium-derived $\mathrm{NO}$ activity in forearm resistance vessels and plasma antibodies against ox-LDL. ${ }^{258}$ The value of vitamins and other antioxidants (eg, vitamins $\mathrm{C}$ and $\mathrm{E}, \boldsymbol{\beta}$-carotene and probocol) in the prevention and treatment of atheroselerosis is controversial since short-term administration of antioxidant vitamins improves endothelial function, ${ }^{259}$ but long-term studies have reported variable results. ${ }^{260-262}$ It is possible that exogenous vitamin antioxidants do not sufficiently change the in vivo redox state, that they reduce the production of endogenous antioxidants, such as glutathione and superoxide dismutase, or that transient bursts of oxidative stress are important secondary messengers for vasoprotective processes. ${ }^{249}$

A number of studies have examined the effects of native and oxidized LDL on NO-mediated vascular functions (references are listed in three recent reviews). ${ }^{249,263,264}$ In most of these studies lipoproteins decreased the bioactivity of NO. Multiple mechanisms are apparently involved in the pathogenesis of endothelial dysfunction in atherosclerosis (Table 2). There is evidence that ox-LDL ${ }^{252}$ and products of lipid peroxidation ${ }^{265}$ can react with NO directly and eliminate its biological activity. Alternatively, the reduced production of $\mathrm{NO}$ is caused by abnormalities in signal transduction pathways, ${ }^{266}$ availability of L-arginine, ${ }^{267}$ cofactors for endothelial NO synthase $\left(\mathrm{eg}, \mathrm{BH}_{4}\right)^{268}$ and activity ${ }^{269}$ and expression of the enzyme. ${ }^{270}$ Administration of the NO precursor L-arginine restores endothelial dysfunction due to ox-LDL, suggesting an impairment in NO synthase or - less likely - a decreased L-arginine availability. In most, ${ }^{271,272}$ but not all, ${ }^{273}$ 
clinical studies infusion of L-arginine improves impaired endothelium-dependent vasodilation, including that due to hypercholesterolemia. Hypercholesterolemia decreases endothelial NO synthase activity by increasing its membrane inhibitor protein, caveolin. ${ }^{269}$ Asymmetrical dimethylarginine (ADMA) is an endogenous nitric oxide synthase inhibitor. It is formed by protein arginine $\mathbf{N}$-methyltransferases (PRMTs), which utilize S-adenosylmethionine as methyl group donor. ADMA plasma concentration is elevated in hypercholesterolemia, leading to proatherogenic changes of endothelial cell function. ${ }^{274}$ Other mechanisms may also be involved in the impaired endothelial functions in atherosclerosis including increased destruction of NO by $\mathrm{O}_{2}, 275$ intimal thickening as a diffusion barrier, altered responsiveness of target cells (eg, vascular smooth muscle and blood platelet) ${ }^{276}$ and concomitant release of proatherogenic factors (eg. endothelin, angiotensin- $\mathrm{II}$ and $\left.\mathrm{TXA}_{2}\right){ }^{277}$

Cholesterol-fed rabbits have increased endothelial production of superoxide radicals, ${ }^{275}$ Removal of the endothelium increases superoxide production in normocholesterolemic animals but reduces it in hypercholesterolemic animals. ${ }^{275}$ The superoxide anions are rapidly degraded to peroxynitrite $\left(\mathrm{ONOO}^{-}\right)$when it binds to $\mathrm{NO}$ resulting in reduced bioavailability of NO. Peroxynitrite is a potent and highly reactant oxidant which can propagate the cascade of oxidation and cell damage. ${ }^{278}$ Indeed, it has been demonstrated that $0 \mathrm{NOO}^{-}$may play an important role in oxidant-induced endothelial injury and that $\mathrm{ONOO}^{-}$-mediated protein modification is increased in human atherosclerotic plaques. ${ }^{279}$ The precise mechanism leading to the increased production of superoxide anions remains uncertain. Several sources of superoxide anions in atherosclerosis have been identified including xanthine oxidase, ${ }^{275} \mathrm{NADH} / \mathrm{NADPH}$ oxidase ${ }^{280}$ and ec-NOS ${ }^{281}$ or i-NOS. ${ }^{282}$ Although experimental studies strongly support a role for increased $\mathrm{O}_{2}$. production in impaired endothelium-derived NO bioactivity in atherosclerosis, specific evidence for this mechanism in human subjects is not available, in part due to lack of specific superoxide scavengers that can gain access to the vascular wall.

Moro, et al (1994) have investigated the effects of $\mathrm{ONOO}^{-}$on human platelets in vitro in order to explore the potential of this oxidant to contribute to tissue damage. ${ }^{283}$ The results obtained with washed platelets are consistent with the possibility that $\mathrm{ONOO}^{-}$causes platelet aggregation by stimulating the exposure of platelet receptors such as GPIIb-IIIa. This seems to be a direct effect of $\mathrm{ONOO}^{-}$and not due to secondary formation of $\mathrm{H}_{2} \mathrm{O}_{2}$ (hydrogen peroxide), $\mathrm{O}_{2}^{-}$or $\mathrm{OH}$ (hydroxyl radical), since it is not affected by scavengers of these oxidants or chelators of transition metals, which could have been involved in their generation. However, because even very small quantities of plasma added to the washed platelets were sufficient to reveal the platelet-inhibiting action of $\mathrm{ONOO}^{-}$, it is likely that $\mathrm{ONOO}^{-}$is converted into a different entity in the presence of plasma. Several substances may be responsible for this action, such as plasma thiols. The data presented in the study of Moro, et al (1994) suggest that $\mathrm{ONOO}^{-}$in plasma is 
activity of glutathione peroxidase that resulted in inereased plasma generation of $\mathrm{H}_{2} \mathrm{O}_{2}$, which inactivates NO. In addition, a missense variation of ec-NOS is positively associated with essential hypertension, myocardial infarction and venous thromboembolism (eg, deep-vein thrombosis, pulmonary embolism or inferior vena cava thrombosis). ${ }^{301,302}$ Reduced generation of NO by platelets is predictive of the presence of acute coronary syndromes in patients with coronary atherosclerosis. ${ }^{303}$ Acetyleholine-induced release of NO is impaired in patients with coronary artery disease, contributing to a reduction in the endothelial capacity to regulate platelet activation. ${ }^{304}$ The data clearly show that the alterations in the generation and action of $\mathrm{NO}$ at the miero- and macrovascular level are important for the pathogenesis of atherogenesis and its isehemic complications.

Most studies on platelet inhibitory actions of L-arginine were performed using in vitro platelet aggregation assays. Therefore, an in vivo study was performed as presented in Chapter 5 of this thesis. In this study the role of NO in hypercholesterolemia related thromboembolic events in mesenteric arterioles and venules was studied by local application of L-arginine on the mesentery of cholesterol-fed rabbits. In conclusion, the endothelium is a novel therapeutic target for the treatment of atherosclerotic cardiovascular disease. 
activity of glutathione peroxidase that resulted in inereased plasma generation of $\mathrm{H}_{2} \mathrm{O}_{2}$, which inactivates NO. In addition, a missense variation of ee-NOS is positively associated with essential hypertension, myocardial infaretion and venous thromboembolism (eg, deep-vein thrombosis, pulmonary embolism or inferior vena cava thrombosis). ${ }^{301,302}$ Reduced generation of NO by platelets is predictive of the presence of acute coronary syndromes in patients with coronary atherosclerosis. ${ }^{303}$ Acetyleholine-induced release of $\mathrm{NO}$ is impaired in patients with coronary artery disease, contributing to a reduction in the endothelial capacity to regulate platelet activation. ${ }^{304}$ The data clearly show that the alterations in the generation and action of $\mathrm{NO}$ at the micro- and macrovascular level are important for the pathogenesis of atherogenesis and its ischemie complications.

Most studies on platelet inhibitory actions of L-arginine were performed using in vitro platelet aggregation assays. Therefore, an in vivo study was performed as presented in Chapter 5 of this thesis. In this study the role of $\mathrm{NO}$ in hypercholesterolemia related thromboembolie events in mesenteric arterioles and venules was studied by local application of L-arginine on the mesentery of cholesterol-fed rabbits. In conclusion, the endothelium is a novel therapeutic target for the treatment of atherosclerotic cardiovascular disease. 


\section{TABLE 1}

The anti- and prothrombotic properties of vaseular cells

\begin{tabular}{|c|c|}
\hline Antithrombotie properties & Prothrombotie properties \\
\hline antiplatelet properties & platelet-stimulating properties \\
\hline prostaglandins $\left(\mathrm{PGI}_{2}, \mathrm{PGD}_{2}, \mathrm{PGE}_{2}\right)$ & collagen \\
\hline nitrie oxide (NO) & fibrinogen (Fng) \\
\hline lipoxygenase metabolites (12-HPETE. 13-HODE) & fibronectin \\
\hline ectonucleotidases (ATP-diphosphohydrolase) & thrombespondin (Tsp) \\
\hline matrix-metalloproteinase-9 (MMP-9) & adenosine diphesphate (ADP) \\
\hline anticoagulant properties & platelet-activating factor (PAF) \\
\hline heparin-like molecules (heparan sulphate) & von Willebrand factor ( $v W f$ ) \\
\hline thrombomodulin (TM) & matrix-metalloproteinase-9 (MMP-9) \\
\hline protein $\mathrm{C} /$ protein $\mathrm{S}$ & procoagulant properties \\
\hline tissue factor pathway inhibitor (TFPI) & coagulation factors (synthesis, binding and activation) \\
\hline annexin $\mathrm{V}$ & tissue factor (TF) \\
\hline profibrinolytic properties & antifibrinolytic properties \\
\hline tissue-type plasminogen activator (t-PA) & plasminogen activator inhibitor (PAI) \\
\hline urokinase-type plasminogen activator (u-PA) & thrombin activatable fibrinolysis inhibitor (TAFI) \\
\hline
\end{tabular}

12-HPETE-12-hydroperoxyeicosatetraenoic acid: 13-HODE-13-hydroxyoctadecadienoic acid 


\section{TABLE 2}

Possible meehanisms involved in the pathogenesis of nitric oxide (NO)-related endothelial dysfunction

- Receptor coupling dysfunction

- Diminished L-arginine availability

- Nitric oxide synthase (NOS):

- decreased expression of endothelial cell (ec)-NOS

- increased inducible (i)-NOS expression leading to production of superoxide anion $\left(\mathrm{O}_{2}{ }^{-}\right)$and peroxynitrite (ONOO')

- polymorphisms/mutations in ec-NOS

- increased ec-NOS/caveolin interaction

- decreased availability of cofactor(s); eg, tetrahydrobiopterin $\left(\mathrm{BH}_{4}\right)$

- endogenous ec-NOS inhibitor; ie, asymmetrical dimethylarginine (ADMA)

- Increased destruction of NO by:

- direct interaction with ox-LDL and products of lipid peroxidation

- radical scavenging $\left(\mathrm{eg}^{-\mathrm{O}_{2}}{ }^{-}\right)$leading to production of $\mathrm{ONOO}^{-}$

- Balance between pro (eg, antiplatelet, vasorelaxant) and anti (eg, platelet stimulating. vasoconstricting): shift is more towards anti (eg, more thromboxane $\mathrm{A}_{2}\left[\mathrm{TXA}_{2}\right]$ ) than to pro (eg, $\mathrm{NO}$ or prostaglandin $\mathrm{I}_{2}\left[\mathrm{PGI}_{2}\right]$ )

- Decrease in sensitivity to NO of target cells (eg, platelets or vascular smooth muscle cells)

- Intimal thickening, causing a diffusion barrier for NO 


\section{NITRIC OXIDE/EICOSANOIDS: ACTIONS AND INTERACTIONS}

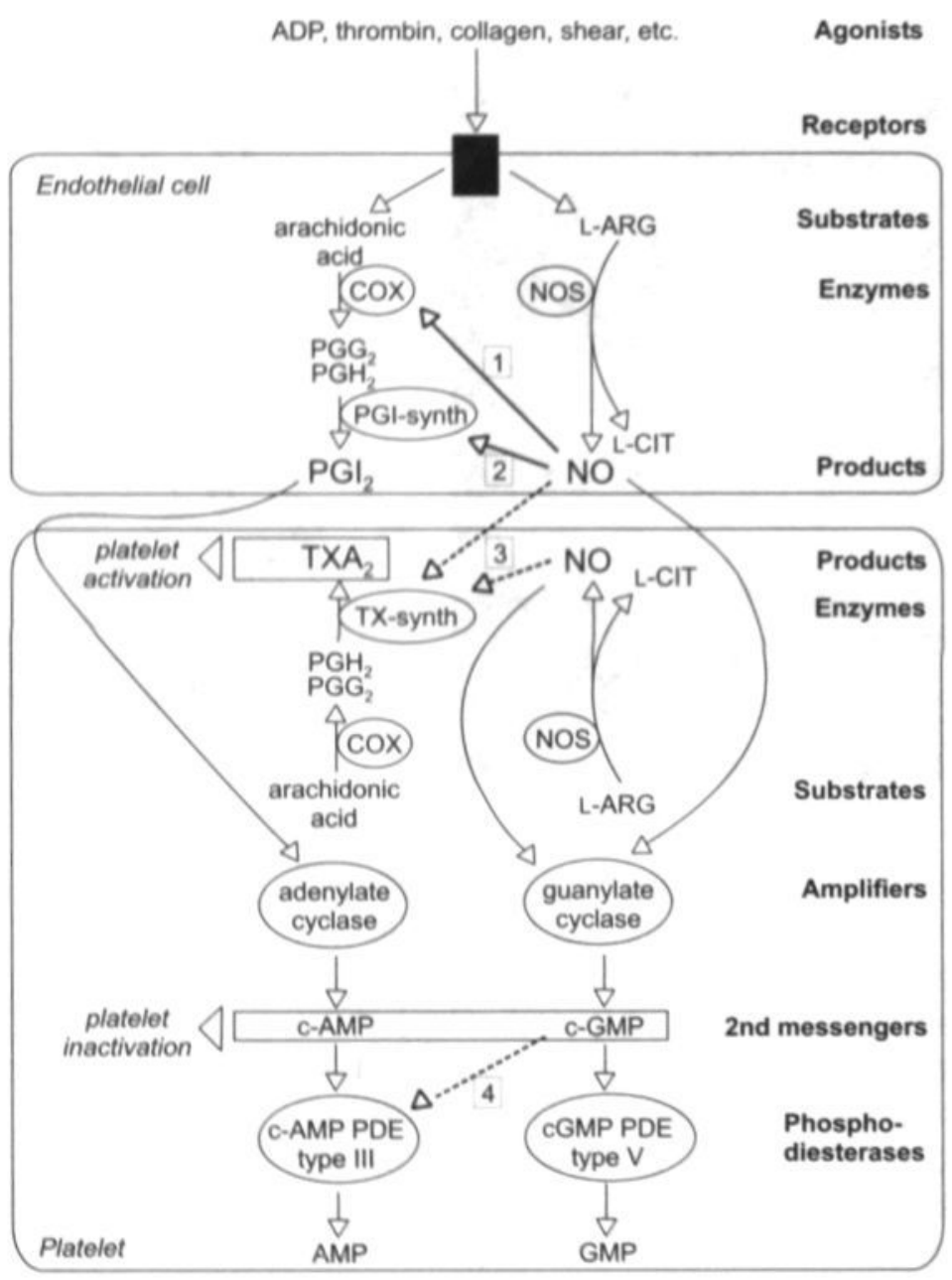

\section{Figure 3}

Scheme showing proposed interactions between the platelet inactivators nitric oxide (NO) and prostaglandin $\mathrm{I}_{2}\left(\mathrm{PGI}_{2}\right)$, and the platelet aetivator thromboxane $\mathrm{A}_{2}\left(\mathrm{TX}_{2}\right)$. Thin black arrows depict signal transduction pathways related to the synthesis of NO (in both endothelial cell and platelet), $\mathbf{P G I}_{2}$ (endothelial cell) and $\mathbf{T X A}_{2}$ (platelet). Synthesis of $\mathrm{NO}$ and eicosanoids is initiated by activation of specific receptors by agonists (eg, ADP [adenosine diphosphate], thrombin, collagen) or shear stress. Most biological actions of $\mathrm{NO}$ and $\mathrm{PGI}_{2}$ are mediated through guanylate cyclase/cGMP (cyclic guanosine 3',5'-monophosphate) and adenylate cyclase/cAMP (cyclie adenosine $3^{\prime}, 5^{\prime}$-monophosphate), respectively. The platelet inactivators cGMP and cAMP are converted to inactive AMP and GMP by respective enzymes cAMP phosphodiesterase (PDE) type III and eGMP PDE type V. Thick black arrows mark proposed stimulating (continuous line) or inhibiting (interrupted line) interactions between the $\mathrm{L}$ arginine/NOS pathway and the arachidonic acid/COX pathway. 1: COX activation by NO. leading to enhanced $\mathrm{PGI}_{2}$ synthesis. 2: PGI-synthase (PGI-synth) activation by NO, leading to enhanced $\mathrm{PGI}_{2}$ synthesis. 3: TX-synthase (TXsynth) inhibition by NO, leading to decreased TXA $_{2}$ synthesis. 4: cAMP PDE type III-inhibition by cGMP, leading to a reduced inactivation of cAMP thereby enhancing actions of $\mathrm{PGI}_{2}$. L-ARG indicates L-arginine; L-CIT, L-citrulline; COX, cyclooxygenase: NOS, nitric oxide synthase; $\mathrm{PGG}_{2}$ and $\mathrm{PGH}_{2}$ indicate prostaglandin endoperoxide $\mathrm{G}_{2}, \mathrm{H}_{2}$, respectively. 


\section{CYCLOOXYGENASE AS A POTENTIAL TARGET FOR NITRIC OXIDE}

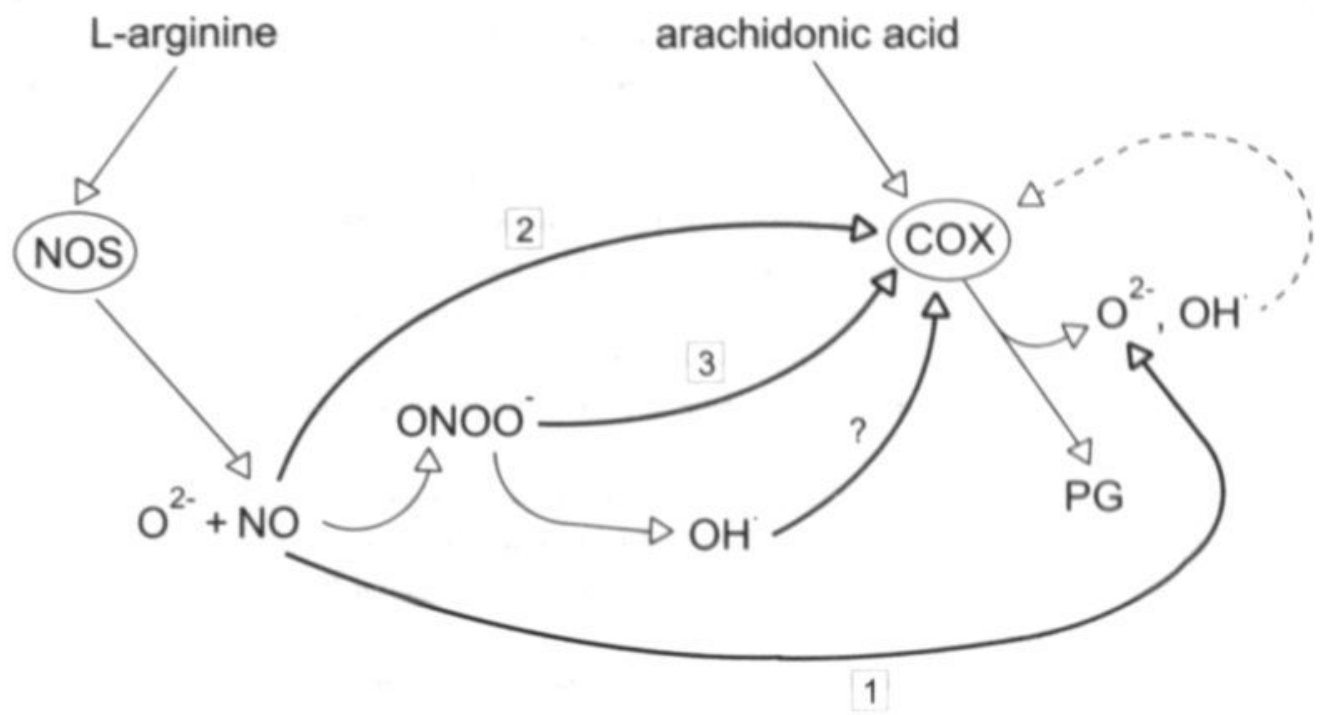

Figure 4

Cyclooxygenase $(\mathrm{COX})$ as a potential target for nitric oxide (NO). For simplicity the nitric oxide synthase (NOS) and COX isoforms are not shown. Thin black arrows depict signal transduction pathways related to the synthesis of $\mathrm{NO}$ and prostaglandins ( $\mathrm{PG} ; \mathrm{eg}, \mathrm{PGI}_{2}$ ). COX enzymes are targets for the (patho)physiological action of NO and once activated in the presence of NO, represent important transduction mechanisms for the actions of NO. Thick black arrows mark proposed stimulating (continuous line) or inhibiting (interrupted line) interactions between the NOS/NO pathway and the arachidonic acid/COX pathway. 1: antioxidant effect of NO preventing the superoxide anion $\left(\mathrm{O}_{2}{ }^{-}\right)$-induced autoinactivation of COX. 2: formation of nitrosothiols inereasing $\mathrm{COX}$ enzyme activity by changing $\mathrm{COX}$ structure. 3: generation of peroxynitrite $\left(\mathrm{ONOO}^{\circ}\right)$ which was shown to increase COX activity. ?: the role of $\mathrm{OH}$ (hydroxyl radical) is not yet known although it is known to increase PG release. Adapted from Salvemini; Cell Mol Life Sci. 1997;53:576-582. 


\section{NITRIC OXIDE/EICOSANOIDS: ACTIONS AND INTERACTIONS}

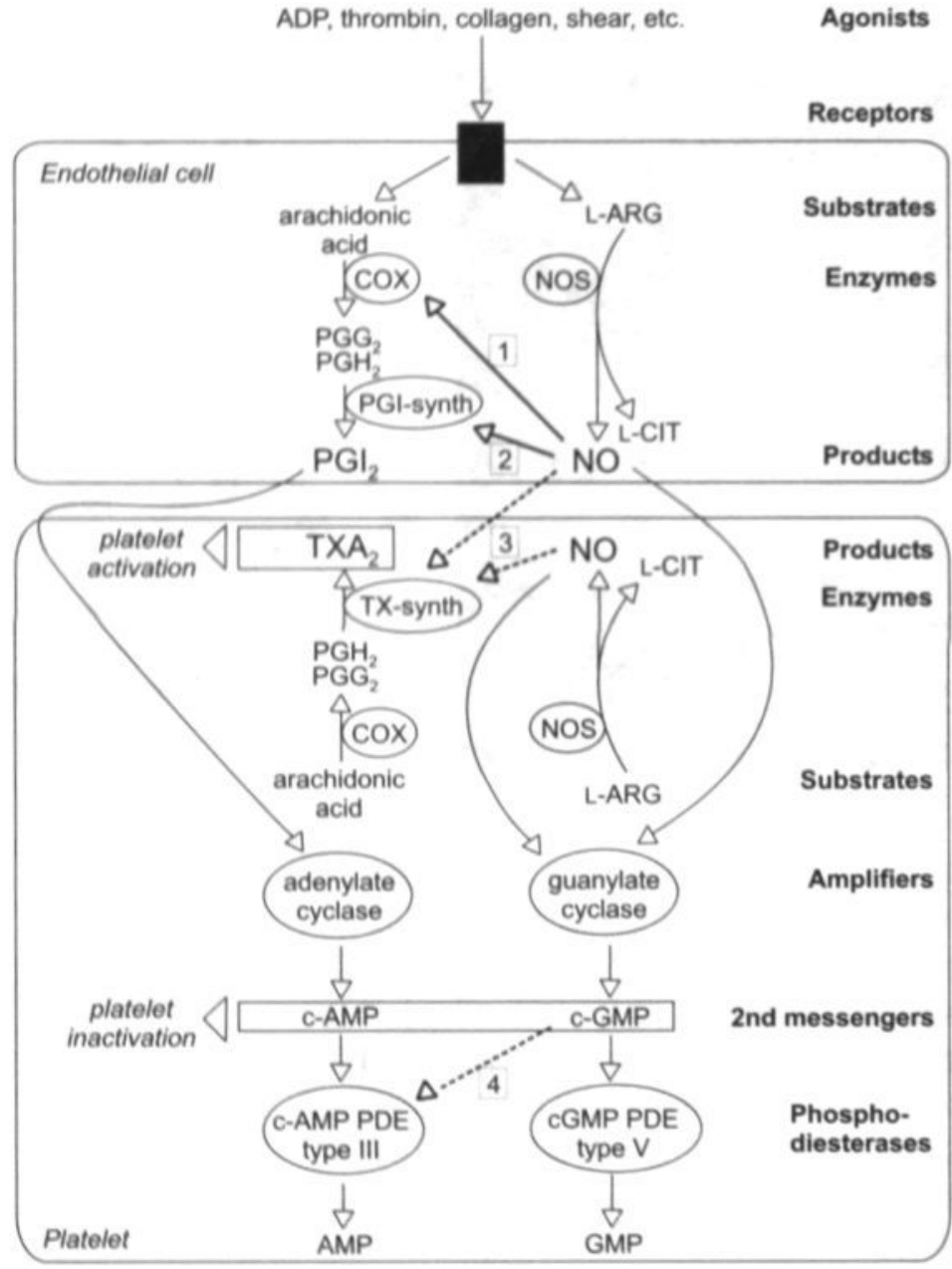

Figure 3

Scheme showing proposed interactions between the platelet inactivators nitric oxide (NO) and prostaglandin $\mathrm{I}_{2}\left(\mathrm{PGI}_{2}\right)$, and the platelet aetivator thromboxane $\mathrm{A}_{2}\left(\mathrm{TXA}_{2}\right)$. Thin black arrows depiet signal transduction pathways related to the synthesis of NO (in both endothelial cell and platelet), $\mathrm{PGI}_{2}$ (endothelial cell) and $\mathrm{TXA}_{2}$ (platelet). Synthesis of NO and eicosanoids is initiated by activation of specific receptors by agonists (eg, ADP [adenosine diphosphate], thrombin, collagen) or shear stress. Most biological actions of $\mathrm{NO}$ and $\mathrm{PGI}_{2}$ are mediated through guanylate cyclase/cGMP (cyclic guanosine 3',5'-monophosphate) and adenylate cyclase/cAMP (cyclic adenosine $3^{\prime}, 5^{\prime}$-monophosphate), respectively. The platelet inactivators eGMP and eAMP are converted to inactive AMP and GMP by respective enzymes cAMP phosphodiesterase (PDE) type III and eGMP PDE type V. Thick black arrows mark proposed stimulating (continuous line) or inhibiting (interrupted line) interactions between the $\mathrm{L}$ arginine/NOS pathway and the arachidonic acid/COX pathway. 1: COX activation by NO, leading to enhanced $\mathrm{PGI}_{2}$ synthesis. 2: PGI-synthase (PGI-synth) activation by NO, leading to enhanced $\mathrm{PGI}_{2}$ synthesis. 3: TX-synthase (TXsynth) inhibition by NO, leading to decreased TXA $_{2}$ synthesis. 4: cAMP PDE type III-inhibition by cGMP, leading to a reduced inactivation of cAMP thereby enhancing actions of $\mathrm{PGI}_{2}$. L-ARG indicates L-arginine; L-CIT, L-citrulline; COX, cyclooxygenase: NOS, nitric oxide synthase; $\mathrm{PGG}_{2}$ and $\mathrm{PGH}_{2}$ indicate prostaglandin endoperoxide $G_{2}, H_{2}$, respectively. 


\section{CYCLOOXYGENASE AS A POTENTIAL TARGET FOR NITRIC OXIDE}

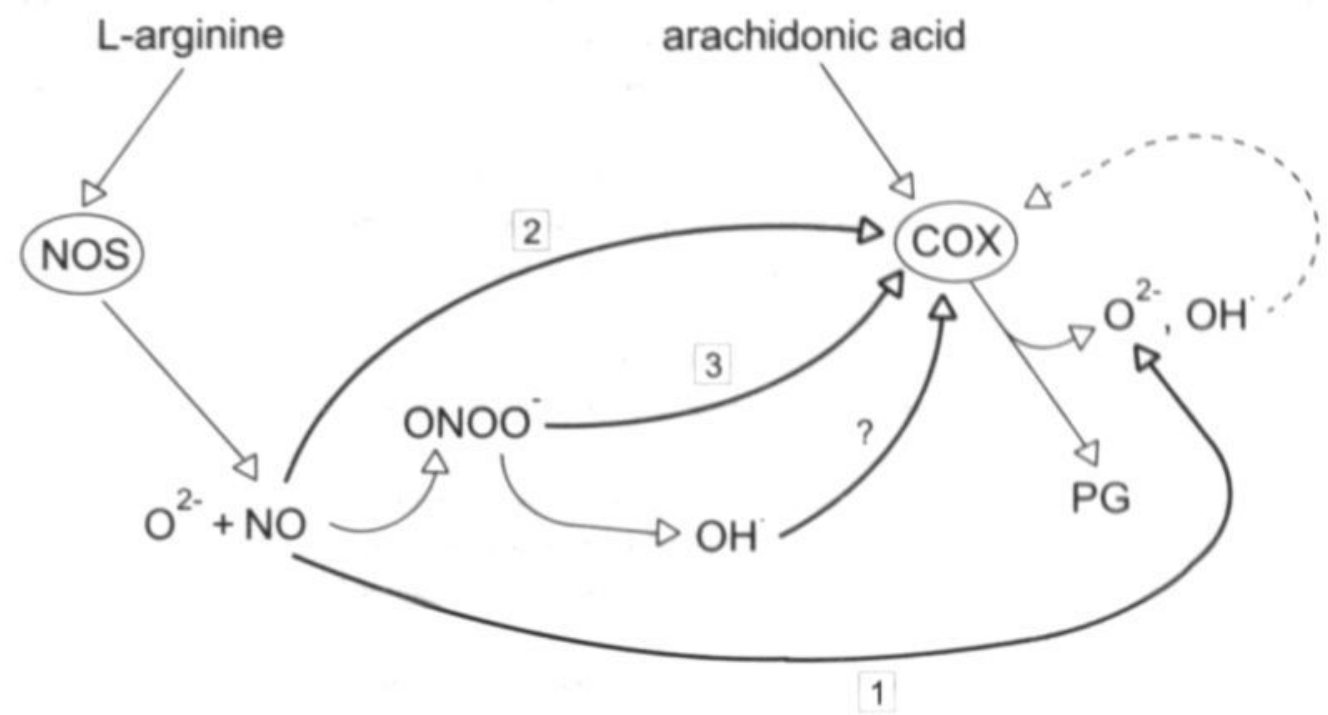

Figure 4

Cyelooxygenase (COX) as a potential target for nitric oxide (NO). For simplicity the nitric oxide synthase (NOS) and COX isoforms are not shown. Thin black arrows depiet signal transduction pathways related to the synthesis of $\mathrm{NO}$ and prostaglandins ( $\mathrm{PG} ; \mathrm{eg}, \mathrm{PGI}_{2}$ ). COX enzymes are targets for the (patho)physiological action of $\mathrm{NO}$ and once activated in the presence of NO, represent important transduction mechanisms for the actions of NO. Thick black arrows mark proposed stimulating (continuous line) or inhibiting (interrupted line) interactions between the NOS/NO pathway and the arachidonic acid/COX pathway. I: antioxidant effect of $\mathrm{NO}$ preventing the superoxide anion $\left(\mathrm{O}_{2}{ }^{-}\right)$-induced autoinactivation of $\mathrm{COX}$. 2: formation of nitrosothiols increasing $\mathrm{COX}$ enzyme activity by changing $\mathrm{COX}$ structure. 3: generation of peroxynitrite $\left(\mathrm{ONO}^{\circ}\right)^{-}$which was shown to increase COX activity. ?: the role of $\mathrm{OH}$ (hydroxyl radical) is not yet known although it is known to increase PG release. Adapted from Salvemini; Cell Mol Life Sci. 1997;53:576-582. 


\section{References}

1. Cines DB, Pollak ES, Buck CA, Loscalzo J, Zimmerman GA, MeEver RP, Pober JS, Wiek TM, Konkle BA, Schwartz BS, Barnathan ES, MeCrae KR, Hug BA, Schmidt AM, Stern DM. Endothelial cells in physiology and in the pathophysiology of vascular disorders. Blood. 1998;91:3527-3561.

2. Sixma JJ, de Groot PG. Regulation of platelet adhesion to the vessel wall. Ann N Y Acad Sci. 1994;714:190-199.

3. Zwaal RF, Comfurius P, Bevers EM. Platelet procoagulant activity and microvesicle formation. Its putative role in hemostasis and thrombosis. Biochim Biophys Acta. 1992;1180:1-8.

4. Huang PY, Hellums JD. Aggregation and disaggregation kinetics of human blood platelets: Part III. The disaggregation under shear stress of platelet aggregates. Biophys J. 1993;65:354-361.

5. Ruggeri ZM, FitzGerald GA, Shattil SJ. Chapter 25: Platelet thrombus formation and antiplatelet therapy. In: Chien KR, ed. Molecular basis of Cardiovascular Disease. San Diego: W.B. Saunders Company: 2000:566-589.

6. Kulkarni S, Dopheide SM, Yap CL, Ravanat C, Freund M, Mangin P, Heel KA, Street A, Harper IS, Lanza F, Jackson SP. A revised model of platelet aggregation. J Clin Invest. 2000;105:783-791.

7. Colman R. Hemostasis and Thrombosis: Basic Principles and Clinical Practice. 4th ed: Lippincott Williams \& Wilkins; 2000.

8. Hemker HC, Beguin S. Thrombin generation in plasma: its assessment via the endogenous thrombin potential. Thromb Haemost. 1995;74:134-138.

9. oude Egbrink MGA. Tangelder GJ, Slaaf DW, Reneman RS. Thromboembolic reaction following wall puncture in arterioles and venules of the rabbit mesentery. Thromb Haemost. 1988;59:23-28.

10. Ruggeri ZM, Ware J. von Willebrand factor. Faseb J. 1993:7:308-316.

11. Hemker HC, van Rijn JL, Rosing J, van Dieijen G, Bevers EM, Zwaal RF. Platelet membrane involvement in blood coagulation. Blood Cells. 1983;9:303-317.

12. Schroit AJ, Zwaal RF. Transbilayer movement of phospholipids in red cell and platelet membranes. Biochim Biophys Acta. 1991;1071:313-329.

13. Kumar R, Beguin S, Hemker HC. The influence of fibrinogen and fibrin on thrombin generation; evidence for feedback activation of the clotting system by clot bound thrombin. Thromb Haemost. 1994;72:713-721.

14. Blombäck B. Fibrinogen and fibrin; proteins with complex roles in hemostasis and thrombosis. Thrombosis Research. 1996;83:1-75.

15. Puri RN, Colman RW. ADP-induced platelet activation. Crit Rev Biochem Mol Biol. 1997;32:437502.

16. Gachet C. Platelet activation by ADP: the role of ADP antagonists. Ann Med. 2000:32:15-20.

17. Shen RF, Tai HH. Thromboxanes: synthase and receptors. J Biomed Sci. 1998:5:153-172. 
18. Sawicki G, Salas E, Murat J, Miszta-Lane H, Rademski MW. Release of gelatinase A during platelet activation mediates aggregation. Nature. 1997;386:616-619.

19. Fernandez-Patron C, Martinez-Cuesta MA, Salas E, Sawieki G, Wozniak M, Radomski MW, Davidge ST. Differential regulation of platelet aggregation by matrix metalloproteinases-9 and -2 . Thromb Haemost. 1999;82:1730-1735.

20. Fernandez-Patron C, Zhang Y, Radomski MW, Hollenberg MD, Davidge ST. Rapid release of matrix metalloproteinase (MMP)-2 by thrombin in the rat aorta: modulation by protein tyrosine kinase/phosphatase. Thromb Haemost. 1999;82:1353-1357.

21. Kohler HP, Grant PJ. Plasminogen-activator inhibiter type I and coronary artery disease. N Engl J Med. 2000;342:1792-1801.

22. Bajzar L. Thrombin activatable fibrinolysis inhibitor and an antifibrinolytic pathway. Arteriosel Thromb Vase Biol. 2000;20:2511-2518.

23. Mareus AJ, Broekman MJ, Drosopoulos JH, Islam N, Alyonycheva TN, Safier L.B, Hajjar KA. Posnett DN, Schoenborn MA, Schooley KA, Gayle RB, Maliszewski CR. The endothelial cell ectoADPase responsible for inhibition of platelet function is CD39. J Clin Invest. 1997;99:1351-1360.

24. Resenberg RD, Shworak NW, Liu J, Sehwartz JJ, Zhang L. Heparan sulfate proteoglyeans of the cardiovascular system. Specifie struetures emerge but how is synthesis regulated? $J$ Clin Invest. 1997; 100:S67-S75.

25. Esmon CT. Regulation of blood coagulation. Biochim Biophys Acta. 2000; 1477:349-360.

26. Gurewich V. Fibrinolysis: an unfinished agenda. Blood Coagul Fibrinolysis. 2000;11:401-408.

27. Sandset PM. Tissue factor pathway inhibitor (TFPI); an update. Haemostasis. 1996;26:154-165.

28. Camici M, Sagripanti A. Tissue factor pathway inhibitor. Minerva Med. 1999:90:25-32.

29. Benz J, Hofmann A. Annexins: from structure to function. Biol Chem. 1997;378:177-183.

30. Rand JH. The annexinopathies: a new category of diseases. Biochim Biophys Acta. 2000;1498:169 173.

31. Romisch J, Seiffge D, Reiner G, Paques EP, Heimburger N. In vivo antithrombotic potency of placenta protein 4 (annexin V). Thromb Res. 1991;61:93-104.

32. Van Ryn-MeKenna J, Merk H, Muller TH, Buchanan MR, Eisert WG. The effects of heparin and annexin $\mathrm{V}$ on fibrin accretion after injury in the jugular veins of rabbits. Thromb Haemost. 1993;69:227-230.

33. van Heerde WL, Sakariassen KS, Hemker HC, Sixma JJ, Reutelingsperger CP, de Groot PG. Annexin $\mathrm{V}$ inhibits the procoagulant activity of matrices of TNF-stimulated endothelium under blood flow conditions. Arterioscler Thromb. 1994;14:824-30.

34. Greaves M. Antiphospholipid syndrome: state of the art with emphasis on laboratory evaluation. Haemostasis. 2000;30:16-25. 
35. Furchgott RF, Zawadzki JV. The obligatory role of endothelial cells in the relaxation of arterial smooth muscle by acetyleholine. Nature. 1980;288:373-377.

36. Palmer RM, Ferrige AG, Moncada S. Nitric oxide release accounts for the biological activity of endothelium-derived relaxing factor. Nature. 1987;327:524-526.

37. Ignarro LJ, Buga GM, Wood KS, Byrns RE, Chaudhuri G. Endothelium-derived relaxing factor produced and released from artery and vein is nitric oxide. Proc Natl Acad Sci U S A. 1987;84:92659269.

38. Palmer RM, Ashton DS, Moncada S. Vascular endothelial cells synthesize nitric oxide from L-arginine. Nature. 1988;333:664-666.

39. Raman CS, Li H, Martasek P, Kral V, Masters BS, Poulos TL. Crystal structure of constitutive endothelial nitric oxide synthase: a paradigm for pterin function involving a novel metal center. Cell. 1998;95:939-950.

40. Masters BS. Chapter 6: Struetural variations to accomodate functional themes of the isoforms of NO synthases, In: Ignarro LJ, ed. Nitric oxide: Biology and pathobiology. San Diego: Academic Press; 2000:91-104.

41. Marsden PA, Heng HH, Seherer SW, Stewart RJ, Hall AV, Shi XM, Tsui LC, Sehappert KT. Structure and chromosomal localization of the human constitutive endothelial nitric oxide synthase gene. J Biol Chem. 1993:268:17478-17488.

42. Kishimoto J, Spurr N, Liao M, Lizhi L, Emson P, Xu W. Localization of brain nitric oxide synthase (NOS) to human chromosome 12. Genomics. 1992;14:802-804.

43. Chartrain NA, Geller DA, Koty PP, Sitrin NF, Nussler AK, Hoffman EP, Billiar TR, Hutehinson NI, Mudgett JS. Molecular cloning, strueture, and chromosomal localization of the human inducible nitric oxide synthase gene. J Biol Chem. 1994;269:6765-6772.

44. Knowles RG, Moncada S. Nitric oxide synthases in mammals. Biochem J. 1994:298:249-258.

45. Pollock JS, Klinghofer V, Förstermann U, Murad F. Endothelial nitric oxide synthase is myristylated. FEBS Lett. 1992;309:402-404.

46. Sessa WC, Barber CM, Lynch KR. Mutation of $\mathbf{N}$-myristoylation site converts endothelial cell nitric oxide synthase from a membrane to a cytosolic protein. Circ Res. 1993;72:921-924.

47. Sessa WC, Gareia-Cardena G, Liu J, Keh A, Pollock JS, Bradley J, Thiru S, Braverman IM, Desai KM. The Golgi association of endothelial nitric oxide synthase is necessary for the efficient synthesis of nitric oxide. J Biol Chem. 1995;270:17641-17644.

48. Pollock JS, Nakane M, Buttery LDK, Martinez A, Springall D, Polak JM, Förstermann U, Murad F. Characterization and localization of endothelial nitric oxide synthase using specific monoclonal antibodies. Am J Physiol. 1993;265:C1379-C1387.

49. Balligand J-L, Cannon PJ. Nitric oxide synthases and cardiac muscle. Arterioscler Thromb Vase Biol. 1997;17:1846-1856. 

oxide synthase (NOS I and NOS III). Faseb J. 1998;12:773-790.

51. Blum-Degen D, Heinemann T, Lan J, Pedersen V, Leblhuber F, Paulus W, Riederer P, Gerlach M. Charaeterization and regional distribution of nitric oxide synthase in the human brain during normal ageing. Brain Res. 1999;834:128-135.

52. Yun HY, Dawson VL, Dawson TM. Nitrie oxide in health and disease of the nervous system. Mol Psychiatry. 1997:2:300-310.

53. Hoffman RA. Zhang G, Nussler NC, Gleixner SL. Ford HR, Simmons RL. Watkins SC. Censtitutive expression of inducible nitric oxide synthase in the mouse ileal mueosa. Am J Physiol. 1997:272:G383-G392.

54. Gue FH, De Raeve HR, Rice TW, Stuehr DJ. Thunnissen FB, Erzurum SC. Continueus nitrie oxide synthesis by inducible nitrie oxide synthase in normal human airway epithelium in vivo. Proc Natl Acad Sci U S A. 1995:92:7809-7813.

55. Mannick JB, Asano K, Izumi K. Kieff E, Stamler JS. Nitric oxide produced by human B lymphocytes inhibits apoptosis and Epstein-Barr virus reactivation. Cell. 1994:79:1137-1146.

56. Cho HJ. Xie QW, Calayeay J, Mumford RA, Swiderek KM, Lee TD, Nathan C. Calmodulin is a subunit of nitric oxide synthase from macrophages. J Exp Med. 1992:176:599-604.

57. Zamora R, Vodovotz Y, Billiar TR. Inducible nitric oxide synthase and inflammatory diseases, Mol Med. 2000;6:347-373.

58. Shah AM. Inducible nitric oxide synthase and cardiovascular disease. Cardiovasc Res. 2000;45:148155.

59. Fukuto JM, Chaudhuri G. Inhibition of constitutive and inducible nitric oxide synthase: potential selective inhibition. Annu Rev Pharmacol Toxicol. 1995;35:165-194.

60. Anggard E. Nitric oxide: mediator, murderer, and medicine. Lancet. 1994:343:1199-1206.

61. Simon DI, Stamler JS, Jaraki O, Keaney JF, Osborne JA, Francis SA, Singel DJ, Loscalzo J. Antiplatelet properties of protein $S$-nitrosothiols derived from nitric oxide and endothelium-derived relaxing factor. Arterioscler Thromb. 1993;13:791-799.

62. Radomski MW, Palmer RM, Moneada S. Comparative pharmacology of endothelium-derived relaxing factor, nitric oxide and prostacyelin in platelets. Br J Pharmacol. 1987;92:181-187.

63. Murad F, Mittal CK, Arnold WP, Katsuki S, Kimura H. Guanylate eyelase: activation by azide, nitro compounds, nitric oxide, and hydroxyl radical and inhibition by hemoglobin and myoglobin. Adv Cyclic Nucleotide Res. 1978;9:145-158.

64. Bolotina VM, Najibi S, Palacino JJ, Pagano PJ, Cohen RA. Nitric oxide directly activates calciumdependent potassium ehannels in vaseular smooth musele. Nature. 1994:368:850-853.

65. Kubes P. Suzuki M. Granger DN. Nitric oxide: an endogenous modulator of leukocyte adhesion. Proc Natl Acad Sci U S A. 1991;88:4651-4655. 
66. Garg UC, Hassid A. Nitrie oxide-generating vasodilators and 8-bromo cyelic guanosine monophosphate inhibit mitogenesis and proliferation of eultured rat vascular smooth muscle cells. J Clin Invest. 1989;83:1774-1777.

67. Section III: Prineiples of pathobiology. Part B: NO and cardiovaseular function (Chapters 31-38). In: Ignarro L, ed. Nitric oxide: Biology and pathobiology. San Diego: Academic Press; 2000:483632.

68. Section III: Prineiples of pathobiology. Part C: Pathophysiological mechanisms of NO (Chapters 39 54). In: Ignarro LJ, ed. Nitric oxide: Biology and pathobiology. San Diego: Academic Press; 2000:633-920.

69. Section III: Principles of pathobiology. Part D: Clinical significance of NO (Chapters 55-58). In: Ignarro LJ, ed. Nitric oxide: Biology and pathobiology. San Diego: Academic Press; 2000:921-981.

70. Hampton JR, Harrison MJ, Honour AJ, Mitchell JR. Platelet behaviour and drugs used in cardiovascular disease. Cardiovasc Res. 1967;1:101-107.

71. Mellion BT, Ignarro LJ, Ohlstein EH, Pontecorvo EG, Hyman AL, Kadowitz PJ. Evidence for the inhibitory role of guanosine 3',5'-monophosphate in ADP-induced human platelet aggregation in the presence of nitric oxide and related vasodilators. Blood. 1981;57:946-955.

72. Azuma H, Ishikawa M, Sekizaki S. Endothelium-dependent inhibition of platelet aggregation. $\mathrm{Br} J$ Pharmacol. 1986;88:411-415.

73. Radomski MW, Palmer RM, Moncada S. Endogenous nitric oxide inhibits human platelet adhesion to vascular endothelium. Lancet. 1987;2:1057-1058.

74. Radomski MW, Palmer RM, Moncada S. The anti-aggregating properties of vascular endothelium: interactions between prostacyelin and nitric oxide. Br J Pharmacol. 1987;92:639-646.

75. Jurasz P, Radomski A, Sawicki G, Mayers I, Radomski MW. Chapter 51: Nitric oxide and platelet function. In: Ignarro LJ, ed. Nitric oxide: Biology and pathobiology. San Diego: Academic Press; 2000:823-840.

76. Freedman JE, Loscalzo J, Barnard MR, Alpert C, Keaney JF, Michelson AD. Nitric oxide released from activated platelets inhibits platelet recruitment. J Clin Invest. 1997:100:350-356.

77. Freedman JE, Sauter R, Battinelli EM, Ault K, Knowles C, Huang PL, Losealzo J. Deficient plateletderived nitric oxide and enhanced hemostasis in mice lacking the NOSIII gene. Circ Res. $1999 ; 84: 1416-1421$.

78. Venturini CM, Del Vecehio PJ, Kaplan JE. Thrombin induced platelet adhesion to endothelium is modified by endothelial derived relaxing factor (EDRF). Biochem Biophys Res Commun. 1989:159:349-354.

79. Pohl U, Busse R. EDRF inereases cyclic GMP in platelets during passage through the coronary vascular bed. Circ Res. 1989;65:1798-1803. 

released from human platelets. Biochem Biophys Res Commun. 1993:194:960-965.

81. Zhou Q. Hellermann GR, Solomonson L.P. Nitric oxide release from resting human platelets. Thromb Res. 1995:77:87-96.

82. Sase K. Michel T. Expression of constitutive endothelial nitrie oxide synthase in human blood platelets. Life Sci. 1995:57:2049-2055.

83. Mareus AJ, Safier LB. Thromberegulation: multicellular medulation of platelet reactivity in hemostasis and thrombosis. Faseb J. 1993;7:516-522.

84. Ambrosio G, Tritte I. Reperfusion injury: experimental evidence and elinical implications. Am Heart J. 1999; 138:S69-S75.

85. Mehta P. Mehta JL. Effects of aspirin in arterial thrombesis: why den't animals behave the way humans do? J Am Coll Cardiol. 1993;21:511-513.

86. Lopez-Farre A, Caramelo C, Esteban A, Alberola ML, Millas I, Monton M, Casade S. Effects of aspirin on platelet-neutrophil interactions. Role of nitric oxide and endothelin-1. Circulation. 1995;91:2080-2088.

87. Lopez-Farre A, Riesce A, Digiuni E, Mosquera JR, Caramele C, de Miguel LS, Millas I, de Frutos T, Cernadas MR, Monton M, Alonso J, Casado S. Aspirin-stimulated nitric exide production by neutrophils after acute myocardial ischemia in rabbits. Circulation. 1996;94:83-87.

88. Megson IL, Sogo N, Mazzei FA, Butler AR, Walton JC, Webb DJ. Inhibition of human platelet aggregation by a novel $S$-nitrosothiol is abolished by haemoglobin and red blood cells in vitro: implications for anti-thrombotic therapy. Br J Pharmacol. 2000;131:1391-1398.

89. Tangelder GJ, Slaaf DW, Tierlinck HC, Alewijnse R, Reneman RS. Localization within a thin optical section of fluorescent blood platelets flowing in a microvessel. Microvasc Res. 1982:23:214-230.

90. Nishimura H, Rosenblum WI, Nelson GH, Boynton S. Agents that modify EDRF formation alter antiplatelet properties of brain arteriolar endothelium in vivo. Am J Physiol. 1991:261:H15-H21.

91. Rosenblum WI, Nishimura H, Ellis EF, Nelson GH. The endothelium-dependent effects of thimerosal on mouse pial arterioles in vivo: evidence for control of mierovascular events by EDRF as well as prostaglandins. J Cereb Blood Flow Metab. 1992;12:703-706.

92. Rosenblum WI, Nishimura H, Nelson GH. L-NMMA in brain microcirculation of mice is inhibited by blockade of cyclooxygenase and by superoxide dismutase. Am J Physiol. 1992;262:H1343-H1349.

93. Ovize M, de Lorgeril M, Cathignol D, Delaye J, Renaud S. Inhibition of coronary artery thrombonis by SIN-1, a donor of nitric oxide. J Cardiovasc Pharmacol. 1990;16:641-645.

94. Yao SK, Ober JC, Krishnaswami A, Ferguson JJ, Anderson HV, Golino P, Buja LM, Willerson JT. Endogenous nitric oxide protects against platelet aggregation and cyclic flow variations in stenosed and endothelium-injured arteries. Circulation. 1992;86:1302-1309. 
95. Paul W, Gresele P, Momi S, Bianchi G, Page CP. The effect of defibrotide on thromboembolism in the pulmonary vaseulature of mice and rabbits and in the cerebral vasculature of rabbits. $\mathrm{Br} J$ Pharmacol. 1993:110:1565-1571.

96. Meng YY, Trachtenburg J, Ryan US, Abendschein DR. Potentiation of endogenous nitric oxide with superoxide dismutase inhibits platelet-mediated thrombosis in injured and stenotic arteries. J Am Coll Cardiol. 1995:25:269-275.

97. Yao SK, Akhtar S, Seottburden T, Ober JC, Golino P, Buja LM, Casscells W, Willerson JT. Endogenous and exogenous nitric oxide protect against intracoronary thrombosis and reocelusion after thrombelysis. Circulation. 1995;92:1005-1010.

98. Pawlak R, Chabielska E, Golatowski J. Azzadin A, Buczko W. Nitric oxide and prostacyelin are involved in antithrombotic action of eaptopril in venous thrombosis in rats. Thromb Haemost. 1998;79:1208-1212.

99. Chabielska E, Pawlak R, Golatowski J, Rolkowski R, Pawlak D, Buczko W. Losartan inhibits experimental venous thrombosis in spontaneously hypertensive rats. Thromb Res. 1998;90:271-278.

100. Pawlak R, Chabielska E, Matys T, Kucharewicz I, Rolkowski R, Buczko W. Thiol repletion prevents venous thrombosis in rats by nitric oxide/prostacyclin-dependent mechanism: relation to the antithrombotic action of captopril. J Cardiovase Pharmacol. 2000:36:503-509.

101. Lindberg RA, Slaaf DW, Miller FN. Involvement of nitric oxide and cyclooxygenase products in photoactivation-induced microvascular ocelusion. Microvasc Res. 1994:47:203-221.

102. Broeders MAW, Tangelder GJ, Slaaf DW, Reneman RS, oude Egbrink MGA. Endogenous nitric oxide protects against thromboembolism in venules but not in arterioles. Arterioscler Thromb Vase Biol. 1998; 18:139-145.

103. Peire MA, Puig-Parellada P. Oxygen-free radicals and nitric oxide are involved in the thrombus growth produced by iontophoresis of ADP. Pharmacol Res. 1998;38:353-356.

104. Andrews NP. Husain M, Dakak N, Quyyumi AA. Platelet inhibitory effect of nitric oxide in the human coronary circulation: impact of endothelial dysfunction. J Am Coll Cardiol. 2001:37:510-516.

105. BodzentaLukaszyk A, Gabryelewicz A, Lukaszyk A, Bielawiec M, Konturek JW, Domschke W. Nitric oxide synthase inhibition and platelet function. Thromb Res. 1994:75:667-672.

106. Simon DI, Stamler JS, Loh E, Loscalzo J, Francis SA, Creager MA. Effect of nitric oxide synthase inhibition on bleeding time in humans. J Cardiovasc Pharmacol. 1995;26:339-342.

107. Adams MR, Forsyth CJ, Jessup W, Robinson J. Celermajer DS. Oral L-arginine inhibits platelet aggregation but does not enhance endothelium-dependent dilation in healthy young men. J Am Coll Cardiol. 1995;26:1054-1061.

108. Houston DS, Buchanan MR. Influence of endothelium-derived relaxing factor on platelet function and hemostasis in vivo. Thromb Res. 1994;74:25-37. 
109. Freedman JE, Loscalzo J, Benoit SE, Valeri CR, Barnard MR, Michelson AD. Deereased platelet inhibition by nitric oxide in two brothers with a history of arterial thrombesis. $J$ Clin Invest. 1996:97:979-987.

110. Kenet G. Freedman J, Shenkman B, Regina E, Brok-Simoni F, Holeman F, Vavva F, Brand N, Michelson A. Trolliet M, Loscalzo J. Inbal A. Plasma glutathione peroxidase defieieney and platelet insensitivity to nitrie oxide in children with familial stroke. Arterioscler Thromb Vase Biol. 1999: 19:2017-2023.

11. Moro MA, Russel RJ, Cellek S, Lizasoain I, Su Y, Darley-Usmar VM, Radomski MW, Moncada S. eGMP mediates the vascular and platelet actions of nitric oxide: confirmation using an inhibitor of the soluble guanylyl eyclase. Proc Natl Acad Sei U S A. 1996:93:1480-1485.

112. Menshikev M, Ivanova K, Sehaefer M, Drummer C, Gerzer R. Influence of the eGMP analog 8 PCPT-eGMP on agonist-induced increases in eytosolie ionized $\mathrm{Ca}^{2+}$ and on aggregation of human platelets. Eur J Pharmacol. 1993;245:281-284.

113. Brune B, Lapetina EG. Aetivation of a cytosolic ADP-ribosyltransferase by nitric oxide-grnerating agents. J Biol Chem. 1989;264:8455-8458.

114. Nakatsuka M, Osawa Y. Selective inhibition of the 12-lipoxygenase pathway of arachidenie acid metabolism by L-arginine or sodium nitroprusside in intact human platelets. Biochem Biophys Res Commun. 1994;200:1630-1634.

115. Ambrosio G. Tritto I, Golino P. Reactive oxygen metabolites and arterial thrombosis. Cardiovasc Res. 1997;34:445-452.

116. Brune B, Ullrich V. 12-hydroperoxyeicosatetraenoic acid inhibits main platelet functions by activation of soluble guanylate cyclase. Mol Pharmacol. 1991;39:671-678.

117. Brune B, Ullrich V. Inhibition of platelet aggregation by earbon monoxide is mediated by activation of guanylate cyclase. Mol Pharmacol. 1987;32:497-504.

118. Walter U. Physiological role of eGMP and eGMP-dependent protein kinase in the cardiovascular system. Rev Physiol Biochem Pharmacol. 1989;113:41-88.

119. Halbrügge M, Friedrich C, Eigenthalter M, Schanzenbächer P, Walter U. Stochiometric and reversible phosphorylation of 46-kDa protein in human platelets in response to cGMP- and cAMP. elevating vasodilators. J Biol Chem. 1990;265:3088-3093.

120. Haffner C, Jarehau T, Reinhard M, Hoppe J, Lohmann SM, Walter U. Molecular cloning, structural analysis and functional expression of the proline-rich focal adhesion and microfilament-associated protein VASP. Embo J. 1995;14:19-27.

121. Reinhard M, Halbrügge M, Scheer U, Wiegand C, Jockuseh BM, Walter U. The 46/50 kDa phosphoprotein VASP purified from human platelets is a novel protein associated with actin filaments and focal contacts. Embo J. 1992;11:2063-2070. 

adhesion vasodilator-stimulated phosphoprotein at Ser 157 in intact human platelets correlates with fibrinogen receptor inhibition. Eur J Biochem. 1994;225:21-27.

123. Wang GR, Zhu Y, Halushka PV, Lincoln TM, Mendelsohn ME. Mechanism of platelet inhibition by nitric oxide: in vivo phosphorylation of thromboxane receptor by cyclic GMP-dependent protein kinase. Proc Natl Acad Sci U S A. 1998;95:4888-4893.

124. Maurice DH, Haslam RJ. Molecular basis of the synergistic inhibition of platelet function by nitrovasodilators and activators of adenylate cyelase: inhibition of cyclic AMP breakdown by cyclic GMP. Mol Pharmacol. 1990;37:671-681.

125. Mendelsohn ME, $\mathbf{O}^{\prime}$ Neill S, George D, Loscalzo J. Inhibition of fibrinogen binding to human platelets by S-nitroso-N-acetyleysteine. J Biol Chem. 1990;265:19028-19034.

126. Murohara T, Parkinson SJ, Waldman SA, Lefer AM. Inhibition of nitric oxide biosynthesis promotes P-selectin expression in platelets. Role of protein kinase C. Arterioscler Thromb Vasc Biol. 1995:15:2068-2075.

127. Michelson AD, Benoit SE. Furman MI, Breckwoldt WL, Rohrer MJ, Barnard MR, Loscalzo J. Effects of nitric oxide/EDRF on platelet surface glycoproteins. Am J Physiol. 1996;270:H1640H1648.

128. Shahbazi T, Jones N, Radomski MW, Moro MA, Gingell D. Nitric oxide donors inhibit platelet spreading on surfaces coated with fibrinogen but not with fibronectin. Thromb Res. 1994;75:631642.

129. Govers R, Rabelink TJ. Cellular regulation of endothelial nitric oxide synthase. Am J Physiol Renal Physiol. 2001;280:F193-F206.

130. Razani B, Engelman JA, Wang XB, Schubert W, Zhang XL, Marks CB, Macaluso F, Russell RG, Li M, Pestell RG, Di Vizio D, Hou H, Jr., Kneitz B, Lagaud G, Christ GJ, Edelmann W, Lisanti MP. Caveolin-1 null mice are viable but show evidence of hyperproliferative and vascular abnormalities. J Biol Chem. 2001;276:38121-38138.

131. Bredt DS, Hwang PM, Glatt CE, Lowenstein C, Reed RR, Snyder SH. Cloned and expressed nitric oxide synthase structurally resembles cytochrome P-450 reductase. Nature. 1991;351:714-718.

132. Bredt DS, Ferris CD. Snyder SH. Nitric oxide synthase regulatory sites. Phosphorylation by cyelie AMP-dependent protein kinase, protein kinase C, and caleium/calmodulin protein kinase; identification of flavin and calmodulin binding sites. J Biol Chem. 1992;267:10976-10981.

133. Kleinert H, Boissel J-P, Schwartz PM, Förstermann U. Chapter 7: Regulation of the expression of nitric oxide synthase isoforms. In: Ignarro LJ, ed. Nitric oxide: Biology and pathobiology. San Diego: Academic Press: 2000: 105-128.

134. Haller H, Elliott HL. Review: the central role of calcium in the pathogenesis of cardiovascular disease. J Hum Hypertens. 1996;10:143-155. 
135. Fleming I. Chapter 38: Aetivation of NOS by $\mathrm{Ca}^{2+}$-dependent and $\mathrm{Ca}^{2+}$-independent mechanisms. In: Ignarro LJ, ed. Nitric oxide: Biology and pathobiology. San Diego: Academic Press; 2000:621-632.

136. Pohl U, Holtz J, Busse R, Bassenge E. Crucial role of endothelium in the vasodilator response to increased flow in vive. Hypertension. 1986;8:37-44.

137. Blatter LA, Taha Z, Mesaros S, Shacklock PS, Wier WG. Malinski T. Simultaneous measurements of $\mathrm{Ca}^{2+}$ and nitric oxide in bradykinin-stimulated vascular endothelial cells. Circ Res. 1995;76:922924.

138. Neufeld G, Cohen T, Gengrinovitch S, Poltorak Z. Vaseular endethelial growth faetor (VEGF) and its receptors. Faseb J. 1999:13:9-22.

139. Morbidelli L, Chang CH, Douglas JG, Granger HJ, Ledda F, Ziche M. Nitric oxide mediates mitogenic effect of VEGF on coronary venular endothelium. Am J Physiol. 1996;270:H411-H415.

140. Van der Zee R. Murohara T, Luo Z, Zollmann F, Passeri J, Lekutat C, Isner JM. Vaseular endethelial growth factor/vascular permeability factor augments nitrie oxide release from quieseent rabbit and human vaseular endothelium. Circulation. 1997;95:1030-1037.

141. Parenti A, Morbidelli L, Cui XL, Douglas JG, Hood JD, Granger HJ, Ledda F, Ziche M. Nitrie oxide is an upstream signal of vascular endothelial growth factor-induced extracellular signal-regulated kinase 1/2 activation in postcapillary endothelium. J Biol Chem. 1998:273:4220-4226.

142. Soker S, Takashima S, Miao HQ, Neufeld G, Klagsbrun M. Neuropilin-1 is expressed by endothelial and tumor cells as an isoform-specific receptor for vascular endothelial growth factor. Cell. 1998:92:735-745.

143. Dulak J, Jozkowicz A, Dembinska-Kiec A, Guevara I, Zdzienicka A, Zmudzinska-Grochot D, Florek I, Wojtowicz A, Szuba A, Cooke JP. Nitric oxide induces the synthesis of vascular endothelial growth factor by rat vascular smooth muscle cells. Arterioscler Thromb Vasc Biol. 2000;20:659-666.

144. Hood JD, Meininger CJ, Ziche M, Granger HJ. VEGF upregulates ec-NOS message, protein, and NO production in human endothelial cells. Am J Physiol. 1998;274:H1054-H1058.

145. Shen BQ, Lee DY, Zioncheck TF. Vascular endothelial growth factor governs endothelial nitric-oxide synthase expression via a KDR/Flk-1 receptor and a protein kinase C signaling pathway. $J$ Biol Chem. 1999;274:33057-33063.

146. Zachary I, Mathur A, Yla-Herttuala S, Martin J. Vascular protection: A novel nonangiogenic eardiovascular role for vascular endothelial growth factor. Arterioscler Thromb Vasc Biol. 2000;20:1512-1520.

147. Kuriyama H, Ito Y, Suzuki H, Kitamura K, Itoh T. Factors modifying contraction-relaxation cycle in vascular smooth muscles. Am J Physiol. 1982;243:H641-H662.

148. Guimaraes S, Moura D. Vascular adrenoceptors: an update. Pharmacol Rev. 2001;53:319-356.

149. Dawes M, Chowienczyk PJ, Ritter JM. Effects of inhibition of the L-arginine/nitric oxide pathway on vasodilation caused by beta-adrenergic agonists in human forearm. Circulation. 1997;95:2293-2297. 
150. Molenaar P. Malta E, Jones CR, Buxton BF, Summers RJ. Autoradiographie localization and funetion of beta-adrenoceptors on the human internal mammary artery and saphenous vein. $\mathrm{Br} J$ Pharmacol. 1988;95:225-233.

151. Ferro A, Queen LR, Priest RM, Xu B, Ritter JM, Poston L, Ward JP. Activation of nitrie oxide synthase by beta 2 -adrenoceptors in human umbilical vein endothelium in vitro. $\mathrm{Br} \mathrm{J}$ Pharmacol. 1999:126:1872-1880.

152. Sobrevia L. Yudilevich DL, Mann GE. Activation of A2-purinoceptors by adenosine stimulates Larginine transport (system $\mathrm{y}_{+}$) and nitric oxide synthesis in human fetal endothelial cells. J Physiol. 1997:499:135-140.

153. Corson MA, James NL, Latta SE, Nerem RM, Berk BC, Harrison DG. Phosphorylation of endothelial nitrie oxide synthase in response to fluid shear stress. Circ Res. 1996;79:984-991.

154. Berkenboom G. Depierreux M, Fontaine J. The influence of atheroselerosis on the mechanical responses of human isolated coronary arteries to substance $\mathrm{P}$, isoprenaline and noradrenaline. $\mathrm{Br} J$ Pharmacol. 1987;92:113-120.

155. Kiuchi K, Sato N, Shannon RP, Vatner DE, Morgan K, Vatner SF. Depressed beta-adrenergic receptor- and endothelium-mediated vasodilation in conscious dogs with heart failure. Circ Res. 1993:73:1013-1023.

156. Arribas S, Marin J, Ponte A, Balfagon G, Salaices M. Norepinephrine-induced relaxations in rat aorta mediated by endothelial beta-adrenoceptors. Impairment by ageing and hypertension. J Pharmacol Exp Ther. 1994:270:520-527.

157. Larosa G, Forster C. Coronary beta-adrenoceptor function is modified by the endothelium in heart failure. J Vase Res. 1996:33:62-70.

158. Funk CD. The molecular biology of mammalian lipoxygenases and the quest for eicosanoid functions using lipoxygenase-deficient mice. Biochim Biophys Acta. 1996:1304:65-84.

159. Breyer RM, Kennedy CR, Zhang Y, Breyer MD. Structure-funetion analyses of eicosanoid receptors. Physiologic and therapeutic implications. Ann N Y Acad Sci. 2000;905:221-231.

160. Austin SC, Funk CD. Insight into prostaglandin, leukotriene, and other eicosanoid functions using mice with targeted gene disruptions. Prostaglandins Other Lipid Mediat. 1999;58:231-252.

161. Gerritsen ME. Physiological and pathophysiological roles of eicosanoids in the microcirculation. Cardiovase Res. 1996:32:720-732.

162. Xie WL, Chipman JG, Robertson DL, Erikson RL, Simmons DL. Expression of a mitogen-responsive gene encoding prostaglandin synthase is regulated by mRNA splicing. Proc Natl Acad Sci U S A. $1991 ; 88: 2692-2696$.

163. Vane J. Towards a better aspirin. Nature. 1994:367:215-216.

164. Moncada S, Vane JR. Arachidonic acid metabolites and the interactions between platelets and bloodvessel walls. N Engl J Med. 1979:300:1142-1147. 
165. Moneada S, Gryglewski R, Bunting S, Vane JR. An enzyme isolated from arteries transforms prostaglandin endoperoxides to an unstable substance that inhibits platelet aggregation. Nature. 1976:263:663-665.

166. Szezeklik A, Gryglewski RJ. Nizankowski R, Musial J, Pieton R, Mruk J. Circulatory and antiplatelet effects of intravenous prostacyelin in healthy men. Pharmacol Res Commun. 1978:10:545556.

167. Higss EA, Moneada S, Vane JR, Caen JP, Michel H, Tobelem G. Effect of prostacyelin (PGI2) on platelet adhesion te rabbit arterial subendothelium. Prostaglandins. 1978:16:17-22.

168. Vane JR. Botting RM. Pharmacodynamic profile of prostacyclin. Am J Cardiol. 1995:75:3a-10a.

169. KaserGlanzmann R, Jakabova M, George JN, Luscher EF. Stimulation of calcium uptake in platelet membrane vesicles by adenosine $3^{\prime}, 5^{\prime}$-eyclic monophosphate and protein kinase. Biochim Biophys Acta. 1977;466:429-440.

170. Moneada S. Eighth Gaddum Memorial Leeture. University of London Institute of Education, December 1980. Biological importance of prostacyelin. Br J Pharmacol. 1982:76:3-31.

171. Lapetina EG, Schmitges CJ, Chandrabose K. Cuatrecases P. Cyelie adenosine $3^{\prime}, 5^{\prime}$-monophosphate and prostacyclin inhibit membrane phospholipase activity in platelets. Biochem Biophys Res Commun. 1977;76:828-835.

172. Minkes M, Stanford N, Chi MM, Roth GJ, Raz A, Needleman P, Majerus PW. Cyclic adenosine 3',5'monophosphate inhibits the availability of arachidonate to prostaglandin synthetase in human platelet suspensions. J Clin Invest. 1977;59:449-454.

173. Malmsten C, Granstrom E, Samuelsson B. Cyclic AMP inhibits synthesis of prostaglandin endoperoxide $\left(\mathrm{PGG}_{2}\right)$ in human platelets. Biochem Biophys Res Commun. 1976;68:569-576.

174. Ito S, Narumiya S, Hayaishi O. Prostglandin $\mathrm{D}_{2}$. A biochemical perspective. Prostglandins Leukotrienes Med. 1989:37:219-234.

175. Smith WL, Garavito RM, DeWitt DL. Prostaglandin endoperoxide $\mathrm{H}$ synthases (eyclooxygenases)-1 and -2. J Biol Chem. 1996;271:33157-33160.

176. Verheugt FW. Aspirin, the poor man's statin? Lancet. 1998;351:227-228.

177. Collaboration AT. Collaborative overview of randomised trials of antiplatelet therapy - I: Prevention of death, myocardial infaretion, and stroke by prolonged antiplatelet therapy in various categories of patients. Antiplatelet Trialists' Collaboration. Bmj. 1994:308:81-106.

178. Smith WL, DeWitt DL, Garavito RM. Cyelooxygenases: struetural, cellular, and molecular biology. Annu Rev Biochem. 2000;69:145-182.

179. Mukherjee D, Nissen SE, Topol EJ. Risk of eardiovaseular events associated with seleetive COX-2 inhibitors. JAMA. 2001:286:954-959. 
180. Langenbach R, Morham SG, Tiano HF, Loftin CD, Ghanayem BI, Chulada PC, Mahler JF, Lee CA, Goulding EH, Kluckman KD, et al. Prostaglandin synthase 1 gene disruption in mice reduces arachidonic acid-induced inflammation and indomethacin-induced gastric ulceration. Cell. 1995;83:483492.

181. Morham SG, Langenbach R, Loftin CD, Tiano HF, Vouloumanos N, Jennette JC, Mahler JF, Kluekman KD, Ledford A, Lee CA, et al. Prostaglandin synthase 2 gene disruption causes severe renal pathology in the mouse. Cell. 1995;83:473-482.

182. Radomski MW, Moneada S. Role of nitrie oxide in endothelial cell-platelet interactions. In: Herman AG, ed. Antithrombotics. Dordrecht, The Netherlands: Kluwer Academic Publications; 1991:25-48.

183. Stamler JS, Vaughan DE, Loscalzo J. Synergistic disaggregation of platelets by tissue-type plasminogen activator, prostaglandin E1, and nitroglycerin. Circ Res. 1989;65:796-804.

184. Davidge ST, Baker PN, Laughlin MK, Roberts JM. Nitric oxide produced by endothelial cells increases production of eicosanoids through activation of prostaglandin $\mathbf{H}$ synthase. Circ Res. 1995:77:274-283.

185. de Nucei G, Gryglewski RJ, Warner TD, Vane JR. Receptor-mediated release of endotheliumderived relaxing factor and prostacyclin from bovine aortic endothelial cells is coupled. Proc Natl Acad Sci U S A. 1988;65:2334-2338.

186. Förstermann U, Warmuth G, Dudel C, Alheid U. Formation and functional importance of endothelium-derived relaxing factor (EDRF) and prostaglandins in the microcirculation. $Z$ Kardiol. 1989;78:85-91.

187. Spiecker M, Darius H, Meyer J. Synergistic platelet antiaggregatory effects of the adenylate cyclase activator iloprost and the guanylate cyclase activating agent SIN-1 in vivo. Thromb Res. 1993:70:405-415.

188. Sinzinger H, Fitscha P, J OG, Rauscha F, Rogatti W, Vane JR. Synergistic effect of prostaglandin $\mathrm{E}_{1}$ and isosorbide dinitrate in peripheral vascular disease. Lancet. 1990;335:627-628.

189. Sinzinger H, Rauscha F, $0^{\prime}$ Grady J, Fitscha $P$. Prostaglandin $I_{2}$ and the nitric oxide donor molsidomine have synergistic effects on thromboresistance in man. Br J Clin Pharmacol. 1992;33:289. 292.

190. Salvemini D. Regulation of cyclooxygenase enzymes by nitric oxide. Cell Mol Life Sci. 1997;53:576582 .

191. Salvemini D, Settle SL, Masferrer JL, Seibert K, Currie MG, Needleman P. Regulation of prostaglandin production by nitric oxide; an in vivo analysis. Br J Pharmacol. 1995;114:1171-1178.

192. Wade ML. Fitzpatrick FA. Nitric oxide modulates the activity of the hemoproteins prostaglandin $\mathbf{I}_{2}$ synthase and thromboxane $A_{2}$ synthase. Arch Biochem Biophys. 1997:347:174-180.

193. Di Rosa M, lalenti A, lanaro A, Sautebin L. Interaction between nitric oxide and cyclooxygenase pathways. Prostaglandins Leukot Essent Fatty Acids. 1996:54:229-238. 
194. Eekly AE, Lugnier C. Role of phosphodiesterases III and IV in the modulation of vascular eyclic AMP content by the NO/eyelie GMP pathway. Br J Pharmacol. 1994;113:445-450.

195. Pohl U, Nolte C, Bunse A, Eigenthalter M, Walter U. Endothelium dependent phespherylation of vasodilator-stimulated protein in platelets during coronary passage. Am J Physiol. 1994:266:H606H612.

196. Zwaginga JJ, de Boer HC, Usseldijk MJ, Kerkhof A, Muller-Berghaus G, Gruhliehhenn J, Sixma JJ, de Groot PG. Thrombogenicity of vaseular cells. Comparison between endothelial cells isolated from different sources and smooth muscle cells and fibroblasts. Arteriosclerosis. 1990;10:437-448.

197. Garlanda C, Dejana E. Heterogeneity of endothelial cells. Specifie markers. Arterioscler Thromb Vase Biol. 1997;17:1193-202.

198. Boegehold MA. Heterogeneity of endethelial function within the eireulation. Curr Opin Nephrol Hypertens. 1998;7:71-78.

199. Rajotte D, Arap W, Hagedorn M, Koivunen E, Pasqualini R, Ruoslahti E. Molecular heterogeneity of the vascular endethelium revealed by in vivo phage display. J Clin Invest. 1998:102:430-437.

200. Quail AW, Cottee DB, Porges WL, White SW. Recent views on integrated coronary control: significance of non-uniform regional control of coronary flow conductance. Clin Exp Pharmacol Physiol. 2000;27:1039-1044.

201. Broeders MA, Doevendans PA, Bekkers BC, Bronsaer R, van Gorsel E, Heemskerk JW, Egbrink MG, van Breda E, Reneman RS, van Der Zee R. Nebivolol: a third-generation beta-blocker that augments vaseular nitric oxide release. Endothelial beta(2)-adrenergic receptor-mediated nitric oxide production. Circulation. 2000;102:677-684.

202. Huang TY, Chu TF, Chen HI, Jen CJ. Heterogeneity of $\left[\mathrm{Ca}^{2+}\right]_{i}$ signaling in intact rat aortic endothelium. Faseb J. 2000;14:797-804.

203. Guillot PV, Liu L, Kuivenhoven JA, Guan J, Rosenberg RD, Aird WC. Targeting of human eNOS promoter to the hprt locus of mice leads to tissue-restricted transgene expression. Physiol Genomics. 2000:2:77-83.

204. Vaughn MW, Kuo L, Liao JC. Effective diffusion distance of nitric oxide in the microcirculation. Am J Physiol. 1998:274:H1705-H1714.

205. Lüscher TF, Diederich D, Siebenmann R, Lehmann K, Stulz P, von Segesser L, Yang ZH, Turina M, Gradel E, Weber E. Difference between endothelium-dependent relaxation in arterial and in venous coronary bypass grafts. N Engl J Med. 1988;319:462-467.

206. Yang ZH, Stulz P, von Segesser L, Bauer E. Turina M, Lüscher TF. Different interactions of platelets with arterial and venous coronary bypass vessels. Lancet. 1991:337:939-943.

207. Yang Z, Arnet U, Bauer E, von-Segesser L, Siebenmann R, Turina M, Lüscher TF. Thrombininduced endothelium-dependent inhibition and direet aetivation of platelet-vessel wall interaction. Role of prostacyclin, nitric oxide, and thromboxane $A_{2}$. Circulation. 1994:89:2266-2272. 
208. Tadjkarimi S, O'Neil GS, Luu TN, Allen SP, Sehyns CJ, Chester AH, Yacoub MH. Comparison of cyelie GMP in human internal mammary artery and saphenous vein: implications for coronary artery bypass graft patency. Cardiovase Res. 1992;26:297-300.

209. Rubanyi GM, Vanhoutte PM. Heterogeneity of endothelium-dependent responses to acetyleholine in canine femoral arteries and veins. Separation of the role played by endothelial and smooth muscle cells. Blood Vessels. 1988:25:75-81.

210. O'Neil GS, Chester AH, Allen SP, Luu TN, Tadjkarimi S, Ridley P, Khagani A, Musumeci F, Yacoub MH. Endothelial function of human gastroepiploie artery. Implications for its use as a bypass graft. J Thorac Cardiovase Surg. 1991:102:561-565.

211. Fukaya Y, Ohhashi T. Acetyleholine- and flow-induced production and release of nitrie oxide in arterial and venous endothelial cells. Am J Physiol. 1996:270:H99-H106.

212. Broeders MAW, Doevendans PA, Maessen JG, van Gorsel E, oude Egbrink MGA, Daemen MJAP, Tangelder GJ, Reneman RS, van Der Zee R. The human internal mammary artery releases more nitric oxide in response to vascular endothelial growth factor than the human saphenous vein. $J$ Thorac Cardiovase Surg. 2001:122:305-309.

213. Collins LC, Roberts AM. Effects of platelet-activating factor on arteriolar and venular tone in rat trachea. Microvasc Res. 1997;53:63-72.

214. Suzuki H, Swei A, Zweifach BW, Schmid-Schönbein GW. In vivo evidence for microvascular oxidative stress in spontaneously hypertensive rats. Hydroethidine microfluorography. Hypertension. 1995:25:1083-1089.

215. Moncada S, Higgs EA, Vane JR. Human arterial and venous tissues generate prostacyclin (prostaglandin $x$ ), a potent inhibitor of platelet aggregation. Lancet. 1977;1:18-20.

216. Chaikhouni A, Crawford FA, Kochel PJ, Olanoff LS, Halushka PV. Human internal mammary artery produces more prostacyelin than saphenous vein. J Thorac Cardiovase Surg. 1986;92:88-91.

217. Gerritsen ME, Cheli CD. Arachadonic acid and prostaglandin andoperoxide metabolism in isolated rabbit and coronary microvessels and isolated and cultivated coronary microvessel endothelial cells. J Clin Invest. 1983:72:1658-1671.

218. Revtyak GE, Johnson AR, Campbell WB. Prostaglandin synthesis in bovine coronary endothelial cells: comparison with other commonly studied endothelial cells. Thromb Res. 1987;48:671-683.

219. Taylor L. Foxall T, Auger K, Heinsohn C, Polgar P. Comparison of prostaglandin synthesis by endothelial cells from blood vessels originating in the rat, baboon, calf and human. Atherosclerosis. $1987 ; 65: 227-236$.

220. Gerritsen ME, Parks TP, Printz MP. Prostaglandin endoperoxide metabolism by bovine cerebral microvessels. Biochim Biophys Acta. 1980;619:196-206.

221. Gerritsen ME, Printz MP. Sites of prostaglandin synthesis in the bovine heart and isolated bovine coronary microvessels. Cire Res. 1981;49:1152-1163.

Chapter 2 
222. Rodrigues AM, Gerritsen ME. Prostaglandin release from isolated rabbit cerebral cortex miero-vessels - comparison of 6-kete PGF 1 alpha and $\mathrm{PGE}_{2}$ release from microvessels ineubated in $100 \% \mathrm{O}_{2}$. room air and 95\% $\mathrm{N}_{2}: 5 \% \mathrm{CO}_{2}$. Stroke. 1984;15:717-722.

223. Charo IF, Shak S, Karasek MA. Davison PM, Goldstein IM. Prostaglandin 12 is not a major metabolite of arachidonic acid in cultured endothelial cells from human foreskin microvessels. J Clin Invest. 1984:74:914-919.

224. Stanimirovie DB, Bacie F. Uematsu S, Spatz M. Profile of prostaglandins induced by endethelin-1 in human brain capillary endothelium. Neurochem Int. 1993:23:385-393.

225. oude Egbrink MGA. Tangelder GJ. Slaaf DW, Reneman RS. Different roles of prostaglandins in thrombeembolic processes in arterioles and venules in vivo. Thromb Haemost. 1993;70:826-833.

226. Yang ZH, von Segesser L, Bauer E, Stulz P. Turina M, Luscher TF. Different activation of the endothelial L-arginine and eyelooxygenase pathway in the human internal mammary artery and saphenous vein. Circ Res. 1991;68:52-60.

227. Shimokawa H, Flavahan NA, Lorenz RR, Vanhoutte PM. Prostacyelin releases endothelium-derived relaxing factor and potentiates its action in coronary arteries of the pig. $\mathrm{Br} J$ Pharmacol. 1988;95:1197-1203.

228. de Wit C, von Bismarck P, Pohl U. Synergistic action of vasodilators that increase eGMP and cAMP in the hamster cremaster microcirculation. Cardiovasc Res. 1994:28:1513-1518.

229. Koller A, Sun D, Huang A, Kaley G. Corelease of nitric oxide and prostaglandins mediates flowdependent dilation of rat gracilis muscle arterioles. Am J Physiol. 1994:267:H326-H332.

230. Koller A, Dornyei G, Kaley G. Flow-induced responses in skeletal muscle venules: modulation by nitric oxide and prostaglandins. Am J Physiol. 1998;275:H831-H836.

231. Aitchison KA, Coker SJ. Potential interactions between iloprost and SIN-1 on platelet aggregation and myocardial infaret size in vivo. Eur J Pharmacol. 1999:374:59-69.

232. Broeders MAW, Tangelder GJ, Slaaf DW, Reneman RS, oude Egbrink MGA. Endogenous nitric oxide and prostaglandins synergistically counteract thromboembolism in arterioles but not in venules. Arterioscler Thromb Vasc Biol. 2001;21:163-169.

233. van Wachem PB, Reinders JH, van Buul-Wortelboer MF, de Groot PG, van Aken WG, van Mourik JA. von Willebrand factor in cultured human vaseular endothelial cells from adult and umbilical cord arteries and veins. Thromb Haemost. 1986;56:189-192.

234. Smith JM, Meinkoth JH, Hochstatter T, Meyers KM. Differential distribution of von Willebrand factor in canine vascular endothelium. Am J Vet Res. 1996:57:750-755.

235. Whatley RE, Zimmerman GA. MeIntyre TM, Prescott SM. Endothelium from diverse vascular sources synthesizes platelet-activating factor. Arteriosclerosis. 1988;8:321-331. 
236. Silverman MD, Waters CR, Hayman GT, Wigboldus J, Samet MM, Lelkes PI. Tissue factor activity is increased in human endothelial cells cultured under elevated static pressure. Am J Physiol. $1999 ; 277:$ C233-C242.

237. Sisto T, Yla-Herttuala S, Luoma J, Riekkinen H, Nikkari T. Biochemical composition of human internal mammary artery and saphenous vein. J Vase Surg. 1990;11:418-422.

238. Ross R, Glomset J, Harker L. Response to injury and atherogenesis. Am J Pathol. 1977;86:675-684.

239. Joseph A, Ackerman D, Talley JD, Johnstone J, Kupersmith J. Manifestations of coronary atherosclerosis in young trauma victims - an autopsy study. J Am Coll Cardiol. 1993;22:459-467.

240. Ross R. Atheroselerosis - an inflammatory disease. N Engl J Med. 1999;340:115-126.

241. Anderson KM, Castelli WP, Levy D. Cholesterol and mortality. 30 years of follow-up from the Framingham study. JAMA. 1987;257:2176-2180.

242. Prevention of cardiovascular events and death with pravastatin in patients with coronary heart disease and a broad range of initial eholesterol levels. The Long-Term Intervention with Pravastatin in Ischaemic Disease (L.IPID) Study Group. N Engl J Med. 1998;339:1349-1357.

243. Downs JR, Clearfield M, Weis S, Whitney E, Shapiro DR, Beere PA, Langendorfer A, Stein EA, Kruyer W, Gotto AM, Jr. Primary prevention of acute coronary events with lovastatin in men and women with average cholesterol levels: results of AFCAPS/TexCAPS. Air Force/Texas Coronary Atherosclerosis Prevention Study. JAMA. 1998;279:1615-1622.

244. Raitakari OT, Pitkanen OP, Lehtimaki T, Lahdenpera S, lida H, Yla-Herttuala S, Luoma J, Mattila K, Nikkari T, Taskinen MR, Viikari JS, Knuuti J. In vivo low density lipoprotein oxidation relates to coronary reactivity in young men. J Am Coll Cardiol. 1997;30:97-102.

245. van Guldener C, Stehouwer CD. Hyperhomocysteinemia, vascular pathology, and endothelial dysfunction. Semin Thromb Hemost. 2000;26:281-289.

246. Libby P. Current concepts of the pathogenesis of the acute coronary syndromes. Circulation. 2001:104:365-372.

247. Dupuis J. Tardif JC, Cernacek P. Theroux P. Cholesterol reduction rapidly improves endothelial function after acute coronary syndromes. The RECIFE (reduction of cholesterol in ischemia and function of the endothelium) trial. Circulation. 1999;99:3227-3233.

248. Davies MJ. Going from immutable to mutable atherosclerotic plaques. Am J Cardiol. 2001;88:2F-9F.

249. Vogel RA. Cholesterol lowering and endothelial function. Am J Med. 1999;107:479-487.

250. Schwartz GG, Olsson AG, Ezekowitz MD, Ganz P, Oliver MF, Waters D, Zeiher A, Chaitman BR, Leslie S, Stern T. Effects of atorvastatin on early recurrent ischemic events in acute coronary syndromes: the MIRACL study: a randomized controlled trial. JAMA. 2001:285:1711-1718.

251. Glavind J. Hartmann S, Clemmensen J, Jessen KE, Dam H. Studies on the role of lipoperoxides in human pathology. II. The presence of peroxidized lipids in the atherosclerotic aorta. Acta Pathol Microbiol Scand. 1952;30:1-6. 
252. Chin JH, Axhar S, Hoffman BB. Inactivation of endothelial derived relaxing factor by oxidized lipoproteins. J Clin Invest. 1992;89:10-18.

253. Matsuda Y, Hirata K, Inoue N, Suematsu M, Kawashima S, Akita H, Yokoyama M. High density lipoprotein reverses inhibitory effect of oxidized low density lipoprotein on endothelium-dependent arterial relaxation. Cire Res. 1993; 72:1103-1109.

254. Kuhn FE, Mohler ER, Satler LF, Reagan K, Lu DY, Rackley CE. Effects of high-density lipoprotein on acetyleholine-induced coronary vasoreactivity. Am J Cardiol. 1991;68:1425-1430.

255. Ohara Y, Peterson TE, Sayegh HS, Subramanian RR, Wileox JN, Harrison DG. Dietary correction of hypercholesterolemia in the rabbit normalizes endothelial superoxide anion production. Circulation. 1995;92:898-903.

256. Chen L, Haught WH, Yang B, Saldeen TG, Parathasarathy S, Mehta JL. Preservation of endogenous antioxidant activity and inhibition of lipid peroxidation as common mechanisms of antiatherosclerotic effects of vitamin E. lovastatin and amlodipine. J Am Coll Cardiol. 1997;30:569-575.

257. Anderson TJ, Meredith IT, Charbonneau F, Yeung AC, Frei B, Selwyn AP, Ganz P. Endotheliumdependent coronary vasomotion relates to the susceptibility of LDL to oxidation in humans. Circulation. 1996;93:1647-1650.

258. Heitzer T, Yla-Herttuala S, Luoma J, Kurz S, Munzel T, Just H, Olsehewski M, Drexler H. Cigarette smoking potentiates endothelial dysfunction of forearm resistance vessels in patients with hypercholesterolemia. Role of oxidized LDL. Circulation. 1996;93:1346-1353.

259. Jha P, Flather M, Lonn E, Farkouh M, Yusuf S. The antioxidant vitamins and cardiovaseular disease. A critical review of epidemiologie and elinical trial data. Ann Intern Med. 1995:123:860-872.

260. Neunteuf T, Kostner K, Katzenschlager R, Zehetgruber M, Maurer G, Weidinger F. Additional benefit of vitamin E supplementation to simvastatin therapy on vasoreactivity of the brachial artery of hypercholesterolemic men. J Am Coll Cardiol. 1998;32:711-716.

261. Elliott TG, Barth JD, Mancini GB. Effects of vitamin $E$ on endothelial function in men after myocardial infarction. Am J Cardiol. 1995;76:1188-1190.

262. Yusuf S, Dagenais G, Pogue J, Bosch J, Sleight P. Vitamin E supplementation and eardiovascular events in high-risk patients. The Heart Outcomes Prevention Evaluation Study Investigators. N Engl J Med. 2000;342:154-160.

263. Shimokawa H. Primary endothelial dysfunction: atherosclerosis. J Mol Cell Cardiol. 1999:31:23-37.

264. Li H, Förstermann U. Nitric oxide in the pathogenesis of vaseular disease. J Pathol. 2000;190:244254.

265. O'Donnell VB, Taylor KB, Parthasarathy S, Kuhn H, Koesling D, Friebe A, Bloodsworth A, DarleyUsmar VM, Freeman BA. 15-Lipoxygenase catalytically consumes nitric oxide and impairn activation of guanylate cyclase. J Biol Chem. 1999;274:20083-20091. 
266. Shimokawa H, Vanhoutte PM. Endothelium and vaseular injury in hypertension and atheroselerosis. In: Zanchetti A, Mareia G, eds. Handbook of Hypertension. New York: Elsevier Science; 1997:1007-1065.

267. Cooke JP, Andon NA, Girerd XJ, Hirseh AT, Creager MA. Arginine restores cholinergic relaxation of hypercholesterolemic rabbit thoracic aorta. Circulation. 1991;83:1057-1062.

268. Stroes E, Kastelein J, Cosentino F, Erkelens W, Wever R, Koomans H, Lüscher T, Rabelink T. Tetrahydrobiopterin restores endothelial funetion in hypercholesterolemia. J Clin Invest. 1997;99 (1):41-46.

269. Feron O, Dessy C, Moniotte S, Desager JP, Balligand JL. Hypereholesterolemia decreases nitric oxide production by promoting the interaction of caveolin and endothelial nitric oxide synthase. J Clin Invest. 1999:103:897-905.

270. Liao JK, Shin WS, Lee WY, Clark SL. Oxidized low-density lipoprotein decreases the expression of endothelial nitric oxide synthase. J Biol Chem. 1995;270:319-324.

271. Creager MA, Gallagher SJ, Girerd XJ, Coleman SM, Dzau VJ, Cooke JP. L-Arginine improves endothelium-dependent vasodilation in hypercholesterolemic humans. J Clin Invest. 1992;90:12481253.

272. Quyyumi AA, Dakak N, Diodati JG, Gilligan DM, Panza JA, Cannon RO, 3rd. Effect of L-arginine on human coronary endothelium-dependent and physiologic vasodilation. J Am Coll Cardiol. $1997 ; 30: 1220-1227$

273. Casino PR, Kilcoyne CM, Quyyumi AA, Hoeg JM, Panza JA. Investigation of decreased availability of nitric oxide precursor as the mechanism responsible for impaired endothelium-dependent vasodilation in hypercholesterolemic patients. J Am Coll Cardiol. 1994:23:844-850.

274. Böger RH, Sydow K, Borlak J, Thum T, Lenzen H, Schubert B, Tsikas D, Bode-Böger SM. LDL cholesterol upregulates synthesis of asymmetrical dimethylarginine in human endothelial cells: involvement of S-adenosylmethionine-dependent methyltransferases. Circ Res. 2000;87:99-105.

275. Ohara Y, Peterson TE, Harrison DG. Hypercholesterolemia inereases endothelial superoxide anion production. J Clin Invest. 1993:91:2546-2551.

276. Schmidt K, Klatt P, Graier WF, Kostner GM, Kukovetz WR. High-density lipoprotein antagonizes the inhibitory effects of oxidized low-density lipoprotein and lysolecithin on soluble guanylyl cyclase. Biochem Biophys Res Commun. 1992:182:302-308.

277. Lerman A, Edwards BS, Hallett JW, Heublein DM, Sandberg SM, Burnett JC, Jr. Circulating and tissue endothelin immunoreactivity in advanced atherosclerosis. N Engl J Med. 1991;325:997-1001.

278. Radi R, Denicola A, Alvarez B, Ferrer-Sueta G, Rubbo H. Chapter 4: The biological chemistry of peroxynitrite. In: Ignarro W, ed. Nitric oxide: Biology and pathobiology. San Diego: Academic Press; 2000:57-82.

Chapter 2 
279. Beckman JS, Koppenol WH. Nitric oxide, superoxide, and peroxynitrite: the good, the bad, and ugly. Am J Physiol. 1996:271:C1424-C1437.

280. Guxik TJ. West NE, Black E, MeDonald D, Ratnatunga C, Pillai R, Channon KM. Funetional effeet of the C242T polymorphism in the NAD(P)H oxidase p22phox gene on vascular superoxide production in atherosclerosis. Circulation. 2000:102:1744-1747.

281. Pritchard KA, Jr., Groszek L, Smalley DM, Sessa WC, Wu M, Villalon P, Wolin MS, Stemerman MB. Native low-density lipoprotein inereases endothelial cell nitrie oxide synthase generation of superoxide anion. Cire Res. 1995;77:510-518.

282. Xia Y, Roman L, Masters BS, Zweier JL. Indueible nitric oxide synthase generates superoxide from the reductase domain. J Biol Chem. 1998;273:22635-22639.

283. Moro MA, Darley-Usmar VM, Goodwin DA, Read NG, Zamora-Pino R, Feeliseh M, Rademski MW. Moncada S. Paradoxical fate and biological action of peroxynitrite on human platelets. Proc Natl Acad Sci U S A. 1994:91:6702-6706.

284. Dembinska-Kiec A, Gryglewska T, Zmuda A, Gryglewski RJ. The generation of prostacyelin by arteries and by the coronary vascular bed is reduced in experimental atheroselerosis in rabbits. Prostaglandins. 1977:14:1025-1034.

285. D'Angelo V, Villa S, Mysliwiec M, Donati MB, de Gaetano G. Defective fibrinolytic and prostacyclinlike activity in human atheromatous plaques. Thromb Haemost. 1978;39:535-536.

286. Beetens JR, Coene MC, Verheyen A. Zonnekeyn L. Herman AG. Biphasic response of intimal prostacyelin production during the development of experimental atherosclerosis. Prostaglandins. 1986:32:319-334.

287. Sinzinger H, Feigl W, Silberbauer K. Prostacyelin generation in atherosclerotic arteries. Lancet. 1979:2:469.

288. Tremoli E, Socini A, Petroni A, Galli C. Increased platelet aggregability is associated with increased prostacyclin production by vessel walls in hypercholesterolemic rabbits. Prostaglandins. 1982:24:397-404.

289. FitzGerald GA, Smith B. Pedersen AK. Brash AR. Increased prostacyclin biosynthesis in patients with severe atherosclerosis and platelet activation. N Engl J Med. 1984:310:1065-1068.

290. Mehta JL, Lawson D, Mehta P. Saldeen T. Increased prostacyelin and thromboxane $A_{2}$ biosynthesis in atherosclerosis. Proc Natl Acad Sci U S A. 1988:85:4511-4515.

291. Wang T, Falardeau P, Powell WS. Synthesis of prostaglandins and thromboxane $B_{2}$ by cholesterolfed rabbits. Arterioscler Thromb. 1991:11:501-508.

292. Pratico D, Cyrus T, Li H, FitzGerald GA. Endogenous biosynthesis of thromboxane and prostacyclin in 2 distinct murine models of atherosclerosis. Blood. 2000;96:3823-3826. 

$F_{2}$-isoprostane 8-epiprostaglandin $F_{2}$ alpha increases platelet adhesion and reduces the antiadhesive and antiaggregatory effects of NO. Arterioscler Thromb Vasc Biol. 1998;18:1248-1256.

294. Bunting S, Gryglewski R, Moneada S, Vane JR. Arterial walls generate from prostaglandin endoperoxides a substance (prostaglandin $\mathrm{X}$ ) which relaxes strips of mesenteric and coeliac ateries and inhibits platelet aggregation. Prostaglandins. 1976;12:897-913.

295. Mickel HS, Horbar J. The effect of peroxidized arachidonic acid upon human platelet aggregation. Lipids. 1974:9:68-71.

296. FitzGerald GA, Austin S, Egan K, Cheng Y, Pratico D. Cyclo-oxygenase products and atherothrombosis. Ann Med. 2000:32:21-26.

297. Pratico D, Tillmann C, Zhang ZB, Li H, FitzGerald GA. Acceleration of atherogenesis by COX-1dependent prostanoid formation in low density lipoprotein receptor knockout mice. Proc Natl Acad Sci U S A. $2001 ; 98: 3358-3363$.

298. Murata T, Ushikubi F, Matsuoka T, Hirata M, Yamasaki A, Sugimoto Y, Ichikawa A, Aze Y, Tanaka T, Yoshida N, Ueno A, Oh-ishi S, Narumiya S. Altered pain perception and inflammatory response in mice lacking prostacyclin receptor. Nature. 1997;388:678-682.

299. Falk E. Unstable angina with fatal outcome: dynamic coronary thrombosis leading to infaretion and/or sudden death. Autopsy evidence of recurrent mural thrombosis with peripheral embolization culminating in total vascular occlusion. Circulation. 1985;71:699-708.

300. Davies MJ, Thomas AC, Knapman PA, Hangartner JR. Intramyocardial platelet aggregation in patients with unstable angina suffering sudden ischemic cardiac death. Circulation. 1986;73:418427.

301. Miyamoto Y, Saito Y, Kajiyama N, Yoshimura M, Shimasaki Y, Nakayama M, Kamitani S, Harada M, Ishikawa M, Kuwahara K, Ogawa E, Hamanaka I, Takahashi N, Kaneshige T, Teraoka H, Akamizu T, Azuma N, Yoshimasa Y, Yoshimasa T, Itoh H, Masuda I, Yasue H, Nakao K. Endothelial nitric oxide synthase gene is positively associated with essential hypertension. Hypertension. $1998: 32: 3-8$.

302. Hooper WC, Lally C, Austin H, Benson J, Dilley A, Wenger NK, Whitsett C, Rawlins P, Evatt BL. The relationship between polymorphisms in the endothelial cell nitric oxide synthase gene and the platelet GPIIla gene with myocardial infarction and venous thromboembolism in African Americans. Chest. 1999;116:880-886.

303. Freedman JE, Ting B, Hankin B, Loscalzo J, Keaney JF, Jr., Vita JA. Impaired platelet production of nitric oxide predicts presence of acute coronary syndromes. Circulation. 1998;98:1481-1486.

304. Diodati JG, Dakak N, Gilligan DM, Quyyumi AA. Effect of atheroselerosis on endothelium-dependent inhibition of platelet activation in humans. Circulation. 1998;98:17-24.

Chapter 2 
Chapter 3

Endogenous Nitric Oxide Protects Against Thromboembolism in Venules but Not in Arterioles 
Martijn A.W. Broeders, ${ }^{1}$ Geert Jan Tangelder, ${ }^{1,2}$ Dick W. Slaaf, ${ }^{3}$ Robert S. Reneman, ${ }^{1}$ Mirjam G.A. oude Egbrink ${ }^{1}$

From the Departments of Physiology ${ }^{1}$ and Biophysics, ${ }^{3}$ Cardiovascular Research Institute Maastricht, Maastricht University, Maastricht, the Netherlands

Laboratory for Physiology, ${ }^{2}$ Institute for Cardiovascular Research, Free University, Amsterdam, the Netherlands

Published in Arteriosclerosis Thrombosis and Vascular Biology 1998;18:139-145 


\begin{abstract}
Because nitric oxide (NO) inhibits aggregation and adhesion of blood platelets, NO may play a role in platelet-vessel wall interactions. Therefore, the purpose of this study was to investigate the involvement of endogenous $\mathrm{NO}$ in thromboembolic processes, as induced by wall puncture, in rabbit mesenteric arterioles and venules (diameters: 20 to $43 \mu \mathrm{m}$ ). In venules, inhibition of NO synthase by superfusion of the mesentery with $N^{6}$-nitro-L-arginine (L-NA; $0.1 \mathrm{mmol} / \mathrm{L}$ ) significantly increased the duration of embolization (from 50 seconds to 511 seconds) and the number of emboli produced (from 2 to 11 emboli per vessel), while the median period of time needed to produce an embolus was not influenced. On the contrary, in arterioles, L-NA had no significant effect on embolization (duration of embolization: 426 seconds in the control and 382 seconds in the L-NA group, with 20 and 12 emboli per vessel, respectively). Addition to the L-NA superfusate of $\mathrm{L}$-arginine (L-ARG; $1 \mathrm{mmol} / \mathrm{L}$ ), the active precursor for endogenous $\mathrm{NO}$ synthesis, resulted in a complete reversal of the $\mathrm{L}-\mathrm{NA}$ effects in venules, while addition of the inactive D-arginine (D-ARG; $1 \mathrm{mmol} / \mathrm{L}$ ) had no effect. Addition of L-ARG and D-ARG had no significant effect in arterioles. Addition to the L-NA superfusate of the exogenous NO donor sodium nitroprusside (SNP: $0.1 \mu \mathrm{mol} / \mathrm{L}$ ) also resulted in reversal of the L-NA effects in venules, while in arterioles, it slightly but significantly decreased embolization duration. The differences in effect of L-NA on embolization between arterioles and venules were not caused by differences in fluid dynamic conditions. It is concluded that the role of endogenous NO in inhibiting thromboembolic processes is more important in venules than in arterioles.
\end{abstract}




\section{Introduction}

Among the various functions of nitric oxide (NO), two are of major importance in the cardiovascular system: its vasodilatory capacity and its inhibitory effect on platelet aggregation and adhesion (for reviews on this issue, see References). ${ }^{1-5}$ NO is synthesized by the enzyme NO synthase (NOS). ${ }^{6}$ Up to now, three different isoforms of this enzyme have been identified. Endothelial cell NOS (ec-NOS) and neural NOS (n-NOS) are both constitutively present in certain cell types. ecNOS is found in endothelial cells ${ }^{7}$ and platelets, ${ }^{8}$ while n-NOS is present in nonadrenergic noncholinergic (NANC) peripheral neurons, in cerebellar and cerebral neurons and in human skeletal muscle fibres. ${ }^{6}$ The third NOS isoform is not expressed under physiological conditions, but ean be induced within several hours after immunological activation with cytokines. ${ }^{6}$ This inducible NOS (i-NOS) was first found in macrophages and more recently also in endothelial cells, smooth muscle cells, mast cells and polymorphonuclear granulocytes. ${ }^{9}$

Because of its influence on blood platelets, NO may play a role in hemostatic plug formation and in thrombotic processes. Moreover, the constitutively present enzyme ec-NOS can be activated in vivo by shear stress and chemical stimulators like thrombin and adenosine diphosphate (ADP), which are factors known also to influence platelet behavior. ${ }^{9,10}$ In vivo studies on the role of $\mathrm{NO}$ in thrombotic processes are scarce. Most of the studies performed have focused on the antithrombogenic properties of NO in arterioles ${ }^{11-13}$ or arteries, ${ }^{14-18}$ but not in venules. Since in vivo the thromboembolic reaction to vessel wall injury differs between arterioles and venules of the same tissue, ${ }^{19.20}$ it might be hypothesized that NO is differently involved in this process in these microvessels.

Therefore, the aim of the present study was to investigate in vivo the antithrombotic role of $\mathrm{NO}$ in platelet-vessel wall interactions in arterioles and venules of the same tissue using an experimental model developed in our laboratory. ${ }^{19}$ In the mesentery of anesthetized rabbits, the wall of arterioles and venules was punctured with a micropipet, and the ensuing thromboembolic reaction was studied with the use of intravital videomicroscopy. In the first series of experiments, the mesentery of one group of rabbits was locally superfused with L-NA ( $N^{G}$-nitro-L-arginine) or its vehicle; L-NA is an irreversible inhibitor of $\mathrm{NOS}^{5}$ in the wall of rabbit blood vessels ${ }^{21-}$ ${ }^{23}$ and in rabbit platelets. ${ }^{24.25}$ To provide evidence that NO production was indeed inhibited under L-NA superfusion, a second series of control experiments was performed. The aim of these experiments was to investigate whether the effects of L-NA superfusion could be reversed by adding either the exogenous NO donor sodium nitroprusside or the active precursor for endogenous NO synthesis L-arginine; as a control for the latter the inactive D-arginine was added in a separate group of animals. 


\section{Methods}

\section{Animals and intraxital videomicroscopy}

All experiments were approved by the local ethical committee on the use of laboratory animals. Experiments were performed on 44 New Zealand White rabbits (weight range, 2.4 to $3.1 \mathrm{~kg}$ ) of either sex. Anesthesia was induced with intramuscular injections of $40 \mathrm{mg} / \mathrm{kg}$ body weight ketamine hydrochloride (Nimatek, AUV) and $5 \mathrm{mg} / \mathrm{kg}$ body weight xylazine hydrochloride (Sedamun, AUV). Anesthesia was maintained with ketamine $\left(40 \mathrm{mg} \cdot \mathrm{kg}^{-1} \cdot \mathrm{h}^{-1}\right)$ and $\mathrm{xylazine}\left(5 \mathrm{mg} \cdot \mathrm{kg}^{-1} \cdot \mathrm{h}^{-1}\right)$ dissolved in a lactetrol solution (15 $\mathrm{mL} / \mathrm{h}$; Aesculaap) and continuously infused through a eatheter (PE-50) in the femoral vein. Throughout the experiments, arterial blood pressure was measured through a catheter (PE-60) in the femoral artery (Uniflow external pressure transducer, Baxter). Heart rate was assessed from the instantaneous pressure signal. To keep the arterial eatheter patent, it was continuously perfused with physiological saline $(3 \mathrm{~mL} / \mathrm{h}) \mathrm{via}$ the Uniflow system; no heparin was used. Both arterial pressure and heart rate were continuously recorded on hard disk with the use of a hemodynamic data acquisition program.

During surgery and throughout the experiment, body temperature was kept at $37^{\circ} \mathrm{C}$ to $38^{\circ} \mathrm{C}$, using an infrared heating lamp controlled by a thermoanalyzer system (Hugo Sachs Elektronik) connected to a rectal probe. After surgery, blood was collected from a central ear artery in EDTA $(0.9 \mathrm{~mL}$ blood/0.1 mL EDTA; $0.027 \mathrm{~mol} / \mathrm{L})$ for electronic platelet counts (Coulter Counter; model ZF) and assessment of hemoglobin concentration (OSM 2 Hemoxymeter) and hematocrit (Autocrit II centrifuge; Clay Adams); these values were corrected for the EDTA dilution.

The rabbits were ventilated throughout the experiments with a mixture of nitrogen (75\%), oxygen $(24.5 \%)$ and carbon dioxide $(0.5 \%)$ to maintain systemic arterial $\mathrm{pH}, \mathrm{pCO}_{2}$ and $\mathrm{pO}_{2}$ at normal values. To this purpose, the trachea was cannulated and the cannula $(3.5$ or $4.5 \mathrm{~mm}$ internal diameter; Mallinckrodt) was connected to an animal ventilator (Technical \& Scientific Equipment; model 4601). Ventilation was performed with a positive end-expiratory pressure of 2 $\mathrm{cm} \mathrm{H}_{2} \mathrm{O}$. The respiratory rate was 60 per minute and the tidal volume varied between 16 and 21 $\mathrm{mL}$, depending on the weight of the rabbit. Blood gas and $\mathrm{pH}$ values were measured with an acidbase analyzer (ABL 3 Radiometer) in blood collected from a central ear artery. Average values throughout the experiments were: $\mathrm{pH} 7.43 \pm 0.03, \mathrm{pCO}_{2} 34 \pm 6 \mathrm{~mm} \mathrm{Hg}$ and $\mathrm{PO}_{2} 93 \pm 13 \mathrm{~mm} \mathrm{Hg}$ (mean \pm standard deviation). These values are within the normal ranges for rabbits. ${ }^{19.26}$ No statistical differences existed between the experimental groups (see "Results").

Through a small midline incision, a segment of the distal ileum was brought outside the abdomen. The mesentery was carefully spread over a siliconized glass plate mounted in an electrically heated microscope table $\left(37^{\circ} \mathrm{C}\right)$. It was continuously superfused with a buffered Tyrode's solution $\left(37^{\circ} \mathrm{C}, \mathrm{pH} 7.35\right.$ to 7.40$)$ that was saturated with $95 \% \mathrm{~N}_{2}$ and $5 \% \mathrm{CO}_{2}$. The exteriorized ileum was kept moist with overlying wet gauze. The mesenteric tissue was visualized with a Leitz 
intravital microscope adapted for telescopic imaging, ${ }^{27}$ using a long-working-distance objective (Leitz LL 25X, numerical aperture 0.35). Transillumination was performed with a tungsten lamp. Images were recorded on videotape (Sony Betamax or Panasonic SVHS) through a CCD camera (Hamamatsu; model C2400, $2 / 3$ ineh) or a Grundig TV camera (model FA 32, 1 inch) for off-line analysis. Final magnification at the front plane of the camera was X40.

In all selected vessels, vascular diameter was measured off-line with an image shearing device. ${ }^{28}$ Mean red blood cell velocity was measured on-line using a dual-slit system connected to a tracking correlator (IPM) ${ }^{29}$ and was recorded on hard disk with the use of the hemodynamic data acquisition program. Reduced velocity (U), which is a measure of wall shear rate, was caleulated by dividing mean red blood cell velocity by vessel diameter.

\section{Vessel wall puncture and the thromboembolic reaction}

Arterioles and venules with an estimated diameter ranging from 20 to $40 \mu \mathrm{m}$ were selected. Vessel wall injury was induced mechanically by puncture with a glass micropipet (tip diameter $\sim 6 \mu \mathrm{m}$ ), as previously described. ${ }^{19}$ To be certain that all layers of the wall were damaged, puncture was considered to be successful only if red blood cells could be seen leaving the vessel.

Immediately after puncture, the thromboembolic reaction started. In all vessels, a white thrombus formed, height and shape of which remained constant, except for one venule in which the whole thrombus embolized after 137 seconds. In most vessels, circulating platelets adhered to this stationary thrombus mainly on its downstream side. From time to time, these newly formed parts embolized. After a certain period of time, embolization stopped, while the thrombus remained at the site of injury for the rest of the observation period of at least 600 seconds. To quantify this thromboembolic reaction, the following variables were determined off-line from videotape: the duration of bleeding (bleeding time), the maximal thrombus height relative to the local vessel diameter, the total duration of embolization, the number of emboli produced within 600 seconds after puncture, and the median embolus production time per vessel, ie, the median of all periods of time needed to produce an embolus per vessel. The latter parameter is a measure of the rate of embolus formation. Emboli were only taken into account when their short axis perpendicular to the vessel wall was greater than $25 \%$ of the local vessel diameter. Aggregates of smaller dimensions could not always be distinguished from the background with enough accuracy. In case of rebleedings through the thrombus, their frequency was determined.

Superfusion of the mesentery with $N^{G}$-nitro-L-arginine, vehicle or combinations of $N^{G}$-nitroL-arginine and D-arginine, L-arginine, or sodium nitroprusside

To determine the role of endogenous NO in the thromboembolic reaction, in a first series of experiments, the effect of the NOS inhibitor L-NA (molecular weight 219.2; Sigma) was studied. 
The mesentery of a group of 12 rabbits (L-NA group; see Table 1) was superfused with L-NA in a concentration of $0.1 \mathrm{mmol} / \mathrm{L}$; this concentration has been shown to be high enough to effectively inhibit NOS in rabbit tissues and blood cells. ${ }^{21-25}$ Moreover, superfusion of higher L-NA concentrations results in an undesirable rise of systemie blood pressure (M.A.W. Broeders, unpublished observations, 1995). In the control group (CON group; 14 rabbits; see Table 1), the mesentery was superfused with the vehicle, a buffered Tyrode's solution. Rabbits were assigned at random to one of these two groups.

A second series of experiments was performed to determine whether the L-NA effects as found in the first series of experiments could be reversed, using a modified protocol as described by Yao and colleagues. ${ }^{15}$ For these experiments, 18 rabbits were equally assigned at random to one of three groups (see Table 1). The mesentery of these rabbits was superfused with a combination of either $\mathrm{L}-\mathrm{NA}(0.1 \mathrm{mmol} / \mathrm{L})$ and excess D-arginine ( $1 \mathrm{mmol} / \mathrm{L}$, molecular weight 210.7 , Sigma; L-NA+D-ARG group), L-NA $(0.1 \mathrm{mmol} / \mathrm{L})$ and excess L-arginine (1 mmol/L, molecular weight 210.7 , Sigma; L-NA+L-ARG group) or L-NA $(0.1 \mathrm{mmol} / \mathrm{L})$ and sodium nitroprusside $(0.1$ $\mu \mathrm{mol} / \mathrm{L}$, molecular weight 298.0, Sigma; L-NA+SNP group).

All drugs were dissolved in buffered Tyrode's solution on the day of the experiment. L-NA was dissolved by sonication and subsequent stirring. Because of its light sensitivity, sodium nitroprusside was dissolved and used with minimal exposure to light.

In all groups, the mesentery was allowed to stabilize during a period of 30 to 35 minutes after exteriorization under continuous superfusion with buffered Tyrode's solution. After this stabilization period, the superfusion was switehed to the L-NA solution alone or to a combination of L-NA and D-arginine, L-arginine or sodium nitroprusside. Superfusion with buffered Tyrode's solution was continued in the CON group. To study the direct effect of L-NA or the combination of drugs on fluid dynamics, in each experiment, a video recording was made and flow velocity was measured in arterioles and venules from 5 minutes before until 5 minutes after the switch of superfusion. The same measurements were performed in the $\mathrm{CON}$ group. Per mesentery, a median number of three vessels (range 1 to 6 vessels) were punctured from about 15 minutes up to 3 hours after the start of the superfusion with L-NA (with or without D-arginine, 1-arginine or sodium nitroprusside) or the vehicle. Each puncture was preceded by a 4-minute period during which mean red blood cell velocity was measured. This 4-minute period, the puncture itself, and the subsequent observation period of at least 600 seconds were recorded on videotape.

\section{Statistical analysis}

Because of their nonsymmetrical distribution, the data are presented and displayed as medians with their interquartile ranges unless otherwise indicated. First, differences between all five groups were tested with the nonparametric Kruskal-Wallis one-way analysis of variance. If a sig- 
nificant difference was found, the same test was used to compare the groups within each series. To test for a possible difference between the two series, the L-NA and L-NA+D-ARG groups were compared. Paired data groups were compared with the Wilcoxon signed rank test. Correlations were performed with the nonparametric Spearman's rank correlation test (coefficient=r. ). In all tests the level of significance was set at $5 \%$.

\section{Results}

Effect of $N^{G}$-nitro-L-arginine alone or combined with D-arginine, L-arginine, or sodium nitroprusside on the thromboembolic reaction in venules and arterioles

In all vessels, bleeding, as well as thrombus formation started immediately following wall puncture. A thrombus started to grow within 0.1 second following puncture and reached its maximal size within 1 to 2 seconds.

\section{Venules}

The effect of L-NA on the venular embolization process is illustrated in Figure 1. The total duration of embolization per vessel was 50 seconds (median value) in the CON venules and was significantly prolonged by L-NA superfusion (511 seconds; $\mathrm{p}=0.0002)$. In accordance with this longer duration of embolization, the number of emboli produced per venule increased significantly ( $\mathrm{p}=0.002)$ from a median value of 2 emboli in the CON venules to 11 emboli in the $\mathrm{L}-\mathrm{NA}$ venules. As shown in Figure 1, the addition of L-arginine or SNP to L-NA completely reversed the effects of L-NA on the duration of embolization and the number of emboli produced in the venules.

The median embolus production time per venule, as a measure of the rate of embolus production, was not influenced by L-NA (CON venules, 16 seconds; L-NA venules, 12 seconds). Concomitantly, the median embolus production time was not influenced by any of the drugs added to the L-NA superfusate (Figure 1).

No significant differences in production time of the first embolus, thrombus height and number of rebleedings could be detected between groups (Table 2). The venular bleeding period was slightly shortened by L-NA ( $\mathrm{p}=0.06$; see Table 2 ). This shortening could not be reversed by addition of L-arginine or SNP to L-NA.

\section{Arterioles}

Figure 2 illustrates the effect of L-NA on arteriolar embolization. In contrast to venules, in arterioles, the total duration of embolization per vessel was not significantly different between the CON and L-NA groups (medians 426 and 382 seconds, respectively). This also holds for the total number of emboli produced per arteriole (medians 20 and 12 emboli, respectively; $\mathrm{p}=0.61$ ). Addition of the active precursor for endogenous NO synthesis, L-arginine, to the L-NA super- 
fusate also did not signifieantly affect embolization duration and the number of emboli produced per vessel (all p-values $>0.10$ ). In contrast, addition of the exogenous NO donor SNP slightly, but significantly, shortened the embolization duration ( 147 seconds; $p=0.04)$, but not the number of emboli produced per arteriole. The median embolus production time was not influenced by L-NA or any of the drug combinations (Figure 2).

After wall puncture, the production of emboli started significantly later in the L-NA arterioles than in the $\mathrm{CON}$ arterioles ( $\mathrm{p}=0.02$; see Table 2). This effeet, however, could not be reversed by the addition of L-arginine or SNP to L-NA. No significant differences could be detected between the groups in any of the other arteriolar thromboembolic parameters determined (Table 2).

\section{Arterioles versus venules}

Embolization was significantly different between arterioles and venules in the $\mathrm{CON}$ group, the L-NA+L-ARG group and the L-NA+SNP group: the total duration of embolization was significantly longer (all p-values $<0.0010$ ) in arterioles, in which significantly more emboli were produced (all p-values $<0.0010$ ). In contrast, in the L-NA group and in the L-NA+D-ARG group, the embolization parameters were similar in venules and arterioles (all p-values $>0.33$ ).

\section{Fluid dynamic conditions}

Five minutes' superfusion with L-NA or any of the drug combinations had no significant effect on the local fluid dynamic parameters compared with their values during superfusion with Tyrode's solution. The fluid dynamic parameters as measured in the vessels immediately before puncture are presented in Table 3 . Diameter, red blood cell velocity and reduced velocity were similar in the venules of all groups. The same holds for diameter and red blood cell velocity in the arterioles of all groups. Reduced veloeity was similar in the arterioles of most of the groups but it was slightly lower in the L-NA arterioles as compared to the CON arterioles $(\mathrm{p}=0.02)$. In the L-NA arterioles, however, no correlation was found between reduced velocity on the one hand and any of the embolization parameters on the other (all $r_{\text {s }}$-values $<0.28$; all p-values $>0.22$ ).

\section{Whole-animal parameters}

Data concerning the rabbits used in the five groups are shown in Table 1. All values are within the ranges normally found in anesthetized rabbits. ${ }^{19,26,30}$ No significant difference in weight, hemoglobin, hematocrit, platelets or heart rate was found between rabbits of the different groups. In the course of the experiment, the combination of SNP with L-NA, however, reduced mean arterial blood pressure, resulting in a significantly lower blood pressure in this group than in the other groups $(\mathrm{p}<0.001)$. In all groups, no significant correlations were found between the whole animal parameters shown in Table 2 on the one hand and the embolization parameters (nee 
"Discussion") in arterioles and venules on the other. These findings indicate that these whole-animal parameters do not significantly influence the thromboembolic reaction after wall puncture in rabbit mesenteric microvessels.

Five minutes of superfusion with L-NA or combinations of L-NA and D-arginine, L-arginine or SNP had no direct effect on mean arterial blood pressure and heart rate.

\section{Discussion}

The findings in the present study show that inhibition of endogenous NO production with the NOS inhibitor L-NA affects the thromboembolic reaction following wall puncture differently in arterioles and venules of the rabbit mesentery. L-NA superfusion of the mesentery results in a prolongation of the period of embolization and in a concomitant increase in the number of emboli produced in venules, while it has no such effect in arterioles. These effects of L-NA on embolization in venules could be reversed by addition of either the active precursor for endogenous NO synthesis, L-arginine, or the exogenous NO donor sodium nitroprusside, but not by the inactive D-arginine. This finding indicates that the venular L-NA effects are the consequence of inhibition of endogenous NO production and therefore suggests that the role of endogenous NO in inhibiting thromboembolism is more important in venules than in arterioles.

The observation that NO plays a more important role in inhibiting thromboembolism in venules than in arterioles could be explained by a difference in production of $\mathrm{NO}$ in these microvessels. Most of the cells likely to be involved in the thromboembolic process studied are able to produce NO. Although smooth muscle cells and mast cells can produce NO through inducible NOS (i-NOS), these cells are less likely candidates because the upregulation of i-NOS requires immunological stimulation with cytokines and transcription of the enzyme takes several hours. ${ }^{6}$ Peripheral neurons may be another source of NOS (neural NOS; n-NOS), but by means of the NADPH (nicotinamide adenine dinucleotide phosphate)-diapherase technique, ${ }^{31}$ we were unable to demonstrate the presence of NOS-positive neurons in the rabbit mesentery (M.A.W. Broeders, unpublished observations, 1997). Cells containing endothelial cell NOS (ec-NOS) are platelets and endothelial cells. It is unlikely that the NO released by platelets is different in arterioles and in venules, because electron and light microscopy showed that the composition of the stationary thrombus, mainly tightly packed platelets, is not different in both types of microvessels (M.A.W. Broeders, unpublished observations, 1997). Moreover, the size of the stationary thrombus was similar in arterioles and venules. Therefore, we conclude that the more important role of $\mathrm{NO}$ in inhibiting thromboembolism in venules than in arterioles might be explained by a difference in NO production by these microvessels. Unfortunately, at the present state of the art it is technically impossible to assess in vivo quantitatively the amount of NO produced by endothelial cells of arterioles and venules with a diameter between 20 and $40 \mu \mathrm{m}$. 
An alternative explanation for the observed difference in the role of $\mathrm{NO}$ in inhibiting thromboembolism in arterioles and venules may be the interplay of NO with other mediators involved in the thromboembolie reaction. For example, superoxide anions can inactivate $\mathrm{NO}^{32}$ and have been reported to be involved in mediating platelet aggregation in thrombosis models in arteries in vivo. ${ }^{33,34}$ Because, Suzuki and colleagues (1995) showed that in rat mesentery more superoxide is generated in arterioles than in venules, ${ }^{35}$ it is conceivable that the less pronounced role of $\mathrm{NO}$ in arterioles as antithrombotic mediator is caused by its inactivation by reactive oxygen species. Prostaglandins may also interfere with NO production or its action. In some preliminary experiments $(n=10)$, cyclooxygenase and hence prostaglandin formation was blocked completely with a high dose of aspirin, as previously described. ${ }^{20}$ In these experiments, in venules, inhibition of endogenous NO production by L-NA had an effect similar to that of L-NA without cyclooxygenase inhibition, ie, a significant increase in the duration of embolization (M.A.W. Broeders, unpublished data, 1997). This observation further illustrates the importance of NO as an antithrombotic agent in venules, in contrast to arterioles in which prostaglandins were shown to play a significant role. ${ }^{20}$ Finally, it is conceivable that the effect of NO on the effector cells, ie, the blood platelets, differs in arterioles and venules because the intravascular milieu is not the same in both vessel types. It is unlikely, however, that differences in blood gas and pH levels are responsible for such a difference in NO sensitivity, because large changes in these parameters have practically no effect on the thromboembolic reaction in these microvessels. ${ }^{26}$

Wall shear rate is considered to be a platelet-stimulating factor in vitro ${ }^{36}$ and in damaged blood vessels in vivo. ${ }^{37}$ In vivo, however, shear forces also stimulate the production of plateletinhibiting factors by the endothelium. ${ }^{38}$ Because no differences in any of the fluid dynamic parameters were found between the venules of the control and L-NA groups, we may conclude that the effect of L-NA on embolization in venules cannot be explained by differences in wall shear rate. In the arterioles, fluid dynamic parameters were also similar in most groups. The reduced velocity, however, was somewhat lower in the L-NA than in control arterioles, although the ranges were similar. This small difference is likely to be of minor biological importance, because in the L-NA arterioles, no correlation was found between reduced velocity on the one hand and any of the embolization parameters on the other. The finding that inhibition or stimulation of NO production has no apparent fluid dynamic consequences in rabbit mesenteric microvessels is in correspondence with our observation that local fluid dynamic conditions do not change after superfusion of the same tissue with vasodilators, such as prostacyclin or adenosine or with vasoconstrictors, such as noradrenaline or potassium chloride (M.A.W. Broeders, unpublished data, 1995). Apparently, the mesenteric microcirculation of the rabbit is not vasoactive.

One could argue that the superfused agents entered the lumen of the mesenteric venules better than that of the arterioles. In experiments with fluorescence microscopy, however, we were 
able to show that superfusion of the mesentery with the fluorescent dye acridine red results in the simultaneous appearance of fluorescence in both arterioles and venules within a few seconds (M.A.W. Broeders, unpublished data, 1996). Because L-NA, L-arginine, D-arginine, sodium nitroprusside and acridine red have similar neutral charges and molecular weights (acridine red: 274.7), the superfused drugs likely enter the lumen of arterioles and venules with little difference.

This is the first in vivo study in which the role of $\mathrm{NO}$ in thromboembolism, as evoked by a mechanical trauma, is investigated in the microcirculation of the rabbit mesentery. Differences between arterioles and venules, as far as the importance of $\mathrm{NO}$ as a platelet-inhibiting agent is concerned, have been demonstrated earlier in only one other in vivo study. In this particular study of Lindberg and coworkers (1994), topical application of the NOS inhibitor $N^{G}$-nitro-1arginine methyl ester $(0.2 \mathrm{mmol} / \mathrm{L})$ enhanced photoactivation-induced thrombus formation more in arterioles (diameter 38 to $68 \mu \mathrm{m}$ ) than in venules (diameter 76 to $98 \mathrm{\mu m}$ ) of the rat cremaster muscle. ${ }^{39}$ Based on these findings, the authors postulated that after photoactivation, the arteriolar endothelium may have a greater capacity for the production of NO than the venular endothelium. The discrepancy between their results and the findings in our study in rabbit mesenteric microvessels (diameter 20 to $43 \mathrm{\mu m}$ ) may be due to differences in the functional properties of microvessels in different organs and/or species and/or in vessels of different diameters. In addition, it cannot be excluded that the NOS inhibitor used ${ }^{40}$ and/or differences in the technique used for induction of platelet-vessel wall interactions may explain this discrepancy. To the best of our knowledge, there are no other studies that have investigated the antithrombogenic role of $\mathrm{NO}$ in vivo, comparing either arterioles with venules or arteries with veins. Our observation that NOS plays a more important role in thromboembolic processes in venules than in arterioles is supported by the observations that inhibition of NOS induced spontaneous aggregation of platelets and leukocytes in venules, ${ }^{41-43}$ but not in arterioles. ${ }^{43}$

An interesting additional finding in the present study, which is illustrated in Figure 3 , is that NOS inhibition with L-NA abolishes the difference in duration of embolization between arterioles and venules, which under control conditions is longer in arterioles (present study). ${ }^{19,20,26}$ Hence, the more important functional role of $\mathrm{NO}$ in venules compared with arterioles may explain the difference in thromboembolic reaction normally found between the two vessel types.

In conclusion, the involvement of endogenous $\mathrm{NO}$ in inhibiting the thromboembolic reaction induced by vessel wall injury is different in rabbit mesenteric arterioles and venules, playing a more important role in this reaction in venules.

\section{Acknowledgments}

This study was supported by the Netherlands Heart Foundation, grant \# 92.339. The authors are indebted to Sabrina van Velzen and Rinus Alewijnse for their skillful technical assistance. 
TABLE 1

General Data on the Rabbits Used in the Five Experimental Groups

\begin{tabular}{|c|c|c|c|c|c|c|c|}
\hline Group & $n$ & $\begin{array}{c}\text { Weight, } \\
\text { kg }\end{array}$ & $\begin{array}{c}\text { Hemoglobin, } \\
\text { mmol/L }\end{array}$ & $\begin{array}{c}\text { Hematoerit, } \\
\text { L/. }\end{array}$ & $\begin{array}{c}\text { Platelet Count, } \\
\times 10^{3} / \mu \mathrm{L}\end{array}$ & $\begin{array}{c}\text { MAP, } \\
\operatorname{mm} \mathbf{H g}_{\mathrm{g}}\end{array}$ & $\begin{array}{l}\text { HR, } \\
\text { bpm }\end{array}$ \\
\hline CON & 14 & $\begin{array}{c}2.7 \\
(2.4-3.1)\end{array}$ & $\begin{array}{c}7.6 \\
(7.3-9.8)\end{array}$ & $\begin{array}{c}37.1 \\
(33.3-40.6)\end{array}$ & $\begin{array}{c}543 \\
(331-707)\end{array}$ & $\begin{array}{c}74 \\
(62-85)\end{array}$ & $\begin{array}{c}145 \\
(117-231)\end{array}$ \\
\hline L-NA & 12 & $\begin{array}{c}2.8 \\
(2.5-3.1)\end{array}$ & $\begin{array}{c}8.2 \\
(6.9-8.9)\end{array}$ & $\begin{array}{c}36.4 \\
(30.9-43.1)\end{array}$ & $\begin{array}{c}431 \\
(338-763)\end{array}$ & $\begin{array}{c}73 \\
(47-82)\end{array}$ & $\begin{array}{c}140 \\
(108-165)\end{array}$ \\
\hline L-NA+D-ARG & 6 & $\begin{array}{c}2.8 \\
(2.5-2.9)\end{array}$ & $\begin{array}{c}7.7 \\
(6.5-8.6)\end{array}$ & $\begin{array}{c}37.9 \\
(33-41.1)\end{array}$ & $\begin{array}{c}750 \\
(334-838)\end{array}$ & $\begin{array}{c}72 \\
(54-78)\end{array}$ & $\begin{array}{c}142 \\
(126-159)\end{array}$ \\
\hline L-NA+L-ARG & 6 & $\begin{array}{c}2.5 \\
(2.4-2.9)\end{array}$ & $\begin{array}{c}7.1 \\
(6.8-8.5)\end{array}$ & $\begin{array}{c}35.3 \\
(33.4-41.3)\end{array}$ & $\begin{array}{c}680 \\
(559-698)\end{array}$ & $\begin{array}{c}72 \\
(56-86)\end{array}$ & $\begin{array}{c}151 \\
(116-177)\end{array}$ \\
\hline $\mathrm{L}-\mathrm{NA}+\mathrm{SNP}$ & 6 & $\begin{array}{c}2.6 \\
(2.5-2.8)\end{array}$ & $\begin{array}{c}7.3 \\
(6.8-7.9)\end{array}$ & $\begin{array}{c}36.4 \\
(33.8-40.1)\end{array}$ & $\begin{array}{c}560 \\
(491-951)\end{array}$ & $\begin{array}{c}63^{*} \\
(51-74)\end{array}$ & $\begin{array}{c}131 \\
(109-165)\end{array}$ \\
\hline
\end{tabular}

MAP indicates mean arterial blood pressure; HR-heart rate; and bpm, beats per minute.

$\mathrm{CON}$-control; L-NA=N $\mathrm{N}^{\mathrm{G}}$-nitro-L-arginine; D-ARG=D-arginine; L-ARG=L-arginine; SNP-sodium nitroprusside.

Median values (ranges) are presented.

${ }^{*} \mathrm{p}<0.001$ compared with the other four groups. 
TABLE 2

Thromboembolic Parameters and Bleeding Times in Venules and Arterioles of the Five Experimental Groups

\begin{tabular}{|c|c|c|c|c|c|c|c|c|c|c|}
\hline & \multicolumn{5}{|c|}{ Venules } & \multicolumn{5}{|c|}{ Arterioles } \\
\hline & $\mathrm{CON}$ & L-NA & $\begin{array}{l}\mathrm{L}-\mathbf{N A}+ \\
\text { D-ARG }\end{array}$ & $\begin{array}{l}\text { L-NA+ } \\
\text { L-ARG }\end{array}$ & $\begin{array}{c}\text { L-NA+ } \\
\text { SNP }\end{array}$ & $\operatorname{con}$ & L-NA & $\begin{array}{c}\text { L-NA+ } \\
\text { D-ARG }\end{array}$ & $\begin{array}{l}\text { L-NA+ } \\
\text { L-ARG }\end{array}$ & $\begin{array}{c}\mathrm{L}-\mathrm{NA}+ \\
\text { SNP }\end{array}$ \\
\hline EPT, & $\begin{array}{c}15 \\
(10-21)\end{array}$ & $\begin{array}{c}23 \\
(1-122)\end{array}$ & $\begin{array}{c}17 \\
(11-35)\end{array}$ & $\begin{array}{c}19 \\
(0-34)\end{array}$ & $\begin{array}{c}18 \\
(0-37)\end{array}$ & $\begin{array}{c}14 \\
(4-36)\end{array}$ & $\begin{array}{c}24^{\circ} \\
(5-56)\end{array}$ & $\begin{array}{c}14 \\
(3-101)\end{array}$ & $\begin{array}{c}9 \\
(2-28)\end{array}$ & $\begin{array}{c}16 \\
(5-42)\end{array}$ \\
\hline $\begin{array}{l}\text { RTH, } \\
\%\end{array}$ & $\begin{array}{c}65 \\
(51-79)\end{array}$ & $\begin{array}{c}63 \\
(38-74)\end{array}$ & $\begin{array}{c}63 \\
(55-82)\end{array}$ & $\begin{array}{c}65 \\
(50-85)\end{array}$ & $\begin{array}{c}69 \\
(55-92)\end{array}$ & $\begin{array}{c}70 \\
(24-94)\end{array}$ & $\begin{array}{c}68 \\
(49-89)\end{array}$ & $\begin{array}{c}65 \\
(40-77)\end{array}$ & $\begin{array}{c}65 \\
(47-87)\end{array}$ & $\begin{array}{c}68 \\
(56-87)\end{array}$ \\
\hline IBT, & $\begin{array}{c}8.6 \\
(0.6-40.4)\end{array}$ & $\begin{array}{c}4.3^{\dagger} \\
(0.0-305.2)\end{array}$ & $\begin{array}{c}2.5 \\
(1.0-27.2)\end{array}$ & $\begin{array}{c}0.9 \\
(0.3-13.4)\end{array}$ & $\begin{array}{c}1.0 \\
(0.1-2.8)\end{array}$ & $\begin{array}{c}3.1 \\
(2.2-28.2)\end{array}$ & $\begin{array}{c}1.8 \\
(0.4-31.6)\end{array}$ & $\begin{array}{c}1.5 \\
(0.2-9.0)\end{array}$ & $\begin{array}{c}2.3 \\
(0.5-11.5)\end{array}$ & $\begin{array}{c}1.5 \\
(0.3-8.1)\end{array}$ \\
\hline $\begin{array}{l}\text { OR, } \\
\%\end{array}$ & 45 & 36 & 0 & 8 & 31 & 27 & 14 & 10 & 8 & 0 \\
\hline
\end{tabular}

$\mathrm{CON}=$ control; L-NA-N $\mathrm{N}^{\mathrm{C}}$-nitro-L-arginine; D-ARG=D-arginine; L-ARG=L-arginine; $\mathrm{SNP}=$-sodium nitroprusside.

EPT indicates production time of first embolus; RTH, relative thrombus height; IBT, initial bleeding time; and OR, occurrence of rebleedings (number of rebleeding blood vessels per total number of vessels). Median values (ranges) are presented.

${ }^{*} \mathrm{p}<0.05 ; \dagger \mathrm{p}=0.06$ compared with control CON. 
TABLE 3

Fluid Dynamie Parameters (Immediately Before Puneture) in Venules and Arterioles of the Five Experimental Groups

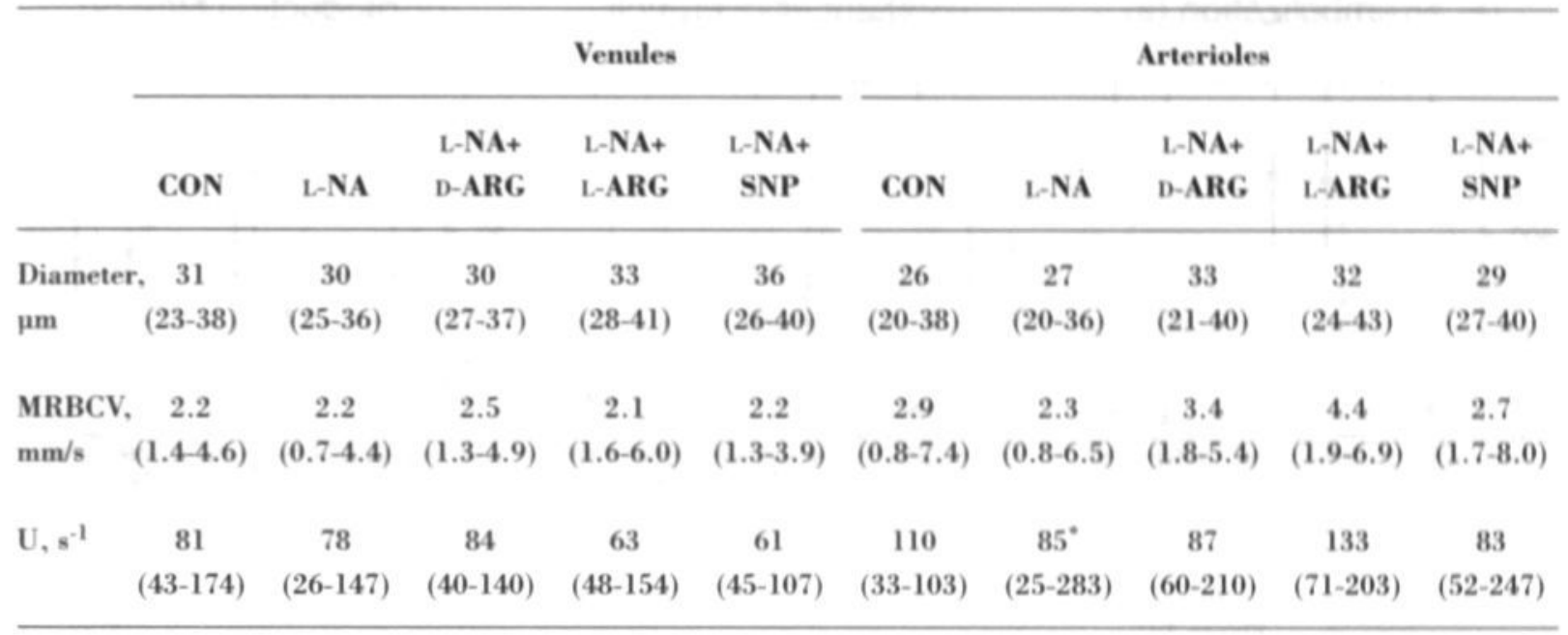

$\mathrm{CON}=$ control; L-NA=NG-nitro-L-arginine; D-ARG=D-arginine; L-ARG-L-arginine; SNP-sodium nitroprusside. MRBCV indicates mean red blood cell velocity and $U$, reduced velocity (mean $R B C$ velocity/diameter).

Median values (ranges) are presented.

${ }^{*} \mathrm{p}<0.05$ compared with control CON. 


\section{EFFECT OF NOS-INHIBITION (L-NA) IN VENULES}

\section{Duration of embolization (s)}

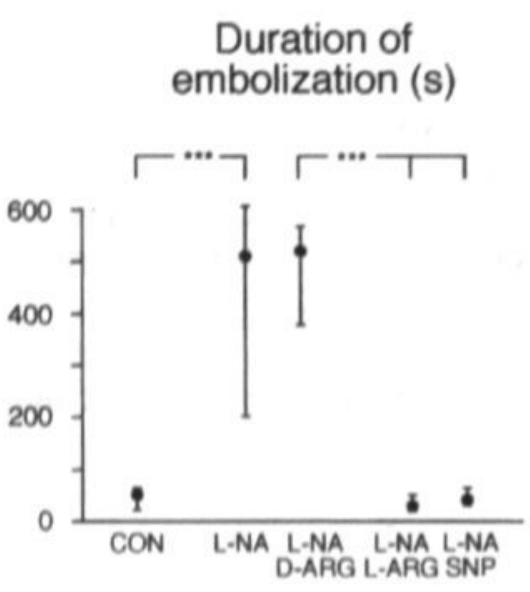

\section{Number of emboli}

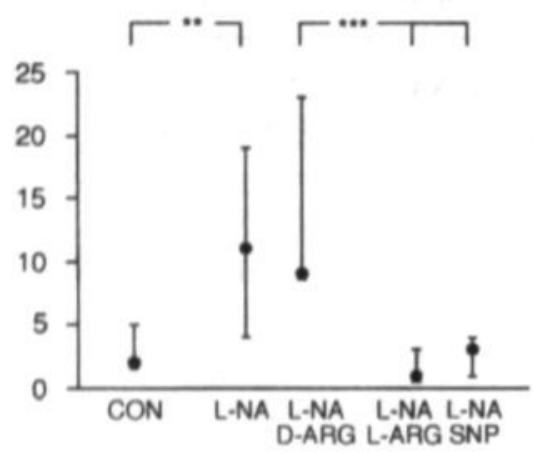

\author{
Median embolus \\ production time (s)
}

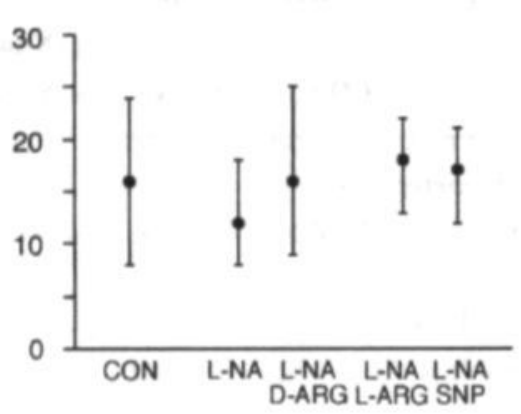

\section{Figure 1}

The effect of inhibition of nitric oxide synthase by $N^{\mathrm{G}}$-nitro-L-arginine (L-NA) alone or in combination with D-arginine (D-ARG), L-arginine (L-ARG), or sodium nitroprusside (SNP) on embolization in venules. Data obtained from rabbits of the control group (CON group; 11 vessels) and rabbits of which the mesentery was superfused with $0.1 \mathrm{mmol} / \mathrm{L}$ L-NA (14 vessels), L-NA and $1 \mathrm{mmol} / \mathrm{L}$ D-ARG (7 vessels), L-NA and $1 \mathrm{mmol} / \mathrm{L}$ L-ARG (13 vessels) or L-NA and $0.1 \mu \mathrm{mol} / \mathrm{L}$ SNP (13 vessels) are presented as medians (dots) with their interquartile ranges (bars). The total duration of embolization, the number of emboli produced and the median embolus production time per vessel are shown.

$*$ p<0.01 and **p<0.001 compared with controls. 


\section{EFFECT OF NOS-INHIBITION (L-NA) IN ARTERIOLES}

\section{Duration of embolization (s)}

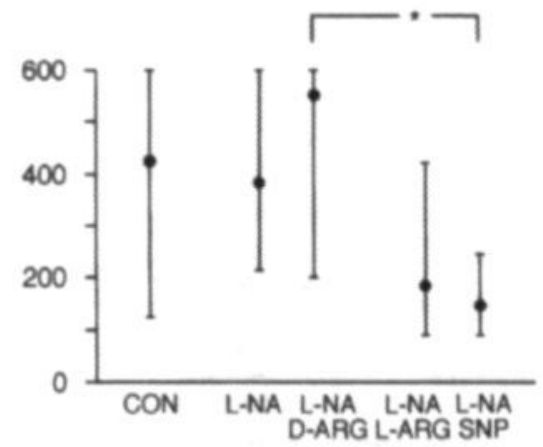

\author{
Number of emboli
}

\section{Median embolus production time (s)}
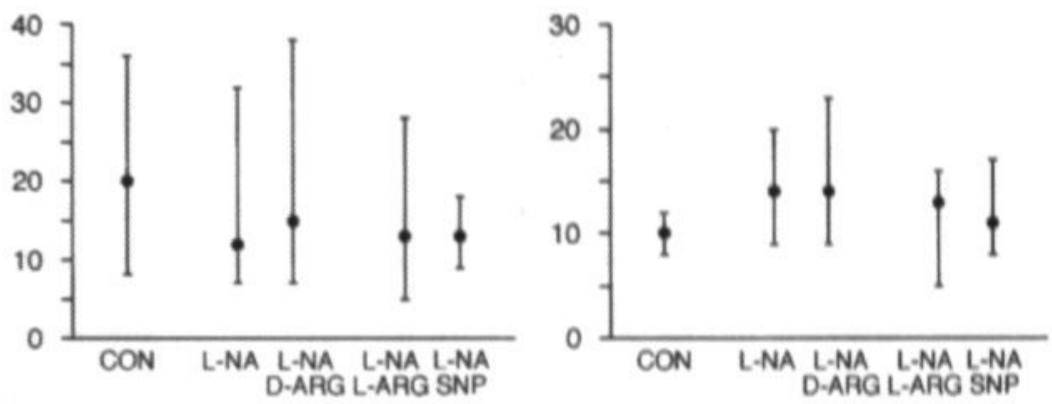

\section{Figure 2}

The effect of inhibition of nitric oxide synthase by $N^{G}$-nitro-L-arginine (L-NA) alone or in combination with D-arginine (D-ARG), L-arginine (L-ARG) or sodium nitroprusside (SNP) on embolization in arterioles. Data obtained from rabbits in the control group (CON group; 26 vessels) and rabbits in which the mesentery was superfused with $0.1 \mathrm{mmol} / \mathrm{L}$ L-NA (2l vessels), L-NA and $1 \mathrm{mmol} / \mathrm{L}$ D-ARG (9 vessels), L-NA and $1 \mathrm{mmol} / \mathrm{L}$ L-ARG (13 vessels) or L-NA and $0.1 \mu \mathrm{mol} / \mathrm{L}$ SNP (12 vessels) are presented as medians (dots) with their interquartile ranges (bars). The total duration of embolization, the number of emboli produced (the range presented in this figure is different from the range presented in Figure 1) and the median embolus produetion time per vessel are shown.

* p<0.05 as compared with control. 


\section{Cumulated number of emboli}

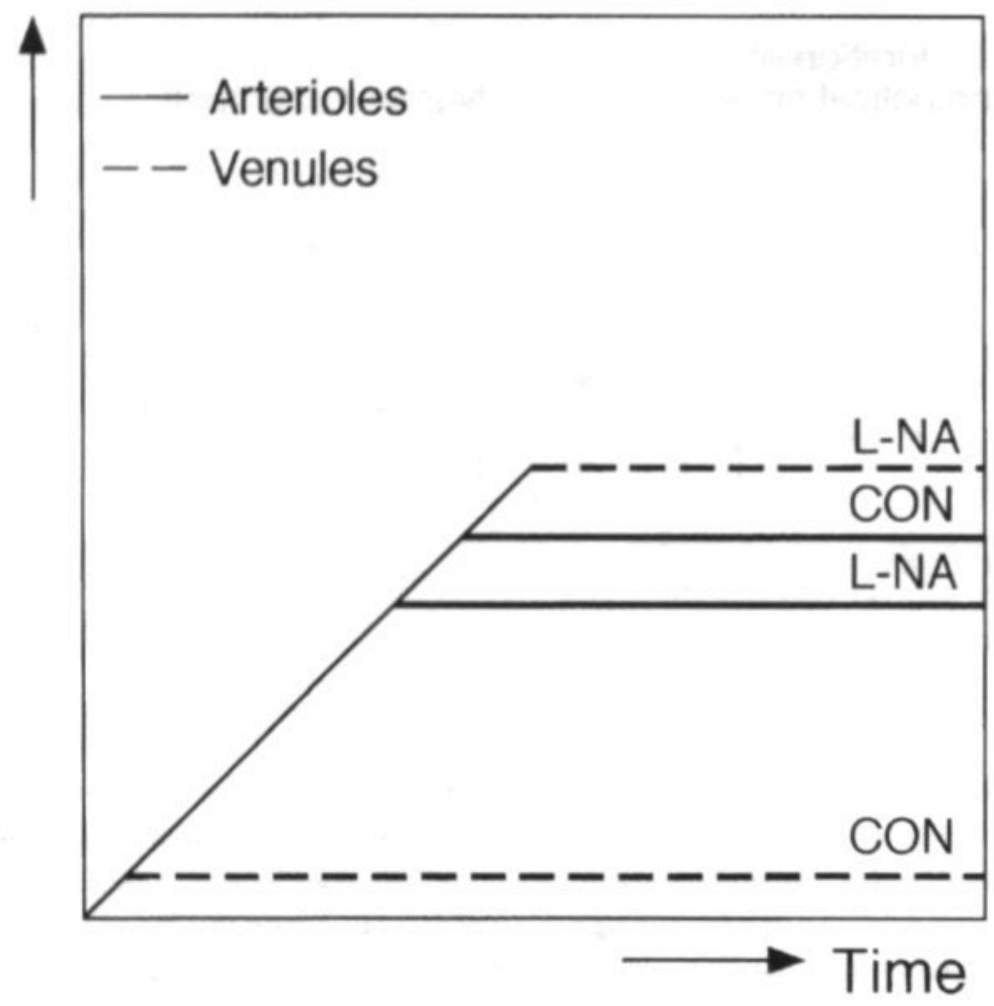

Figure 3

Schematic representation of the average effects of inhibition of nitric oxide synthase by $N^{\mathrm{G}}$-nitro$\mathrm{L}$-arginine (L-NA) on embolization in arterioles and venules. The rate of embolus production is represented by the slope of the curve. When the curve becomes horizontal, embolus production stops. 


\section{References}

1. Moncada S, Palmer RMJ, Higgs EA. Nitric oxide; physiology, pathophysiology, and pharmacology. Pharmacol Rev. 1991:43:109-142.

2. Radomski MW, Moncada S. The biological and pharmacological role of nitrie oxide in platelet funetion. Adv Exp Med Biol. 1993:344:251-264.

3. Anggard E. Nitric oxide: mediator, murderer, and medicine, Lancet. 1994:343:1199-1206.

4. Vanhoutte PM, Scott-Burden T. The endothelium in health and disease. Tex Heart Inst J. $1994 ; 21: 62-67$.

5. Fukute JM, Chaudhuri G. Inhibition of constitutive and inducible nitric oxide synthase: potential selective inhibition. Annu Rev Pharmacol Toxicol. 1995:35:165-194.

6. Knowles RG, Moncada S. Nitrie oxide synthases in mammals. Biochem J. 1994:298:249-258.

7. Pollock JS, Nakane M, Buttery LDK, Martinez A, Springall D. Polak JM, Forstermann U, Murad F. Characterization and localization of endothelial nitric oxide synthase using specifie monoclonal antibodies. Am J Physiol. 1993;265:C1379-C1387.

8. Radomski MW, Palmer RM, Moncada S. Characterization of the L-arginine: nitric oxide pathway in human platelets. Br J Pharmacol. 1990:101:325-328.

9. Förstermann U, Closs EI, Pollock JS, Nakane M, Schwarz P, Gath I, Kleinert H. Nitric oxide nynthase isozymes. Characterization, purification, molecular cloning, and functions. Hypertension. 1994;23:1121-1131.

10. Busse R, Hecker M, Fleming I. Control of nitric oxide and prostacyclin synthesis in endothelial cells, Arzneimittelforschung. 1994;44:392-396.

11. Nishimura H, Rosenblum WI, Nelson GH, Boynton S. Agents that modify EDRF formation alter antiplatelet properies of brain arteriolar endothelium in vivo. Am J Physiol. 1991:261:H15-H21.

12. Rosenblum WI, Nishimura H, Ellis EF, Nelson GH. The endothelium-dependent effects of thimerosal on mouse pial arterioles in vivo: evidence for control of microvascular events by EDRF as well as prostaglandins. J Cereb Blood Flow Metab. 1992;12:703-706.

13. Rosenblum WI, Nishimura H, Nelson GH. L-NMMA in brain microcirculation of mice is inhibited by blockade of cyclooxygenase and by superoxide dismutase. Am J Physiol. 1992:262:H1343-H1349.

14. Ovize M, de Lorgeril M, Cathignol D, Delaye J, Renaud S. Inhibition of coronary artery thrombosis by SIN-1, a donor of nitric oxide. J Cardiovasc Pharmacol. 1990:16:641-5.

15. Yao SK, Ober JC, Krishnaswami A, Ferguson JJ, Anderson HV, Golino P, Buja LM, Willerson JT. Endogenous nitric oxide protects against platelet aggregation and cyclic flow variations in stenosed and endothelium-injured arteries. Circulation. 1992;86:1302-1309. 
16. Paul W, Gresele P, Momi S, Bianchi G, Page CP. The effect of defibrotide on thromboembolism in the pulmonary vaseulature of mice and rabbits and in the cerebral vasculature of rabbits. $\mathrm{Br} J$ Pharmacol. 1993:110:1565-1571.

17. Meng YY, Trachtenburg J, Ryan US, Abendschein DR. Potentiation of endogenous nitric oxide with superoxide dismutase inhibits platelet-mediated thrombosis in injured and stenotic arteries. $\mathbf{J} \mathbf{A m}$ Coll Cardiol. 1995;25:269-275.

18. Yao SK, Akhtar S, Seottburden T, Ober JC, Golino P, Buja LM, Casscells W, Willerson JT. Endogenous and exogenous nitric oxide protect against intracoronary thrombosis and reocelusion after thrombolysis. Circulation. 1995:92:1005-1010.

19. oude Egbrink MGA, Tangelder GJ, Slaaf DW, Reneman RS. Thromboembolic reaction following wall puncture in arterioles and venules of the rabbit mesentery. Thromb Haemost. 1988;59:23-28.

20. oude Egbrink MGA, Tangelder GJ. Slaaf DW, Reneman RS. Different roles of prostaglandins in thromboembolic processes in arterioles and venules in vivo. Thromb Haemost. 1993:70:826-833.

21. Moore PK, al-Swayeh OA, Chong NW, Evans RA, Gibson A. L- $N^{G}$-nitro arginine (L-NOARG), a novel, L-arginine-reversible inhibitor of endothelium-dependent vasodilatation in vitro. Br J Pharmacol. 1990;99:408-412.

22. Mugge A, Lopez JA, Piegors DJ, Breese KR, Heistad DD. Acetylcholine-induced vasodilatation in rabbit hindlimb in vivo is not inhibited by analogues of L-arginine. Am J Physiol. 1991:260:H242H247.

23. Pohl U, Lamontagne D. Impaired tissue perfusion after inhibition of endothelium-derived nitric oxide. Basic Res Cardiol. 1991;86:97-105.

24. Radomski MW, Palmer RM, Moncada S. Comparative pharmacology of endothelium-derived relaxing factor, nitric oxide and prostacyclin in platelets. Br J Pharmacol. 1987;92:181-187.

25. Hogan JC, Lewis MJ, Henderson AH. In vivo EDRF activity influences platelet funetion. $B r J$ Pharmacol. 1988;94:1020-1022.

26. oude Egbrink MGA. Tangelder GJ, Slaaf DW, Reneman RS. Effect of blood gases and pH on thromboembolic reactions in rabbit mesenteric microvessels. Eur J Physiol (Pflügers Arch). 1989;414:324330.

27. Slaaf DW, Alewijnse R, Wayland H. Use of telescopic imaging in intravital microscopy: a simple solution for conventional microscopes. Int J Microcirc: Clin Exp. 1982;1:121-134.

28. Intaglietta M. Tompkins WR. Microvascular measurements by video image shearing and splitting. Microvase Res, 1973:5:309-312.

29. Slaaf DW, Arts T, Jeurens TJM, Tangelder GJ, Reneman RS. Electronic measurement of red blood cell velocity and volume flow in microvessels. In: Chayen J, Bitensky L, eds. Investigative microtechniques in medicine and biology. New York and Basel: Marcel Dekker, ine.; 1984:327-364. 
30. Kozma C, Macklin W, Cummins L.M, Mauer R. The anatomy, physiology, and the biochemistry of the rabbit. In: Weisbroth SE, Flatt RE, Kraus AL, eds. The biology of the laboratory rabbit. New York: Academic Press, Ine.; 1974:50-72.

31. Nichols K, Krantis A, Staines W. Histochemical localization of nitric oxide-synthesizing neurons and vascular sites in the guinea-pig intestine. Neuroscience. 1992;51:791-799.

32. Gryglewski RJ. Palmer RM, Moncada S. Superoxide anion is involved in the breakdown of endothelium-derived vascular relaxing factor. Nature. 1986;320:454-456.

33. Yao SK, Ober JC, Gonenne A, Clubb F, Jr., Krishnaswami A, Ferguson JJ, Anderson HV, Gorecki M, Buja LM, Willerson JT. Active oxygen species play a role in mediating platelet aggregation and eyclic flow variations in severely stenosed and endothelium-injured coronary arteries. Cire Res. $1993 ; 73: 952-967$.

34. Ikeda H, Koga Y, Oda T, Kuwano K, Nakayama H, Ueno T, Toshima H, Michael L.H, Entman ML. Free oxygen radicals contribute to platelet aggregation and eyclic flow variations in stenosed and endothelium-injured canine coronary arteries. J Am Coll Cardiol. 1994:24:1749-1756.

35. Suzuki H, Swei A. Zweifach BW, Schmid Schönbein GW. In vivo evidence for microvascular oxidative stress in spontaneously hypertensive rats. Hydroethidine microfuorography. Hypertension. 1995;25:1083-1089.

36. Hellums JD, 1993 Whitaker Lecture: biorheology in thrombosis research. Ann Biomed Eng. 1994;22:445-455.

37. Maalej N, Folts JD. Increased shear stress overcomes the antithrombotic platelet inhibitory effect of aspirin in stenosed dog coronary arteries. Circulation. 1996;93:1201-1205.

38. Mazeaud MM, Levenson J, Le-Quan-Sang KH, Simon A, Devynck MA. Platelet aggregation and in vivo shear forces. Thromb Haemost. 1994;71:26-31.

39. Lindberg RA, Slaaf DW, Miller FN. Involvement of nitric oxide and eyclooxygenase products in photoactivation-induced microvascular ocelusion. Microvasc Res. 1994:47:203-221.

40. Buxton ILO, Cheek DJ, Eckman D, Westfall DP, Sanders KM, Keef KD. $N^{C}$-nitro-1-arginine methyl esther and other alkyl esters of arginine are muscarinic receptor antagonists. Circ Res. 1993;72:387395.

41. Kurose I, Kubes P, Wolf R, Anderson DC, Paulson J, Miyasaka M, Granger DN. Inhibition of nitric oxide production. Mechanisms of vascular albumin leakage. Circ Res. 1993:73:164-171.

42. Kurose I, Wolf R, Grisham MB, Granger DN. Modulation of ischemia/reperfusion-induced microvancular dysfunction by nitric oxide. Circ Res. 1994;74:376-382.

43. Persson MG, Gustafsson LE. Wiklund NP, Hedqvist P. Moncada S. Endogenous nitric oxide an a modulator of rabbit skeletal muscle microcirculation in vivo. Br J Pharmacol. 1990:100:463-466. 
Chapter 4

Endogenous Nitric Oxide and Prostaglandins

Synergistically Counteract

Thromboembolism in Arterioles

but Not in Venules 
Martijn A.W. Broeders, ${ }^{1}$ Geert-Jan Tangelder, ${ }^{1,2}$ Dick W. Slaaf,${ }^{3}$ Robert S. Reneman, ${ }^{1}$ Mirjam G.A. oude Egbrink' ${ }^{1}$

From the Departments of Physiology ${ }^{1}$ and Biophysics, ${ }^{3}$ Cardiovascular Research Institute Maastricht, Maastricht University, Maastricht, the Netherlands

Laboratory for Physiology, ${ }^{2}$ Institute for Cardiovascular Research, Free University, Amsterdam, the Netherlands

Published in Arteriosclerosis Thrombosis and Vascular Biology 2001;21:163-169 


\begin{abstract}
Abstraet
It has been shown that nitric oxide (NO) and prostacyclin (prostaglandin $\mathrm{I}_{2}: \mathrm{PGI}_{2}$ ) from cultured endothelium synergistically inhibit blood platelet aggregation in vitro. However, it is unknown whether this synergism is also effective in the inhibition of thromboembolism in vivo and, if it is, whether it differs between vessel types. Therefore, the effect of endogenous $\mathrm{NO}$ and $\mathrm{PGI}_{2}$, in combination or alone, on thromboembolism was studied in an in vivo model. Thromboembolism was induced by micropipet puncture of rabbit mesenteric arterioles and venules (diameter 18 to 40 $\mu \mathrm{m})$. In addition, the influence of wall shear rate was analyzed. In arterioles, the combined inhibition of NO synthase ( $N^{6}$-nitro-L-arginine; L-NA; $0.1 \mathrm{mmol} / \mathrm{L}$; local superfusion) and of eyclooxygenase (aspirin; acetylsalicylic acid; ASA; $100 \mathrm{mg} / \mathrm{kg}$ iv) resulted in a pronounced, significant prolongation of embolization duration (median $>600$ seconds) compared with control (median 153 seconds) or treatment with either L-NA (234 seconds) or ASA ( 314 seconds). This combined effect of L-NA+ASA was greater than the sum of the individual effects of L-NA and ASA. In contrast, in venules L-NA+ASA had no additional effect on embolization duration (209 seconds) compared with the effect of L-NA alone (230 seconds): ASA alone had no effect (122 seconds; control 72 seconds). Interestingly, only in the L-NA+ASA arterioles did embolization correlate positively with wall shear rate $\left(r_{s}=0.687 ; p=0.028\right)$. In conclusion, this study indicates that in arterioles, but not in venules, endogenous $\mathrm{NO}$ and prostaglandins synergistically counteract ongoing thromboembolism after vessel wall injury and that the combination of endogenous NO and prostaglandins appears to protect against enhancement of arteriolar thromboembolism by wall shear rate.
\end{abstract}




\section{Introduction}

After vessel wall injury, platelets are activated and a platelet thrombus is formed. To limit the extent of platelet activation, the vessel wall releases potent platelet-inhibiting substances such as prostacyclin (prostaglandin $\mathrm{I}_{2} ; \mathrm{PGI}_{2}$ ) and nitric oxide (NO). Better insight into the role of endogenous antithromboembolic substances is of major importance to improve our understanding of elinical disorders in which thromboembolic processes play a role. Clinical studies indicate that atheromatous changes in the arterial wall are preceded by macrovasular ${ }^{1,2}$ and microvaseular ${ }^{3,4}$ "endothelial dysfunction". It has been established that reduced bioavailabilities of vascular $\mathrm{NO}$ and $\mathrm{PGI}_{2}$ are key factors in this dysfunction, ${ }^{5}$ which may be reversed by stimulating endogenous production of $\mathrm{NO}$ or $\mathrm{PGI}_{2} \cdot{ }^{4.5}$

In two separate in vivo studies, we investigated the individual roles of endogenous prostaglandins and $\mathrm{NO}$ in inhibition of thromboembolism in arterioles and venules ${ }^{6,7}$ From these studies, we concluded that in arterioles, this process is predominantly inhibited by endogenous prostaglandins, ${ }^{6}$ whereas inhibition by endogenous $\mathrm{NO}$ is more important in venules. ${ }^{7}$ These antithromboembolic mediators can be produced simultaneously by vascular endothelium at a site of wall injury, and their production is stimulated by platelet agonists like thrombin and adenosine diphosphate (ADP). ${ }^{8,9}$ Therefore, in injured vessels, activated blood platelets are likely to be exposed to a combination of the platelet antagonists $\mathrm{PGI}_{2}$ and NO. This combination may exert a more pronounced antithromboembolic effect than expected on the basis of their individual antithromboembolic effects, because in vitro studies have shown that $\mathrm{PGI}_{2}$ and $\mathrm{NO}$ released by cultured endothelial cells can act synergistically in the inhibition of platelet aggregation. ${ }^{10} \mathrm{It}$ is unknown, however, whether this synergistic interaction is also effective in the inhibition of thromboembolism in vivo and, if it is, whether it differs between vessel types.

The aim of the present study was to investigate in vivo the effect of combined inhibition of endogenous prostaglandin and NO production on thromboembolism in arterioles and venules by using a model described in detail previously. ${ }^{11}$ In anesthetized rabbits, the wall of mesenteric arterioles and venules is punctured with a micropipet, and the ensuing thromboembolic reaction is studied with the use of intravital videomicroscopy. To study the combined effects of endogenous prostaglandins and $\mathrm{NO}$ on this thromboembolic reaction, rabbits were pretreated with intravenous aspirin and their mesentery was superfused with the $N O$ synthase inhibitor $N^{G}$-nitro-Larginine (L-NA) before wall puncture. In separate experiments, rabbits were treated with aspirin or L-NA alone, or served as controls (CON group).

\section{Methods}

\section{Animals and intravital videomicroscopy}

Experiments were performed on 27 New Zealand White rabbits of either sex (weight from 2.3 to 
$2.8 \mathrm{~kg}$ ). The experiments were approved by the local ethics committee on the use of laboratory animals. Anesthesia was induced with ketamine hydrochloride (40 mg/kg body weight Nimatek, im; AUV) and xylazine hydrochloride ( $5 \mathrm{mg} / \mathrm{kg}$ body weight Sedamun, im; AUV). Anesthesia was maintained by continuous infusion of ketamine $\left(40 \mathrm{mg} \cdot \mathrm{kg}^{-1} \cdot \mathrm{h}^{-1}\right)$, xylazine $\left(5 \mathrm{mg} \cdot \mathrm{kg}^{-1} \cdot \mathrm{h}^{-1}\right)$ and lactetrol (15 mL/h; Aesculaap) through a catheter (PE-50) in the femoral vein. Arterial blood pressure was continuously measured through a catheter (PE-60) in the femoral artery (Uniflow external pressure transducer, Baxter). Heart rate was assessed from the instantaneous pressure signal. To keep the arterial catheter patent it was continuously perfused with physiological saline $(3 \mathrm{~mL} / \mathrm{h})$ via the Uniflow system; no heparin was used. Arterial pressure and heart rate values were stored on hard disk.

During surgery and throughout the experiment, body temperature was maintained at $37^{\circ} \mathrm{C}$ to $38^{\circ} \mathrm{C}$ with an infrared heating lamp controlled by a thermoanalyzer system (Hugo Sachs Elektronik) connected to a rectal probe. After surgery, blood from a central ear artery was colleeted in EDTA $(0.9 \mathrm{~mL}$ blood $/ 0.1 \mathrm{~mL}$ EDTA; $0.027 \mathrm{~mol} / \mathrm{L})$ for electronic platelet counts and assessment of hemoglobin concentration and hematocrit (Coulter Counter; model ZF); these values were corrected for EDTA dilution.

During the experiments, the rabbits were ventilated (animal ventilator model 4601; Technical \& Scientific Equipment) at a positive end-expiratory pressure of $2 \mathrm{~cm} \mathrm{H}_{2} \mathrm{O}$ through a trachea cannula (3.5 or $4.5 \mathrm{~mm}$ internal diameter; Mallinckrodt) with a mixture of nitrogen $(75 \%)$, oxygen $(24.5 \%)$ and carbon dioxide $(0.5 \%)$ to maintain systemic arterial $\mathrm{pH}, \mathrm{pCO}_{2}$, and $\mathrm{pO}_{2}$ at normal values. ${ }^{11,12}$ Throughout the experiments, average blood gas and $\mathrm{pH}$ values (ABL 3 Radiometer) were $\mathrm{pH} 7.42 \pm 0.02, \mathrm{pCO}_{2} 40 \pm 2 \mathrm{~mm} \mathrm{Hg}$, and $\mathrm{pO}_{2} 100 \pm 10 \mathrm{~mm} \mathrm{Hg}_{\text {(mean } \pm n t a n d a r d}$ deviation), which are normal values for rabbits. ${ }^{11,12}$ No statistical differencen existed among the experimental groups.

A segment of the distal ileum was exteriorized through a small midline incision in the abdominal wall and was carefully spread over a siliconized glass plate mounted in an electrically heated microscope table $\left(37^{\circ} \mathrm{C}\right)$. It was continuously superfused with a buffered Tyrode's solution $\left(37^{\circ} \mathrm{C}\right.$, pH 7.35 to 7.40$)$ saturated with $95 \% \mathrm{~N}_{2}$ and $5 \% \mathrm{CO}_{2}$. The exteriorized ileum was kept moist with overlying wet gauze. The mesenteric tissue was visualized with a Leitz intravital microscope with a long-working-distance objective (Leitz LL X25, numerical aperture 0.35). Transillumination of microvessels in the transparent mesentery was performed with a tungsten lamp. For off-line analysis, images were recorded on videotape (Panasonic SVHS) through a Grundig TV camera (model FA 32; 1 inch). Final magnification at the front plane of the camera was $\mathrm{X} 40$.

Vascular diameter was measured off-line with an image shearing device. Mean red blood cell velocity was measured on-line using a dual-slit system connected to a tracking correlator 
(IPM). Reduced velocity (U), a well-known first-order approximation of wall shear rate, ${ }^{13}$ was calculated by dividing mean red blood cell velocity by vessel diameter.

\section{Vessel wall puncture and the thromboembolic reaction}

Arterioles and venules with an estimated diameter ranging from 20 to $40 \mu \mathrm{m}$ were selected. Vessel wall injury was mechanically induced by puncture with a glass micropipet (tip diameter $-6 \mu \mathrm{m}$ ), as described previously. ${ }^{11}$ To be certain that all layers of the wall were damaged, puncture was considered to be successful only if red blood cells could be seen leaving the vessel.

Immediately after puncture, the thromboembolic reaction started. In all vessels a white thrombus was formed that consisted of tightly packed platelets. The height and shape of the thrombus remained constant in time. Circulating platelets adhered to this stationary thrombus mainly on its downstream side, forming a loosely packed platelet mass that did not affect the height of the stationary thrombus. From time to time these platelet masses embolized. After a certain period of time, embolization stopped in most vessels, whereas the thrombus remained unchanged at the site of injury for the remainder of the experiment. Only in a minority of vessels (2 of all 49 venules; none of the arterioles) did bleeding and thrombus formation occur without the subsequent production of emboli. In these 2 venules, no distinguishable emboli were produced.

To quantify the thromboembolic reaction, the following variables were determined offline from videotape: the duration of bleeding (bleeding time), the maximal thrombus height relative to the local vessel diameter, the duration of embolization, the number of emboli produced and as a measure of the rate of embolus formation the median embolus production time per vessel (ie, the median of all periods of time needed to produce an embolus; MEPT). In short, all points in time that an embolus broke off the stationary thrombus were determined (time of vessel wall puncture: $t=0$ ). The time needed to produce an embolus was defined as the interval between puncture and the breaking off of the first embolus or as the interval between the breaking off of successive emboli. Per vessel, the median of these imtervals was determined, representing the MEPT for that vessel. Each vessel was observed continuously for 600 seconds from the moment of puncture. Vessels in which embolization continued for $>600$ seconds were observed again intermittently every 15 minutes, for 1 to 2 minutes, during the remainder of the experiment; therefore, in these vessels, the total duration of embolization could only be approximated. Emboli were taken into account only when their short axis, perpendicular to the vessel wall, was $>5 \mu \mathrm{m}$. Aggregates of smaller dimensions could not always be distinguished from the background with sufficient accuracy. To increase the number of blood vessels in each group, we punctured several vessels per rabbit mesentery. 


\section{Experimental groups and protocol}

Rabbits were assigned at random to one of four groups. In the group of rabbits that is most important for this study $(\mathrm{n}=8)$, both endogenous NO and endogenous prostaglandin synthesis was inhibited (L-NA+ASA group). Rabbits in this group were pretreated with aspirin (acetylsalieylie acid; ASA; $100 \mathrm{mg} / \mathrm{kg}$ iv), whereas their mesentery was continuously superfused with the NO synthase inhibitor $N^{6}$-nitro-L-arginine ( $-N A ; 0.1 \mathrm{mmol} / \mathrm{L}$; molecular weight 219.2; Sigma), L-NA is an irreversible inhibitor of $\mathrm{NO}$ synthase ${ }^{14}$ and a concentration of $0.1 \mathrm{mmol} / \mathrm{L}$. has been shown to be sufficiently high to effectively inhibit $\mathrm{NO}$ synthase in the wall of rabbit blood vessels ${ }^{15}$ and in rabbit platelets. ${ }^{16} \mathrm{ASA}$ at a dose of $100 \mathrm{mg} / \mathrm{kg}$ inhibits not only the endogenous production of the proaggregatory thromboxane $A_{2},{ }^{6}$ but also that of the antiaggregatory prostaglandins $\left(\mathrm{eg}, \mathrm{PGI}_{2}\right)$ for at least the duration of our experiments. ${ }^{17}$ Aspirin was administered through a polyethylene catheter in the marginal ear vein. High doses of ASA irreversibly acetylate the active site of the prostaglandin-synthesizing enzyme cyclooxygenase (COX). ${ }^{18}$

In two additional groups of rabbits, the role of endogenous NO (L-NA group, $n=6$ ) and endogenous prostaglandins (ASA group, $n=7$ ) was studied separately. The inhibition of endogenous NO and endogenous prostaglandin production was performed according to exactly the same methods as used in the L-NA+ASA group. In the CON group ( $n=6)$, the mesentery was superfused with the vehicle, a buffered Tyrode's solution. The experiments in these three groups were newly performed and not used before in previous studies. ${ }^{6.7}$ Such control experiments have to be performed with rabbits from the same population and within the same period of time to prevent an increase in variability due to seasonal influences.

Both the L-NA- and ASA-containing solutions were freshly prepared on the day of each experiment. L-NA was dissolved in buffered Tyrode's solution and aspirin was suspended at a concentration of $100 \mathrm{mg} / \mathrm{mL}$ as previously described. ${ }^{6,7}$ The aspirin solution was administered intravenously at a rate of $1 \mathrm{~mL} / \mathrm{min}$. In a previous study, we showed that the vehicle solution (with the same $\mathrm{pH}$ ) did not affect thromboembolism when administered intravenously. ${ }^{6}$

In all groups, the mesentery was allowed to stabilize for a period of 30 to 35 minutes after exteriorization under continuous superfusion with buffered Tyrode's solution. Fifteen minutes before the start of this stabilization period the rabbits in the ASA and L-NA+ASA groups were pretreated with aspirin, as described earlier. After the stabilization period, the superfusion was switched to the L-NA solution in the L-NA and L-NA+ASA groups; in the CON and ASA groups, superfusion was continued with buffered Tyrode's solution. Per experiment, a median number of four vessels (range 1 to 6 vessels) was punctured from 30 to 35 minutes up to 3 hours after exteriorization of the mesentery. Each puncture was preceded by a 4-minute period during which mean red blood cell velocity was measured. This 4-minute period, the puneture itself, and the subsequent observation period of $\geq 600$ seconds were recorded on videotape. 


\section{Statistical analysis}

Because of their nonsymmetrical distribution, the data are presented and displayed as median values with their interquartile ranges unless otherwise indicated. Embolization data are presented per blood vessel. Puncture of different numbers of vessels per rabbit in the various groups did not influence interpretation of the data, because averaging of data per animal led to similar results and conclusions. Differences between two groups were tested with the nonparametric Mann-Whitney $U$ test. Correlations were performed with the nonparametric Spearman's rank correlation test (coefficient=r $r_{s}$ ). In all tests, the level of significance was set at $5 \%$.

Endogenous NO and prostaglandins were considered to act synergistically when the effect of inhibition of both was greater than the sum of the effects of inhibition of NO (by L-NA) and prostaglandins (by ASA) alone; this definition of synergism has been used by others. ${ }^{19}$

\section{Results}

\section{Thromboembolic reaction in vivo}

In all vessels, bleeding and thrombus formation started immediately after wall puncture. Bleeding duration did not differ between the groups (Table 1). A thrombus started to grow within 0.1 second after puncture and reached its maximal size within 1 to 2 seconds. This fast thrombus formation, as well as the height of the thrombus (Table 1) was not influenced by combined L-NA and ASA treatment or treatment with L-NA or ASA alone, in both arterioles and venules. In both the L-NA and ASA groups, no significant correlation was found between the duration of the experiment until a vessel was punctured and the embolization process in that vessel, indicating that there was no time dependency of the embolization parameters measured, and that L-NA and ASA treatment were effective throughout the experiments.

\section{Arterioles}

In these vessels, the combination of L-NA and ASA resulted in a pronounced, significant prolongation of the duration of embolization (median $>600$ seconds) compared to each of the other three groups (CON 153 seconds, L-NA 234 seconds, ASA 314 seconds; all p-values $<0.008$; Figure 1, left panel). It should be noted that the median value of 600 seconds is an underestimation of the combined effect of L-NA and ASA due to the finite observation period. In the $70 \%$ of the arterioles of this group in which embolization continued at $>600$ seconds, it continued during the remainder of the experiment ( 30 minutes to 3 hours). L-NA alone had no significant effect, whereas ASA pretreatment induced a significant prolongation compared with CON. The latter effect, however, was significantly less than the effect of combined L-NA and ASA treatment. Moreover, in only $21 \%$ of the ASA arterioles did embolization continue for $>600$ seconds, which also shows that the effect of ASA alone is clearly less than the combined effect of L-NA+ASA. 
The number of emboli produced per vessel within 600 seconds (Table 1) was also significantly larger in the L-NA+ASA group (29 emboli) than in the other three groups (CON 14, L-NA 16, ASA 12 emboli).

The median embolus production time, as a measure of the rate of embolus production (Table 1), was not significantly influenced by L-NA+ASA or by L-NA or ASA alone.

\section{Venules}

In venules, combined treatment with L-NA and ASA resulted in a significant, but far less pronounced, prolongation of embolization duration (L-NA+ASA 209 seconds; Figure 1, right panel) compared with CON (72 seconds); this prolongation was not significantly different from the increase observed after L-NA treatment alone (230 seconds) but was significantly greater than the increase after ASA pretreatment alone (122 seconds). The increase in duration of embolization after L-NA superfusion was significant compared with the CON group. In only 1 of the 49 venules did embolization continue for longer than the 600-second observation period.

Compared with the CON group ( 3 emboli), the number of emboli produced (Table 1) was not significantly changed by combined L-NA and ASA treatment ( 8 emboli), whereas L-NA superfusion alone significantly increased the number of emboli (10 emboli). ASA pretreatment alone had no significant effect ( 5 emboli).

The median embolus production time (Table 1) in the L-NA+ASA group was not significantly different compared with the CON, ASA and L-NA groups.

\section{Synergism in arterioles and/or venules?}

In arterioles, the median effect of a combination of L-NA and ASA on embolization duration ( $>600$ seconds, which is $>447$ seconds longer than in the CON group [153 seconds]) and on the number of emboli produced ( $>29$ emboli, which is an increase of $\geq 15$ emboli compared with the CON group [ 14 emboli]) was greater than the sum of the median effects of L-NA (234 seconds, which is 81 seconds longer than the CON group; 16 emboli, which is an increase of 2 emboli) and ASA (314 seconds, which is 161 seconds longer than the CON group: 12 emboli, which is a decrease of 2 emboli) alone. Hence, synergism is present because 447 seconds is longer than 242 $(81+161)$ seconds and 15 emboli is $>0([+2]+[-2])$ emboli. In contrast, no such synergistic effect of the combined inhibition of $\mathrm{NO}$ synthase and $\mathrm{COX}$ was found in venules.

\section{Arterioles versus venules}

In the CON, ASA and L-NA+ASA groups, the duration of embolization and the number of emboli produced was significantly larger in arterioles than in venules. In contrast, in the L-NA group, the embolization parameters were similar in arterioles and venules (all p-valuen>0.218). 


\section{Fluid dynamic conditions}

The fluid dynamic parameters as measured in all vessels immediately before puncture are presented in Table 2. Neither L-NA+ASA nor L-NA or ASA alone had a significant effect on diameter, red blood cell velocity and reduced velocity in the venules. Except for a slightly lower red blood cell velocity and reduced velocity in the L-NA+ASA arterioles than in the L-NA arterioles $(\mathrm{p}=0.049)$, the fluid dynamic parameters were similar in the arterioles of the four groups.

In the L-NA+ASA arterioles reduced velocity, which is a measure of wall shear rate, correlated positively with the number of emboli produced within 600 seconds $\left(r_{s}=0.687, p=0.028\right.$; Figure 2, left panel). In contrast, in all arterioles of the other three groups (all $r_{s}$-values $<0.209$, all p-values $>0.214$; data not shown), as well as in the venules of all groups (all $r_{s}$-values $<0.251$, all p-values>0.092; data not shown), no correlation was found between reduced velocity and the embolization parameters.

\section{Whole-animal parameters}

In all rabbits, the values of hemoglobin (overall median value $7.9 \mathrm{mmol} / \mathrm{L}$, range 7.0 to 9.6 $\mathrm{mmol} / \mathrm{L})$, hematocrit $(38.2 \mathrm{~L} / \mathrm{L}, 32.4$ to $45.8 \mathrm{~L} / \mathrm{L})$, platelet count $\left(548 \times 10^{3} / \mu \mathrm{L}, 384\right.$ to $\left.978 \times 10^{3} / \mu \mathrm{L}\right)$, mean arterial blood pressure $(69 \mathrm{~mm} \mathrm{Hg}, 53$ to $102 \mathrm{~mm} \mathrm{Hg}$ ) and heart rate (142 beats per minute, 115 to 172 beats per minute) were within the ranges normally found in anesthetized rabbits. ${ }^{11,12}$ Arterial blood pressure and heart rate did not change after ASA pretreatment or L-NA superfusion. No significant differences in hemoglobin, hematocrit, platelet counts, mean arterial blood pressure and heart rate were found between rabbits of the different groups. In addition, no significant correlations were found between these whole-animal parameters and the embolization parameters in arterioles and venules.

\section{Discussion}

The findings in the present study show that combined inhibition of endogenous NO and prostaglandin production affects the thromboembolic reaction after wall puncture differently in arterioles and venules of the rabbit mesentery. In arterioles, combined inhibition of endogenous NO and prostaglandin production with $N^{6}$-nitro-L-arginine (L-NA) and aspirin (ASA) results in a prolongation of the duration of embolization and a concomitant increase in the number of emboli produced that was greater than the sum of the individual effects of L-NA and ASA. Such a synergistic effect was not observed in venules. In addition, this combined inhibition unmasked a positive relation between embolization and wall shear rate in arterioles, but not in venules.

The present study shows that the inhibition of endogenous NO and prostaglandin formation only influences embolization but has no effect on thrombus formation. In both arterioles and venules, wall puncture induces a thromboembolic reaction that consists of these two stages. First, 
a stable thrombus is formed by heavily activated blood platelets that are tightly packed and completely degranulated and shape changed. Subsequently, emboli are produced at the downstream side of this thrombus. Platelets in the emboli are loosely packed without clear signs of shape change or degranulation. ${ }^{20}$ Hence, the level of platelet activation appears to be clearly different during thrombus formation and embolization. Therefore, it is not surprising that platelet influencing substances like $\mathrm{PGI}_{2}$ and $\mathrm{NO}$ exert different actions during thrombus formation and embolization.

Wall shear rate has been shown to be a platelet-stimulating factor in vitro ${ }^{21}$ and in damaged arteries in vivo. ${ }^{22}$ In intact vessels in vivo, however, shear forces also stimulate the endothelial production of such platelet-inhibiting factors as $\mathrm{NO}$ and $\mathrm{PGI}_{2}{ }^{23}$ Therefore, shear forces may have only a stimulating effeet on thromboembolism in vivo after both vessel wall damage and complete inhibition of endothelium-derived antiplatelet factors. In the present study, we demonstrate for the first time that in arterioles, wall shear rate enhances the thromboembolic reaction only when the endogenous production of both NO and prostaglandins is blocked. This finding indieates that under normal circumstances, these autacoids play an important role in counteracting wall shear rate-enhanced platelet activation in arterioles.

In venules, platelet-vessel wall interactions are reported to be shear-dependent, too. ${ }^{24}$ Because in our study the parameters that describe these interactions are independent of wall shear rate, even when both endogenous $\mathrm{NO}$ and prostaglandin synthesis is blocked, other factors that oppose a wall shear rate-enhanced platelet activation have to be considered. In this respect. ectonucleotidases, anticoagulant agents or fibrinolytic substances should be taken into account. ${ }^{25}$

An additional possible element in the marked effect of wall shear rate on embolization in arterioles when both endogenous $\mathrm{NO}$ and prostaglandin synthesis are blocked is that unlike in venules, the balance between antithromboembolic and prothromboembolic properties of the wall is more towards prothromboembolic. This is supported by our repeated finding that under control conditions, the duration of embolization is significantly longer in arterioles than in venules. ${ }^{6,7,11,12,26}$

The present study presents for the first time a pronounced synergistic effect of endogenous $\mathrm{NO}$ and prostaglandins on thromboembolism in vivo in arterioles but not in venules. The combined action of both substances has been studied before with regard to vaseular reactivity, either with isolated human arteries ${ }^{27}$ and veins ${ }^{28}$ or in vivo in hamster arterioles ${ }^{29}$ and rat arterioles $^{30}$ and venules, ${ }^{31}$ but not with regard to their antithromboembolic function. Several reports describe the combined effects of exogenously added $\mathrm{NO}$ and $\mathrm{PGI}_{2}$ on platelet function in vivo (or ex vivo) in both animal ${ }^{32}$ and human studies. ${ }^{33}$ It is interesting to consider the meehanism that underlies the putative synergistic interaction between the L-arginine/NO pathway on the one hand and the arachidonic acid/prostaglandin pathway on the other. Such a possible mechanism was 
described by Salvemini and coworkers, who showed in an in vitro study that in endothelial cells, NO-mediated activation of COX leads to $\mathrm{PGI}_{2}$ release and eAMP (cyclic adenosine 3',5'monophosphate) elevation, contributing to the antithromboembolic effect of endogenously released NO. ${ }^{34}$ The exact molecular mechanisms by which $\mathrm{NO}$ activates the COX enzyme remain to be identified. Several possible mechanisms have been proposed by Salvemini and coworkers, most of them involving superoxide radicals. ${ }^{35}$ Another possible mechanism underlying synergism includes cGMP (cyclic guanosine 3',5'-monophosphate)-mediated inhibition of cAMP-phosphodiesterase, thus reducing cAMP degradation, ${ }^{36}$ as well as activation of certain target proteins which can be phosphorylated by protein kinases dependent on both eGMP and eAMP. This has been demonstrated for a 46-kDa vasodilator-stimulated phosphoprotein (VASP) in platelets. ${ }^{37}$ If these mechanisms are specific for arteriolar endothelium, these in vitro findings may provide an explanation for our observation that in arterioles, the antithromboembolic effect of endogenous $\mathrm{NO}$ alone is negligible but that it is pronounced in combination with endogenous prostaglandins, provided sufficient $\mathrm{NO}$ is produced to activate the arachidonic acid/prostaglandin pathway.

The effects of inhibition of the endogenous production of either NO or prostaglandins were similar to those observed in previous studies from our institute. ${ }^{6,7}$ In addition, our finding that in the L-NA group the embolization parameters were similar in arterioles and venules is in agreement with the observation in one of these studies. ${ }^{7}$ Apparently, L-NA superfusion abolishes the difference in embolization duration between arterioles and venules, which is larger in the arterioles under control conditions. ${ }^{6,7,11,12,26} \mathrm{It}$ is unkown whether the insignificant role of NO alone in inhibiting thromboembolism in arterioles is due to low local NO synthesis by the arteriolar wall or to a limited bioavailability of $\mathrm{NO}$ in arterioles in vivo. By means of immunohistochemistry, we showed a similar expression of endothelial NO synthase in arterioles and venules, making a reduced capacity for NO synthesis in arterioles unlikely (M.A.W. Broeders, unpublished observations, 1998). A low bioavailability of $\mathrm{NO}$ in arterioles may be due to the scavenging effect of superoxides, which at least in rats are generated in higher quantities in mesenteric arterioles than venules. ${ }^{38}$ In the present study, aspirin was used for complete and selective irreversible inhibition of the enzyme cyclooxygenase. However, an influence on other enzymes or proteins, such as kinases involved in the nuclear factor- $\kappa \beta$ pathway, cannot be excluded. ${ }^{39}$ This inflammatory pathway is activated by such stimuli as tumor necrosis factor- $\alpha$. Because our experiments were conducted under near-physiological circumstances, it is unlikely that this pathway played a role in our study. The findings in the present study and those in an earlier study from our institute ${ }^{6}$ show that the involvement of both proaggregatory prostaglandins (eg, thromboxane $A_{2}$ ) and antiaggregatory prostaglandins $\left(e g, P G I_{2}\right.$ ) in thromboembolic processes is more pronounced in arterioles than in venules. This can likely be explained by a functional difference 
between arteriolar and venular endothelium; damaged or stimulated endothelial cells seem to synthesize more antiplatelet and proplatelet prostaglandins in arterioles than in venules.

It is unlikely that the route of administration of L-NA and ASA accounts for the difference in effect between arterioles and venules. In a previous study, we provided evidence that superfused L-NA enters the lumen of mesenterie arterioles and venules similarly, ${ }^{7}$ whereas the intravenous administration of aspirin most likely results in similar plasma concentrations in arterioles and venules. ${ }^{6}$ Beside endothelial cells, blood platelets also constitutively express $N O$ synthase and eyclooxygenase. It is unlikely that the release of $\mathrm{NO}$ and prostaglandins by platelets is different in arterioles and venules, because electron and light mieroscopy showed that the composition of the stationary thrombus (ie, mainly tightly packed platelets) is not different in the two types of microvessels. ${ }^{20}$ Moreover, the size of the stationary thrombus was similar in arterioles and venules. Therefore, we conclude that the different effects of L-NA and ASA on thromboembolism in arterioles and venules have to be accounted for by differences in vessel wall properties.

In conclusion, this is the first study to provide evidence of a synergistic effect of endogenous $\mathrm{NO}$ and prostaglandins in protecting against ongoing thromboembolism after vessel wall injury in arterioles but not in venules. Furthermore, this study indicates that under normal circumstances, endogenous $\mathrm{NO}$ and prostaglandins counteract proaggregatory effects of wall shear rate in arterioles. In venules, other, as-yet-unidentified antithromboembolic substances are likely to play a role.

\section{Acknowledgments}

This study was supported by the Netherlands Heart Foundation, grant \# 92.339. The authors are indebted to Sabrina van Velzen for her skillful technical assistance. 
Thromboembolic Parameters and Bleeding Times in Arterioles and Venules of the Four Experimental Groups

\begin{tabular}{|c|c|c|c|c|c|c|c|c|}
\hline & \multicolumn{4}{|c|}{ Arterioles } & \multicolumn{4}{|c|}{ Venules } \\
\hline & $\mathrm{CON}$ & L-NA & ASA & $\begin{array}{c}\text { L-NA+ } \\
\text { ASA }\end{array}$ & $\operatorname{CON}$ & L-NA & ASA & $\begin{array}{c}\text { L-NA + } \\
\text { ASA }\end{array}$ \\
\hline IBT & $\begin{array}{c}1.2 \\
(0.4-13.9)\end{array}$ & $\begin{array}{c}0.5 \\
(0.1-5.3)\end{array}$ & $\begin{array}{c}1.7 \\
(0.4-5.0)\end{array}$ & $\begin{array}{c}1.0 \\
(0.3-5.2)\end{array}$ & $\begin{array}{c}3.8 \\
(0.5-11.4)\end{array}$ & $\begin{array}{c}1.6 \\
(0.6-14.1)\end{array}$ & $\begin{array}{c}2.5 \\
(0.2-36.9)\end{array}$ & $\begin{array}{c}1.6 \\
(0.0-4.8)\end{array}$ \\
\hline $\begin{array}{l}\text { RTH } \\
\%\end{array}$ & $\begin{array}{c}74 \\
(28-85)\end{array}$ & $\begin{array}{c}71 \\
(49-88)\end{array}$ & $\begin{array}{c}68 \\
(55-83)\end{array}$ & $\begin{array}{c}67 \\
(54-78)\end{array}$ & $\begin{array}{c}74 \\
(48-91)\end{array}$ & $\begin{array}{c}75 \\
(56-84)\end{array}$ & $\begin{array}{c}69 \\
(41-84)\end{array}$ & $\begin{array}{c}70 \\
(57-82)\end{array}$ \\
\hline $\begin{array}{l}\text { Emboli } \\
n\end{array}$ & $\begin{array}{c}14 \\
(5-34)\end{array}$ & $\begin{array}{c}16 \\
(3-52)\end{array}$ & $\begin{array}{c}12 \\
(2-54)\end{array}$ & $\begin{array}{c}29^{*} \\
(13-63)\end{array}$ & $\begin{array}{c}3 \\
(1-18)\end{array}$ & $\begin{array}{c}10^{\dagger} \\
(3-29)\end{array}$ & $\begin{array}{c}5 \\
(0-23)\end{array}$ & $\begin{array}{c}8 \\
(1-15)\end{array}$ \\
\hline $\begin{array}{l}\text { MEPT } \\
s\end{array}$ & $\begin{array}{c}12 \\
(6-23)\end{array}$ & $\begin{array}{c}11 \\
(4-19)\end{array}$ & $\begin{array}{c}21 \\
(7-44)\end{array}$ & $\begin{array}{c}8 \\
(4-20)\end{array}$ & $\begin{array}{c}23 \\
(7-42)\end{array}$ & $\begin{array}{c}23 \\
(4-38)\end{array}$ & $\begin{array}{c}14 \\
(0-29)\end{array}$ & $\begin{array}{c}23 \\
(4-82)\end{array}$ \\
\hline
\end{tabular}

CON-control; L-NA= $N^{G}$-nitro-L-arginine; ASA-acetylsalicylic acid. IBT indicates initial bleeding time; RTH, relative thrombus height; Emboli, number of emboli produced within 600 seconds after puncture; and MEPT, median embolus production time, a measure of the rate of embolus formation. Median values (ranges) are presented.

${ }^{*} p<0.05$ compared with each of the other groups; $\dagger^{p}<<0.01$ compared with CON. 
TABLE 2

Fluid Dynamic Parameters (Immediately Before Puneture) in Arterioles and Venules of the Four Experimental Groups

\begin{tabular}{|c|c|c|c|c|c|c|c|c|}
\hline & \multicolumn{4}{|c|}{ Arterioles } & \multicolumn{4}{|c|}{ Venules } \\
\hline & $\operatorname{CON}$ & L-NA & ASA & $\begin{array}{c}\mathrm{L}-\mathrm{NA}+ \\
\mathbf{A S A}\end{array}$ & $\mathrm{CON}$ & $\mathrm{L}-\mathrm{NA}$ & ASA & $\begin{array}{c}\mathbf{L}-\mathbf{N A}+ \\
\mathbf{A S A}\end{array}$ \\
\hline $\begin{array}{l}\text { Diameter, } \\
\mu \mathrm{m}\end{array}$ & $\begin{array}{c}27 \\
(32-37)\end{array}$ & $\begin{array}{c}30 \\
(24-36)\end{array}$ & $\begin{array}{c}29 \\
(18-40)\end{array}$ & $\begin{array}{c}27 \\
(22-39)\end{array}$ & $\begin{array}{c}35 \\
(23-48)\end{array}$ & $\begin{array}{c}32 \\
(25-48)\end{array}$ & $\begin{array}{c}32 \\
(26-40)\end{array}$ & $\begin{array}{c}27 \\
(32-37)\end{array}$ \\
\hline $\begin{array}{l}\text { MRBCV, } \\
\mathrm{mm} / \mathrm{s}\end{array}$ & $\begin{array}{c}3.0 \\
(1.5-4.8)\end{array}$ & $\begin{array}{c}3.8 \\
(1.5-5.0)\end{array}$ & $\begin{array}{c}2.4 \\
(1.1-5.8)\end{array}$ & $\begin{array}{c}2.0^{*} \\
(0.6-4.5)\end{array}$ & $\begin{array}{c}1.7 \\
(1.0-2.7)\end{array}$ & $\begin{array}{c}1.7 \\
(0.9-3.2)\end{array}$ & $\begin{array}{c}1.5 \\
(0.7-2.6)\end{array}$ & $\begin{array}{c}1.5 \\
(0.7-2.8)\end{array}$ \\
\hline
\end{tabular}

$\mathrm{CON}=$ control; $\mathrm{L}-\mathrm{NA}=\mathrm{N}^{\mathrm{G}}$-nitro-L-arginine; $\mathrm{ASA}=$ acetylsalicylie acid. MRBCV indicates mean red blood cell velocity; and $\mathrm{U}$, reduced velocity (mean $\mathrm{RBC}$ velocity/diameter). Median values (ranges) are presented.

* p<0.05 compared with L-NA. All groups were compared for statistical significance; significance is only indicated for $\mathrm{p}<0.05$. 

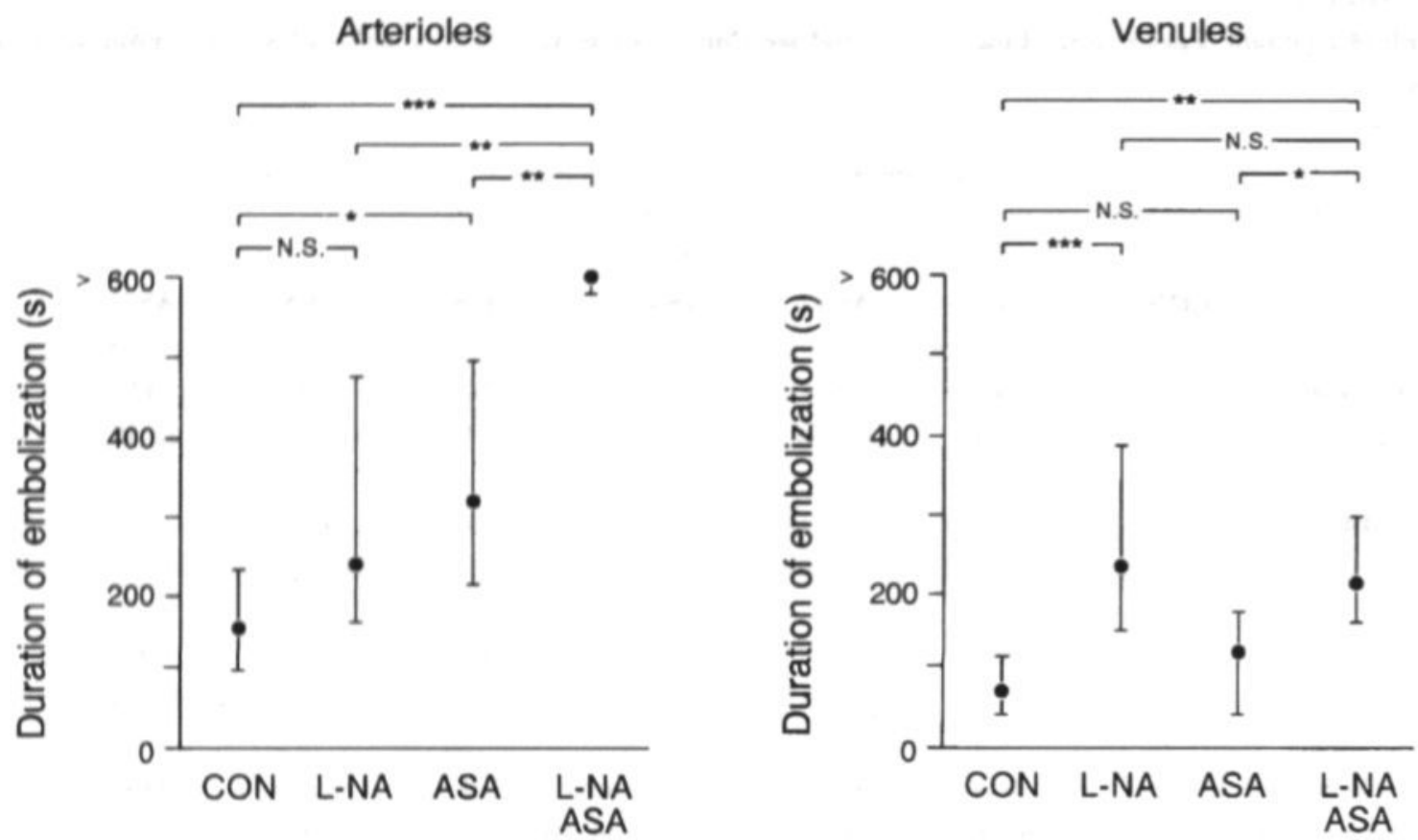

Figure 1

The effect of inhibition of nitric oxide synthase by $N^{G}$-nitro-L-arginine (L-NA), of cyclooxygenase by acetylsalicylic acid (ASA) or of both (L-NA+ASA) on the duration of embolization in arterioles (left panel) and venules (right panel). Data obtained in control group (CON: 8 arterioles, 11 venules), L-NA group (11 arterioles, 12 venules), ASA group (19 arterioles, 14 venules) and L-NA+ASA group (10 arterioles, 12 venules) are presented as medians (dots) with their interquartile ranges (bars).

* $p<0.05, * * p<0.01$ and *** $p<0.001$ compared with control. 


\section{Arterioles}

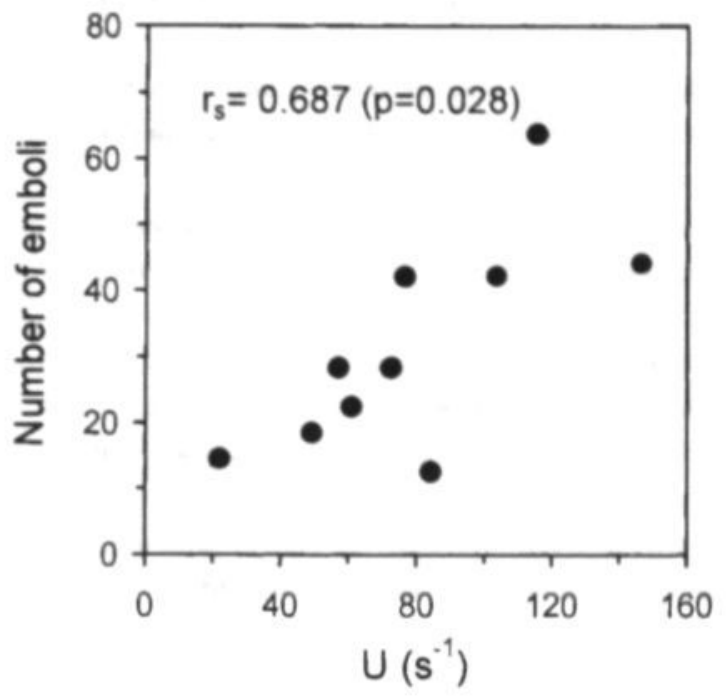

Venules

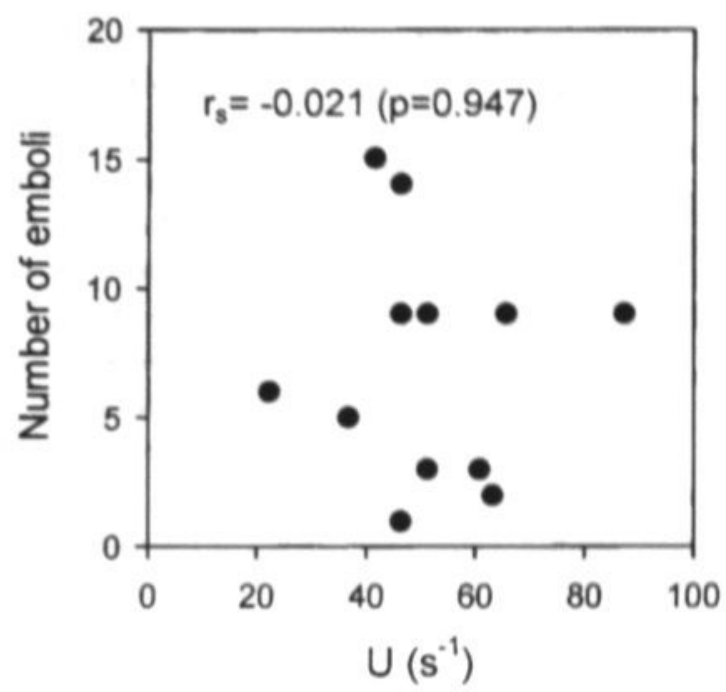

Figure 2

Number of emboli produced during the 600-second period of observation in the arterioles (left panel) and venules (right panel) of the L-NA+ASA group as a function of reduced velocity (U-mean red blood cell velocity/diameter), which is a measure of wall shear rate. Note that the range of the number of emboli produced differs between arterioles and venules.

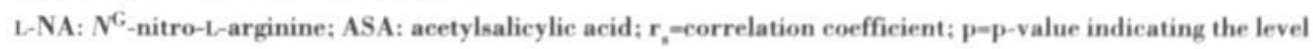
of significance. 


\section{References}

1. Drexler H, Zeiher AM. Endothelial function in human coronary arteries in vivo. Focus on hypercholesterolemia. Hypertension. 1991;18(suppl II):II90-II99.

2. Celermajer DS, Sorensen KE, Gooch VM, Spiegelhalter DJ, Miller OI, Sullivan ID, Lloyd JK, Deanfield JE. Non-invasive detection of endothelial dysfunction in ehildren and adults at risk of atheroselerosis. Lancet. 1992;340:1111-1115.

3. Zeiher AM, Drexler H, Wollschläger H, Just H. Endothelial dysfunction of the coronary microvasculature is associated with coronary blood flow regulation in patients with early atherosclerosis. Circulation. 1991;84:1984-1992.

4. Drexler H, Zeiher AM, Meinzer K, Just H. Correction of endothelial dysfunction in coronary microcirculation of hypercholesterolaemic patients by L-arginine. Lancet. 1991;338:1546-1550.

5. Mombouli JV, Vanhoutte PM. Endothelial dysfunction: from physiology to therapy. J Mol Cell Cardiol. 1999;31:61-74.

6. oude Egbrink MGA, Tangelder GJ, Slaaf DW, Reneman RS. Different roles of prostaglandins in thromboembolic processes in arterioles and venules in vivo. Thromb Haemost. 1993;70:826-833.

7. Broeders MAW, Tangelder GJ, Slaaf DW, Reneman RS, oude Egbrink MGA. Endogenous nitric oxide protects against thromboembolism in venules but not in arterioles. Arterioscler Thromb Vasc Biol. 1998;18:139-145.

8. Förstermann U, Pollock JS, Schmidt HH, Heller M, Murad F. Calmodulin-dependent endotheliumderived relaxing factor/nitric oxide synthase activity is present in the particulate and cytosolic fractions of bovine aortic endothelial cells. Proc Natl Acad Sci U S A. $1991 ; 88: 1788-1792$.

9. Yang Z, Arnet U, Bauer E, von-Segesser L, Siebenmann R, Turina M, Lüscher TF. Thrombininduced endothelium-dependent inhibition and direct activation of platelet-vessel wall interaction. Role of prostacyclin, nitric oxide, and thromboxane $A_{2}$. Circulation. 1994;89:2266-2272.

10. Radomski MW, Palmer RM, Moncada S. The anti-aggregating properties of vascular endothelium: interactions between prostacyclin and nitric oxide. Br J Pharmacol. 1987;92:639-646.

11. oude Egbrink MGA, Tangelder GJ, Slaaf DW, Reneman RS. Thromboembolic reaction following wall puneture in arterioles and venules of the rabbit mesentery. Thromb Haemost. 1988;59:23-28.

12. oude Egbrink MGA, Tangelder GJ, Slaaf DW, Reneman RS. Effect of blood gases and $\mathrm{pH}$ on thromboembolic reactions in rabbit mesenteric microvessels. Eur J Physiol (Pflügers Arch). 1989;414:324330.

13. Charm SE, Kurland GS. Blood flow and microcirculation. Harvard Medical School, Boston, Mass: Johns Wiley \& Sons (ISBN: 0-471-14820-2): 1974.

14. Fukuto JM, Chaudhuri G. Inhibition of constitutive and inducible nitric oxide synthase: potential selective inhibition. Annu Rev Pharmacol Toxicol. 1995;35:165-194. 
15. Moore PK, al-Swayeh OA, Chong NW, Evans RA, Gibson A. L-NG-nitro arginine (L-NOARG), a novel, L-arginine-reversible inhibitor of endothelium-dependent vasodilatation in vitro, $\mathrm{Br} J$ Pharmacol. 1990;99:408-412.

16. Radomski MW, Palmer RM, Moncada S. Comparative pharmacology of endothelium-derived relaxing factor, nitric oxide and prostacyelin in platelets. Br J Pharmacol. 1987;92:181-187.

17. Wu KK, Chen YC, Fordham E. Ts'Ae CH, Rayudu G, Matayoshi D. Differential effects of two doses of aspirin on platelets-vessel wall interaction in vive. J Clin Invest. 1981;68:382-387.

18. Roth GJ, Stanford N, Majerus PW. Acetylation of prostaglandin synthase by aspirin. Proc Natl Acad Sci U S A. 1975;72:3073-3076.

19. Boczkowski J, Vicaut E, Danialou G, Aubier M. Role of nitric oxide and prostaglandins in the regulation of diaphragmatic arteriolar tone in the rat. J Appl Physiol. 1994:77:590-596.

20. oude Egbrink MGA. Chapter 10: General Discussion. In: Thromboembolic reaction following vessel wall injury in arterioles and venules. Maastricht: PhD thesis; Maastricht University (ISBN: 90-5291002-2); 1989:107-113.

21. Hellums JD. 1993 Whitaker Leeture: biorheology in thrombosis research. Ann Biomed Eng. 1994:22:445-455.

22. Maalej N, Folts JD. Increased shear stress overcomes the antithrombotic platelet inhibitory effect of aspirin in stenosed dog coronary arteries. Circulation. 1996;93:1201-1205.

23. Mazeaud MM, Levenson J, Le-Quan-Sang KH, Simon A, Devynck MA. Platelet aggregation and in vivo shear forces. Thromb Haemost. 1994:71:26-31.

24. Sato M, Ohshima N. Effect of wall shear rate on thrombogenesis in microvensels of the rat mesentery. Circ Res. 1990;66:941-949.

25. Cines DB, Pollak ES, Buck CA, Loscalzo J, Zimmerman GA, MeEver RP, Pober JS, Wiek TM, Konkle BA, Sehwartz BS, Barnathan ES, MeCrae KR, Hug BA, Schmidt AM, Stern DM. Endothelial cells in physiology and in the pathophysiology of vascular disorders. Blood. 1998;91:3527-3561.

26. oude Egbrink MG, Tangelder GJ, Slaaf DW, Reneman RS. Fluid dynamics and the thromboembolie reaction in mesenteric arterioles and venules. Am J Physiol. 1991:260:H1826-H1833.

27. O'Neil GS, Chester AH, Allen SP, Luu TN, Tadjkarimi S, Ridley P, Khagani A, Musumeci F, Yacoub MH. Endothelial function of human gastroepiploic artery. Implications for its use as a bypans graft. J Thorac Cardiovasc Surg. 1991:102:561-565.

28. Fukaya Y, Ohhashi T. Acetylcholine- and flow-induced production and release of nitric oxide in arterial and venous endothelial cells. Am J Physiol. 1996;270:H99-H106.

29. de Wit C, von Bismarck P. Pohl U. Synergistic action of vasodilators that inerease eGMP and $c A M P$ in the hamster cremaster microcirculation. Cardiovasc Res. 1994:28:1513-1518.

30. Koller A, Sun D, Huang A, Kaley G. Corelease of nitric oxide and prostaglandins mediates flowdependent dilation of rat gracilis muscle arterioles. Am J Physiol. 1994:267:H326-H332. 
31. Koller A, Dornyei G, Kaley G. Flow-induced responses in skeletal muscle venules: modulation by nitrie oxide and prostaglandins. Am J Physiol. 1998;275:H831-H836.

32. Aitehison KA, Coker SJ. Potential interactions between iloprost and SIN-1 on platelet aggregation and myocardial infaret size in vivo. Eur J Pharmacol. 1999;374:59-69.

33. Sinzinger H, Rauscha F, O'Grady J, Fitseha P. Prostaglandin $\mathbf{I}_{2}$ and the nitric oxide donor molsidomine have synergistie effects on thromboresistance in man. Br J Clin Pharmacol. 1992;33:289. 292.

34. Salvemini D, Currie MG, Mollace V. Nitrie oxide-mediated eyclooxygenase aetivation. A key event in the antiplatelet effects of nitrovasodilators. J Clin Invest. 1996:97:2562-2568.

35. Salvemini D. Regulation of eyelooxygenase enzymes by nitric oxide. Cell Mol Life Sci. 1997;53:576582.

36. Maurice DH, Haslam RJ. Molecular basis of the synergistic inhibition of platelet function by nitrovasodilators and activators of adenylate cyclase: inhibition of cyclic AMP breakdown by cyelic GMP. Mol Pharmacol. 1990;37:671-681.

37. Halbrïgge M, Friedrich C, Eigenthalter M, Schanzenbächer P, Walter U. Stochiometric and reversible phosphorylation of 46-kDa protein in human platelets in response to cGMP- and cAMPelevating vasodilators. J Biol Chem. 1990;265:3088-3093.

38. Suzuki H, Swei A, Zweifach BW, Schmid-Schönbein GW. In vivo evidence for mierovaseular oxidative stress in spontaneously hypertensive rats. Hydroethidine microfluorography. Hypertension. $1995 ; 25: 1083-1089$.

39. Yin MJ, Yamamoto Y, Gaynor RB. The anti-inflammatory agents aspirin and salicylate inhibit the activity of I(kappa)B kinase-beta. Nature. 1998;396:77-80. 
Chapter 5

Hypercholesterolemia Enhances Thromboembolism in Arterioles but Not in Venules; Complete Reversal by L-Arginine 
Martijn A.W. Broeders, ${ }^{1}$ Geert Jan Tangelder, ${ }^{1,2}$ Dick W. Slaaf, ${ }^{3}$ Robert S. Reneman, ${ }^{1}$ Mirjam G.A. oude Egbrink ${ }^{1}$

From the Departments of Physiology ${ }^{1}$ and Biophysics, ${ }^{3}$ Cardiovascular Research Institute Maastricht, Maastricht University, Maastricht, the Netherlands

Laboratory for Physiology, ${ }^{2}$ Institute for Cardiovascular Research, Free University, Amsterdam, the Netherlands

Published in Arteriosclerosis Thrombosis and Vascular Biology 2002;22:680-685 


\begin{abstract}
Abstraet
We investigated in vivo the effect of cholesterol diet-induced hypercholesterolemia on thromboembolism in nonatherosclerotic rabbit mesenteric arterioles and venules (diameter 21 to 45 $\mu \mathrm{m})$. After mechanical vessel wall injury, the ensuing thromboembolic reaction was studied by intravital videomicroscopy. A dramatic prolongation of embolization duration (median $>600 \mathrm{sec}$ onds) was observed in the arterioles of the high cholesterol (HC) group compared with the arterioles of a normal chow-fed (NC) control group (142 seconds, p<0.0001); concomitantly, relative thrombus height increased (thrombus height/vessel diameter was $68 \%$ for the $\mathrm{HC}$ group and $58 \%$ for the NC group; $\mathrm{p}<0.05)$. By contrast, in venules, cholesterol did not affect embolization duration (42 seconds for HC group, 34 seconds for $\mathrm{NC}$ group) and thrombus height (66\% for HC group, $64 \%$ for $\mathrm{NC}$ group). Furthermore, the role of endothelial nitric oxide (NO) synthesis was studied. In arterioles, stimulation of endogenous NO synthesis through mesenteric superfusion of L-arginine ( $1 \mathrm{mmol} / \mathrm{L}$ ) completely reversed cholesterol-enhanced embolization (152 seconds) but did not influence thrombus height $(63 \%)$. L-arginine had no effect in venules of the $\mathrm{HC}$ group (51 seconds) nor in the arterioles and venules of the $\mathrm{NC}$ group ( 177 seconds for arterioles, 43 seconds for venules). This study indicates that hypercholesterolemia selectively enhances thrombus formation and embolization in arterioles but not in venules and that stimulation of endogenous NO production antagonizes this enhancement of arteriolar thromboembolism.
\end{abstract}




\section{Introduction}

Patients with hypercholesterolemia are prone to the development of atherosclerosis, ultimately leading to myocardial infaretion, cerebral infarction, and/or critical limb ischemia. ${ }^{1.2}$ Most of these disorders result from thromboembolic processes at the site of the lesion. ${ }^{3}$ The vascular lesion plays an important role in these processes ${ }^{3,4}$ but the role of hypercholesterolemia, as such, in thromboembolic events is less clear. Besides, the mediators involved in hypercholesterolemiarelated thromboembolic events are, as yet, not well-known.

Platelets derived from hypercholesterolemic patients and rabbits show in vitro an enhanced tendency to aggregate..$^{5,6}$ The observation that L-arginine, the substrate of endogenous nitric oxide (NO) synthase, reverses the enhanced platelet aggregation in hypercholesterolemia in vitro suggests that reduced production or bioavailability of NO is involved in hypercholesterolemia-induced thromboembolic processes.$^{5,6}$ An additional argument for the involvement of NO is that in vivo endothelium-dependent vasodilation has been shown to be reduced in hypercholesterolemic states, an effect that could be reversed by $\mathrm{L}$-arginine. ${ }^{7-10}$

Because studies performed in vitro on interactions between blood platelets and the vessel wall lack the contribution of natural microenvironmental factors (eg, local fluid dynamic conditions and the balance between activating and inhibiting agents), which may be of key importance for platelet-vessel wall interactions, in vivo studies are essential in evaluating the role of hypercholesterolemia in thromboembolic processes. To shed more light on this role, in vivo studies should be performed in preatherosclerotic models, excluding factors induced by the advanced atherosclerotic lesion. Therefore, the first aim of the present study was to investigate in vivo the effect of diet-induced hypercholesterolemia on thromboembolism, with the use of a previously described nonatherosclerotic rabbit model. ${ }^{11}$ The second aim of the present study was to investigate whether changes in endogenous $\mathrm{NO}$ are involved in the effect of hypercholesterolemia on thromboembolism. The latter was studied by stimulating endogenous NO synthesis by local application of $\mathrm{L}$-arginine during this process. Because in vivo the antithrombotic properties of arteriolar and venular vessel walls differ remarkably, ${ }^{12-14}$ the present study was performed in arterioles and venules.

\section{Methods}

\section{Animals and intravital videomicroscopy}

Experiments were approved by the local animal ethics committee. Thirty-one male New Zealand White rabbits (weight range 2.1 to $2.9 \mathrm{~kg}$ ) were used. Anesthesia was induced and maintained with ketamine hydrochloride and xylazine hydrochloride (for induction, 40 and $5 \mathrm{mg} / \mathrm{kg}$ body weight im, respectively; for maintenance, 40 and $5 \mathrm{mg} / \mathrm{kg}$ iv per hour, respectively). A catheter was inserted into the femoral artery to measure mean arterial blood pressure and heart rate.

Chapter 5 
Body temperature was kept at $37^{\circ} \mathrm{C}$ to $38^{\circ} \mathrm{C}$ by using a thermocontrolled infrared heating lamp.

After surgery, blood was collected from a central ear artery in EDTA $(10 \%)$. Electronic platelet counts, hemoglobin concentration and hematocrit were assessed using a Coulter Counter (model ZF). Total cholesterol, low-density lipoprotein cholesterol (LDL) and high-density lipoprotein cholesterol (HDL) levels were assessed by using enzymatic colorimetry (Roche Cholesterol plus assays).

Rabbits were ventilated (animal ventilator 4601 , Technical \& Scientifie Equipment) to maintain systemic arterial $\mathrm{pH}, \mathrm{pCO}_{2}$, and $\mathrm{pO}_{2}$ at normal values (meansstandard deviation) ${ }^{11,15}$; $\mathrm{pH} 7.47 \pm 0.02, \mathrm{pCO}_{2} 36 \pm 4 \mathrm{~mm} \mathrm{Hg}$ and $\mathrm{pO}_{2} 98 \pm 7 \mathrm{~mm} \mathrm{Hg}$ (ABL 3 Radiometer). No statistical differences existed between the experimental groups.

After laparotomy, a segment of the distal ileum was exteriorized and continuously superfused with buffered Tyrode's solution $\left(37^{\circ} \mathrm{C}, \mathrm{pH} 7.35\right.$ to 7.40$)$. The mesenterie tissue was visualized with a Leitz intravital microscope by use of transillumination with a tungsten lamp and a X25 objective (Leitz LL X25, numerical aperture 0.35). Images were recorded on videotape. Final magnification at the front plane of the TV camera was X40 (Grundig FA 32, 1 inch).

Vascular diameter was measured off-line with an image shearing device. Mean red blood cell velocity was measured on-line by using the dual-slit photometric technique. Reduced velocity (U), a well-known first-order approximation of wall shear rate, ${ }^{16}$ was calculated by dividing mean red blood cell velocity by vessel diameter.

\section{Vessel wall puncture and the thromboembolic reaction}

Arterioles and venules with a diameter between 20 and $45 \mu \mathrm{m}$ were selected. Vessel walls were punctured with a glass micropipet (tip diameter $\sim 6 \mu \mathrm{m}$ ). ${ }^{11}$ Immediately after puncture, the thromboembolic reaction started. In all vessels, a white thrombus was formed, consisting of tightly packed platelets, the height and shape of which remained constant. Circulating platelets adhered to this stationary thrombus mainly on its downstream side, forming a loosely packed platelet mass that did not affect the thrombus height. In nearly all vessels, except for 2 arterioles and 5 venules, these platelet masses embolized from time to time. The 7 microvessels without embolization were evenly distributed over the experimental groups. After a certain period of time, embolization stopped in most vessels.

To quantify this thromboembolic reaction, we determined the following off-line from videotape: the duration of bleeding (bleeding time), the maximal thrombus height relative to the local vessel diameter, the duration of embolization and the number of emboli produced. Each vessel was observed continuously for 600 seconds from the moment of puncture. Vessels in which embolization continued for $>600$ seconds were examined again intermittently during the remainder of the experiment (maximum duration 3 hours). 


\section{Experimental groups and protocol}

In experimental series 1, the effeet of diet-induced hypercholesterolemia on thromboembolism was studied by using two groups of rabbits. Rabbits of the high cholesterol-fed group (HC group, $n=8$ ) received a diet containing $0.4 \%$ cholesterol, $3 \%$ coconut oil and $3 \%$ peanut oil for two weeks. The normal chow-fed (control) rabbits ( $\mathrm{NC}$ group, $\mathrm{n}=7$ ) received a similar but cholesterolfree diet for two weeks (for both groups, $80 \mathrm{~g} /$ day; Hope Pharms). Rabbits were randomly assigned to one of these two groups. On day 15, the rabbits were anesthetized, and the arteriolar and venular thromboembolic reactions were studied.

Experimental series 2 was performed to determine whether the role of endogenous NO as an inhibitor of thromboembolism is changed by diet-induced hypercholesterolemia. To this purpose, endogenous NO synthesis was stimulated by continuously superfusing the mesentery with excess L-arginine ( $1 \mathrm{mmol} / \mathrm{L}$, molecular weight 210.7$)$, which is the substrate for NO synthase. Before each experiment, L-arginine was dissolved in buffered Tyrode's solution, ${ }^{13}$ which did not influence the $\mathrm{pH}$ of the Tyrode's solution. Previously, we demonstrated the specificity of L-arginine superfusion compared with D-arginine superfusion in enhaneing endogenous NO production. ${ }^{13}$ The rabbits of this series were randomly assigned to either two weeks of high cholesterol diet (HCarg group, $n=8$ ) or two weeks of normal chow (NCarg, $n=8$ ). The composition and amount of the diets were the same as in experimental series 1 .

On the experimental day, the mesentery was allowed to stabilize for 30 minutes after exteriorization under continuous superfusion with buffered Tyrode's solution without (series 1) or with $\mathrm{L}$-arginine $(1 \mathrm{mmol} / \mathrm{L}$, series 2$)$. These superfusions were continued during the rest of the experiments. A median number of three vessels was punctured per experiment. Each puncture was preceded by a 4-minute period to measure mean red blood cell velocity.

\section{Statistical analysis}

Because of their nonsymmetrical distribution, data are presented as medians with interquartile ranges, unless otherwise indicated. Embolization data are presented per blood vessel; averaging of data per animal led to similar results and conclusions. Differences between two groups were tested with the Mann-Whitney $U$ test. Correlations were performed with the Spearman's rank correlation test (coefficient=r $r_{s}$ ). The level of significance was set at $5 \%$.

\section{Results}

\section{Cholesterol levels and other whole-animal parameters}

Total plasma cholesterol level, LDL concentration, LDL/HDL ratio, and (to a lesser extent) HDL concentration were significantly elevated in cholesterol-fed rabbits ( $\mathrm{HC}$ and $\mathrm{HCarg}$ groups) compared with rabbits assigned to control chow (NC and NCarg groups, Figure 1). All plasma lipid 
concentrations in the control groups and also the plasma HDL concentration in the cholesterolfed groups are normal for rabbits. 17

Whole-animal parameters were not influenced by the increase in cholesterol levels, except for a slight increase in mean arterial blood pressure (MAP) in the HC rabbits (overall median value $76 \mathrm{~mm} \mathrm{Hg}$, range 73 to $85 \mathrm{~mm} \mathrm{Hg}$ ) compared with the $\mathrm{NC}$ rabbits (median $70 \mathrm{~mm} \mathrm{Hg}$, range

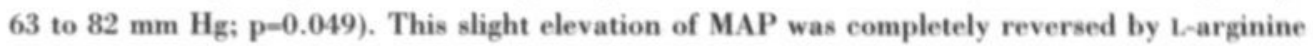
(for HCarg group, median $72 \mathrm{~mm} \mathrm{Hg}$, range 67 to $83 \mathrm{~mm} \mathrm{Hg}$; p= 0.046 compared with $\mathrm{HC}$ ). Overall, hemoglobin concentration (median $8.1 \mathrm{mmol} / \mathrm{L}$, range 7.0 to $9.3 \mathrm{mmol} / \mathrm{L}$ ), hematocrit (median 39.2 L/L, range $33.7 \mathrm{~L} / \mathrm{L}$ to $45.4 \mathrm{~L} / \mathrm{L}$ ), platelet count (median $449 \mathrm{X} 10^{3} / \mu \mathrm{L}$, range 231 to $689 \times 10^{3} / \mu \mathrm{L}$ ), heart rate (median 112 beats per minute, range 86 to 147 beats per minute), and also mean arterial blood pressure (median $72 \mathrm{~mm} \mathrm{Hg}$, range 63 to $85 \mathrm{~mm} \mathrm{Hg}$ ) were within normal ranges for anesthetized rabbits. ${ }^{11,15,17}$ No significant correlations were found between any of these whole-animal parameters and embolization parameters in either arterioles or venules.

\section{Thromboembolic reaction in vivo}

In all vessels, bleeding and thrombus formation started immediately after wall puncture. A thrombus started to grow within 0.1 second after puncture and reached its maximal size within one to two seconds. This time frame was not influenced by hypercholesterolemia and/or $\mathrm{L}$-arginine in arterioles or in venules.

\section{Arterioles}

Hypercholesterolemia nonsignificantly shortened arteriolar bleeding duration ( $\mathrm{p}=0.07$, Table 1) and significantly increased thrombus height $(\mathrm{p}=0.021$, Table 1). The tendency of hypercholesterolemia to shorten bleeding time was reversed by $\mathrm{L}$-arginine ( $\mathrm{p}=0.004$ for $\mathrm{HCarg}$ verwus $\mathrm{HC}$ ). In contrast, the effect of hypercholesterolemia on thrombus height was not affected by $\mathrm{L}$-arginine ( $\mathrm{p}=0.103$ for HCarg versus $\mathrm{HC}$ ).

Hypercholesterolemia caused a pronounced significant increase in embolization duration (HC median >600 seconds, NC median 142 seconds; p 0.0001 ; Figure 2); in these periods, 21 emboli were produced in $\mathrm{HC}$ arterioles, and only 5 were produced in NC vessels ( $\mathrm{p}<0.0001$, Table 1). In the $58 \%$ of the $\mathrm{HC}$ arterioles in which embolization continued $>600$ seconds, it continued during the rest of the experiment ( 30 minutes to 3 hours). In contrast, embolization stopped within 600 seconds in all $\mathrm{NC}$ arterioles.

$\mathrm{L}$-arginine completely reversed the prolongation of embolization duration in $\mathrm{HC}$ rabbits (for HCarg group, 152 seconds, 9 emboli; p<0.0001 compared with HC; Figure 2). Moreover, in none of the 25 HCarg arterioles did embolization continue for $>600$ seconds. In NC arterioles, L-arginine had no significant effect (for NCarg group, 177 seconds, 9 emboli). 


\section{Venules}

The venular bleeding duration was significantly prolonged in $\mathrm{HC}$ rabbits ( $\mathrm{p}<0.05$, Table 1$)$; this effect could not be reversed by L-arginine. Venular thrombus height was not influenced by hypercholesterolemia or L-arginine (Table 1).

As opposed to the marked effect observed in arterioles, hypercholesterolemia did not affect embolization duration and embolus production in venules (for HC group, 42 seconds, 2 emboli; for NC group, 34 seconds, 3 emboli; Figure 2 and Table 1). In addition, L-arginine had no effect on embolization duration and embolus production in both $\mathrm{HC}$ rabbits (for $\mathrm{HCarg}$ group, 51 seconds, 3 emboli) and NC rabbits (for NCarg group, 43 seconds, 2 emboli). In all but one venule embolization stopped within the observation period of 600 seconds.

\section{Arterioles versus venules}

In all four groups, embolization duration and embolus production were significantly greater in arterioles than in venules (Figure 2 ).

\section{Cholesterol levels and embolization}

When data of all groups were pooled, levels of total plasma cholesterol and LDL cholesterol were positively and significantly correlated with embolus production in arterioles $\left(r_{s}-v a l u e s>0.271\right.$; p-values<0.016). In contrast, in venules, no correlations were found $\left(r_{s}-\right.$ values $<0.194$; p-values $>0.133)$.

\section{Fluid dynamic conditions}

Hypercholesterolemia and/or L-arginine had no statistically siginificant effect on diameter, red blood cell velocity or reduced velocity in arterioles or venules (Table 2). The effects of L-arginine in hypercholesterolemic rabbits were near the level of significance, although all p-values were $>0.05$. However, no significant correlations between fluid dynamic and thromboembolic parameters were found in these vessels, with and without L-arginine, indicating that the minimal fluid dynamic effects of L-arginine did not affect thromboembolic parameters such as thrombus height and bleeding time.

\section{Diseussion}

The findings in the present study show that diet-induced hypercholesterolemia differently affects the thromboembolic reaction after wall puncture in mesenteric arterioles and venules in preatheroselerotic rabbits: vessel wall injury results in greater thrombus height and increased duration of embolization with a concomitant increase in the number of emboli produced in arterioles, whereas it has no such effects in venules. In arterioles, the effects of hypercholesterolemia on 
embolization can be completely reversed by L-arginine, the active precursor of endogenous NO synthesis.

The observation that the increase in total plasma cholesterol mainly results from an increase in LDL cholesterol suggests that the observed effects of hypereholesterolemia on arteriolar thromboembolism are caused by LDL cholesterol. This plasma lipid may influence platelet aggregation direetly ${ }^{18}$ or indireetly through an influence on arteriolar vascular cell function. ${ }^{19,20}$ Although direct effects of LDL cholesterol on platelets may have activated them, this cannot explain the differences in thromboembolic effeets between arterioles and venules, because the plasma concentration of LDL cholesterol was probably the same in both vessel types. Therefore, the effects of LDL cholesterol on arteriolar thromboembolism are probably indirect and a consequence of interaction of LDL cholesterol with the arteriolar vessel wall, leading to oxidation of LDL. The involvement of oxidized LDL (ox-LDL) is consistent with the observation that ox-LDL depletes caveolae of cholesterol, resulting in displacement of endothelial cell NO synthase (ec-NOS) from caveolae and impaired ec-NOS activation without affecting prostacyelin ( $\mathrm{PGI}_{2}$ ) production. ${ }^{21-23}$

The dramatic stimulating effect of hypercholesterolemia on thromboembolism in arterioles is similar to the effect of complete inhibition of endogenous production of NO and prostaglandins, as observed previously. ${ }^{14}$ From this previous study and another study, ${ }^{13}$ we concluded that in arterioles, the antithromboembolic effect of endogenous $N O$ alone is negligible but that its effect is pronounced in the presence of endogenous prostaglandins, provided that sufficient $\mathrm{NO}$ is produced to synergize with the arachidonic acid/prostaglandin pathway. Therefore, the observed effects of increased plasma cholesterol on thromboembolism in arterioles may be explained by loss of $\mathrm{NO} /$ prostaglandin synergism that is due to reduced $\mathrm{NO}$ synthesis and/or bioavailability as a consequence of LDL/ox-LDL-generated reactive oxygen species, such as $\mathrm{O}_{2}$ (ie, superoxide anion). ${ }^{24.25}$ This notion is supported by our finding that excess amounts of $\mathrm{L}$-arginine completely reverse the increased embolization in arterioles as induced by hypercholesterolemia. The latter observation indicates that the putatively reduced NO synthesis and/or bioavailability can be overcome by a surplus of the active precursor of NO synthesis. Additional support for this explanation is provided by studies showing reduced NO synthesis and/or bioavailability in microvessels from hypercholesterolemic animals or humans, an effect that could be overcome by the addition of arginine analogues in all studies. ${ }^{7-10,26,27}$

An alternative explanation for our results could be that hypercholesterolemia changes arteriolar prostaglandin production, which may also result in loss of NO/prostaglandin synergism. The increased NO production due to $\mathrm{L}$-arginine administration may have compensated for such a change in prostaglandin production. The formation of proplatelet and antiplatelet prostaglandins was found to be increased in aortic segments from hypercholesterolemic rabbits 
compared with those from normocholesterolemic rabbits. ${ }^{28,29}$ Other studies have shown that platelets isolated from hypercholesterolemic rabbits are hyperreactive to arachidonic acid ${ }^{28}$ and thromboxane $\mathrm{A}_{2},{ }^{30}$ and less sensitive to the inhibitory activity of prostacyclin. ${ }^{28,31}$ Such effects may have contributed to the observed inerease in arteriolar thromboembolism in hypercholesterolemic rabbits. Unfortunately, to the best of our knowledge, no data are available on prostaglandin production in arterioles and venules of hypercholesterolemic animals or humans. Therefore, at this point in time, it is not known to what extent changes in prostaglandin metabolism affect thromboembolism in microvessels of hypercholesterolemic rabbits.

The reversal of enhanced arteriolar embolism in hypercholesterolemia by $\mathrm{L}$-arginine may be explained as follows: first, in the absence of excess L-arginine, the arteriolar concentration of reactive oxygen species, which is relatively high in the arterioles of normocholesterolemic normotensive rodents, ${ }^{32}$ is further increased in hypercholesterolemic animals as a result of the stimulating effect of LDL cholesterol on endothelial reactive oxygen species production. ${ }^{24,25} \mathrm{By}$ the addition of excess amounts of L-arginine, stimulation of ec-NOS will lead to a high level of NO and reduce reactive oxygen species production by a reaction between $\mathrm{NO}$ and $\mathrm{O}_{2}$, resulting in the formation of $\mathrm{ONOO}^{-}$(ie, peroxynitrite). In vitro, $\mathrm{ONOO}^{-}$has either stimulating or inhibiting effects on the aggregation of platelets isolated from humans ${ }^{33}$ or rabbits. ${ }^{34}$ The net biological effect of $\mathrm{ONOO}^{-}$on platelet aggregation in vivo probably depends on the concentration of $\mathrm{ONOO}^{-}$itself and the presence of factors facilitating conversion of $\mathrm{ONOO}^{-}$to platelet inhibitory $\mathrm{NO}^{33-35}$ Second, the endothelial formation and release of asymmetrical dimethylarginine (ADMA), an endogenous NO synthase inhibitor that competes with L-arginine, ${ }^{36}$ may be enhanced in the presence of native LDL or ox-LDL. ${ }^{36}$ In support of this notion is the observation that plasma concentrations of ADMA are elevated in hypercholesterolemic patients ${ }^{37}$ and rabbits. ${ }^{38}$ The biological effect of ADMA was confirmed by the observation that ADMA reduces endothelium/NOdependent dilation of rabbit brain arterioles, an effect prevented by L-arginine application. ${ }^{39}$ Elevation of the L-arginine/ADMA ratio by exogenous L-arginine in hypercholesterolemia, as in the present study, may restore NO formation in rabbits. ${ }^{40}$

The stimulating effect of hypercholesterolemia on arteriolar thrombus height indicates that native LDL and/or ox-LDL cholesterol changes the (anti)thrombogenic properties of the arteriolar wall in primary thrombus formation. This is an intriguing observation because blocking NO synthesis, ${ }^{13}$ prostaglandin synthesis ${ }^{12}$ or both ${ }^{14}$ does not affect thrombus height. In vitro, elevated concentrations of LDL/ox-LDL cholesterol sensitize platelets to thrombin activation. ${ }^{41,42}$ In our model, thrombin very likely plays a role in thrombus formation and not in embolization (M.G.A. oude Egbrink, unpublished data, 1995). ${ }^{43}$ Most likely, LDL/ox-LDL cholesterol and thrombin synergistically enhance platelet thrombus formation at the site of arteriolar wall injury.

The observation that hypercholesterolemia does not influence the thromboembolic 
process in venules, despite the fact that endogenous $\mathrm{NO}$ is an important antithromboembolic mediator in these vessels, ${ }^{13}$ is surprising. It is conceivable that in venules, in which the reactive oxygen species concentration appears to be lower than in arterioles, ${ }^{32}$ the effect of LDL/ox-LDL. cholesterol on reactive oxygen species production and, hence, on NO production/bioavailability is very limited. Therefore, in these vessels, the endogenous NO concentration may be maintained at the antithromboembolic level required. The absence of an effect of L-arginine on venular thromboembolism indicates that NO synthesis is already maximal in these vessels; as a result, the low number of emboli produced cannot be reduced further.

Hypercholesterolemia induced a slight increase in mean arterial blood pressure, which was reversed by stimulation of endogenous NO synthesis with L-arginine. Although during hypercholesterolemia, the arteriolar diameter in the transparant part of the mesentery was not different from the control diameter, it should not be concluded that there was no increase in peripheral resistance. This particular part of the rabbit mesentery is known to be a vascular bed with very limited vasoactivity. ${ }^{13}$ During hypercholesterolemia, arteriolar diameters may have been reduced in other vascular areas.

In conclusion, this is the first study providing evidence of a pronounced stimulating effect of diet-induced hypercholesterolemia, as such, on in vivo thrombus formation and subsequent embolization after vessel wall injury in arterioles but not in venules. These effects were observed without the presence of atherosclerotic vascular lesions. Endogenously produced NO as stimulated by excess L-arginine is able to antagonize this cholesterol-enhanced arteriolar thromboembolism.

\section{Acknowledgements}

This study was supported by the Netherlands Heart Foundation, grant \# 92.339. 


\section{TABLE I}

Thromboembolic Parameters and Bleeding Times in Arterioles and Venules of the Four Experimental Groups

\begin{tabular}{|c|c|c|c|c|c|c|c|c|}
\hline & \multicolumn{4}{|c|}{ Arterioles } & \multicolumn{4}{|c|}{ Venules } \\
\hline & NC & HC & NCarg & HCarg & NC & HC & NCarg & HCarg \\
\hline IBT, & $\begin{array}{c}1.4 \\
(0.2-4.2)\end{array}$ & $\begin{array}{c}0.9^{*} \\
(0.2-1.5)\end{array}$ & $\begin{array}{c}2.4 \\
(0.4-6.9)\end{array}$ & $\begin{array}{c}1.9^{8} \\
(0.3-7.6)\end{array}$ & $\begin{array}{c}0.7 \\
(0.1-0.9)\end{array}$ & $\begin{array}{c}2.2^{\dagger} \\
(0.4-23.3)\end{array}$ & $\begin{array}{c}1.1^{\dagger} \\
(0.6-15.4)\end{array}$ & $\begin{array}{c}5.9 \\
(0.6-10.6)\end{array}$ \\
\hline $\begin{array}{l}\text { RTH, } \\
\%\end{array}$ & $\begin{array}{c}58 \\
(25-85)\end{array}$ & $\begin{array}{c}68^{\dagger} \\
(48-89)\end{array}$ & $\begin{array}{c}62 \\
(45-81)\end{array}$ & $\begin{array}{c}63 \\
(12-96)\end{array}$ & $\begin{array}{c}64 \\
(55-82)\end{array}$ & $\begin{array}{c}66 \\
(29-90)\end{array}$ & $\begin{array}{c}64 \\
(29-90)\end{array}$ & $\begin{array}{c}67 \\
(42-75)\end{array}$ \\
\hline $\begin{array}{l}\text { Emboli, } \\
n\end{array}$ & $\begin{array}{c}5 \\
(0-20)\end{array}$ & $\begin{array}{c}21^{t} \\
(4-74)\end{array}$ & $\begin{array}{c}9 \\
(1-66)\end{array}$ & $\begin{array}{c}9 \| \\
(3-31)\end{array}$ & $\begin{array}{c}3 \\
(0-6)\end{array}$ & $\begin{array}{c}2 \\
(0-21)\end{array}$ & $\begin{array}{c}2 \\
(1-6)\end{array}$ & $\begin{array}{c}3 \\
(0-7)\end{array}$ \\
\hline
\end{tabular}

NC=2-tveek normal chou control diet (no cholesterol); HC=2-uceek $0.4 \%$ cholesterol diet; arg=L-arginine. IBT indicates initial bleeding time; RTH, relative thrombus height; and Emboli, number of emboli produced within 600 seconds after puncture. Median values (ranges) are presented.

${ }^{*} p=0.07,+p<0.05$ and $\ddagger p<0.001$ versus $\mathrm{NC} ; \S_{\mathrm{p}}<0.01$ and $\| p<0.001$ versus $\mathrm{HC}$. 
TABLE 2

Fluid Dynamie Parameters (Immediately Before Puneture) in Arterioles and Venules of the Four Experimental Groups

\begin{tabular}{|c|c|c|c|c|c|c|c|c|}
\hline & \multicolumn{4}{|c|}{ Arterioles } & \multicolumn{4}{|c|}{ Venules } \\
\hline & $\mathrm{NC}$ & HC & NCarg & HCarg & NC & HC & NCarg & HCarg \\
\hline $\begin{array}{l}\text { Diameter, } \\
\mu \mathrm{m}\end{array}$ & $\begin{array}{c}34 \\
(27-41)\end{array}$ & $\begin{array}{c}33 \\
(23-40)\end{array}$ & $\begin{array}{c}33 \\
(23-4)\end{array}$ & $\begin{array}{c}35 \\
(24-42)\end{array}$ & $\begin{array}{c}35 \\
(28-45)\end{array}$ & $\begin{array}{c}33 \\
(21-41)\end{array}$ & $\begin{array}{c}34 \\
(25-44)\end{array}$ & $\begin{array}{c}35 \\
(29-45)\end{array}$ \\
\hline $\begin{array}{l}\text { MRBCV, } \\
\mathrm{mm} / \mathrm{s}\end{array}$ & $\begin{array}{c}3.4 \\
(1.6-6.0)\end{array}$ & $\begin{array}{c}3.0 \\
(1.3-5.2)\end{array}$ & $\begin{array}{c}2.7 \\
(1.1-5.4)\end{array}$ & $\begin{array}{c}2.5 \\
(1.0-5.7)\end{array}$ & $\begin{array}{c}2.2 \\
(1.1-5.0)\end{array}$ & $\begin{array}{c}2.2 \\
(1.0-4.6)\end{array}$ & $\begin{array}{c}2.0 \\
(0.9-4.1)\end{array}$ & $\begin{array}{c}1.9 \\
(0.8-5.7)\end{array}$ \\
\hline $\begin{array}{l}\mathrm{U}, \\
\mathrm{s}^{-1}\end{array}$ & $\begin{array}{c}94 \\
(42-186)\end{array}$ & $\begin{array}{c}100 \\
(40-189)\end{array}$ & $\begin{array}{c}78 \\
(30-142)\end{array}$ & $\begin{array}{c}75 \\
(33-136)\end{array}$ & $\begin{array}{c}65 \\
(27-152)\end{array}$ & $\begin{array}{c}61 \\
(31-153)\end{array}$ & $\begin{array}{c}55 \\
(25-106)\end{array}$ & $\begin{array}{c}47 \\
(25-195)\end{array}$ \\
\hline
\end{tabular}

NC=2-iceek normal chov control diet (no cholesterol); $\mathrm{HC}=2-$-teek $0.4 \%$ cholesterol diet; arg-L-arginine. MRBCV indicates mean red blood cell velocity; $U$, reduced velocity (MRBCV/diameter). Median values (ranges) are presented. 


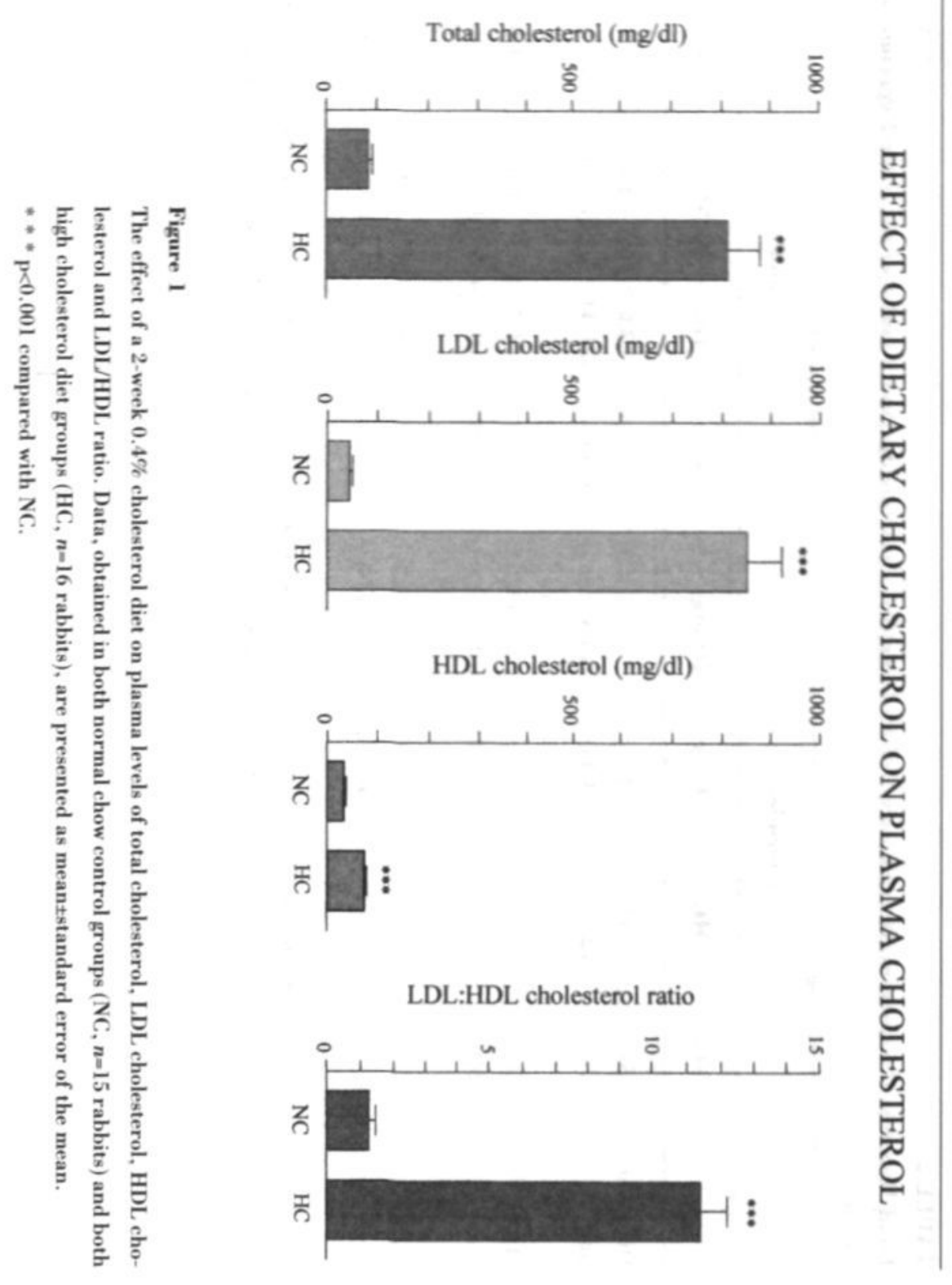




\section{EFFECT OF DIETARY CHOLESTEROL AND L-ARGININE}
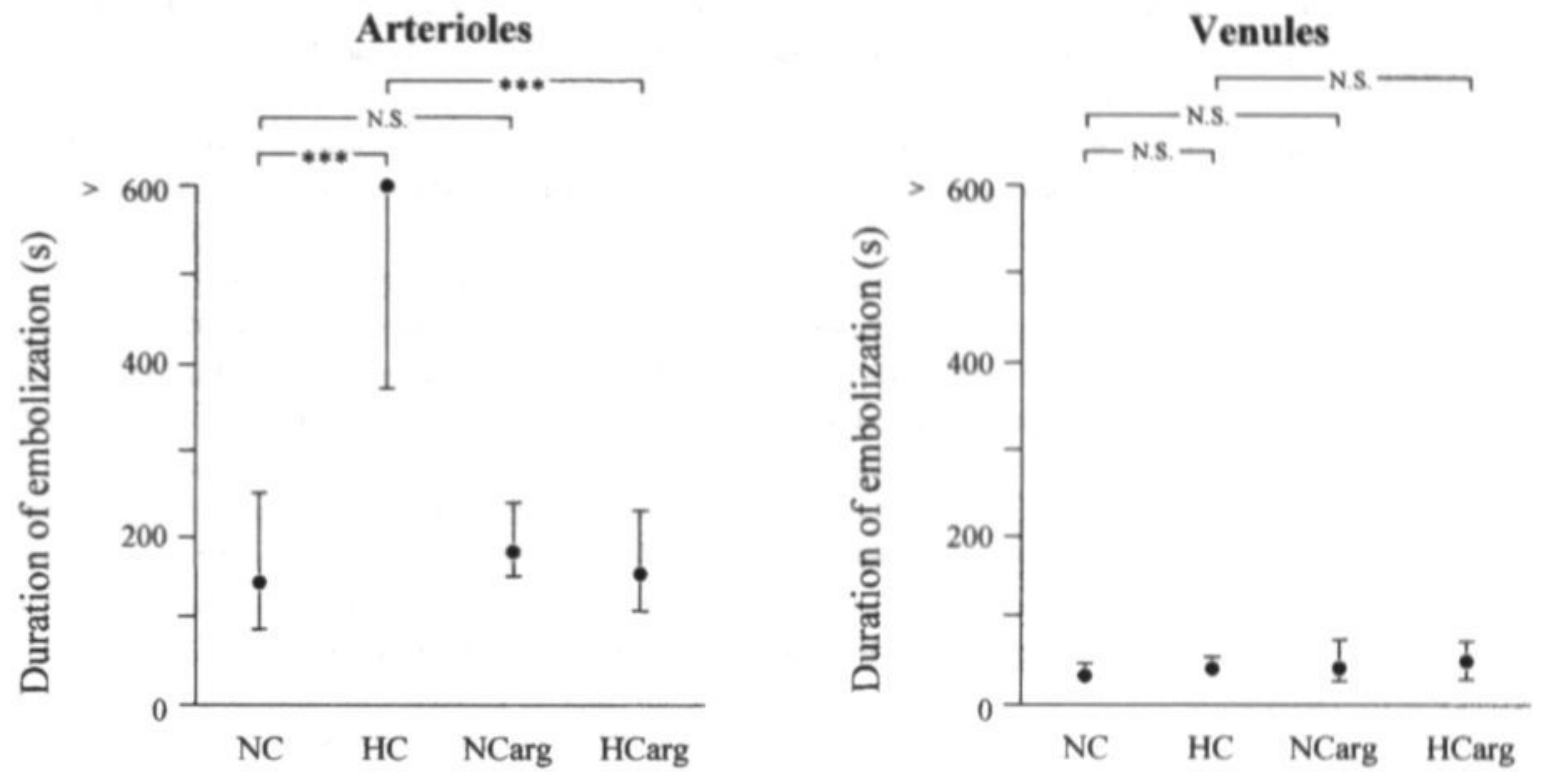

Figure 2

Effect of a 2-week $0.4 \%$ cholesterol diet and of local superfusion with L-arginine on the duration of embolization in arterioles (left panel) and venules (right panel). Data, obtained in the normal chow control group (NC. 21 arterioles and 19 venules), high cholesterol diet group ( $\mathrm{HC}, 19$ arterioles and 22 venules), $\mathrm{NC}$ and $\mathrm{L}$-arginine group (NCarg, 24 arterioles and 20 venules) and $\mathrm{HC}$ and L-arginine group (HCarg, 25 arterioles and 12 venules), are presented as medians (dots) with their interquartile ranges (bars).

$* * *_{p} 0.001$ compared with control; N.S. indicates not significant. 


\section{References}

1. Benfante R, Yano K. Hwang LJ, Curb JD, Kagan A, Ross W. Elevated serum cholesterol is a risk factor for both coronary heart disease and thromboembolic stroke in Hawaiian Japanese men. Implications of shared risk. Stroke. 1994:25:814-820.

2. Aronow WS, Ahn C. Correlation of serum lipids with the presence or absence of atherothrombotic brain infaretion and peripheral arterial disease in 1,834 men and women aged $>$ or $=62$ years. Am J Cardiol. 1994:73:995-997.

3. Ross R. Atherosclerosis - an inflammatory disease. N Engl J Med. 1999;340:115-126.

4. Ross R. Glomset J, Harker L. Response to injury and atherogenesis. Am J Pathol. 1977;86:675-684.

5. Wolf A. Zalpour C. Theilmeier G, Wang BY, Ma A, Anderson B, Tsao PS, Cooke JP. Dietary L-arginine supplementation normalizes platelet aggregation in hypercholesterolemic humans. J Am Coll Cardiol. 1997:29:479-485.

6. Twao PS, Theilmeier G, Singer AH, Leung LLK, Cooke JP. L-Arginine attenuates platelet reactivity in hypercholesterolemic rabbits. Arterioscler Thromb. 1994;14:1529-1533.

7. Creager MA, Gallagher SJ, Girerd XJ, Coleman SM, Dzau VJ, Cooke JP. L-Arginine improves endothelium-dependent vasodilation in hypercholesterolemic humans. J Clin Invest. 1992;90:12481253.

8. Quyyumi AA, Dakak N, Andrews NP, Gilligan DM, Panza JA, Cannon RO. Contribution of nitric oxide to metabolic coronary vasodilation in the human heart. Circulation. 1995;92:320-326.

9. Girerd XJ, Hirsch AT, Cooke JP, Dzau VJ, Creager MA. L-Arginine augments endothelium-dependent vasodilation in cholesterol-fed rabbits. Circ Res. 1990;67:1301-1308.

10. Jeremy RW, MeCarron H, Sullivan D. Effects of dietary L-arginine on atherosclerosis and endothelium-dependent vasodilatation in the hypercholesterolemic rabbit. Response according to treatment duration, anatomic site, and sex. Circulation. 1996;94:498-506.

11. oude Egbrink MGA, Tangelder GJ, Slaaf DW, Reneman RS. Thromboembolic reaction following wall puncture in arterioles and venules of the rabbit mesentery. Thromb Haemost. 1988;59:23-28.

12. oude Egbrink MGA, Tangelder GJ, Slaaf DW, Reneman RS. Different roles of prostaglandins in thromboembolic processes in arterioles and venules in vivo. Thromb Haemost. 1993;70:826-833.

13. Broeders MAW, Tangelder GJ, Slaaf DW, Reneman RS, oude Egbrink MGA. Endogenous nitric oxide protects against thromboembolism in venules but not in arterioles. Arterioscler Thromb Vasc Biol. 1998;18:139-145.

14. Broeders MAW. Tangelder GJ, Slaaf DW, Reneman RS, oude Egbrink MGA. Endogenous nitric oxide and prostaglandins synergistically counteract thromboembolism in arterioles but not in venules. Arterioscler Thromb Vasc Biol. 2001:21:163-169. 
15. oude Egbrink MGA. Tangelder GJ, Slaaf DW, Reneman RS. Effeet of blood gases and pH on thromboembolie reactions in rabbit mesenterie microvessels. Eur J Physiol (Pflügers Arch). 1989;414:324330.

16. Charm SE, Kurland GS. Blood flow and microcirculation. Harvard Medical School, Boston, MA: Johns Wiley \& Sons (ISBN: 0-471-14820-2); 1974.

17. Kozma C, Maeklin W, Cummins LM, Mauer R. The anatomy, physiology, and the biochemistry of the rabbit. In: Weisbroth SE, Flatt RE, Kraus AL, eds. The biology of the laboratory rabbit. New York. NY: Academie Press, Inc.; 1974:50-72.

18. Chen LY, Mehta P, Mehta JL. Oxidized LDL decreases L-arginine uptake and nitrie oxide synthase protein expression in human platelets: relevance of the effect of oxidized LDL on platelet function. Circulation. 1996:93:1740-1746.

19. Lehr HA, Frei B, Olofsson AM, Carew TE, Arfors KE. Protection from oxidized LDL-induced leukoeyte adhesion to microvascular and macrovascular endothelium in vivo by vitamin $\mathrm{C}$ but not by vitamin E. Circulation. 1995;91:1525-1532.

20. Hein TW, Liao JC, Kuo L. oxLDL specifically impairs endothelium-dependent, NO-mediated dilation of coronary arterioles. Am J Physiol. 2000;278:H175-H183.

21. Feron O, Dessy C, Moniotte S, Desager JP, Balligand JL. Hypercholesterolemia decreases nitric oxide production by promoting the interaction of caveolin and endothelial nitric oxide synthase. $J$ Clin Invest. 1999;103:897-905.

22. Blair A, Shaul PW, Yuhanna IS, Conrad PA, Smart EJ. Oxidized low density lipoprotein displaces endothelial nitric oxide synthase (eNOS) from plasmalemmal caveolae and impairs eNOS activation. J Biol Chem. 1999;274:32512-32519.

23. Uittenbogaard A, Shaul PW, Yuhanna IS, Blair A, Smart EJ. High density lipoprotein prevents oxidized low density lipoprotein-induced inhibition of endothelial nitric oxide synthase localization and activation in caveolae. J Biol Chem. 2000;275:11278-11283.

24. Lehr HA, Becker M, Marklund SL, Hubner C, Arfors KE, Kohlsehutter A, Messmer K. Superoxidedependent stimulation of leukocyte adhesion by oxidatively modified LDL in vivo. Arterioscler Thromb. 1992:12:824-829.

25. Pritehard KA, Jr., Groszek L, Smalley DM, Sessa WC, Wu M, Villalon P, Wolin MS, Stemerman MB. Native low-density lipoprotein inereases endothelial cell nitric oxide synthase generation of superoxide anion. Circ Res. 1995;77:510-518.

26. Scalia R, Appel JZ, Lefer AM. Leukocyte-endothelium interaction during the early stages of hypercholesterolemia in the rabbit: role of P-selectin, ICAM-1, and VCAM-1. Arterioscler Thromb Vasc Biol. 1998;18:1093-1100. 
27. Paniagua OA, Bryant MB, Panza JA. Role of endothelial nitric oxide in shear stress-induced vasodilation of human microvaseulature: diminished activity in hypertensive and hypercholesterolemic patients. Circulation. 2001;103:1752-1758.

28. Tremoli E, Socini A, Petroni A, Galli C. Inereased platelet aggregability is associated with increased prostacyelin production by vessel walls in hypercholesterolemic rabbits. Prostaglandins. $1982 ; 24: 397-404$.

29. Mehta JL, Lawson D, Mehta P, Saldeen T. Inereased prostacyelin and thromboxane $\mathbf{A}_{2}$ biosynthesis in atheroselerosis. Proc Natl Acad Sci U S A. 1988;85:4511-4515.

30. Latta EK, Packham MA, Gross PL, Rand ML. Enhanced collagen-induced responses of platelets from rabbits with diet-induced hypereholesterolemia are due to increased sensitivity to $\mathbf{T X A}_{2}$. Response inhibition by chronic ethanol administration in hypercholesterolemia is due to reduced TXA $_{2}$ formation. Arterioscler Thromb. 1994;14:1379-1385.

31. Weber AA, Hohlfeld T, Strobach H, Sehrör K. Oral naftidrofuryl prevents platelet hyperreactivity ex vivo and inhibits functional desensitization to prostacyclin in hypercholesterolemic rabbits. $J$ Cardiovasc Pharmacol. 1993;21:332-338.

32. Suzuki H, Swei A, Zweifach BW, Schmid-Schönbein GW. In vivo evidence for microvascular oxidative stress in spontaneously hypertensive rats. Hydroethidine microfluorography. Hypertension. 1995;25:1083-1089.

33. Moro MA, Darley-Usmar VM, Goodwin DA, Read NG, Zamora-Pino R, Feelisch M, Radomski MW, Moncada S. Paradoxical fate and biological action of peroxynitrite on human platelets. Proc Natl Acad Sci U S A. 1994;91:6702-6706.

34. Moro MA, Darley-Usmar VM, Lizasoain I, Su Y, Knowles RG, Radomski MW, Moncada S. The formation of nitric oxide donors from peroxynitrite. Br J Pharmacol. 1995;116:1999-2004.

35. Ma XL, Gao F, Lopez BL, Christopher TA, Vinten-Johansen J. Peroxynitrite, a two-edged sword in post-ischemic myocardial injury-dichotomy of action in crystalloid- versus blood-perfused hearts. J Pharmacol Exp Ther. 2000;292:912-920.

36. Böger RH, Sydow K, Borlak J, Thum T, Lenzen H, Sehubert B, Tsikas D, Bode-Böger SM. LDL cholesterol upregulates synthesis of asymmetrical dimethylarginine in human endothelial cells: involvement of S-adenosylmethionine-dependent methyltransferases. Circ Res. 2000;87:99-105.

37. Böger RH, Bode-Böger SM, Szuba A, Tsao PS, Chan JR, Tangphao O, Blaschke TF, Cooke JP. Asymmetric dimethylarginine (ADMA): a novel risk factor for endothelial dysfunction: its role in hypercholesterolemia. Circulation. 1998;98:1842-1847.

38. Ito A, Tsao PS, Adimoolam S, Kimoto M, Ogawa T, Cooke JP. Novel mechanism for endothelial dysfunction: dysregulation of dimethylarginine dimethylaminohydrolase. Circulation. 1999;99:30923095. 
39. Faraci FM, Brian JE, Jr., Heistad DD. Response of cerebral blood vessels to an endogenous inhibitor of nitric oxide synthase. Am J Physiol. 1995;269:H1522-H1527.

40. Bode-Böger SM, Böger RH, Kienke S, Böhme M, Phivthong ngam L, Tsikas D, Frölieh JC. Chronie dietary supplementation with L-arginine inhibits platelet aggregation and thromboxane $\mathbf{A} 2$ synthesis in hypercholesterolaemic rabbits in vivo. Cardiovase Res. 1998;37:756-764.

41. Haller H, Rieger M, Lindschau C, Kuhlmann M, Philipp S, Luft FC. LDL inereases $\left[\mathrm{Ca}^{2 *}\right]_{4}$ in human endothelial cells and augments thrombin-induced cell signalling. J Lab Clin Med. 1994:124:708-714.

42. Hackeng CM, Huigsloot M, Pladet MW, Nieuwenhuis HK, van Rijn HJ, Akkerman JW. Low density lipoprotein enhances platelet secretion via integrin-alphallb beta3-mediated signaling. Arterioscler Thromb Vase Biol. 1999;19:239-247.

43. oude Egbrink MGA, Tangelder GJ, Béguin S, Wielders JS, Weijmer JS, Slaaf DW, Hemker HC, Reneman RS. Role of thrombin in the thromboembolic reaction following vessel wall injury in microvessels. In: Proceedings of the fifth world congress for microcirculation. Louisville; 1991: abstract no. 496. 
Chapter 6

\section{The Human Internal Mammary}

Artery Releases More Nitric

Oxide in Response to Vascular

Endothelial Growth Factor than

the Human Saphenous Vein 
Martijn A.W. Broeders, ${ }^{1}$ Pieter A. Doevendans, ${ }^{2}$ Jos G. Maessen, ${ }^{3}$ Erik van Gorsel, ${ }^{1}$ Mirjam G.A. oude Egbrink, ${ }^{1}$ Mat J.A.P. Daemen, ${ }^{4}$ Geert Jan Tangelder, ${ }^{5}$ Robert S. Reneman, ${ }^{1}$ Rien van der Zee ${ }^{6}$

From the Departments of Physiology, ${ }^{1}$ Cardiology, ${ }^{2}$ Cardiopulmonary Surgery, ${ }^{3}$ Pathology, ${ }^{4}$ Cardiovascular Research Institute Mastricht, Maastricht University, Maastricht, The Netherlands

Laboratory for Physiology, ${ }^{5}$ Institute for Cardiovascular Research, Free University, Amsterdam, the Netherlands

Reinier de Graaf Group, ${ }^{6}$ Department of Cardiology, Delft, The Netherlands.

Published in The Journal of Thoracic and Cardiovascular Surgery 2001;122:305-309 


\begin{abstract}
Abstraet
Endothelial nitric oxide (NO) inhibits smooth muscle cell proliferation, reducing the chance of vaseular intimal thickening. In this study we investigated whether the superior long-term pateney of the internal mammary artery in human coronary bypass grafting compared with that of the saphenous vein could be explained by different levels of NO production. The baseline endogenous NO appeared to be $50 \%$ higher in internal mammary artery than in saphenous vein. Previously, it was shown that vascular endothelial growth factor (VEGF) and the VEGF-receptors KDR (Flk-1) and Flt-1 are expressed in both internal mammary artery and saphenous vein and that VEGF-receptor density was higher in internal mammary artery than in saphenous vein. Therefore, we also investigated the influence of VEGF on NO release in both internal mammary artery and saphenous vein. VEGF augmented NO production by approximately $50 \%$ in saphenous vein and $100 \%$ in internal mammary artery. This effect was abrogated by endothelium denudation, inhibition of $\mathrm{NO}^{\mathrm{s}}$ snthase (NOS) by $\mathrm{N}^{\mathrm{C}}$-nitro-L-arginine methyl ester, and by removal of calcium from the organ bath solution. As shown by immunohistochemistry, expression of endothelial cell constitutive NOS (ec-NOS) was similar in internal mammary artery and saphenous vein, and no inducible NO synthase (i-NOS) was expressed in any of the vascular segments. It is concluded that VEGF augments endothelial constitutive NOS-dependent NO release to a greater extent in internal mammary artery than in saphenous vein. The previously reported higher VEGF-receptor density in internal mammary artery than in saphenous vein may explain the higher VEGF-stimulated NO production in internal mammary artery. These findings may help to explain the long-term superiority of internal mammary artery versus saphenous vein as a conduit for coronary artery bypass.
\end{abstract}




\section{Introduction}

Intimal thickening is an important cause of late coronary vein graft occlusion. The internal mammary artery (IMA) has been shown to have a much better long-term patency as a conduit for coronary artery bypass than the saphenous vein (SV). ${ }^{1}$ Because nitric oxide (NO) has been reported to reduce vascular smooth muscle cell mitogenesis, ${ }^{2}$ a process known to contribute to intimal thickening, it is conceivable that a difference in baseline and vascular endothelial growth factor (VEGF)-stimulated NO production between arteries and veins is responsible for the difference in patency rate between these vessels.

Previously, it was shown that in rabbits the baseline production of NO was significantly higher in segments of arteries than in segments of veins. ${ }^{3}$ This baseline NO production was found to be endothelium-derived and dependent on endothelial cell constitutive NO synthase (ec-NOS). In addition, we found that at least in rabbits, VEGF augments NO release more in arteries than in veins. VEGF is a $45-\mathrm{kDa}$ heparin-binding dimeric glycoprotein that has been reported to induce mitogenesis in endothelial cells but not in other cell types. ${ }^{4}$ Because of the unique aspect of its narrow target specificity, VEGF plays a crucial role in endothelial cell differentiation and is obligatory for normal development of the vasculature in mammalian embryos. ${ }^{5,6}$ The presence of VEGF protein and the expression of both VEGF-receptors, KDR (Flk-1) and Flt-1, in normal segments of human IMA and $\mathrm{SV},{ }^{7}$ also suggest a biological function of this growth factor in maintenance and repair of the luminal endothelium in human subjects.

In the present study we investigated the basal NO release from freshly isolated segments of human IMA and SV using the Griess method. ${ }^{3}$ In addition, we studied to which extent VEGF influences NO production in these vascular segments. Differences in VEGF-mediated NO production between arteries and veins, if any, may be caused by higher VEGF-receptor expression (Flk-1/KDR and $F l t-1)^{7}$ or a higher expression of ec-NOS or inducible NO synthase (i-NOS) protein in IMA than in SV. Therefore, in both types of human vessels we also assessed the expression of ec-NOS and i-NOS protein with the use of immunohistochemistry.

\section{Methods}

\section{Patients and vessel preparation}

Experiments were performed on vessels isolated from 32 patients (23 males and 9 females). All women were postmenopausal. All patients underwent coronary artery bypass grafting. Informed consent was obtained for the ex vivo use of blood vessel specimens. The study was approved by the ethical committees on clinical research of the University Hospital Maastricht and Maastricht University (Maastricht, The Netherlands). A small sample of IMA and/or SV was obtained during surgery. Further preparation of the vessels was conducted in the laboratory as described previously. ${ }^{3}$ In short, immediately after excision of SV and IMA segments, the vessels 
were washed for $\mathbf{5}$ to $\mathbf{1 0}$ minutes with a phosphate-buffered solution (PBS) at room temperature. Connective and other adhesive tissues as well as blood were carefully removed from the abluminal surface of the vessel segments. During these procedures care was taken not to streteh the vessel to avoid endothelial damage.

Vascular segments from 15 patients were used for measurement of NO production. They were placed in organ chambers (total volume: $10 \mathrm{~mL}$; Radnoti glass technology) and washed again in Krebs solution (in mmol/L: $\mathrm{NaCl} 118, \mathrm{KCl} 4.6, \mathrm{NaHCO}_{3} 27.2, \mathrm{MgSO}_{4} 1.2, \mathrm{CaCl}_{2} 2.5, \mathrm{KH}_{2} \mathrm{PO}_{4}$

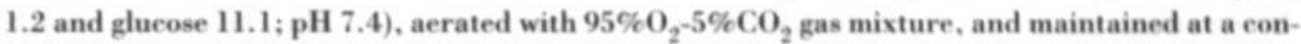
stant temperature of $37^{\circ} \mathrm{C}$. Because of the high affinity of hemoglobin for NO, vessel segments were allowed to float freely in the Krebs solution for 10 minutes to remove any remaining hemoglobin before the original Krebs buffer was replaced by $10 \mathrm{~mL}$ of freshly aerated Krebs solution. If necessary, the segments were eut at $5 \mathrm{~mm}$ intervals to ensure optimal exposure of the endothelium to oxygen and reagents added to the organ chamber. To study the involvement of endothelium in the putative effect of VEGF on NO production, in some vessel segments the endothelium was mechanically removed by gentle rubbing of the interior of the vessel rings with a moist cotton swab. Vessel segments of 17 other patients (IMA: $n=9 ; \mathrm{SV}: n=8$ ) were fixed in buffered $4 \%$ formaline for at least 24 hours, dehydrated, embedded in paraffin and stored for immunohistochemistry.

\section{Measurement of $\mathrm{NO}$}

Vascular segments were distributed over two organ chambers and were allowed to equilibrate for 15 minutes. Subsequently, concentrated test substances were administered to one of the chambers $(t=0)$; the other chamber served as control to obtain baseline NO values. NO was determined at different points in time before and after administration of the reagents to be tested $(t=-2,0,4$, $6,7,8,9,12$ minutes). In short, at each time point a $0.7 \mathrm{~mL}$ aliquot was taken from the organ chamber and added to a cuvet prefilled with $0.07 \mathrm{~mL}$ of Griess solution $(1 \%$ w/v sulfanie acid, $0.1 \% \mathrm{w} / \mathrm{v}$ naphthalene-ethylene diamine and $5 \% \mathrm{v} / \mathrm{v} \mathrm{H}_{3} \mathrm{PO}_{4}$; Sigma). Naphthalene-ethylene diamine reacts with both $\mathrm{NO}$ and $\mathrm{NO}_{2}$; the product renders the solution pink. The method used to calculate $\mathrm{NO}$ concentration ([NO]) from the photometrically determined absorbance $(548 \mathrm{~nm})$ of the pink colored Griess/sample-mixture was extensively described in an earlier study. ${ }^{3}$

\section{Use of drugs}

Heterodimeric recombinant human VEGF, purified from $E$. Coli, was used to study the VEGF effect on NO release from IMA and SV. The role of NO synthase in mediating the supposed VEGF. induced NO production was investigated by coadministration of a blocker of NO synthesis ( $N^{\mathrm{C}}$. monomethyl-L-arginine; L-NMMA, $0.2 \mathrm{~mol} / \mathrm{L}$; Sigma) together with VEGF (10 mg/mL). Because 
the constitutive endothelial NO synthase is dependent on both endothelial $\mathrm{Ca}^{2+}$ and the active precursor $\mathrm{L}$-arginine, for its activity, ${ }^{8}$ the role of $\mathrm{Ca}^{2+}$ was studied by bathing vaseular segments in $\mathrm{CaCl}_{2}$-free $\mathrm{Krebs}$ and the role of $\mathrm{L}$-arginine was studied by bathing segments in $\mathrm{Krebs}$ containing $\mathrm{L}$-arginine (added at $\mathrm{t}=-15$ minutes; $0.2 \mathrm{~mol} / \mathrm{L}$; Sigma); in some experiments VEGF was added at $t=0$ to $\mathrm{L}$-arginine containing organ bath solution.

\section{Histology, immunohistochemistry and morphometry}

To investigate the presence and localization of ec-NOS and i-NOS, paraffin-embedded segments of IMA and SV were used. Samples from normal human colon and from colon affected by active ulcerative colitis (active lesions) were used as positive controls for ec-NOS, ${ }^{9}$ and $\mathrm{i}-\mathrm{NOS},{ }^{10}$ respectively.

Tissue sections $(4 \mathrm{\mu m})$ were deparaffinized on the day of staining. For ec-NOS detection, endogenous peroxidase activity was blocked for 15 minutes with $0.3 \% \quad \mathrm{H}_{2} \mathrm{O}_{2}$ dissolved in methanol and the tissue was predigested with pepsin ( $1 \mathrm{mg} / \mathrm{mL})$ for 30 minutes. For i-NOS detection, tissue sections were placed in a $0.01 \mathrm{~mol} / \mathrm{L}$ citrate buffer $(\mathrm{pH} 6.0$ ) and boiled in a microwave oven for 5 minutes. In both cases bovine serum albumin (1\%) was applied to prevent nonspecific binding of the secondary antibody. After subsequent washes in $\mathrm{H}_{2} \mathrm{O}$ and tris- $\mathrm{HCl}$ buffered saline (TBS), the slides were overlaid with mouse monoclonal anti-human ec-NOS or i-NOS antibodies ( 1 hour at room temperature, 1:1000 and 1:100, respectively, in 1\% BSA/0.1\% tween TBS; Santa Cruz Biotechnology, Santa Ana, CA). Both antibodies have been shown to be specific for the tested proteins. For negative control the primary antibody was omitted. For ec-NOS detection indirect immunoperoxidase staining (biotinylated sheep anti-mouse antibody, 30 minutes at room temperature, 1:250 in 1\% BSA/0.1\% tween TBS; DAKO), followed by indirect Tyramide Signal Amplification (indirect TSA-kit; DuPont) was utilized. For i-NOS detection the avidin-biotin method was employed (avidin-biotin complex, 30 minutes at room temperature, 1:100 in 1\% BSA/0.1\% tween TBS; Santa Cruz Biotechnology, Santa Ana, CA). Incubating the sections with 3,3'-diaminobenzide (DAB) caused a brown color. The tissue was counterstained with hematoxylin and after dehydration through graded series of alcohols slides were mounted and coverslipped.

To specifically estimate which fraction of luminal endothelial cells positively stained for ec-NOS or i-NOS, parallel sections were incubated with the endothelial-specific anti-Ulex Europeus lectin peroxidase complex (45 minutes at room temperature, 1:100; DAKO), as described earlier. ${ }^{11}$ In two parallel sections of each specimen, the endothelial cell coverage of the lumen was determined by morphometry (Quantimet 570, Image Analyzer; Leica). The extent of endothelial cell coverage was defined as the circumference of the lumen covered by Ulex Europeus-positive cells divided by the total luminal circumference. Vascular samples were only 
selected for inclusion in the subsequent analysis if endothelial coverage was equal to or greater than 0.80. Average values for endothelial coverage in these selected vascular samples were (meanzstandard deviation): $0.93 \pm 0.07(n=9)$ in IMA and $0.93 \pm 0.04$ in $S V(n=8)$. The same method was applied to determine the extent of ec-NOS or i-NOS expression by endothelial cells. Hence, per specimen the proportion of luminal endothelial cells positively staining for either ec-NOS or i-NOS was calculated. Tissue processing and morphometric analysis was performed with the investigator blinded to the elinical information.

\section{Statistical analysis}

Values are given as meantstandard error of the mean, unless indicated otherwise. If $n=2$, bars indieate the range of obtained values. The data on NO measurements were evaluated by using a 2-factorial (significance over time, significance of drug effect) analysis of variance (ANOVA) for repeated measurements. Arterial and venous vessel segments were evaluated separately. Therefore, the vessel specimen was not introduced as a third variable. For comparison of paired values, the 2-tailed Student $t$-test was applied. In both tests statistical significance was inferred when $p<0.05$. In all experiments $n$ equals the number of vessels used for each experiment.

\section{Results}

NO release by segments of IMA and $S V$

The baseline production of NO was approximately $50 \%$ higher in IMA than in SV (Figure 1A). After administration of VEGF, release of NO significantly increased by about $100 \%$ in IMA and by about $50 \%$ in SV. Both vessel types displayed a maximal value after 8 minutes, reflecting the time necessary for downstream signaling after ligation of the VEGF-receptors. ${ }^{3,12}$

Addition of L-arginine to the organ bath solution (at $t=-15$ minutes) resulted in a significant approximately 2 -fold increase of baseline NO production in IMA (Figure IB). In SV, addition of $\mathrm{L}$-arginine (at $\mathrm{t}=-15$ minutes) also resulted in a significant increase of baseline $\mathrm{NO}$ production of approximately 1.5-fold, as can be seen in Figure ID ( $t=-3$ to $t=0$ minutes). Coadministration of the NOS-inhibitor L-NMMA totally abrogated the response to VEGF in both IMA (Figure 1B) and SV (Figure ID). In both IMA (Figure IB; t=12) and SV (Figure ID; t=12) NO production decreased to levels significantly lower than baseline values when L-NMMA was coadministered. Mechanical disruption of the endothelium in IMA (Figure IC) or removal of Ca ${ }^{2+}$ from the organ bath solution in which segments of IMA (Figure IC) or SV (Figure ID) were bathed, also prevented a rise in NO production after administration of VEGF. Interestingly, after coadministration of VEGF and L-arginine to segments of SV both baseline and maximal NO production increased (Figure ID) to levels observed after administration to IMA-segments of VEGF alone (compare with Figure 1A). 


\section{Expression of ec-NOS and i-NOS in IMA and SV}

In all IMA ( $n=9)$ and SV $(n=8)$ samples, ec-NOS positive endothelial cells were observed, indicating proper expression of this constitutively active enzyme in quiescent endothelium of both vessel types (Figure 2). The proportion of endothelial cells positively staining for ec-NOS was not statistically different between IMA $(0.92 \pm 0.11$; mean \pm standard deviation) and SV $(0.90 \pm 0.11)$. In contrast, the i-NOS protein was not expressed in any of the IMA and SV segments.

\section{Discussion}

The findings in the present study show that baseline NO release is approximately $50 \%$ higher in human internal mammary arteries than in saphenous veins and that vascular endothelial growth factor (VEGF) is capable of indueing a significant increase in NO release in these vessels through activation of endothelial cell constitutive NO synthase (ec-NOS). Administration of VEGF results in an approximately $100 \%$ rise in NO release in internal mammary arteries, and an approximately $50 \%$ rise in saphenous veins. The higher density of the VEGF tyrosine kinase receptors KDR ( $\left.F^{\prime} l k-1\right)$ and $F^{\prime} t-1$ in internal mammary arteries than in saphenous veins, as shown in a previous study, ${ }^{7}$ provides a possible explanation for the higher VEGF-stimulated release of NO in internal mammary artery compared to saphenous vein. ec-NOS seems to be equally expressed in human internal mammary artery and saphenous vein endothelium. Inducible NO synthase (iNOS) does not seem to play a role in these processes. The higher NO production at baseline and after VEGF stimulation in internal mammary arteries than in saphenous veins may play a role in the superior long-term patency of internal mammary artery when used as coronary artery bypass graft. ${ }^{13}$

The enhanced release of $\mathrm{NO}$ in both internal mammary arteries and saphenous veins after the administration of $\mathrm{L}$-arginine indicates that these vessels are able to produce more NO when stimulated but does not explain the difference in baseline NO release between this artery and this vein. From our study, it may be concluded that VEGF augments NO production when ligated to its receptors $F l k-1 / K D R$ and $F l t-1$ on human internal mammary artery and saphenous vein endothelial cells. The unique presence of these receptors on endothelial cells is demonstrated by the finding that mechanical disruption of the vascular endothelium totally abrogated the response to VEGF. Both internal mammary artery and saphenous vein endothelial cells contain ec-NOS. This ec-NOS constitutes a membrane-bound complex with calmodulin, thus being sensitive to cytosolic calcium fluctuations. ${ }^{8}$ This complex is involved in the conversion of L-arginine to citrulline, yielding NO. When VEGF binds to its tyrosine kinase receptors, they must dimerize to activate downstream signaling. After dimerization, phospholipase $\mathrm{C}_{\gamma 1}$ is phosphorylated, which causes the release of inositol-triphosphate $\left(\mathrm{IP}_{3}\right)$, resulting in an increase in cytosolic $\mathrm{Ca}^{2+}$ and a subsequent increase of ec-NOS activity and NO production. ${ }^{12}$ Consistent with this mechanism is 
the observation in the present study that removal of $\mathrm{Ca}^{2+}$ from the organ bath solution abolishes the increase in NO production after VEGF administration.

The role of VEGF in adult human blood vessels still needs to be clarified. VEGF was originally discovered as a result of its ability to increase permeability of vascular endothelium and to induce endothelial cell mitogenesis; it has been reported as mandatory in the normal development of the vasculature of mammalian embryos. ${ }^{6}$ In the adult, vascular smooth muscle cells from internal mammary artery and saphenous vein actively secrete VEGF. ${ }^{7}$ However, both VEGF-receptors, Flk-1/KDR and Flt-I, appear to be upregulated, predominantly at sites of recurrent neovessel proliferation and especially in conjunction with hypoxia ${ }^{14}$ and ischemia. ${ }^{15}$ Endogenous VEGF expression is also increased in skeletal muscle ${ }^{16}$ and heart muscle ischemia. ${ }^{17}$ The expression of VEGF-receptors by quiescent endothelium is considered to be reduced ${ }^{18}$ and in some organs, such as the human adult brain, to be altogether absent. ${ }^{19}$

In the present study we have documented that the VEGF-receptors are functional in both artery and vein as demonstrated by the increased NO release following VEGF administration.

Taken together with the notion that VEGF itself is expressed in adult vascular smooth muscle cells, ${ }^{7}$ and that it may traffic to the adjacent endothelium and ligate endothelial VEGF-receptors, this observation suggests that in healthy, mature vessels the biological function of this growth factor is not limited to angiogenesis. Preservation of an intact barrier between circulating blood and the vessel wall constitutes a critical condition for normal vessel behavior. Throughout life, blood vessels are often exposed to cytokines, proteases, oxidative stress and other factors that may damage or impair endothelial function. Under such circumstances, VEGF-augmented NO production may be required for recurrent repair of damaged or dysfunctional endothelium, thus protecting the vessel from thrombotic events, leukocyte adhesion and/or vasospasm. In addition, intact endothelial NO production is mandatory to inhibit medial smooth muscle cell proliferation. ${ }^{2,20}$ This feature is relevant to the preservation of vaseular patency as well, because migration of proliferating medial smooth muscle cells has been shown to contribute to the occurrence of intimal thickening in coronary bypass grafts and native coronary arteries. Therefore, in mature vessels VEGF could play a role in maintenance and/or repair of the luminal endothelium by augmenting NO production.

\section{Acknowledgment}

The authors are indebted to Jan de Vente for his helpful ideas and Helen Steinbusch for her skillful technical assistance. 

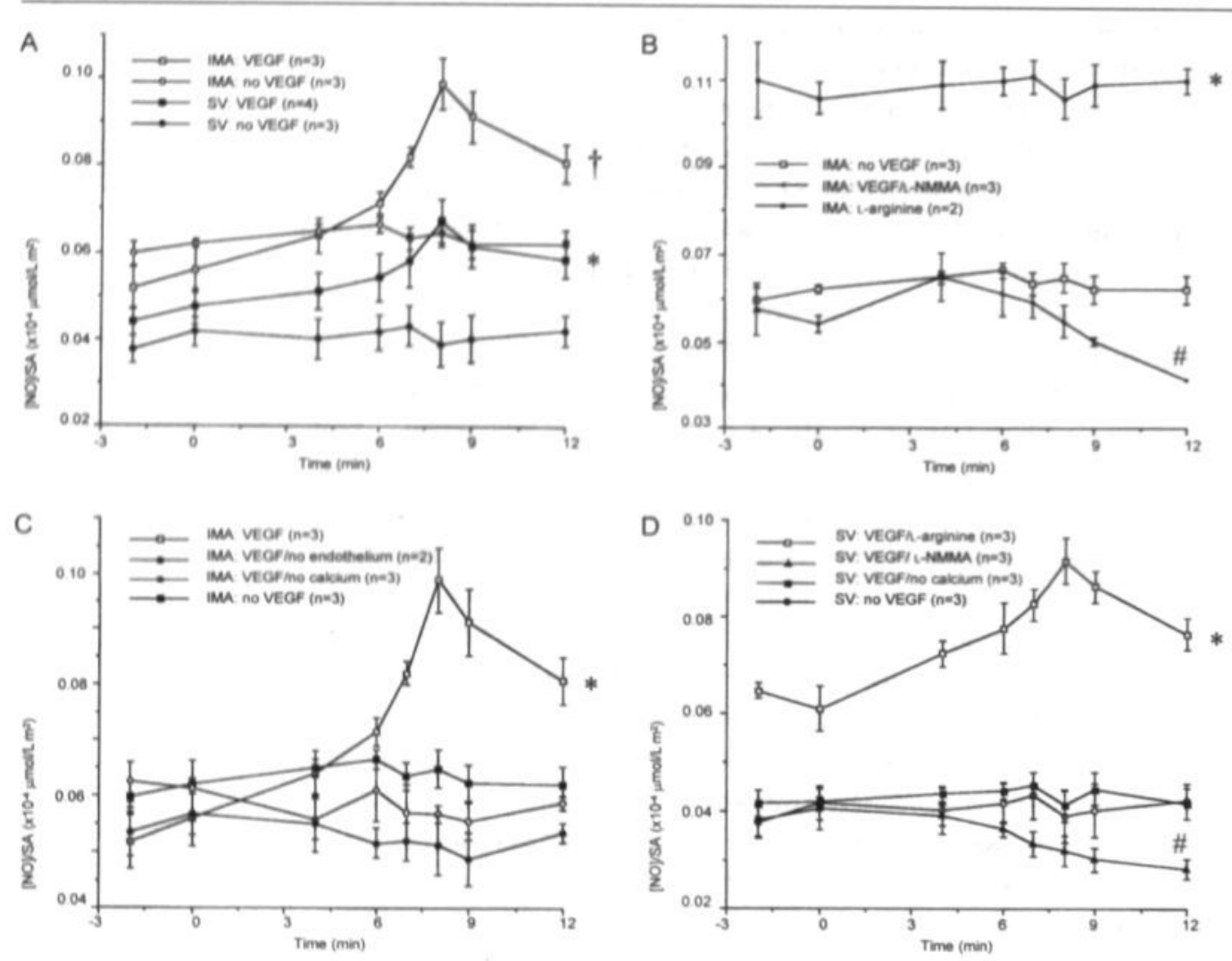

Figure 1

The effect of VEGF (vascular endothelial growth factor; $10 \mathrm{mg} / \mathrm{mL}$ ) on nitric oxide (NO) release from human internal mammary artery (IMA) and saphenous vein (SV). The involvement of NO synthase was studied by adding the active substrate L-arginine $(0.2 \mathrm{~mol} / \mathrm{L})$ or by adding $N^{\mathrm{C}}$-monomethyl-L-arginine (L-NMMA; $0.2 \mathrm{~mol} / \mathrm{L}$ ), which is an inhibitor of $\mathrm{NO}$ synthesis. L-Arginine was added at $\mathrm{t}=-15$ minutes; other substances were added at $t=0$ minutes. All concentrations represent final bath concentrations. Involvement of the endothelium and $\mathrm{Ca}^{2+}$ was studied as well. $n$ Indicates the number of vascular segments; [NO], NO concentration; SA, surface area.; no endothelium, endothelium-denuded vascular segments; and no calcium, $\mathrm{CaCl}_{2}$-free organ bath solution.

" p<0.05 (in A) "SV: VEGF" versus "SV: no VEGF", (in B) "IMA: L-arginine" versus "IMA: no VEGF", (in C) "IMA: VEGF" versus all other curves, and (in D) "SV: VEGF/L-arginine" versus all other curves; † $p<0.05$ (in A) "IMA: VEGF" versus "IMA: no VEGF"; \# p<0.05 (in B) "IMA: VEGF/L-NMMA" versus "IMA: no VEGF" at t=12 minutes, and (in D) "SV: VEGF/L-NMMA" versus "SV: no VEGF" at $t=12$ minutes. 

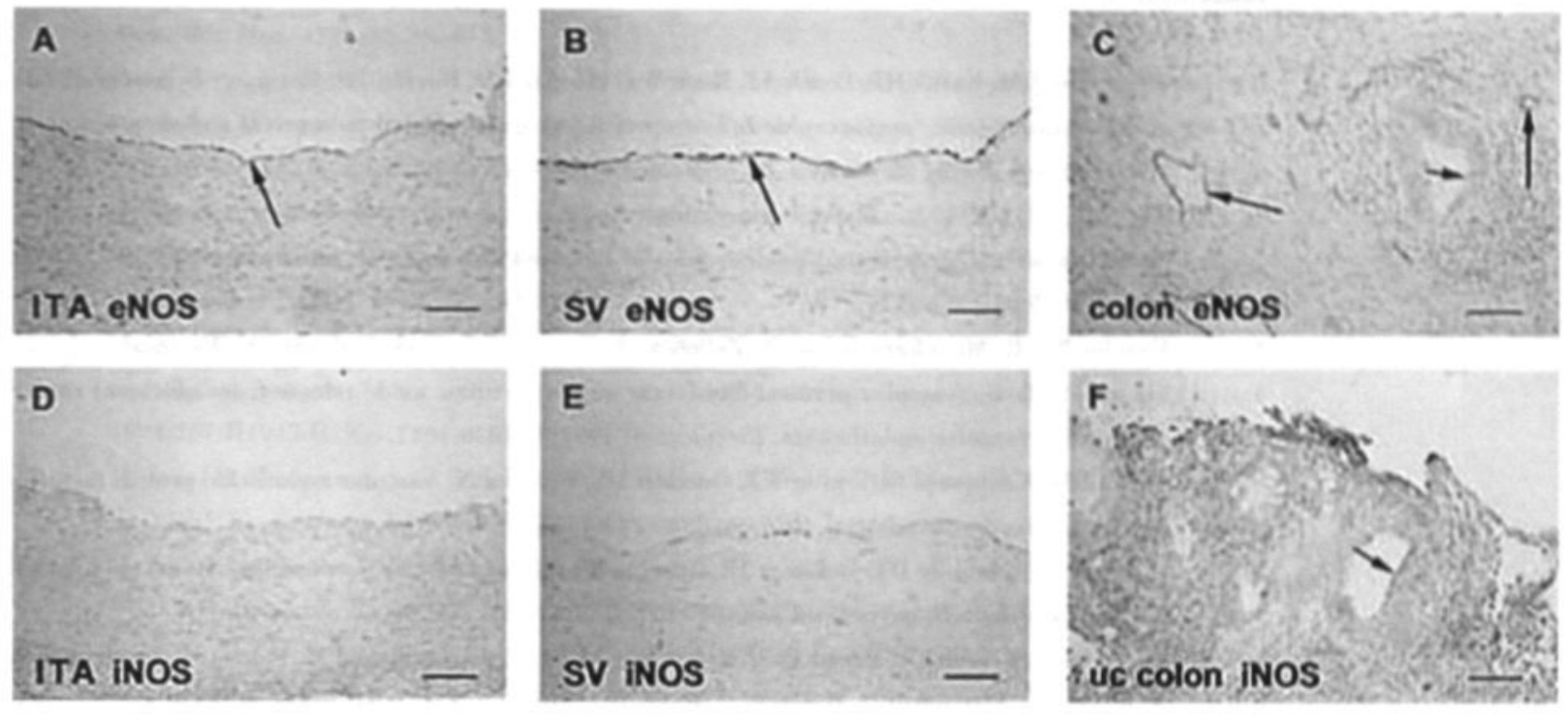

Figure 2

The expression of endothelial cell constititutive NO synthase (eNOS) and inducible NO synthase (iNOS) on endothelial cells in human internal mammary artery (IMA) and saphenous vein (SV). Mouse monoclonal anti-human eNOS- or iNOS-protein antibodies were used for immunohistochemistry. The brown color indicates a signal specifie for the primary antibody used. Panel A shows positive eNOS staining on luminal endothelial cells (arrow) of human IMA. Panel B shows positive eNOS staining on luminal endothelial cells (arrow) of human SV. Panel C shows positive eNOS staining on vaseular endothelial cells of blood vessels of different caliber in the stroma of human colon. Panel A-C: large arrows indicate the endothelium; small arrow indicates a colon villus. Panel D shows no iNOS staining on human IMA. Panel E shows no iNOS staining on human SV. Panel F shows positive iNOS staining on stromal cells in a sample from an active lesion of a human colon affected by ulcerative colitis (uc); arrow indicates a colon villus. Seale bars represent $100 \mu \mathrm{m}$. 


\section{References}

1. Fitzgibbon GM, Kafka HP, Leach AJ, Keon WJ, Hooper GD, Burton JR. Coronary bypass graft fate and patient outcome: angiographie follow-up of 5,065 grafts related to survival and reoperation in 1,388 patients during 25 years. J Am Coll Cardiol. 1996:28:616-626.

2. Garg UC, Hassid A. Nitrie oxide-generating vasodilators and 8-bromo cyclic guanosine monophosphate inhibit mitogenesis and proliferation of eultured rat vascular smooth muscle cells. $J$ Clin Invest. 1989;83:1774-1777.

3. Van der Zee R, Murohara T, Luo Z, Zollmann F, Passeri J, Lekutat C, Isner JM. Vascular endothelial growth factor/vaseular permeability factor augments nitric oxide release from quiescent rabbit and human vascular endothelium. Circulation. 1997;95:1030-1037.

4. Leung DW, Cachianes G, Kuang WJ, Goeddel DV, Ferrara N. Vascular endothelial growth factor is a secreted angiogenic mitogen. Science. 1989;246:1306-1309.

5. Olander JV, Connolly DT, DeLarco JE. Specifie binding of vascular permeability factor to endothelial cells. Biochem Biophys Res Commun. 1991;175:68-76.

6. Carmeliet P, Ferreira V, Breier G, Pollefeyt S, Kieckens L, Gertsenstein M, Fahrig M, Vandenhoeck A, Harpal K, Eberhardt C, Declercq C, Pawling J, Moons L, Collen D, Risau W, Nagy A. Abnormal blood vessel development and lethality in embryos lacking a single VEGF allele. Nature. 1996;380:435-439.

7. Couffinhal T, Kearney M, Witzenbichler B, Chen D, Murohara T, Losordo DW, Symes J, Isner JM. Vascular endothelial growth factor/vascular permeability factor (VEGF/VPF) in normal and atherosclerotic human arteries. Am J Pathol. 1997;150:1673-1685.

8. Stamler JS, Singel DJ, Loscalzo J. Biochemistry of nitric oxide and its redox-activated forms. Science. 1992;258:1898-1902.

9. Ambs S, Merriam WG, Bennett WP, Felley Bosco E, Ogunfusika MO, Oser SM, Klein S, Shields PG, Billiar TR, Harris CC. Frequent nitric oxide synthase-2 expression in human colon adenomas: implication for tumor angiogenesis and colon cancer progression. Cancer Res. 1998;58:334-341.

10. Kimura H, Hokari R, Miura S, Shigematsu T, Hirokawa M, Akiba Y, Kurose I, Higuchi H, Fujimori H, Tsuzuki Y, Serizawa H, Ishii H. Increased expression of an inducible isoform of nitric oxide synthase and the formation of peroxynitrite in colonic mucosa of patients with active ulcerative colitis. Gut. 1998;42:180-187.

11. Hofstra L, Tordoir JHM, Kitslaar PJEHM, Hoeks APG, Daemen MJAP. Enhanced cellular proliferation in intact stenotic lesions derived from human arteriovenous fistulas and peripheral bypass grafts. Circulation. 1996;94:1283-1290.

12. Ku DD, Zaleski JK, Liu S, Brock TA. Vascular endothelial growth factor induces EDRF-dependent relaxation in coronary arteries. Am J Physiol. 1993;265:H586-H592.

Chapter 6 
13. Lüscher TF, Tanner FC, Tschudi MR, Noll G. Endothelial dysfunction in coronary artery disease. Annu Rev Med. 1993;44:395-418.

14. Brogi E, Schatteman G, Wu T, Kim EA, Varticovski L, Keyt B, Isner JM. Hypoxia-induced paracrine regulation of vascular endothelial growth factor recepter expression. J Clin Invest. 1996:97:469-476.

15. Li J, Brown LF, Hibberd MG, Grossman JD, Morgan JP, Simons M. VEGF, $f k$ - 1 , and $f t$ - $l$ expression in a rat myocardial infaretion model of angiogenesis. Am J Physiol. 1996:270:H1803-H1811.

16. Couffinhal T, Silver M. Zheng L.P. Kearney M, Witzenbichler B, Isner JM. Mouse model of angiogenesis. Am J Pathol. 1998;152:1667-1679.

17. Hashimote E, Ogita T, Nakaoka T, Matsuoka R, Takao A, Kira Y. Rapid induetion of vaseular endothelial growth factor expression by transient ischemia in rat heart. Am $J$ Physiol. 1994:267:H1948-H1954.

18. Millauer B, Wizigmann Voos S, Schnürch H, Martinez R, Miller NP, Risau W, Ullrich A. High affinity VEGF binding and developmental expression suggest $F l k-1$ as a major regulator of vaseulogenesis and angiogenesis. Cell. 1993:72:835-846.

19. Plate KH, Breier G, Weich HA, Mennel HD, Risau W. Vascular endothelial growth factor and glioma angiogenesis: coordinate induction of VEGF receptors, distribution of VEGF protein and possible in vivo regulatory mechanisms. Int J Cancer. 1994:59:520-529.

20. Asahara T, Bauters C, Pastore C, Kearney M, Rossow S, Bunting S, Ferrara N, Symes JF, Isner JM. Local delivery of vascular endothelial growth factor accelerates reendothelialization and attenuates intimal hyperplasia in balloon-injured rat carotid artery. Circulation. 1995:91:2793-2801. 

Chapter 7

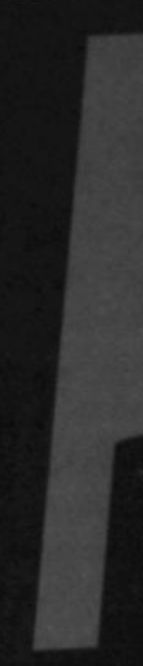

Nebivolol: a Third-Generation $\beta$-Blocker that Augments

Vascular Nitric Oxide Release. Endothelial $\beta 2$-Adrenergic Receptor-Mediated Nitric Oxide Production 
Martijn A.W. Broeders, ${ }^{1}$ Pieter A. Doevendans, ${ }^{2}$ Bas C.A.M. Bekkers,${ }^{2}$ Ronald Bronsaer, ${ }^{2}$ Erik van Gorsel, ${ }^{1}$ Johan W.M. Heemskerk, ${ }^{3}$ Mirjam G.A. oude Egbrink, ${ }^{1}$ Eric van Breda, ${ }^{1}$ Robert S. Reneman, ${ }^{1}$ Rien van der Zee ${ }^{4}$

From the Departments of Physiology, ${ }^{1}$ Cardiology ${ }^{2}$ and Biophysics, ${ }^{3}$ Cardiovascular Research Institute Maastricht, Mastricht University, Maastricht, the Netherlands

Reinier de Graaf Group, ${ }^{4}$ Department of Cardiology, Delft, The Netherlands.

Published in Circulation 2000;102:677-684 


\begin{abstract}
Abstraet
Nebivolol is a $\beta 1$-selective adrenergic receptor antagonist with proposed nitric oxide (NO)-mediated vasodilating properties in humans. In this study, we explored whether nebivolol indeed induces NO production and, if so, by what mechanism. We hypothesized that not nebivolol itself, but rather its metabolites augment NO production. Mouse thoracic aorta segments were bathed in an organ chamber. Administration of nebivolol did not affect NO production. When nebivelol was allowed to metabolize in vivo in mice, addition of plasma of these mice caused a sustained 2 . fold increase in NO release. Interestingly, coadministration of a selective $\beta 2$-adrenergic receptor antagonist (butoxamine) prevented the response. Immunohistochemistry and Western blot analysis demonstrated the presence of $\beta 2$ - but not $\beta 1$-adrenergic receptors on endothelial cells. In the absence of calcium, metabolized nebivolol failed to increase NO production, suggesting a role for caleium-dependent NO synthase. With digital fluorescent imaging, a rapid and sustained rise in endothelial eytosolic free $\mathrm{Ca}^{2+}$ concentration $\left(\left[\mathrm{Ca}^{2+}\right]_{\mathrm{i}}\right)$ was observed after administration of metabolized nebivolol, which also was abrogated by butoxamine pretreatment. It is concluded that in vivo metabolized nebivolol increases vascular NO production. This phenomenon involves endothelial $\beta 2$-adrenergic receptor ligation, with a subsequent rise in endothelial free $\left[\mathrm{Ca}^{2+}\right]_{i}$ and endothelial NO synthase-dependent NO production. This may be an important mechanism underlying the nebivolol-induced, NO-mediated arterial dilation in humans.
\end{abstract}




\section{Introduction}

The use of $\beta$-blockers, especially the so-called third-generation blockers with vasodilating properties, in the treatment of hypertension, heart failure and ischemic syndromes is increasing. ${ }^{1.2}$ In addition to the third-generation blockers, the clinically used $\beta$-blockers are classified either as first-generation nonselective drugs, which block both $\beta 1$ - and $\beta 2$-adrenergic receptors, or as second-generation, $\beta 1$-selective drugs. $\beta$-Blockers may also have $\alpha$-receptor-blocking effects (labetolol, carvedilol), intrinsic sympathomimetic effects (pindolol), or elass III antiarrhythmic effects (sotalol). ${ }^{3}$

Nebivolol, a newly developed $\beta$-adrenergic receptor-blocking drug, is a racemic mixture of D- and L-enantiomeres, of which D-nebivolol is considered to be a highly selective $\beta 1$-adrenergic receptor antagonist. ${ }^{4}$ In addition, nebivolol has been shown to cause vasodilation in animals ${ }^{4}$ and humans. ${ }^{4-6}$ it has been suggested that this effect is mediated by increased nitric oxide (NO) production, because it can be abrogated by inhibitors of NO synthase (NOS). ${ }^{5,6}$ NO released by endothelial cells has been shown to be a key participant in numerous biological processes, serving the maintenance of vascular integrity; one of its main actions is induction of vascular relaxation. ${ }^{7,8}$

The present study was performed to explore whether nebivolol indeed induces NO production and to obtain insight into the mechanism underlying this enhanced NO production, ${ }^{6}$ if any. We hypothesized that not nebivolol itself but its metabolites increase NO production, because pilot experiments in our institute indicated that nebivolol itself does not induce NO release. In vitro techniques were used to test the influence of plasma metabolites formed in vivo on NO production and endothelial $\mathrm{Ca}^{2+}$ concentration in isolated vascular segments; because it is known that the stimulation of adrenergic receptors and 5-HT serotonergic receptors can activate endothelial cell constitutive (ec)-NOS, leading to NO release, ${ }^{9,10}$ we investigated the involvement of both $\alpha$ - and $\beta$-adrenergic receptors and 5 -HT ${ }_{14}$ serotonergic receptors.

\section{Methods}

\section{Animal and vessel preparation}

Experiments were performed on thoracic aortas isolated from 51 male wild-type Swiss mice. The experiments were conducted according to protocols approved by the local committee on the use of laboratory animals. Aorta segments were placed in either one of two organ chambers, both containing continuously aerated $\left(95 \% \mathrm{O}_{2} / 5 \% \mathrm{CO}_{2}\right)$ and warmed $\left(37^{\circ} \mathrm{C}\right) \mathrm{Krebs}$ solution. The first, a glass organ chamber was specially suited for $\mathrm{NO}$ measurements (total volume, $10 \mathrm{~mL}$; Radnoti Glass Technology). The second, an aluminium organ chamber (total volume, $15 \mathrm{~mL}$; Applied Imaging), was designed to fit the stage of a fluorescent imaging inverted microscope (Nikon) to allow measurements of endothelial cytosolic free $\mathrm{Ca}^{2+}$ concentrations. 


\section{Use of drugs and mouse plasma}

The effects of a mixture of $\mathrm{D}$ - and $\mathrm{L}$-nebivolol (50/50 mixture; $1 \mu \mathrm{mol} / \mathrm{L}$ final bath concentration: Menarini) and of metoprolol ( 1 pmol/L; CIBA-Geigy), another commonly used $\beta 1$-selective antagonist without indications of NO release-inducing activity, on vascular NO release and endothelial cytosolic free $\mathrm{Ca}^{2+}$ concentration $\left(\left[\mathrm{Ca}^{2+}\right]_{1}\right)$ were assessed in separate experiments. To test the hypothesis that not nebivolol itself but rather its metabolites induce NO release and increase endothelial $\left[\mathrm{Ca}^{2+}\right]_{i}, 0.5 \mathrm{~mL}$ of $\mathrm{D}$ - and $\mathrm{L}$-nebivolol $(50 / 50 ; 0.5 \mathrm{mg} / \mathrm{mL})$ was injected into the tail vein of mice. In separate experiments, the effect of metabolites of metoprolel $(0.5 \mathrm{mg} / \mathrm{mL})$ was tested by the same procedure $(0.5 \mathrm{~mL}$, iv $)$. In these experiments, in vivo drug metabolization was allowed for $\mathbf{4 5}$ minutes. Then, anesthesia was induced, the abdomen opened, and blood collected. Blood samples were centrifuged (2 minutes, $12,000 \mathrm{rpm}$ at $4^{\circ} \mathrm{C}$; centrifuge 5412 . Eppendorf) to obtain plasma, which was stored at $4^{\circ} \mathrm{C}$ for use in an $\mathrm{NO}$ or $\mathrm{Ca}^{2+}$ assay on the same day. Plasma of noninjected mice treated similarly was used to test the effects of plasma factors. In these experiments, plasma volume constituted $3 \%$ of the total volume of the final bath solution. Acetylcholine ( $1 \mu \mathrm{mol} / \mathrm{L}$ in $\mathrm{NO}$ assay; $0.1 \mathrm{mmol} / \mathrm{L}$ in $\mathrm{Ca}^{2+}$ assay; Sigma) was administered to investigate whether a normal response could be induced in endothelium-intact aorta segments.

To study the involvement of endothelium, in some experiments, endothelium-denuded aorta segments were used. The role of NOS was investigated by use of a blocker of NO synthesis ( $N^{G}$-nitro-L-arginine methyl ester; L-NAME; $0.1 \mathrm{mmol} / \mathrm{L}$; Sigma). Because ec-NOS is dependent on endothelial $\mathrm{Ca}^{2+}$ for its activity, ${ }^{7}$ the role of $\mathrm{Ca}^{2+}$ was studied by bathing aorta segments in $\mathrm{CaCl}_{2}$-free solution. Finally, to test the contribution of vascular $\alpha$-or $\beta$-adrenergic receptors and 5 -HT serotonergic receptors to NO production, an $\alpha$-adrenergic receptor blocker (phentolamine; $10 \mu \mathrm{mol} / \mathrm{L} ;$ CIBA-Geigy), a $\beta 2$-adrenergic receptor antagonist (butoxamine; $0.1 \mathrm{mmol} / \mathrm{L}$; Sigma), or a $5-\mathrm{HT}_{1 \mathrm{~A}}$ antagonist (NAN-190; $\left.1 \mu \mathrm{mol} / \mathrm{L} ; \mathrm{ICN}\right)$ was used. A $\beta 2$-adrenergic receptor agonist (salbutamol; $10 \mu \mathrm{mol} / \mathrm{L}$; Sigma) was administered to study a possible role for $\beta 2$-adrenergic receptor-mediated NO release.

\section{Measurement of NO}

NO was determined at different time points before and after administration of the reagents to be tested ( $t=-5,0,2,5,10,15,20$ and 25 minutes). NO production was quantified by the Griess method, which was described extensively in an earlier study. ${ }^{11}$ To correct for the differences in size of the vascular segments, the NO production was standardized for intimal surface area (SA). The NO concentration ([NO]) per SA was expressed in $(\mu \mathrm{mol} / \mathrm{L}) / \mathrm{m}^{2}$, assuming that the production of $\mathrm{NO}$ was equal across the endothelium of the excised vascular segment. 


\section{Digital fluorescence imaging}

ec-NOS is dependent on the endothelial cytosolic free $\mathrm{Ca}^{2+}$ concentration $\left(\left[\mathrm{Ca}^{2+}\right]_{\mathrm{i}}\right)$ for its activity. ${ }^{7}$ For measurement of $\left[\mathrm{Ca}^{2+}\right]_{\mathrm{i}}$ in endothelial cells, segments of the thoracic aorta were opened longitudinally and pinned onto a silicon dise. The vessel segments were loaded with the calcium probe fura 2-AM (10pmol/L; Molecular Probes). Subsequently, the silicon disk with the aortic segment was placed in an aluminum organ chamber containing Krebs solution, aerated with $95 \%$ $\mathrm{O}_{2} / 5 \% \mathrm{CO}_{2}$ at $37^{\circ} \mathrm{C}$. The method used to measure $\left[\mathrm{Ca}^{2+}\right]_{\mathrm{i}}$ using a digital fluorescence imaging system connected to an inverted microscope was adapted from the method described earlier by Raat and coworkers. ${ }^{12}$ Typically, $80 \%$ to $100 \%$ of the endothelial cells responded after administration of a test agent within each microscopic field (see Figure 2). Because calibration values differed per cell, data are presented as 340/380-ratios. To obtain an impression about absolute $\left[\mathrm{Ca}^{2+}\right]_{\mathrm{i}}$, averaged $340 / 380$-ratios of all cells in a field were translated into $\left[\mathrm{Ca}^{2+}\right]_{\mathrm{i}}$ by a calibration according to Grynkiewicz. ${ }^{13}$ Calculated baseline $\left[\mathrm{Ca}^{2+}\right]_{i}$ in the aorta endothelial cells was, on average, $45 \mathrm{nmol} / \mathrm{L}$.

\section{Immunohistochemistry}

To investigate the presence of $\beta 1$ - and/or $\beta 2$-adrenergic receptors, segments of the mouse thoracic aorta were embedded in Tissue-Tek. Samples of mouse left ventricular myocardium and brain were embedded and used as positive controls for $\beta 1$ - and $\beta 2$-adrenergic receptors, respectively. Frozen tissue sections were overlaid with rabbit polyclonal anti-mouse $\beta 1$ - or $\beta 2$-adrenergic receptor antibodies (30 minutes at room temperature, 1:100 in 1\% BSA/0.1\% Tris- $\mathrm{HCl}$ buffered saline; Santa Cruz Biotechnology, CA). For negative control, the primary antibody was omitted.

\section{Cell culture techniques}

To investigate whether $\beta 1$ - or $\beta 2$-adrenergic receptor protein could be detected in endothelial and smooth muscle cells, these cells were cultured for use in Western blot analysis. Because we, like many other groups, did not succeed in keeping mouse aorta endothelial cells viable under culture conditions, cells from rat heart endothelial cell line-50 (RHEC-50 $)^{14}$ were used. The cells were used for Western blot analysis after the second passage. Smooth muscle cells were derived from 3-mm mouse aortic segments from which the endothelium was mechanically removed.

\section{Western blot procedures}

Cultured endothelial cells and smooth muscle cells were lysed in a standard lysis buffer. Rabbit polyclonal anti-mouse $\beta 1$ - or $\beta 2$-adrenergic receptor antibodies (Santa Cruz Biotechnology), diluted 1:1000 in PBS, were used as primary antibodies and were applied for overnight 
incubation at $4^{\circ} \mathrm{C}$. After several washing procedures, the membranes were subjected to enhanced chemiluminescence (ECL, Amersham).

\section{Use of mouse hepatic microsomes}

To obtain direct evidence in favor of action via active metabolites, we performed additional experiments using hepatic microsomes. D,L-nebivolol $(0.5 \mathrm{~mL} ; 50 / 50 ; 0.5 \mathrm{mg} / \mathrm{mL})$ was ineubated with freshly harvested hepatic microsomes from male Swiss mice $(n-3)$. Incubation was allowed for $\mathbf{4 5}$ minutes to obtain liver metabolites of nebivolol. After ineubation, hepatic mierosomes were centrifuged, and the supernatant was directly added to RHEC-50 cells. NO production was quantified with a calibrated porphyrinic NO sensor (World Precision Instruments, FL) positioned on top of a confluent layer of RHEC-50 cells.

\section{Statistical analysis}

Values are given as meantstandard error of the mean. The data were evaluated using a 2-factorial (significance over time and significance of drug effect) analysis of variance (ANOVA) for repeated measurements. Statistical significance was inferred when p<0.05. In all experiments, $n$ equals the number of aortas, corresponding with the number of mice used.

\section{Results}

\section{NO release by segments of mouse aorta}

Administration of nebivolol did not augment NO release above baseline levels, nor did metoprolol (Figure 1A). Acetylcholine, however, caused a significant increase in NO production, demonstrating a normal response of endothelium. When plasma of nebivolol-injected mice was applied, a significant increase in NO production was observed (Figure 1B). This phenomenon was not seen when plasma of metoprolol-injected mice was added. Administration of plasma alone or plasma with freshly added nebivolol did not result in an augmented NO release. The increase in NO production after the administration of metabolized nebivolol was abrogated when the endothelium was mechanically disrupted, when L-NAME was coadministered, or in the absence of calcium (Figure IC). Interestingly, selective blockade of the vascular adrenergic $\beta 2$-receptors with butoxamine also prevented the increase in NO production after the administration of metabolized nebivolol. Coadministration of the $\alpha$-blocker phentolamine or the 5-HT 1 antagonist NAN-190, however, had no effect (Figure ID). Selective stimulation of vascular $\beta 2$-receptors with salbutamol resulted in an augmentation of NO release similar to that of metabolized nebivolol (Figure 1D). 


\section{Cytosolic free $\mathrm{Ca}^{2+}$ concentration}

Figure 2 illustrates the typical heterogeneity in response between single endothelial cells within the same vascular segment and shows the effect of metabolized nebivolol on $\left[\mathrm{Ca}^{2+}\right]_{i}$ with and without butoxamine pretreatment. In Figure 3, responses in single endothelial cells are plotted. The average reaction to the same substances is presented in the Table. Figure $3 \mathrm{~A}$ depicts the effect of fresh nebivolol $(1 \mu \mathrm{mol} / \mathrm{L})$ together with plasma from a noninjected mouse: a short-lasting response with a maximum increase of $\left[\mathrm{Ca}^{2+}\right]_{i}$ from 45 to $175 \mathrm{nmol} / \mathrm{L}$. This effect could not be blocked by butoxamine. Administration of $10 \mu \mathrm{mol} / \mathrm{L}$ nebivolol resulted in a similar short-lasting response with a somewhat higher peak value (data not shown); $0.1 \mathrm{mmol} / \mathrm{L}$ nebivolol resulted in an even higher increase, but the applied concentration appeared to be toxic and resulted in lysis of the cell membrane with subsequent leakage of fura 2 (data not shown). Plasma from nebivololinjected mice caused a rapid and sustained increase in $\left[\mathrm{Ca}^{2+}\right]_{i}$ from 45 to $65 \mathrm{nmol} / \mathrm{L}$ (Figure 3B). Blockade of the adrenergic $\beta 2$-receptors with butoxamine abrogated this increase in $\left[\mathrm{Ca}^{2+}\right]_{i}$ (Figure 3C). As a positive control, acetylcholine was administered (Figure 3D).

\section{Immunohistochemistry and Western blotting}

Both immunohistochemistry and Western blot analysis indicate that mice aortic vascular smooth muscle cells contained mainly $\beta 1$-adrenergic receptors (Figure 4A, Figure 5). In contrast, endothelial cells selectively express $\beta 2$-adrenergic receptors (Figure $4 \mathrm{C}$, Figure 5). Mouse myocardium was used as a positive control for $\beta 1$-staining (Figure 4B), whereas the choroid plexus in mouse brain tissue was used as a positive control for $\beta 2$-staining (Figure $4 \mathrm{D}$ ).

\section{Hepatic microsomes}

After nebivolol had been incubated with mouse hepatic microsomes for $\mathbf{4 5}$ minutes, addition of these nebivolol-incubates to three separate dishes containing RHEC-50 cells resulted in a significant rise in NO concentration in each of the dishes (Figure 6). Baseline NO concentration was on average $40 \mathrm{nmol} / \mathrm{L}$, which increased to a peak value of $88 \mathrm{nmol} / \mathrm{L}$ after administration of nebivolol-incubate. After the endothelial cell monolayer had been washed, addition of acetylcholine caused a significant increase in NO production, from 50 to $98 \mathrm{nmol} / \mathrm{L}$ (Figure 6). Addition of nebivolol itself to RHEC-50 cells, however, had no effect.

\section{Discussion}

Plasma of nebivolol-injected mice (metabolized nebivolol) induces the release of $\mathrm{NO}$ from mouse aorta and augments the free $\left[\mathrm{Ca}^{2+}\right]_{i}$ in endothelial cells, processes that are $\beta 2$-adrenergic receptor-mediated and endothelium-dependent. Immunohistochemistry and Western blot analysis demonstrate that $\beta 2$-adrenergic receptors are present predominantly on endothelial cells. 
Nebivolol alone or bound to plasma has no such effects. The effects seem to be specifie for metabolized nebivolol, because metoprolol, pure or metabolized, is devoid of these effects.

The metabolism of nebivolel is complex, and many metabolites have been described. ${ }^{4}$ The results of the hepatic microsome experiments show that mouse liver cells metabolize nebivolol, during which process at least one substance is formed that is capable of activating NO production in endothelial cells. These findings strongly suggest that one or more active metabolite(s) of nebivolol is/are responsible for the observed effects of plasma from nebivolol-injected animals on endothelial NO release and $\left[\mathrm{Ca}^{2 *}\right]_{i}$. The alternative that a nebivolol/plasma-complex is responsible for the observed effects can be ruled out by our observation that addition of nonmetabolized nebivolol together with plasma from noninjected mice to cultured endothelium does not lead to stimulation of NO release. The other possibility, that nebivolol releases some endogenous mediator with $\beta 2$-agonist activity (eg, epinephrine), is unlikely in the light of the present results.

The rise in NO production in isolated segments of mouse aorta in response to metabolized nebivolol was prevented by mechanical removal of the endothelium. Further evidence for the exclusive role of endothelial cells in this response is provided by the involvement of $\beta 2$-adrenergic receptors, which are shown to be present on endothelial cells and not on vaseular smooth muscle cells. The involvement of $\beta 2$-adrenergic receptors is supported by our observations that the $\beta 2$-adrenergic receptor antagonist butoxamine prevented the rise in NO production in response to metabolized nebivolol and that the $\beta 2$-adrenergic receptor agonist salbutamol induced a rise in NO production similar to the one induced by metabolized nebivolol. Interestingly, Dawes et al (1997) showed vasodilator responses in the human forearm that were mediated predominantly through $\beta 2$-adrenergic receptors and that were dependent on NO synthesis. ${ }^{15} \alpha$-Adrenergic receptors are not involved in the vasodilating effect of metabolized nebivolol, because phentolamine failed to affect the augmented NO production induced by metabolized nebivolol. Administration of phentolamine alone did also not affect NO production (data not shown).

Recently, Kakoki et al (1999) observed that nebivolol induces NO-mediated vasorelaxation in isolated rat aorta, which could be blocked with a 5-HT ${ }_{1 \mathrm{~A}}$ antagonist. ${ }^{10}$ We show that NO production in response to metabolized nebivolol was completely blocked by butoxamine, a $\beta 2$ adrenergic receptor antagonist with no known affinity for 5 -HT receptors, ${ }^{16}$ but not by the 5-HT ${ }_{1 A}$ antagonist NAN-190. This is in agreement with the results obtained in earlier studies showing that the documented affinity of nebivolol for the $5-\mathrm{HT}_{1 \mathrm{~A}}$ receptor has no functional consequences. ${ }^{17}$ Moreover, in contrast to the results of Kakoki et al, Gao and coworkers (1991) found that the nebivolol-induced relaxation of isolated rings of canine left anterior descending coronary arteries was not affected by methysergide, ${ }^{18}$ a nonspecifie blocker of $5-\mathrm{HT}_{1 \mathrm{~A}^{-}}$and other 5 -HTserotonergic receptors. ${ }^{19}$ 
Metabolized nebivolol caused a small but significant increase in free $\left[\mathrm{Ca}^{2+}\right]_{i}$ in endothelial cells of $-20 \mathrm{nmol} / \mathrm{L}$. It cannot be concluded from the present study whether the measured rise in free $\left[\mathrm{Ca}^{2+}\right]_{i}$ is sufficient to stimulate the activity of ec-NOS. In this respect, it is interesting to note that a relatively high concentration of acetylcholine was needed to induce a measurable rise in endothelial free $\left[\mathrm{Ca}^{2+}\right]_{i}$. This may be the consequence either of a relative insensitivity of the fluorescence imaging method used to quantitate free $\left[\mathrm{Ca}^{2+}\right]_{i}$ or of the stimulation of ec-NOS in a calcium-independent way. ${ }^{20}$ The first possibility could explain why the increase in free $\left[\mathrm{Ca}^{2+}\right]_{\mathrm{i}}$ as caused by metabolized nebivolol or acetylcholine was relatively low in proportion to their more pronounced effects on NO production. Regarding the second possibility, it is interesting to note that metabolized nebivolol was not able to induce a rise in NO release in the absence of extracellular calcium. It may well be that both intracellular and extracellular $\mathrm{Ca}^{2+}$ are necessary to stimulate ec-NOS. After all, it has been shown by other groups that the delayed component contributing to the plateau phase of the elevated $\left[\mathrm{Ca}^{2+}\right]_{i}$ is dependent on $\mathrm{Ca}^{2+}$ influx from the extracellular space, whereas the initial rise may be the result of release from intracellular stores. ${ }^{21}$

In separate experiments, plasma of human volunteers on nebivolol $5 \mathrm{mg} /$ day did not evoke a similar rise in NO production in cultured human umbilical vein endothelial cells. The dose of nebivolol used in this study was much higher than the ones used in oral treatment in humans. One should realize, however, that the mouse aortic endothelium is only moderately sensitive to agonists, because relatively high concentrations of salbutamol and acetylcholine were needed to augment endothelial $\left[\mathrm{Ca}^{2+}\right]_{i}$ and $\mathrm{NO}$ production.

The clinical finding that endogenous $\mathrm{NO}$ appears to be involved in the acute arterial and venous dilation after local nebivolol infusion is not necessarily in diasagreement with the observation in the present study. ${ }^{5,6}$ The dilating effect of nebivolol in the human forearm could be a result of nebivolol-induced peripheral arterial dilation, ${ }^{4}$ inducing shear stress-related endothelium/NO-mediated dilation. The observation of Bowman et al $(1994)^{5}$ that nebivolol induces limited vasodilation in hand veins is also not necessarily in disagreement with our observations in mouse aorta, because venous and arterial mechanisms of vasodilation are known to be different. ${ }^{22}$ However, the results of the present study do not exclude the possibility of local nebivololmetabolite production with subsequent NO release in the peripheral vasculature of the forearm.

The finding that metabolization of nebivolol provides a stimulatory ligand for vascular endothelial $\beta 2$-adrenergic receptors, which results in increased endothelial cell NO production in mice, may have several potential implications for the clinical use of this $\beta$-blocker, provided that the mechanism described is representative of the human situation. Beneficial effects of thirdgeneration $\beta$-blocking drugs in hypertension and heart failure have been demonstrated. ${ }^{23}$ It has been established that reduced bioavailability of vascular NO is a key factor in endothelial dysfunction associated with these disorders. ${ }^{8}$ The results of the present study indicate that selective 
$\beta 2$-adrenergic receptor-mediated increase of endothelial NO production might become an additional therapeutic target in disorders associated with endothelial dysfunction and with preserved $\beta$-receptor mediated NO-dependent vasodilation.

In conclusion, the findings of the present study indicate that metabolized nebivolol induces a $\beta 2$-adrenergic receptor-mediated rise in endothelial $\left[\mathrm{Ca}^{2+}\right]_{\mathrm{i}}$ and consequently, augmented NO production.

\section{Acknowledgments}

This study was supported by grants from the Cardiovascular Biology Foundation, the Netherlands. The authors are indebted to Jan Cornelissen and Irma Grabowsky for helpful ideas and to Sabrina van Velzen and Helen Steinbusch for technical assistance. The rat heart endothelial cells were a generous gift from Ger van der Vusse. 


\begin{tabular}{|c|c|c|c|c|c|c|}
\hline \multirow[b]{2}{*}{ Group } & \multicolumn{3}{|c|}{$340 / 380, \mathrm{~nm}$} & \multicolumn{3}{|c|}{$\left[\mathrm{Ca}^{2+}\right]_{i}, \mathrm{nmol} / \mathrm{L}$} \\
\hline & Baseline & Maximum & Persistent & Baseline & Maximum & Persistent \\
\hline $\begin{array}{l}\text { Nebiv./plasma } \\
(n=3)\end{array}$ & $\begin{array}{c}0.47 \\
( \pm 0.01)\end{array}$ & $\begin{array}{c}0.77 \\
( \pm 0.06)\end{array}$ & $\begin{array}{c}0.47 \\
( \pm 0.00)\end{array}$ & 45 & 175 & 45 \\
\hline $\begin{array}{l}\text { Nebiv. }{ }^{*} \\
(n=4)\end{array}$ & $\begin{array}{c}0.47 \\
( \pm 0.01)\end{array}$ & $\begin{array}{c}0.53 \\
( \pm 0.00)^{*}\end{array}$ & $\begin{array}{c}0.52 \\
( \pm 0.00)^{*}\end{array}$ & 45 & 69 & 65 \\
\hline $\begin{array}{l}\text { Nebiv. }{ }^{+} / \text {butox. } \\
(n=3)\end{array}$ & $\begin{array}{c}0.43 \\
( \pm 0.00)\end{array}$ & $\begin{array}{c}0.43 \\
( \pm 0.00)\end{array}$ & $\begin{array}{c}0.43 \\
( \pm 0.00)\end{array}$ & 30 & 30 & 30 \\
\hline $\begin{array}{l}\mathrm{ACh} \\
(n=6)\end{array}$ & $\begin{array}{c}0.43 \\
( \pm 0.00)\end{array}$ & $\begin{array}{c}0.71 \\
( \pm 0.02)\end{array}$ & $\begin{array}{c}0.59 \\
( \pm 0.02)\end{array}$ & 30 & 147 & 94 \\
\hline
\end{tabular}

$\left[\mathrm{Ca}^{2+}\right]_{\mathrm{i}}$ indicates average cytosolic free $\mathrm{Ca}^{2+}$ concentration changes in endothelium of mouse thoracic aorta; $340 / 380 \mathrm{~nm}$, fura 2 fluorescence ratio; Baseline, baseline values obtained over 300 seconds before drug administration; Maximum, maximal response to the applied substance; Persistent, a plateau lasting for $\geq 300$ seconds after addition of substances; $n$, number of mouse aorta segments. Nebiv.=nebivolol; plasma=plasma from noninjected mice; Nebiv. ${ }^{+}=$plasma from nebivolol-injected mice; butox.=butoxamine; $\mathrm{ACh}=$ acetylcholine.

${ }^{*} \mathrm{p}<0.05$, Nebiv. ${ }^{+}$compared with the other three groups. Data represent mean \pm standard error of the mean. 

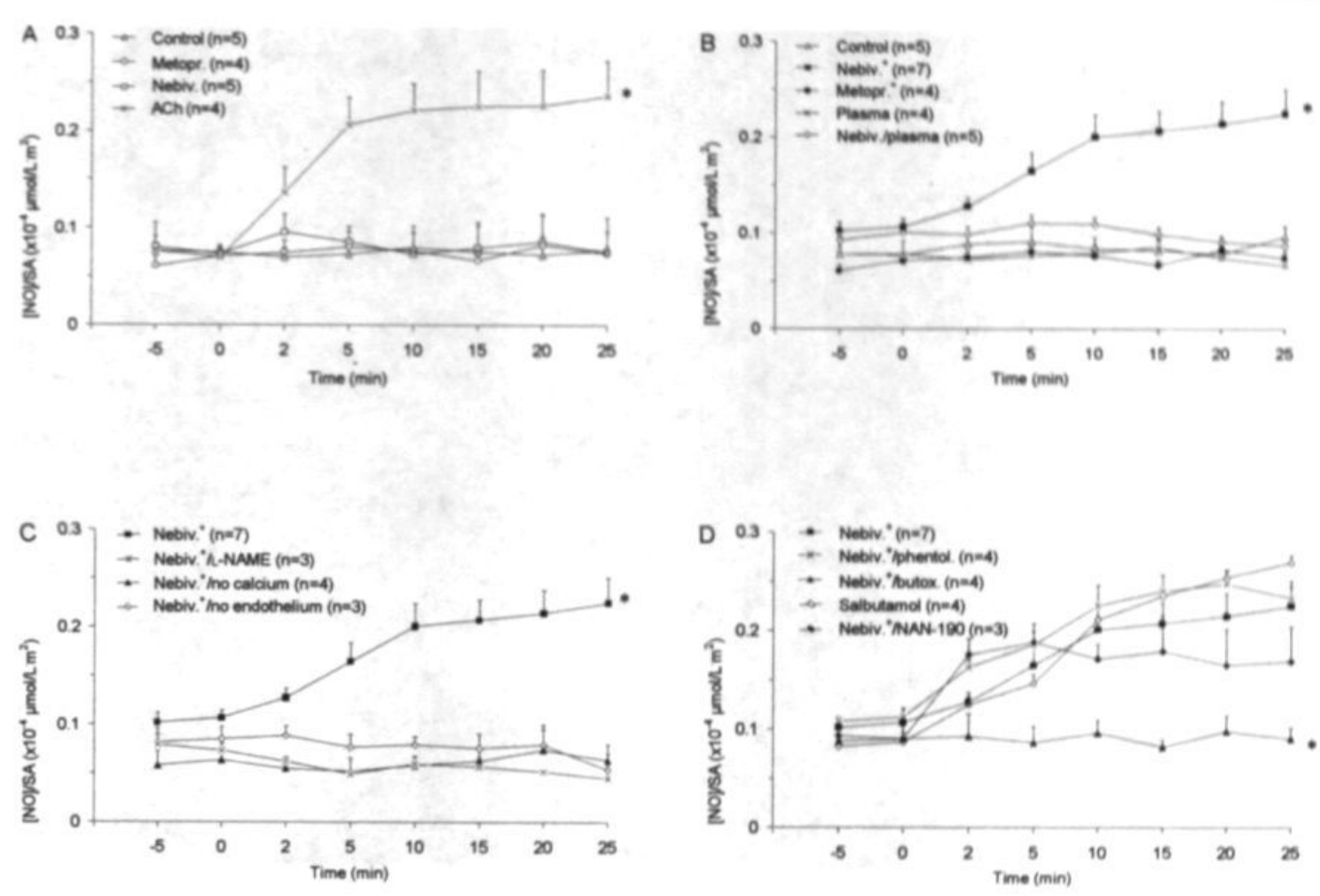

\section{Figure 1}

Effect on nitric oxide (NO) release from mouse aorta of nebivolol alone (panel A) or in vivo metabolized nebivolol (B): metoprolol was used as control $\beta 1$-adrenergic receptor blocker ( $\mathrm{A}$ and $\mathrm{B}$ ). Involvement of endothelium (A and $\mathrm{C}$ ), $\mathrm{Ca}{ }^{2+}$.

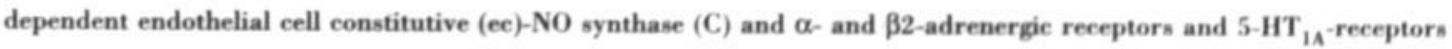
(D). Control indicates no drugs added; $n$, number of mouse aorta segments; [NO], NO concentration; SA, surface area. Substances added at $t=0$ minutes (concentrations represent final bath concentrations): Metopr. indicates metoprolol ( 1

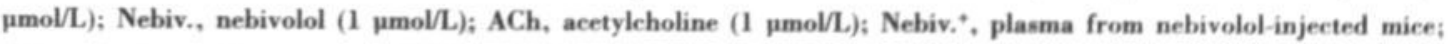
Metopr. ${ }^{*}$, plasma from metoprolol-injected mice; Plasma, plasma from noninjected mice; Nebiv./plasma, coadministration of nebivolol $(1 \mu \mathrm{mol} / \mathrm{L})$ and plasma; Nebiv. ${ }^{*} / \mathrm{L}-\mathrm{NAME}$, coadministration of Nebiv. ${ }^{*}$ and $N^{6}$-nitro-L-arginine methyl ester $(0.1 \mathrm{mmol} / \mathrm{L}) ;$ Nebiv. ${ }^{*}$ no calcium, Nebiv. ${ }^{*}$ in $\mathrm{CaCl}_{2}$-free organ bath solution; Nebiv. ${ }^{*} / \mathbf{n o}$ endothelium, Nebiv. ${ }^{*}$ added to endothelium-denuded aorta segments; Nebiv. $\%$ phentol., coadministration of phentolamine (10 $\mu$ mol/L) and Nebiv. ${ }^{*}$; Nebiv. ${ }^{+/ b u t o x ., ~ c o a d m i n i s t r a t i o n ~ o f ~ b u t o x a m i n e ~}(0.1 \mathrm{mmol} / \mathrm{L})$ and Nebiv. ${ }^{*}$; Salbutamol, salbutamol $(10 \mu \mathrm{mol} / \mathrm{L})$; Nebiv. ${ }^{*} / \mathrm{NAN}-190$, coadministration of NAN-190 (1 umoL/L) and Nebiv. ${ }^{*}$.

* p 0.05 compared with other lines in the figure. 


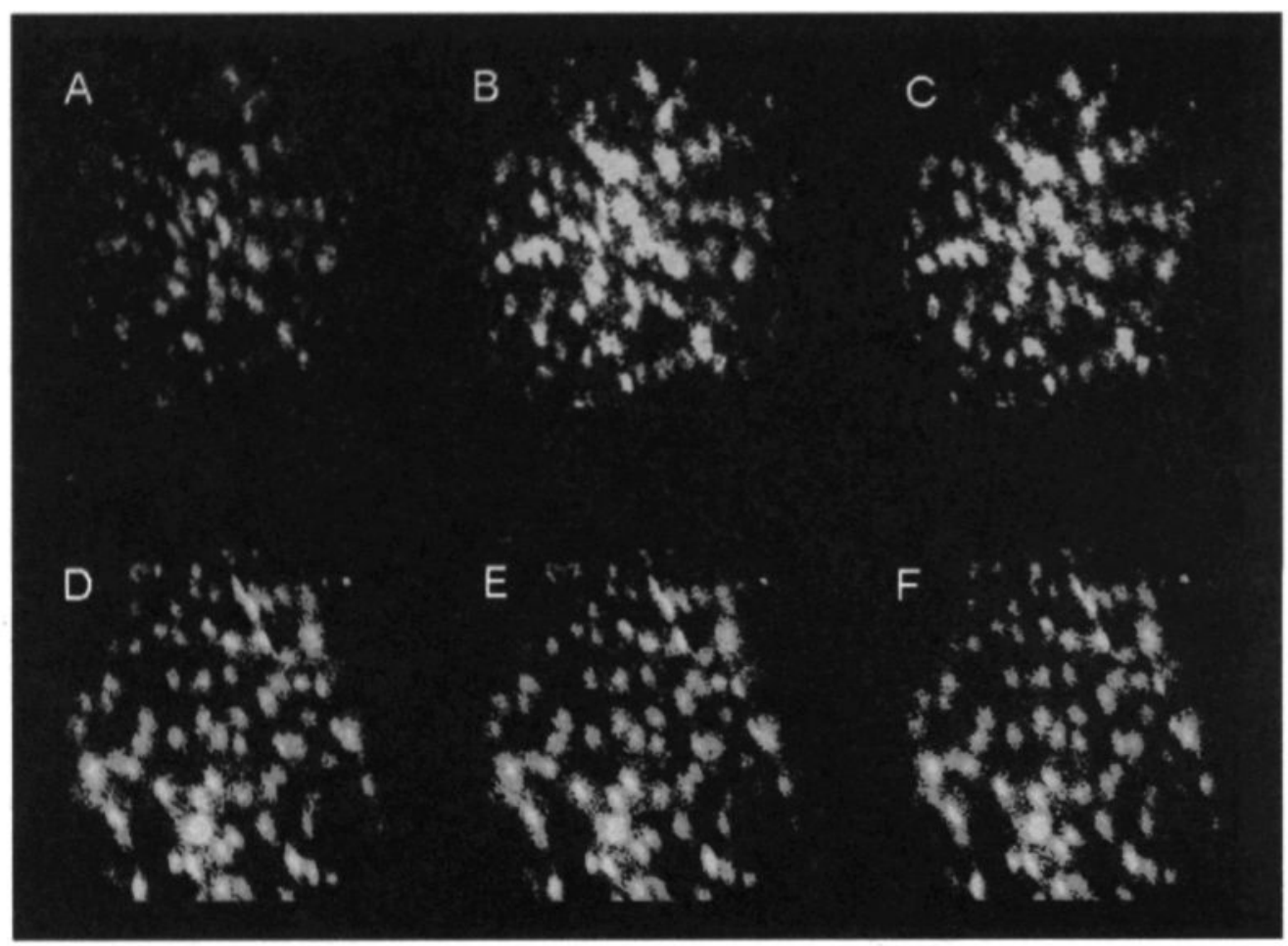

\section{Figure 2}

Examples of two representative experiments showing typical changes in cytosolic free $\mathrm{Ca}^{2+}$ concentration $\left(\left[\mathrm{Ca}^{2+}\right]_{i}\right)$ in mouse thoracic aorta endothelium as depicted by digital fluorescent microscopy using fluorescent $\mathrm{Ca}^{2+}$-probe fura 2-AM; 340/380 nm fura 2 ratio images are presented. Each image represents an area of $-200 \mathrm{X} 200 \mathrm{\mu m}$, in which individual endothelial cells can be identified. Every color corresponds with a certain $\left[\mathrm{Ca}^{2+}\right]_{\mathrm{i}}$, as indicated by the color bar (in $\mathrm{nmol} / \mathrm{L}$ ). Panel $\mathrm{A}$, (baseline) 300 seconds before administration of plasma. B and C, 60 and 300 seconds, respectively, after administration of plasma from a nebivolol-injected mouse. In this experiment, $\sim 95 \%$ of cells reacted (overall: 80 to $100 \%$ ). D, baseline of a butoxamine-pretreated (final bath concentration: $0.1 \mathrm{mmol} / \mathrm{L}$ ) aorta segment, 300 seconds before plasma administration. E and F, 60 and 300 seconds, after administration of plasma from a nebivolol-injected mouse.

Chapter 7 

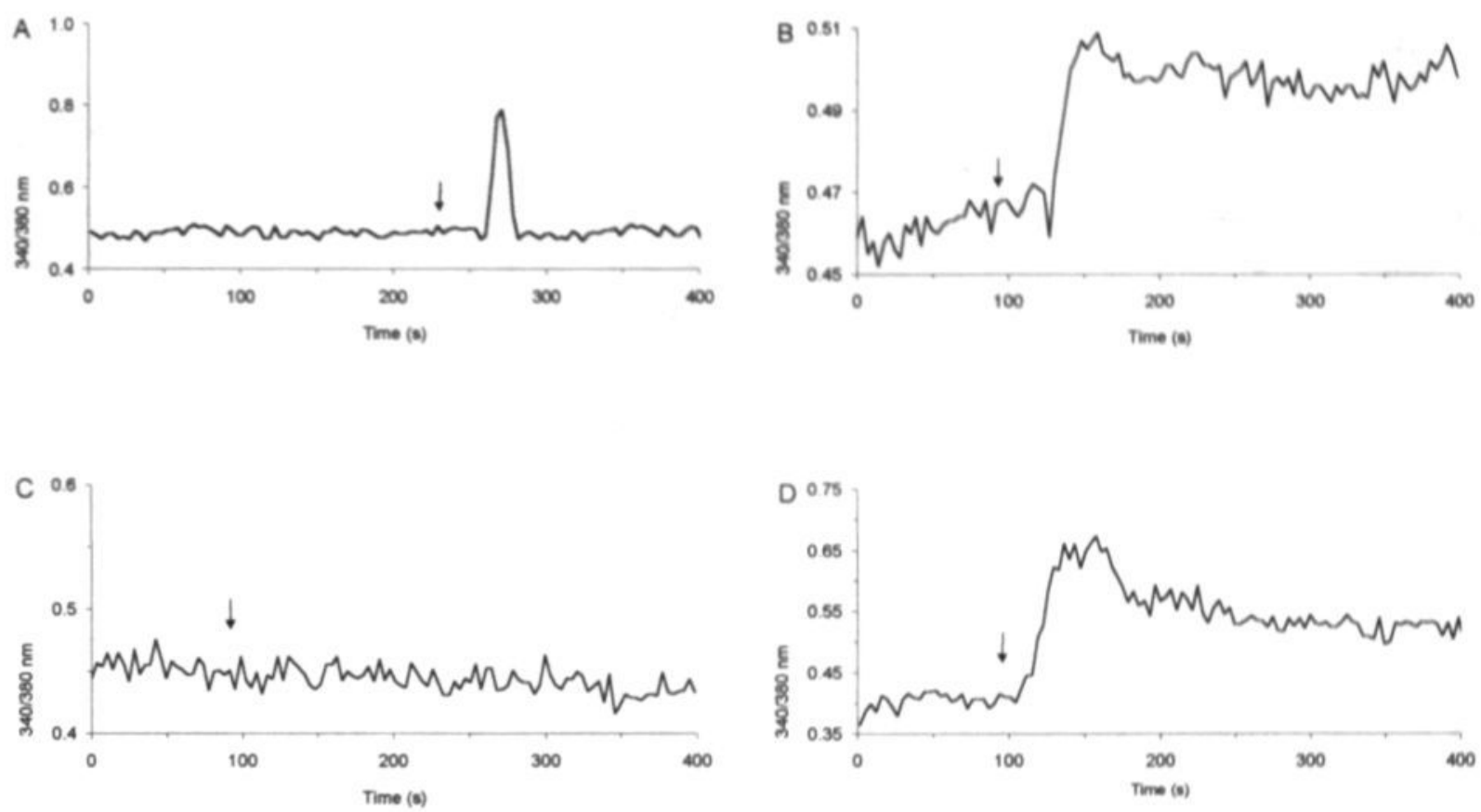

\section{Figure 3}

Cytosolic free $\mathrm{Ca}^{2+}$ concentration $\left(\left[\mathrm{Ca}^{2+}\right]_{i}\right)$ changes in mouse thoracie aorta endothelium. Typical changen in fura 2 ratios in single endothelial cells. Other cells in same segments showed similar responses. Substances used (with concentrations representing final bath concentrations): panel A, nebivolol ( 1 mmol/L) together with plasma from noninjected mice; B, plasma from nebivolol-injected mice; C, plasma from nebivolol-injected mice 300 seconds after pretreatment with butoxamine $(0.1 \mathrm{mmol} / \mathrm{L}) ; \mathrm{D}$, acetyleholine $(0.1 \mathrm{mmol} / \mathrm{L})$. Arrows indicate time of drug administration. $340 / 380 \mathrm{~nm}$ indicates fura 2 fluorescence ratio, proportional to $\left[\mathrm{Ca}^{2 \cdot}\right]_{i}$. 

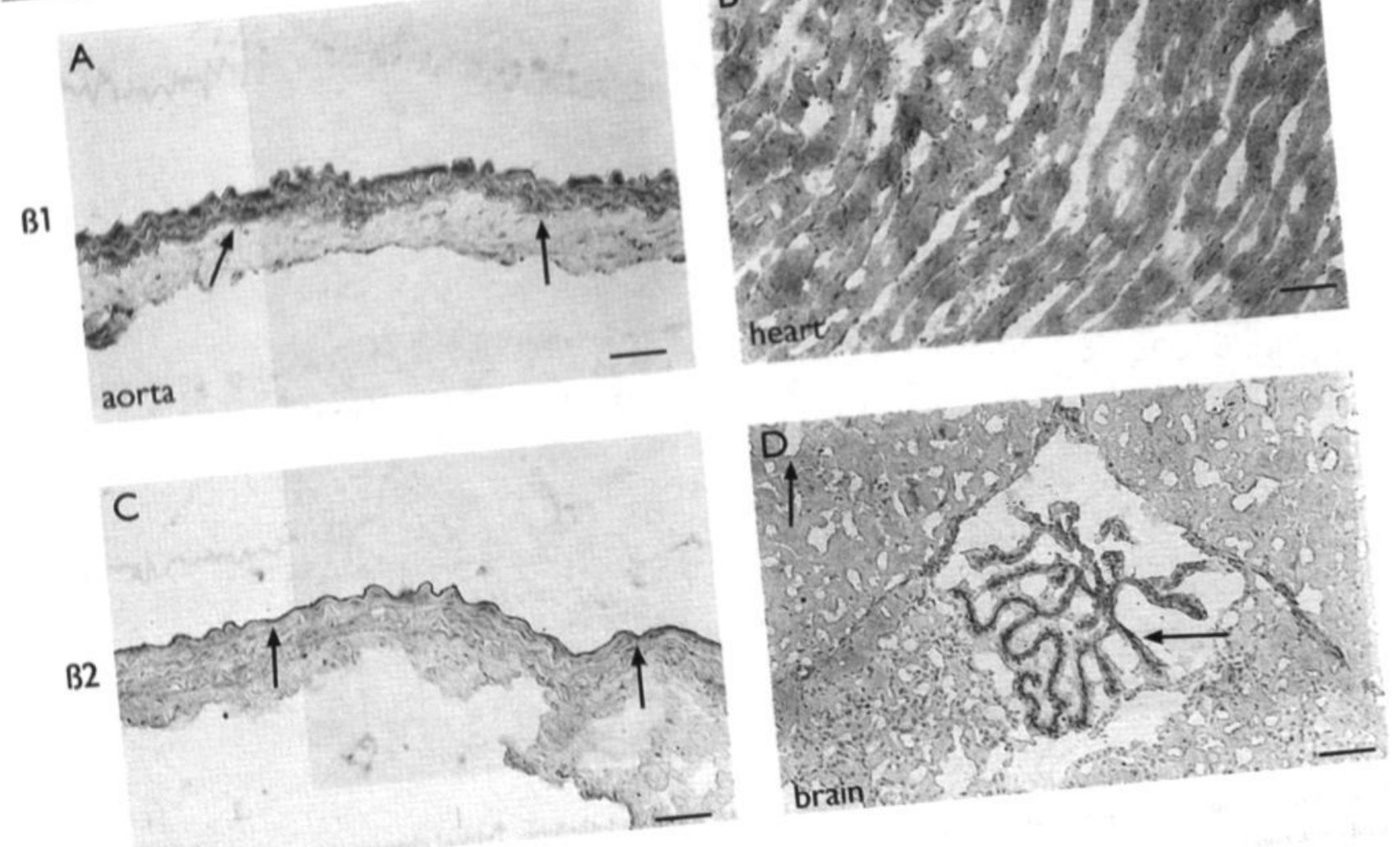

aorta

Figure 4

Expression of $\beta 1$ - and $\beta 2$-adrenergic receptors on mouse thoracic aoracells of mouse thoracic aorta; the mary antibody used. Panel A, $\beta 1$-Adrenergic receptors on stentriele. arrow indicates external elastic lamina. $B$, $\beta 1$ end mouse thoracic aorta: the arrow indicates internal elastic C, $\beta 2$-adrenergic receptors on endothelial cells of lamina. D, $\beta 2$-adrenergic receptors in 


\section{CBB Staining}

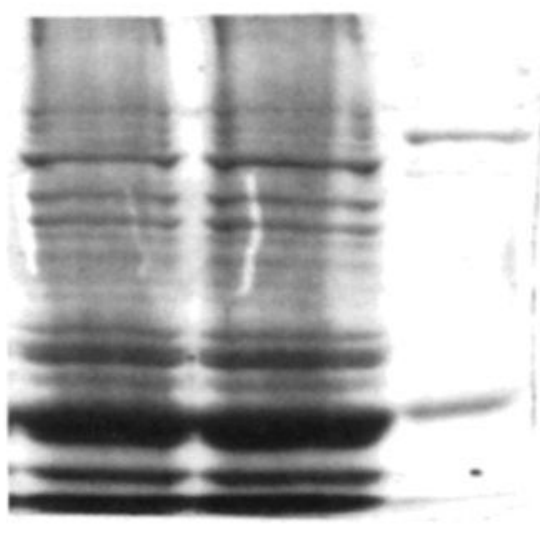

\section{Western analysis}

\author{
$17 \mathrm{kD}$ \\ $\leftarrow 66 \mathrm{kD}$
}

$45 \mathrm{kD}$ $\leftarrow B 1,60 \mathrm{kD}$

B2, $52 \mathrm{kD}$

\section{SMC EC}

Figure 5

Western blot analysis showing expression of $\beta 1$ - and $\beta 2$-adrenergic receptor protein $(\beta 1, \beta 2)$ in cultured mouse thoracic aorta smooth muscle cells (SMC) and cultured rat heart endothelial cells (EC). Rabbit polyclonal anti-mouse $\beta 1$ - or $\beta 2$-adrenergic receptor antibodies, eross-reactive with rat, were used. CBB indicaten Coomassie Brilliant Blue. 


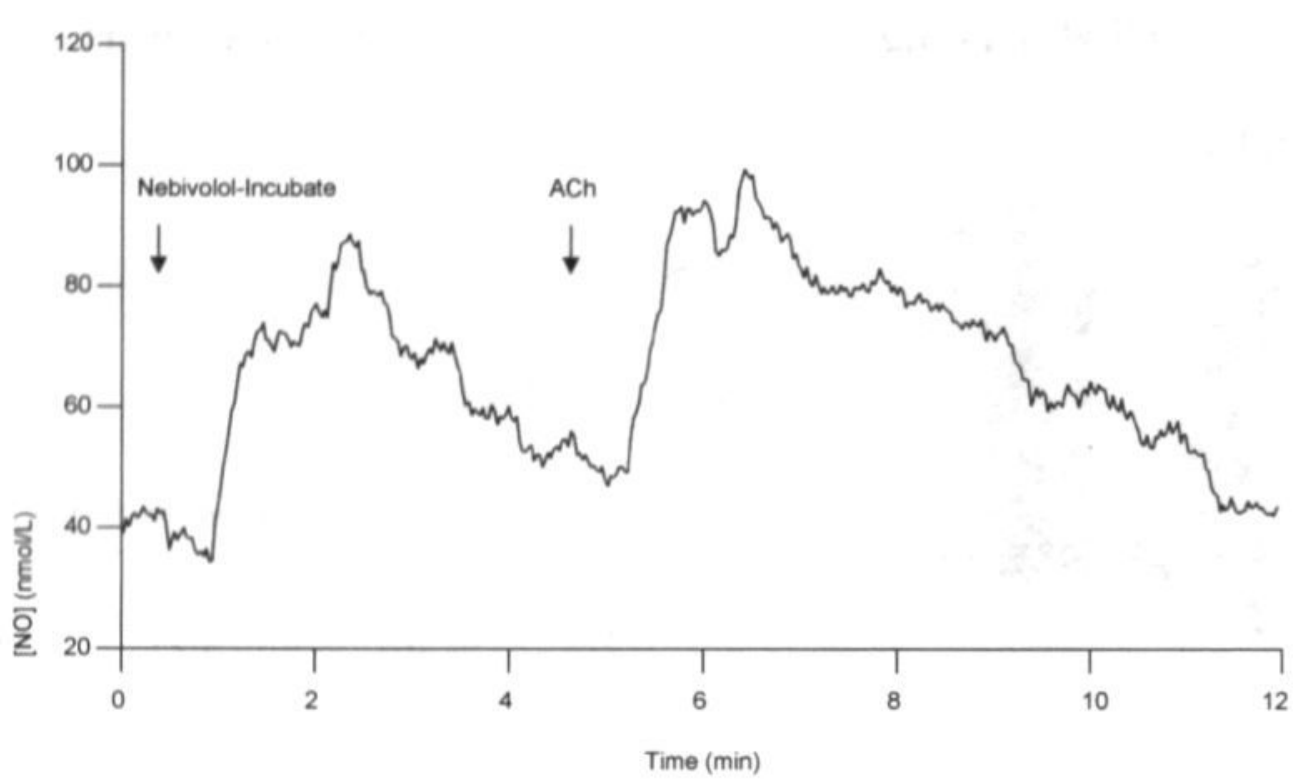

Figure 6

Effect of nebivolol (50/50; $0.5 \mathrm{mg} / \mathrm{mL}$ ) incubated for 45 minutes ("Nebivolol-Incubate") with mouse hepatic microsomes on nitric oxide (NO) release from cultured rat heart endothelial cells. [NO]: NO concentration; ACh: acetyleholine (final bath concentration: $0.1 \mathrm{mmol} / \mathrm{L}$ ). 


\section{References}

1. Goldstein S. Beta-blocking drugs and coronary heart disease. Cardiovase Drugs Ther. 1997:11(suppl 1):219-225.

2. Heidenreich PA. Lee TT, Massie BM. Effect of beta-blockade on mortality in patients with heart failure: a meta-analysis of randomized elinical trials. J Am Coll Cardiol. 1997;30:27-34.

3. Prichard BN, Tomlinson B. The additional properties of beta-adrenoceptor blocking drugs. J Cardiovase Pharmacol. 1986;8(suppl 4):S1-\$15.

4. Van de Water A. Janssens W, Van Nueten J, Xhonneux R, De Cree J, Verhaegen H, Reneman RS, Janssen PA. Pharmacological and hemodynamic profile of nebivolol, a chemically novel, potent, and selective beta 1-adrenergie antagonist. J Cardiovase Pharmacol. 1988:11:552-563.

5. Bowman AJ, Chen CP, Ford GA. Nitrie oxide mediated venodilator effeets of nebivolol. Br J Clin Pharmacol. 1994:38: 199-204.

6. Cockeroft JR, Chowienczyk PJ, Brett SE, Chen CP, Dupont AG, Van Nueten L, Wooding SJ, Ritter JM. Nebivolol vasodilates human forearm vaseulature: evidence for an L-arginine/NO-dependent mechanism. J Pharmacol Exp Ther. 1995:274:1067-1071.

7. Moncada S, Palmer RMJ, Higgs EA. Nitric oxide: physiology, pathophysiology, and pharmacology. Pharmacol Rev. 1991:43:109-142.

8. Cardillo C, Kilcoyne CM, Quyyumi AA, Cannon III RO, Panza JA. Selective defect in nitrie oxide synthesis may explain the impaired endothelium-dependent vasodilation in patients with essential hypertension. Circulation. 1998:97:851-856.

9. Ming $\mathbf{Z}$, Parent R, Lavallee M. $\beta 2$-Adrenergic dilation of resistance coronary vessels involves $K_{A T P}$ channels and nitric oxide in conscious dogs. Circulation. 1997;95:1568-1576.

10. Kakoki M, Hirata Y, Hayakawa H, Nishimatsu H, Suzuki Y, Nagata D, Suzuki E, Kikuchi K, Nagano T, Omata M. Effects of vasodilatory $\beta$-adrenoceptor antagonists on endothelium-derived nitric oxide release in rat kidney. Hypertension. 1999;33:467-471.

11. Van der Zee R, Murohara T, Luo Z, Zollmann F, Passeri J, Lekutat C, Isner JM. Vascular endothelial growth factor/vaseular permeability factor augments nitric oxide release from quiescent rabbit and human vascular endothelium. Circulation. 1997;95:1030-1037.

12. Raat NJ. Wetzels GE, De Mey JG. Calcium-contraction relationship in rat mesenteric arterial smooth muscle. Effects of exogenous and neurogenic noradrenaline. Pfliigers Arch. 1998:436:262. 269.

13. Grynkiewicz G. Poenie M. Tsien RY. A new generation of $\mathrm{Ca}^{2 *}$ indicatorn with greatly improved fluorescence properties. J Biol Chem. 1985;260:3440-3450.

14. Linssen MCJG, van Nieuwenhoven FA, Duijvestijn AM, Glatz JFC, van der Vusse GJ. Continuous endothelial cell lines from adult rat heart. In Vitro Cell Dev Biol Anim. 1993;29A:611-613. 
15. Dawes M, Chowienczyk PJ, Ritter JM. Effects of inhibition of the L-arginine/nitric oxide pathway on vasodilation caused by $\beta$-adrenergic agonists in human forearm. Circulation. 1997;95:2293-2297.

16. Costain DW, Green AR. Beta-adrenoceptor antagonists inhibit the behavioural responses of rats to increased brain 5-hydroxytryptamine. Br J Pharmacol. 1978;64:193-200.

17. Janssens WJ, Xhonneux R, Janssen PAJ. Animal pharmacology of nebivolol. Drug Investigation. $1991 ; 3: 13-24$.

18. Gao YS, Nagao T, Bond RA, Janssens WJ, Vanhoutte PM. Nebivolol induces endothelium-dependent relaxations of canine coronary arteries. J Cardiovasc Pharmacol. 1991;17:964-969.

19. Jörgensen H, Knigge U, Kjaer A, Warberg J. Adrenocorticotropic hormone secretion in rats induced by stimulation with serotonergie compounds. J Neuroendocrinol. 1999;11:283-290.

20. Ferro A, Queen LR, Priest RM, Xu B, Ritter JM, Poston L, Ward JP. Activation of nitric oxide synthase by beta 2 -adrenoceptors in human umbilical vein endothelium in vitro. $\mathrm{Br} J$ Pharmacol. $1999 ; 126: 1872-1880$.

21. Dolor RJ, Hurwitz LM, Mirza Z, Strauss HC, Whorton AR. Regulation of extracellular calcium entry in endothelial cells: role of intracellular calcium pool. Am J Physiol. 1992;262:C171-C181.

22. Chalon S, Tejura B, Moreno H, Jr., Urae A, Blaschke TF, Hoffman BB. Role of nitric oxide in isoprenaline and sodium nitroprusside-induced relaxation in human hand veins. Br J Clin Pharmacol. 1999;47:91-98.

23. Ruffolo RR, Feuerstein GZ, Ohlstein EH. Recent observations with beta-adrenoceptor blockade: beneficial effects in hypertension and heart failure. Am J Hypertens. 1998;11:S9-S14. 
Chapter 8

\section{General Discussion}


Well known vascular phenomena in which nitric oxide (NO) is involved include stimulation of vascular relaxation, ${ }^{1,2}$ inhibition of platelet adhesion and aggregation ${ }^{3-5}$ and inhibition of vascular smooth muscle cell mitogenesis. ${ }^{6}$ In many cardiovascular diseases, the bioavailability of nitric oxide (NO) is decreased, which may contribute to vasospasm, thrombus formation and intimal thickening, ultimately leading to ischemia and infarction. Prevention of identified predisposing conditions is crucial. Therefore, the studies described in this thesis were performed to obtain more knowledge of the production and function of NO with special emphasis on its antithromboembolic activity. Both aspects were investigated in the arterial as well as the venous part of the circulation, because many studies indicate significant functional differences between the walls of arteries and veins, ${ }^{7-9}$ and of arterioles and venules. ${ }^{10-15}$ The obtained insights into production and function of NO enhance our understanding of the complex multifactorial origin of thromboembolic processes and intimal thickening in the arterial and venous system.

\section{Function of nitric oxide}

Substances produced and released by the vessel wall either counteract thrombus formation or promote it (ie, anti- and prothrombotic properties, respectively). Under normal conditions, the vessel wall is thromboresistant through antithrombotic activities. Injury of the wall, however, induces an increased expression of prothrombotic factors, while antithrombotic factors may be depressed. Such anti- and prothrombotic factors not only originate from the vessel wall, but also from the platelets themselves, other blood cells or blood plasma. Studies performed in vitro lack the contribution of natural microenvironmental factors and, therefore, may easily introduce artifacts. Hence, in addition to in vitro studies the processes of thrombosis and hemostasis have to be investigated in vivo to be able to assess the role of such mediators as NO in physiological conditions or under pathophysiological circumstances.

In our in vivo rabbit model, ${ }^{10}$ a platelet thrombus forms immediately after injury of the microvascular wall, thereby plugging the hole and covering the exposed subendothelial layers. Under control conditions growth rate, height and shape of this thrombus is similar in arterioles and venules. ${ }^{10,11,16-18}$ In most vessels, circulating platelets are activated and adhere to this stationary thrombus. They form a loosely packed platelet mass on the downstream side of the thrombus, often without loosing their shape and without a pronounced release reaction. ${ }^{19}$ From time to time these platelet aggregates break loose and are swept away with the blood stream; this process is called embolization. After a certain period of time embolization stops, while the thrombus remains at the site of injury. The activation of platelets during this thromboembolic process has to be the consequence of the local dominance of stimulating over inhibiting factors, while the inhibiting factors must prevail from the moment the thromboembolic reaction stops. In this model, the total duration of embolization (ie, the time from vessel wall injury to breaking off of 
the last embolus) appears to be two to eight times longer in arterioles than in venules, ${ }^{10,11,16-18}$ This difference cannot be explained by fluid dynamic factors or by the different blood gas and pH values in these vessel types. ${ }^{20,21}$ Functional differences in anti- and prothrombotic properties of the vessel wall may be responsible for the difference in thromboembolic reaction in these vessels.

Both platelet activating and inhibiting prostaglandins (for example, thromboxane $\mathrm{A}_{2}$ $\left[\mathrm{TX}_{2}\right]$ and prostacyclin $\left[\mathrm{PGI}_{2}\right]$ ) play a more important role in thromboembolism in arterioles than in venules. This suggests a difference in prostaglandin synthetic capacity between arteriolar and venular endothelium. " The difference in embolization between arterioles and venules, however, cannot be explained by the different role of prostaglandins in these vessels. A possible other candidate is NO. Therefore, in three studies presented in this thesis (Chapter 3-5) the role of endogenous $\mathrm{NO}$ in inhibiting thromboembolism in microvessels was investigated, using our in vivo rabbit model. ${ }^{16-18}$

The rabbit mesentery, is well suited to investigate platelet-vessel wall interactions. It can be exposed without extensive surgical interventions and it is thin and translucent, allowing observation under transillumination which provides microscopic images with high contrast. An additional advantage of the mesentery with regard to the present studies is the low vasoactivity of its microvessels. No vasoconstriction occurs following puncture. Therefore, bleeding has to be stopped by platelet-vessel wall interactions alone. In addition, because mesenterie microvessels do not react with diameter variations to exogenously added vasodilators (such as sodium nitroprusside, L-arginine and prostacyclin) or vasoconstrictors (such as the $N O$ synthase inhibitor $N^{6}$. nitro-L-arginine and high doses of aspirin), involvement of $\mathrm{NO}$ and prostaglandins in the thromboembolic reaction can be studied without interfering changes in fluid dynamic conditions. ${ }^{11,16 .}$ 18,22

The aim of the study presented in Chapter 3 was to investigate in vivo the role of NO in plateletvessel wall interactions in arterioles and venules of the same tissue. ${ }^{16} \mathrm{NO}$ appeared to be more important in protecting against thromboembolism in venules than in arterioles. Because fluid dynamic effects of NO, if any, could have influenced the platelet-vessel wall interactions, their role was investigated as well. It appeared that no differences in any of the fluid dynamic parameters were found between the control group and the group in which nitrie oxide synthase (NOS) was inhibited by L-NA ( $N^{G}$-nitro-L-arginine). Therefore, the effect of $\mathrm{L}-\mathrm{NA}$ on embolization in venules cannot be explained by differences in wall shear rate.

The absence of an effect of excess $\mathrm{L}$-arginine, the active precursor of endogenous NO synthesis, on thromboembolism in venules (Chapter 5$)^{18}$ indicates that the basal level of NO synthesis after vessel wall injury is already maximal in these vessels so that the low number of emboli 
produced under control conditions cannot be reduced further by stimulation of NO synthesis. The more important role of $\mathrm{NO}$ in venules than in arterioles cannot be explained by a higher capacity for NO synthesis in venules, as compared to arterioles, because the expression of endothelial NOS was similar in both vessel types (Chapter3). ${ }^{16}$ A lower bioavailability of NO in arterioles is another possible explanation, which may be due to the scavenging effect of superoxides; at least in rats, superoxides are generated in higher quantities in mesenteric arterioles than in venules. ${ }^{23}$

An interesting additional finding of the study presented in Chapter 3 was that NOS inhibition with L-NA abolished the difference in duration of embolization between arterioles and venules. ${ }^{16}$ Thus, the more important functional role of $\mathrm{NO}$ in venules, as compared to arterioles, provides a possible explanation for the difference in thromboembolic reaction normally found between the two vessel types.

Whereas, vascular nitric oxide appears to be more important as an antithromboembolic factor in venules than in arterioles, ${ }^{16}$ vascular prostaglandins $\left(\mathrm{eg}, \mathrm{PGI}_{2}\right)$ are more important inhibitors of thromboembolism in arterioles than in venules. ${ }^{11}$ However, at a site of wall injury antithrombotic endothelium-derived mediators (eg, $\mathrm{PGI}_{2}$ and $\mathrm{NO}$ ) are probably produced simultaneously and activated platelets are likely to be exposed to a combination of both. This combination may exert a more pronounced antithrombotic effect than expected on the basis of their individual antithrombotic effects, because in vitro studies have shown that $\mathrm{PGI}_{2}$ and $\mathrm{NO}$ released by cultured endothelial cells can act synergistically in the inhibition of platelet aggregation. ${ }^{4}$ It is unknown, however, whether such a synergistic interaction is also effective in vivo and whether this interaction, if any, differs between vessel types. Hence, this question was dealt with in Chapter 4 of this thesis. ${ }^{17}$

The experiments described in Chapter 4 showed that combined actions of NO and prostaglandins inhibit thromboembolism in a synergistic manner in arterioles. ${ }^{17}$ No such synergistic effect was found in venules. Taken together, in arterioles the antithromboembolic effect of endogenous $\mathrm{NO}$ alone is negligible, but its effect is pronounced in the presence of endogenous prostaglandins, provided that sufficient $\mathrm{NO}$ is available to activate the arachidonic acid/prostaglandin pathway.

In addition, it can be concluded from the data presented in Chapter 4 that $\mathrm{NO}$ and prostaglandins play an important role in counteracting wall shear rate-enhanced platelet activation involved in thromboembolism in arterioles. ${ }^{17}$ In venules other antithromboembolic substances are likely to oppose such wall shear rate-enhanced platelet activation. In rat mesenteric resistance arterioles in vivo it was demonstrated by Bohlen and Nase that $60-80 \%$ of the resting NO concentration depends on flow-mediated mechanisms. ${ }^{24}$ Possibly, NO production in 
arterioles is relatively more shear-mediated, thereby protecting these vessels to the relatively high shear rates these resistance vessels are exposed to.

Hypercholesterolemia is an important risk factor for atheroselerosis, which affects the arterial system and may ultimately lead to ischemia and infaretion. Most of these disorders result from thromboembolic processes at the site of the lesion. ${ }^{25}$ The vascular lesion plays an important role in these processes, ${ }^{25,26}$ but the role of hypercholesterolemia, as such, in thromboembolie events is less clear. Besides, the mediators involved in hypercholesterolemia-related thromboembolic events are, as yet, not well known.

In our study described in Chapter 5, in which our nonatherosclerotic in vivo rabbit model was used, evidence was provided for a pronounced stimulating effect of diet-induced hypercholesterolemia on thrombus formation and subsequent embolization in arterioles, but not in venules. ${ }^{18}$ These effects of hypercholesterolemia on arteriolar embolization, but not on thrombus formation, could be completely reversed by stimulation of endogenous NO synthesis with excess L-arginine. The observation that the increase in total plasma cholesterol mainly results from an increase in low-density lipoprotein (LDL) cholesterol suggests that the observed effects of high-cholesterol diet on arteriolar thromboembolism are caused by native LDL and/or ox-LDL (oxidized-LDL) cholesterol, changing the (anti)thrombogenic properties of the arteriolar wall. The effect of hypercholesterolemia on arteriolar thrombus formation is intriguing because blocking NO synthesis (Chapter 3 and 4), ${ }^{16,17}$ prostaglandin synthesis (Chapter 4), ${ }^{11,17}$ or both NO and prostglandin synthesis (Chapter 4) ${ }^{17}$ does not affect thrombus height. In vitro, elevated concentrations of LDL/ox-LDL cholesterol sensitize platelets to thrombin activation. ${ }^{27-29}$ In our rabbit model thrombin very likely plays a role in thrombus formation, but not during embolization. ${ }^{30}$ Most likely, combined effects of LDL/oxLDL cholesterol and thrombin enhance platelet thrombus formation at the site of arteriolar wall injury.

Under control conditions thromboembolism stopped within 600 seconds after vessel wall injury in more than $95 \%$ of the arterioles and venules studied (Chapters $3-5$ ). ${ }^{16-18}$ However, when both prostaglandin and NO synthesis were blocked, embolization did not stop in $70 \%$ of the arterioles during the remainder of the experiment (ie, 30 minutes to 3 hours; Chapter 4). ${ }^{17}$ Diet-induced hypercholesterolemia had a similar dramatic effect on thromboemboembolism in arterioles ("ongoing thromboembolism" in $58 \%$ of arterioles; Chapter 5). ${ }^{18}$ Because in arterioles the effects of hypercholesterolemia and combined prostaglandin/NO inhibition on thromboembolism are similar, loss of NO/prostaglandin synergism may be involved in the hypercholesterolemia-enhanced thromboembolism. 
Although inhibition of NO synthesis led to marked prolongation of the duration of embolization in venules, embolization stopped in the vast majority of injured venules in this group within 600 seconds after puncture (in more than 95\% of venules; Chapter 3-4). ${ }^{16,17}$ Apparently, NO is an important factor reducing thromboembolism in venules and, together with platelet-inhibiting prostaglandins, also in arterioles. An additional possibility is that in arterioles, unlike in venules, the balance between antithromboembolic and prothromboembolic properties of the wall is more towards as-yet-unidentified prothromboembolic factors (eg, adenosine diphosphate [ADP], tissue factor).

In contrast to the consistently found difference in embolization duration between arterioles and venules, the rate of embolus production, ie the median time period per embolus to be produced, as well as the size of the thrombus and emboli ${ }^{19}$ were always similar in both vessel types (Chapter 3-5). ${ }^{16-18}$ The latter findings indicate that after vessel wall injury the number of platelets activated per unit of time is similar in arterioles and venules, but that this activation continues during a longer period of time in arterioles. Again, this indicates that in arterioles the balance between pro- and antithrombotic factors seems to be in favor of the prothrombotic factors for a longer period of time than in venules. During the period of embolization the net quantitative difference between pro- and antithrombotic contributions may be equal in arterioles and venules.

A possible candidate for such a specific arteriolar prothrombotic activity could be tissue factor and consecutively formed thrombin. A low dose of tissue factor was shown to be expressed differently between endothelial cells form different sources ${ }^{31}$ Under elevated static pressure conditions in vitro, tissue factor was found to be more intensely expressed in human aortic endothelial cells than in human caval vein endothelial cells. ${ }^{32}$ Furthermore, selective inhibition of tissue factor results in $\mathbf{7 8 \%}$ reduction in so-called cyclic flow variations due to thromboembolism after mechanical damage to the subendothelium of a moderately stenosed rabbit carotid artery. ${ }^{33}$ Although no selective inhibition of tissue factor has been used in our model, previously we showed that low molecular weight heparin treatment influenced thrombus formation in arterioles, but not in venules, ${ }^{30}$ indicating that after vessel wall injury arterioles express tissue factor to a greater extent than venules. Therefore, the role of tissue factor in our model should be studied in the near future.

In view of the ultrastructural appearance of the embolizing part of the thrombus, ${ }^{19}$ being a loosely packed mass of discoid platelets which still contain most of their secretory vesicles, it is likely that one or more "weak" platelet activating substances, like ADP, play an important role in platelet activation during the embolization period. Therefore, ADP is another likely candidate. Arteriovenous differences in blood platelet clumping by ADP have been known for quite some time ${ }^{34}$ ADP-induced aggregation in arterioles and venules was previously studied in other 
in vivo thombosis models. ${ }^{35,36}$ The difference in embolization activity between arterioles and venules in our model might be related to a different availability of ADP at the site of vessel wall injury in both vessel types. This might be caused by different adenosine triphosphate (ATP)/ADP contents of vascular cells or different amounts or activity rates of ectonucleotidases, which degrade ATP or ADP, on the luminal side of the endothelial cells. Therefore, in a future study it would be most interesting to study the role of ADP in thromboembolism in these two vessel types.

Findings of a study from our group suggest that prostaglandins other than $\mathrm{TXA}_{2}$, produced by activated platelets and/or damaged vascular cells, diminish leukocyte rolling from upstream to downstream of the venular thrombus (median decrease, $45 \%$ ). ${ }^{37}$ On the other hand, it has been proposed that in venules with a low number of rolling leukocytes the number of emboli produced was similar to the number of emboli produced in arterioles. ${ }^{38}$ Therefore, the exclusive presence of rolling leukocytes in venules, but not in arterioles, may offer an alternative explanation for the difference in thromboembolism between the two vessel types, either through a direet interaction between leukocytes and platelets or indirectly through involvement of vascular cells. In vitro studies have provided additional information on the possible pathways of these interactions and their relevance for thrombotic and atherosclerotic disease (for reviews on this subject the reader is referred to the cited literature). ${ }^{25,39-41}$ In a small set of control venules from the study presented in Chapter 3 the number of rolling leukocytes, counted following puncture in a segment about 10 to $50 \mathrm{\mu m}$ upstream of the thrombus, was not different from the number counted in venules after inhibition of NOS with L-NA. ${ }^{16}$ At the very least this suggests that rolling leukocytes probably play an inferior role, if any, in the explanation for the difference in thromboembolism between arterioles and venules. However, this was not the aim of this thesis and therefore in future studies this subject might be specifically addressed.

In conclusion, the studies in the first part of this thesis clearly indicate that NO is prominently involved in the protection against thromboembolism in venules. This more important functional role of endogenous NO in venules than in arterioles provides an explanation for the difference in thromboembolism normally found between the two vessel types. Other antithrombotic properties of the venular wall or alternative possible explanations for the difference, such as a more prominant role of as yet to be identified prothrombotic factors in arterioles and/or the role of leukocyte-vessel wall interactions in venules, remain to be tested. Secondly, it was shown that in arterioles, but not in venules, endogenous $\mathrm{NO}$ and prostaglandins synergistically counteract ongoing thromboembolism after vessel wall injury and that the combination of endogenous NO and prostaglandins appears to protect against enhancement of arteriolar thromboembolism by wall shear rate. Finally, we showed that hypercholesterolemia selectively enhances thrombus formation and thromboembolization in arterioles, but not in venules. Stimulation of endogenous NO 
production with L-arginine reverses the dramatic effect of hypercholesterolemia on thromboembolism. It was concluded that in arterioles hypercholesterolemia has an impairing effect on the L-arginine/NO system and/or NO/prostaglandin synergism. Very likely, combined actions of cholesterol and thrombin enhance platelet thrombus formation at the site of arteriolar wall injury.

\section{Production of nitric oxide}

In the second part of this thesis two studies are described to obtain more insight into mechanisms involved in agonist-induced NO production in arteries and veins of mice and men (Chapter 6 and 7). ${ }^{42,43}$ These studies were performed on isolated vascular segments.

Graft failure is one of the major causes of recurrent angina after coronary artery bypass grafting. The internal mammary artery (IMA) has been shown to have a much better long-term patency rate than the saphenous vein (SV) when used as a conduit for coronary artery bypass. ${ }^{4}$ Intimal thickening is an important cause of late coronary vein graft occlusion. ${ }^{45}$ Because NO has been reported to reduce vascular smooth muscle cell mitogenesis, ${ }^{6}$ a process known to contribute to intimal thickening, it is conceivable that a difference in NO production between arteries and veins may contribute to this phenomenon. ${ }^{46,47}$ Vascular endothelial growth factor (VEGF) is an endothelial cell mitogen. This feature is considered central to the documented role of VEGF in promoting angiogenesis. More recent evidence suggests that VEGF may also serve a "maintenance" function, modulating various aspects of endothelial cell biology. A greater stimulating effect of VEGF on NO production in arteries than in veins could contribute to the difference in long-term patency rate. ${ }^{9}$ To investigate whether the superior long-term patency in human coronary bypass grafting of IMA compared to SV could be explained by different levels of NO production, in Chapter 6 basal and VEGF-stimulated NO release from isolated segments of human IMA and SV was studied. ${ }^{42}$

The baseline endogenous NO production was $50 \%$ higher in IMA than in SV. Stimulation of endogenous NO production with excess L-arginine resulted in a 2 -fold increase of baseline NO production in IMA and in a 1.5 -fold increase in SV. The enhanced $\mathrm{L}$-arginine induced release of NO in both IMA and SV indicated that these vessels are able to produce more NO when stimulated, but it cannot explain the difference in baseline NO release between this artery and this vein. Stimulation of vascular segments with VEGF augmented endothelium-, ec-NOS- (endothelial cell type NOS) and calcium-dependent NO release more pronouncedly in IMA (2-fold) than in SV (1.5-fold). The expression of ec-NOS was equal in IMA and SV; i-NOS (inducible type NOS) could not be detected. Therefore, differences in NO production between IMA and SV are not caused by a higher vascular expression of NOS. From the study it was concluded that the higher VEGF-receptor density in IMA, as previously reported, ${ }^{48}$ and/or a possibly more efficient 
VEGF/NO transduction pathway in IMA explain(s) the superior VEGF-stimulated and basal NO production in IMA. These properties of IMA may provide a possible explanation for the better long-term patency of IMA compared with SV.

The increased NO release following exogenous VEGF administration demonstrated that VEGF-receptors are functional in both human IMA and SV. Taking together that VEGF itself is expressed in adult vascular smooth muscle cells of both human IMA and SV, ${ }^{48}$ and that it may traffie to the adjacent endothelium and ligate endothelial VEGF-receptors, it is conceivable that in healthy, mature vessels the biological function of this growth factor is not limited to angiogenesis. Preservation of an intact barrier between circulating blood and the vessel wall constitutes a critical condition for normal vessel behavior. Throughout life blood vessels are often exposed to cytokines, proteases, oxidative stress and other factors that may damage endothelial cells or impair their function. Under such circumstances VEGF-augmented NO production may be required for recurrent repair of damaged or dysfunctional endothelium, thus protecting the vessel from thrombotic events, excessive leukocyte adhesion and/or vasospasm. In addition, intact endothelial NO production is mandatory to inhibit medial smooth muscle cell proliferation. ${ }^{6,49}$ This feature is relevant to the preservation of vascular patency as well, since migration of proliferating medial smooth muscle cells has been shown to contribute to the occurrence of intimal thickening in coronary bypass grafts and native coronary arteries. Therefore, in mature vessels VEGF could play a role in maintenance and/or repair of the luminal endothelium by augmenting NO production.

Because in many cardiovascular diseases the capacity of the endogenous L-arginine/NO system is decreased, an obvious therapeutic measure would be the pharmacological stimulation of this system. Such effects have been attributed to statins ${ }^{50}$ and angiotensin-converting enzyme (ACE) inhibitors. ${ }^{51,52}$ One of the third-generation $\beta$-blockers, nebivolol, has been shown to cause vasodilation in animals ${ }^{53}$ and humans. ${ }^{53-55}$ It has been suggested that this effect of nebivolol is also mediated by increased NO production, since it can be abrogated by inhibitors of NO synthase. ${ }^{54,55}$ However, no direct evidence is available on the NO production stimulating properties of nebivolol and the mechanisms involved. In Chapter 7 a study is presented to explore whether nebivolol indeed induces vascular NO production and to obtain insight into the mechanism underlying this enhanced NO production, if any. ${ }^{43}$ Since $\beta$-blockers are predominantly prescribed in cardiovascular disease states related to arterial disease, such as hypertension and atherosclerosis, in the study presented in Chapter 7 only arteries were studied. ${ }^{43}$ Because pilot experiments in our institute indicated that nebivolol does not induce NO release, we hypothesized that not nebivolol itself, but its metabolites augment NO production. 
In vivo metabolized nebivolol, but not nebivolol itself, indeed increased NO production from isolated mouse aorta. This phenomenon was dependent on the presence of endothelium and involved endothelial $\beta 2$-adrenoceptor ligation with a subsequent rise in endothelial free intracellular $\mathrm{Ca}^{2+}\left(\left[\mathrm{Ca}^{2+}\right]_{i}\right)$ and endothelial NOS-dependent NO production. Neither $\alpha$-adrenergic receptors nor 5-HT ${ }_{1 \mathrm{~A}}$ (ie, type 1A 5-hydroxytryptamine/serotonin) receptors were involved. In addition, it was shown that selective stimulation of vascular $\beta 2$-receptors with salbutamol resulted in an augmentation of $\mathrm{NO}$ release similar to that of metabolized nebivolol. The effects seemed to be specific for metabolized nebivolol, because another frequently used $\beta$-blocker, metoprolol (pure or metabolized), was found to be devoid of these effects. In line with these results the unique presence of $\beta 2$-adrenoceptors, but not of $\beta 1$-adrenoceptors, on vascular endothelial cells was demonstrated.

From the data presented in Chapter 7 it can be concluded that endothelial $\beta 2$-adrenergic receptor ligation stimulates vascular NO production. ${ }^{43}$ Dawes et al (1997) showed vasodilator responses in human forearm, mediated predominantly through $\beta 2$-adrenergic receptors and dependent on NO synthesis. ${ }^{56}$ These data are consistent with the idea that in humans NO is important in modulating and ameliorating sympathetic effects in peripheral tissues. ${ }^{57}$ Interestingly, in a recent study by Gosgnach et al (2001) it was reported that nebivolol induced calcium-independent, adenylate cyclase/cyclic adenosine 3',5'-monophosphate (cAMP) and phospholipase A2-dependent activation of endothelial NO production mediated by $\beta 3$-, but not $\beta 1$ or $\beta 2$-adrenergic receptor ligation. ${ }^{58}$ In contrast to our study, in which effects of in vivo metabolized nebivolol on NO release from freshly isolated segments of aorta were described, the study by Gosgnach et al (2001) showed direct effects of nebivolol itself on cultured human endothelial cells, but they were derived from umbilical veins. In our view, the study by Gosgnach et al (2001) provides a possible mechanistic explanation for the NO-mediated acute vasodilator effects after local nebivolol infusion in humans, but not for the NO-mediated vasodilation after in vivo systemic circulation of nebivolol and its metabolites. "Atypical" $\beta$-adrenoceptors (ie, $\beta 3$ adrenoceptors and/or putative $\beta 4$-adrenoceptors) have been reported to coexist with $\beta 1$ - and $\beta 2$ adrenoceptors in thoracic aorta of the rat. ${ }^{59}$ Therefore, "atypical" $\beta$-adrenoceptors may also play a role in $\beta$-adrenoceptor mediated NO release from mouse thoracic aorta. It should be noted, however that the results of another study show that $\beta$-adrenoceptor mediated vasorelaxation in rat aorta is relatively more dependent on "classical" $\beta$-adrenoceptors (ie, $\beta 1$ and/or $\beta 2$ ) than on "atypical" $\beta$-adrenoceptors. ${ }^{60}$

On the basis of evidence provided by our study (partly unpublished) and other studies it may be concluded that $\beta$-adrenoceptor mediated endothelium-dependent vasorelaxation is, at least partly, due to the elevation of cAMP caused by endothelial $\beta 2$-adrenoceptor stimulation, subsequently activating the endothelial L-arginine/NO system. ${ }^{60-62}$ Endothelial NO production 
stimulated by endothelial $\beta$-adrenergie receptor ligation ( $\beta 2$ and/or $\beta 3$ and/or $\beta 4$ ) may well be an important mechanism in normal vascular human physiology. Therefore, endothelial $\beta$-adrenoceptor mediated increase of endothelial NO production might become an additional therapeutic target in disorders associated with endothelial dysfunction and with preserved $\beta$-receptor mediated NO-dependent vasodilation.

The digital fluorescence imaging technique used for measurement of $\left[\mathrm{Ca}^{2+}\right]_{1}$ in endothelial cells revealed two additional results. Although typically 80 to $100 \%$ of the endothelial cells responded, considerable heterogeneity in response between single endothelial cells within the same vascular segment was consistently observed, irrespective of the type of agonist or antagonist used. Another observation was that metabolized nebivolol caused only a small inerease in endothelial free $\left[\mathrm{Ca}^{2+}\right]_{\mathrm{i}}$. It cannot be concluded from the present study whether the measured rise in free $\left[\mathrm{Ca}^{2+}\right]_{\mathrm{i}}$ was sufficient to stimulate the activity of endothelial constitutive NOS. The minimal increase in endothelial free $\left[\mathrm{Ca}^{2+}\right]_{i}$ may be indicative of a calcium-independent stimulation of endothelial constitutive NO synthase. ${ }^{62}$ However, metabolized nebivolol was not able to induce a rise in NO release in the absence of extracellular calcium. Therefore, it may well be that both intra- and extracellular $\mathrm{Ca}^{2+}$ is required to stimulate endothelial constitutive NOS. After all, it has been shown by other groups that the delayed component contributing to the plateau phase of the elevated $\left[\mathrm{Ca}^{2+}\right]_{i}$ is dependent on $\mathrm{Ca}^{2+}$ influx from the extracellular space, whereas the initial rise may be the result of release from intracellular stores. ${ }^{63}$

\section{Heterogeneity in production and function of nitric oxide}

In summary, the present thesis provides strong experimental evidence for a large heterogeneity in function between arterioles and venules as well as between arteries and veins. It was shown that the simple molecule NO is essential in protecting against prolonged thromboembolism in venules and in combination with prostaglandins also in arterioles. One should realize, however, that pathophysiological conditions, like hypercholesterolemia, can significantly influence the protecting role of NO. The important role of endogenous NO in venules provides an explanation for the substantially lower thromboembolic activity in venules than in arterioles. In arterioles, production of $\mathrm{NO}$ alone was not enough to protect against thromboembolism. This may seem contradictory. However, it illustrates the marked heterogeneity in endothelial function in different vessel types, also within the arterial system. Although this was not directly studied in this thesis, it may well be that the most likely explanation for the superior role of NO in rabbit mesenterie venules compared with its role in arterioles is a lower bioavailability of $\mathrm{NO}$ in arterioles due to the scavenging effect of superoxides. ${ }^{23}$

In the macrocirculatory system, the basal and VEGF-stimulated production of NO was found to be higher in the arterial than in the venous wall. The higher blood pressure and wall 
shear rate in the arterial system may provide an explanation for the arteriovenous difference in production of this strong vasodilating mediator. Even in the same vessel (ie, mouse thoracic aorta) the acute response of individual endothelial cells to $\beta 2$-adrenoceptor or muscarinic receptor ligation appeared to be heterogenous. Several biochemical mechanisms may underly this observed heterogeneity in endothelial function. We focused on VEGF-receptor mediated vascular NO production. It was concluded that the higher VEGF-receptor density in mammary $\operatorname{artery}^{48}$ and/or a possibly more efficient VEGF/NO transduction pathway in mammary artery helps to explain that the VEGF-stimulated NO production in mammary artery is superior to that in saphenous vein. In other vessels a more efficient (agonist and/or stress activated) receptor/NO transduction pathway may also explain superior NO production.

\section{Implications}

With regard to many cardiovascular disease states it is important from a therapeutic point of view to select a drug which specifically acts on endothelial cells of diseased/endangered blood vessels. The concept of "endothelial dysfunction" is being recognized by many clinicians, which is reflected by the increasing use of statins, $\beta$-blockers, ACE inhibitors and calcium-antagonists with beneficial effects on endothelial function. The data presented in this thesis indicate that enhancing endothelial NO production protects against dietary cholesterol-induced thromboembolism, which is a well-know complication in atherosclerosis. Selective $\beta 2$-adrenergic receptor- or VEGFmediated increase of endothelial NO production might become an additional therapeutic target in disorders associated with "endothelial dysfunction". 


\section{References}

1. Ignarro LJ, Buga GM, Wood KS, Byrns RE, Chaudhuri G. Endothelium-derived relaxing factor produced and released from artery and vein is nitric oxide. Proc Natl Acad Sci U S A. 1987;84:9265. 9269.

2. Palmer RM, Ferrige AG, Moneada S. Nitrie oxide release aceounts for the biological aetivity of endothelium-derived relaxing factor. Nature. 1987;327:524-526.

3. Radomski MW, Palmer RM, Moneada S. Endogenous nitrie oxide inhibits human platelet adhesion to vascular endothelium. Lancet. 1987;2:1057-1058.

4. Radomski MW, Palmer RM, Moncada S. The anti-aggregating properties of vaseular endothelium: interactions between prostacyelin and nitric oxide, Br J Pharmacol. 1987;92:639-646.

5. Radomski MW, Palmer RM, Moneada S. An L-arginine/nitrie oxide pathway present in human platelets regulates aggregation. Proc Natl Acad Sci U S A. 1990;87:5193-5197.

6. Garg UC, Hassid A. Nitric oxide-generating vasodilators and 8-bromo cyclic guanosine monophosphate inhibit mitogenesis and proliferation of cultured rat vascular smooth muscle cells. J Clin Invest. 1989;83:1774-1777.

7. Lüscher TF, Diederich D, Siebenmann R, Lehmann K, Stulz P, von Segesser L, Yang ZH, Turina M. Gradel E, Weber E. Difference between endothelium-dependent relaxation in arterial and in venous coronary bypass grafts. $N$ Engl J Med. 1988;319:462-467.

8. Yang ZH, Stulz P, von Segesser L, Bauer E, Turina M, Lüscher TF. Different interactions of platelets with arterial and venous coronary bypass vessels. Lancet. 1991;337:939-943.

9. Van der Zee R, Murohara T, Luo Z, Zollmann F, Passeri J, Lekutat C, Isner JM. Vascular endothelial growth factor/vascular permeability factor augments nitric oxide release from quiescent rabbit and human vascular endothelium. Circulation. 1997;95:1030-1037.

10. oude Egbrink MGA, Tangelder GJ, Slaaf DW, Reneman RS. Thromboembolic reaction following wall puncture in arterioles and venules of the rabbit mesentery. Thromb Haemost. 1988:59:23-28.

11. oude Egbrink MGA, Tangelder GJ, Slaaf DW, Reneman RS. Different roles of prostaglandins in thromboembolic processes in arterioles and venules in vivo. Thromb Haemost. 1993:70:826-833.

12. Falcone JC, Bohlen HG. EDRF from rat intestine and skeletal muscle venules causes dilation of arterioles. Am J Physiol. 1990;258:H1515-H1523.

13. Persson MG, Gustafsson LE, Wiklund NP, Hedqvist P, Moncada S. Endogenous nitrie oxide as a modulator of rabbit skeletal muscle microcirculation in vivo. Br J Pharmacol. 1990;100:463-466.

14. Mitchell D, Tyml K. Nitric oxide release in rat skeletal muscle capillary. Am J Physiol. 1996;270:H1696-H1703.

15. Boegehold MA. Shear-dependent release of venular nitric oxide: effect on arteriolar tone in rat striated muscle. Am J Physiol. 1996;271:H387-H395.

General Discussion 
16. Broeders MAW, Tangelder GJ, Slaaf DW, Reneman RS, oude Egbrink MGA. Endogenous nitric oxide protects against thromboembolism in venules but not in arterioles. Arterioscler Thromb Vasc Biol. 1998: 18:139-145.

17. Broeders MAW, Tangelder GJ, Slaaf DW, Reneman RS, oude Egbrink MGA. Endogenous nitric oxide and prostaglandins synergistically counteract thromboembolism in arterioles but not in venules. Arterioscler Thromb Vase Biol. 2001;21:163-169.

18. Broeders MAW, Tangelder GJ, Slaaf DW, Reneman RS, oude Egbrink MGA. Hypercholesterolemia enhances thromboembolism in arterioles but not in venules; complete reversal by L-arginine. Arterioscler Thromb Vasc Biol. 2002;22:680-685.

19. oude Egbrink MGA. Chapter 10: General Discussion. In: Thromboembolic reaction following vessel wall injury in arterioles and venules. Maastricht: PhD thesis; Maastricht University (ISBN: 90-5291002-2): 1989:107-113.

20. oude Egbrink MG, Tangelder GJ, Slaaf DW, Reneman RS. Fluid dynamics and the thromboembolic reaction in mesenteric arterioles and venules. Am J Physiol. 1991;260:H1826-H1833.

21. oude Egbrink MGA, Tangelder GJ, Slaaf DW, Reneman RS. Effect of blood gases and pH on thromboembolic reactions in rabbit mesenteric microvessels. Eur J Physiol (Pflügers Arch). 1989;414:324 330 .

22. Tromp SC, Tangelder GJ, Slaaff DW, Reneman RS, van Velzen S, oude Egbrink MG. The influence of prostaglandins on leukocyte-endothelium interactions in rabbit mesenteric venules. Prostaglandins Other Lipid Mediat. 2000;60:71-82.

23. Suzuki H, Swei A, Zweifach BW, Schmid-Schönbein GW. In vivo evidence for microvascular oxidative stress in spontaneously hypertensive rats. Hydroethidine microfluorography. Hypertension. 1995;25: 1083-1089.

24. Bohlen HG, Nase GP. Dependence of intestinal arteriolar regulation on flow-mediated nitric oxide formation. Am J Physiol Heart Circ Physiol. 2000;279:H2249-H2258.

25. Ross R. Atherosclerosis - an inflammatory disease. N Engl J Med. 1999;340:115-126.

26. Ross R, Glomset J, Harker L. Response to injury and atherogenesis. Am J Pathol. 1977;86:675-684.

27. Haller H, Rieger M, Lindschan C, Kuhlmann M, Philipp S, Luft FC. LDL inereases $\left[\mathrm{Ca}^{2+}\right]_{i}$ in human endothelial cells and augments thrombin-induced cell signalling. J Lab Clin Med. 1994;124:708-714.

28. Hackeng CM, Huigsloot M, Pladet MW, Nieuwenhuis HK, van Rijn HJ, Akkerman JW. Low density lipoprotein enhances platelet secretion via integrin-alphaIlb beta3-mediated signaling. Arterioscler Thromb Vasc Biol. 1999;19:239-247.

29. Hackeng CM, Pladet MW, Akkerman JW, van Rijn HJ. Low density lipoprotein phosphorylates the focal adhesion-associated kinase p125(FAK) in human platelets independent of integrin alphaIIb beta3. J Biol Chem. 1999:274:384-388. 
30. oude Eggrink MGA, Tangelder GJ, Béguin S, Wielders JS, Weijmer JS, Slaaf DW, Hemker HC. Reneman RS. Role of thrombin in the thrombeembolic reaction following vessel wall injury in microvessels. In: Proceedings of the fifth world congress for microcirculation. Louisville; 1991:abstract no. 496.

31. Zwaginga JJ, de Beer HC, Usseldijk MJ, Kerkhof A, Muller-Berghaus G, Gruhlichhenn J, Sixma JJ, de Groot PG. Thrombogenicity of vascular cells. Comparison between endothelial cells isolated from different sources and smooth muscle eells and fibroblasts. Arteriosclerosis. 1990;10:437-448.

32. Silverman MD, Waters CR, Hayman GT, Wigboldus J, Samet MM, Lelkes PI. Tissue factor activity is increased in human endothelial cells eultured under elevated static pressure. Am $J$ Physiol. 1999;277:C233-C242.

33. Himber J, Kirchhofer D, Riederer M, Tschopp TB, Steiner B, Reux SP. Dissociation of antithrombotic effect and bleeding time prolongation in rabbits by inhibiting tissue factor function. Thromb Haemost. 1997;78:1142-1149.

34. Bottecehia D, Doni MG. Artero-venous differences in blood platelet elumping by ADP. Experientia. 1973;29:211-212.

35. Seiffge D, Kremer E. Influence of ADP, blood flow velocity, and vessel diameter on the laser-induced thrombus formation. Thromb Res. 1986;42:331-341.

36. Benner KU, Frede KE. Platelet aggregation induced by ADP in vivo: continuous and quantitative measurements in different vaseular beds. Microvasc Res. 1972;4:264-272.

37. oude Egbrink MG, Tangelder GJ, Slaaf DW, Reneman RS. Influence of platelet-vessel wall interactions on leukocyte rolling in vivo. Circ Res. 1992;70:355-363.

38. oude Egbrink MGA. Chapter 8: Interaction between leukocytes and platelets in venules. In: Thromboembolic reaction following vessel wall injury in arterioles and venules. Maastricht: PhD thesis; Maastricht University (ISBN: 90-5291-002-2); 1989:81-92.

39. May AE, Neumann FJ, Preissner KT. The relevance of blood cell-vessel wall adhesive interactions for vascular thrombotic disease. Thromb Haemost. 1999;82:962-970.

40. Zimmerman GA, MeIntyre TM, Prescott SM. Adhesion and signaling in vascular cell-cell interactions. J Clin Invest. 1997;100:S3-S5.

41. Celi A, Lorenzet R, Furie B, Furie BC. Platelet-leukocyte-endothelial cell interaction on the blood vessel wall. Semin Hematol. 1997;34:327-335.

42. Broeders MAW, Doevendans PA, Maessen JG, van Gorsel E, oude Egbrink MGA, Daemen MJAP, Tangelder GJ, Reneman RS, van Der Zee R. The human internal mammary artery releases more nitric oxide in response to vascular endothelial growth factor than the human saphenous vein. $J$ Thorac Cardiovase Surg. 2001;122:305-309. 
43. Broeders MA, Doevendans PA, Bekkers BC, Bronsaer R, van Gorsel E, Heemskerk JW, Egbrink MG, van Breda E, Reneman RS, van Der Zee R. Nebivolol: a third-generation $\beta$-blocker that augments vascular nitric oxide release. Endothelial $\beta 2$-adrenergic receptor-mediated nitric oxide production. Circulation. 2000;102:677-684.

44. Fitzgibbon GM, Kafka HP, Leach AJ, Keon WJ, Hooper GD, Burton JR. Coronary bypass graft fate and patient outcome: angiographic follow-up of $5,065 \mathrm{grafts}$ related to survival and reoperation in 1,388 patients during 25 years. J Am Coll Cardiol. 1996;28:616-626.

45. Lawrie GM, Lie JT, Morris GC, Jr., Beazley HL. Vein graft patency and intimal proliferation after aortocoronary bypass: early and long-term angiopathologic correlations. Am J Cardiol. 1976;38:856862.

46. Ku DD, Caulfield JB, Kirklin JK. Endothelium-dependent responses in long-term human coronary artery bypass grafts. Circulation. 1991;83:402-411.

47. Buttery LD, Chester AH, Springall DR, Borland JA, Michel T, Yacoub MH, Polak JM. Explanted vein grafts with an intact endothelium demonstrate reduced focal expression of endothelial nitric oxide synthase specific to atherosclerotic sites. J Pathol. 1996;179:197-203.

48. Couffinhal T, Kearney M, Witzenbichler B, Chen D, Murohara T, Losordo DW, Symes J, Isner JM. Vascular endothelial growth factor/vascular permeability factor (VEGF/VPF) in normal and atherosclerotic human arteries. Am J Pathol. 1997;150:1673-1685.

49. Asahara T, Bauters C, Pastore C, Kearney M, Rossow S, Bunting S, Ferrara N, Symes JF, Isner JM. Local delivery of vascular endothelial growth factor accelerates reendothelialization and attenuates intimal hyperplasia in balloon-injured rat carotid artery. Circulation. 1995;91:2793-2801.

50. Hernandez-Perera O, Perez-Sala D, Navarro-Antolin J, Sanchez-Pascuala R, Hernandez G, Diaz C, Lamas S. Effects of the 3-hydroxy-3-methylglutaryl-CoA reductase inhibitors, atorvastatin and simvastatin, on the expression of endothelin-1 and endothelial nitric oxide synthase in vascular endothelial cells. J Clin Invest. 1998;101:2711-2719.

51. Mancini GB, Henry GC, Macaya C, O'Neill BJ, Pucillo AL, Carere RG, Wargovich TJ, Mudra H, Luscher TF, Klibaner MI, Haber HE, Uprichard AC, Pepine CJ, Pitt B. Angiotensin-converting enzyme inhibition with quinapril improves endothelial vasomotor dysfunction in patients with coronary artery disease. The TREND (Trial on Reversing ENdothelial Dysfunction) Study. Circulation. 1996;94:258-265.

52. Yusuf S, Sleight P, Pogue J, Bosch J, Davies R, Dagenais G. Effects of an angiotensin-convertingenzyme inhibitor, ramipril, on cardiovascular events in high-risk patients. The Heart Outcomes Prevention Evaluation Study Investigators. N Engl J Med. 2000;342:145-153.

53. Van de Water A, Janssens W, Van Nueten J, Xhonneux R, De Cree J, Verhaegen H, Reneman RS, Janssen PA. Pharmacological and hemodynamic profile of nebivolol, a chemically novel, potent, and selective beta 1-adrenergic antagonist. J Cardiovasc Pharmacol. 1988;11:552-563. 
54. Bowman AJ, Chen CP, Ford GA. Nitrie oxide mediated venodilater effects of nebivolol. Br J Clin Pharmacol. 1994;38:199-204.

55. Coekeroft JR, Chowienezyk PJ, Brett SE, Chen CP, Dupont AG, Van Nueten L, Woeding SJ, Ritter JM. Nebivolol vasodilates human forearm vasculature: evidence for an L-arginine/NO-dependent mechanism. J Pharmacol Exp Ther. 1995;274:1067-1071.

56. Dawes M, Chowienczyk PJ, Ritter JM. Effects of inhibition of the L-arginine/nitric oxide pathway on vasodilation caused by beta-adrenergic agonists in human forearm. Circulation. 1997;95:2293-2297.

57. Jordan J, Tank J, Stoffels M, Franke G, Christensen NJ, Luft FC, Bosehmann M. Interaction between beta-adrenergic receptor stimulation and nitric oxide release on tissue perfusion and metabolism. J Clin Endocrinol Metab. 2001;86:2803-2810.

58. Gosgnach W, Boixel C, Nevo N, Poiraud T, Michel JB. Nebivolol induces caleium-independent signaling in endothelial cells by a possible beta-adrenergic pathway. J Cardiovase Pharmacol. 2001;38: 191-199.

59. Brawley L, Shaw AM, MacDonald A. Beta 1-, beta 2- and atypical beta-adrenoceptor-mediated relaxation in rat isolated aorta. $\mathrm{Br} J$ Pharmacol. 2000;129:637-644.

60. Brawley L, Shaw AM, MacDonald A. Role of endothelium/nitric oxide in atypical beta-adrenoceptormediated relaxation in rat isolated aorta. Eur J Pharmacol. 2000;398:285-296.

61. Gray DW, Marshall I. Novel signal transduction pathway mediating endothelium-dependent betaadrenoceptor vasorelaxation in rat thoracic aorta. Br J Pharmacol. 1992;107:684-690.

62. Ferro A, Queen LR, Priest RM, Xu B, Ritter JM, Poston L, Ward JP. Activation of nitric oxide synthase by beta 2 -adrenoceptors in human umbilical vein endothelium in vitro. $\mathrm{Br} J$ Pharmacol. 1999;126:1872-1880.

63. Dolor RJ, Hurwitz LM, Mirza Z, Strauss HC, Whorton AR. Regulation of extracellular calcium entry in endothelial cells: role of intracellular calcium pool. Am J Physiol. 1992;262:C171-C181. 


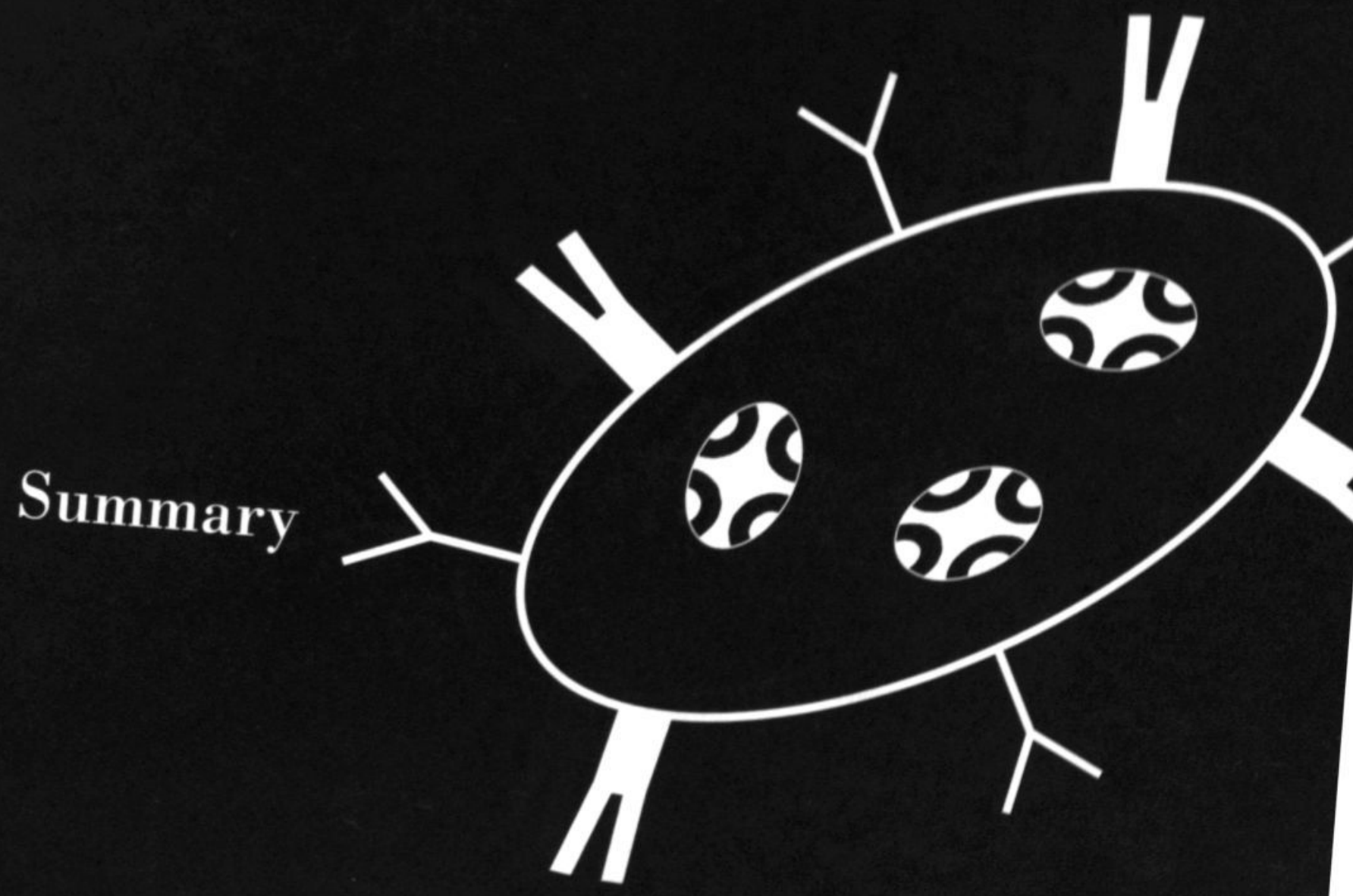


Fundamental discoveries in vascular biology have led to the recognition that endothelial-derived nitric oxide (NO) is a major factor that mediates a great number of phenomena, all contributing to normal vessel anatomy and function. In many cardiovascular diseases, the bioavailability of NO is decreased, which may contribute to vasospasm, thrombus formation and intimal thickening, ultimately leading to ischemia and infarction. The studies in this thesis suggest that differences in mechanisms of production and antithromboembolic function of endothelial NO exist between the arterial and venous system. After a general introduction (Chapter 1) and a review of the literature on production and functions of nitric oxide (Chapter 2), the experimental studies are described (Chapters 3-5) and discussed (Chapter 8).

In the three studies on antithromboembolic function of NO (Chapters 3-5) a thromboembolic reaction, ie the formation of an intravascular thrombus and subsequent embolization, was induced in microvessels of the rabbit mesentery. The thromboembolic reaction is known to be different in arterioles and venules, the period of embolization (ie, the time from vessel wall injury to breaking off of the last embolus) being two to eight times longer in arterioles than in venules. Based on previous findings, it was hypothesized that functional differences in antiand prothrombotic properties of the vessel wall may be responsible for the difference in thromboembolic reaction in these vessels.

Both platelet activating and inhibiting prostaglandins (for example, thromboxane $\mathrm{A}_{2}$ $\left[\mathrm{TXA}_{2}\right]$ and prostacyclin $\left[\mathrm{PGI}_{2}\right]$ ) play a more important role in thromboembolism in arterioles than in venules, possibly though a difference in prostaglandin synthetic capacity between arteriolar and venular endothelium. Because the difference in embolization between arterioles and venules cannot be explained by the different role of prostaglandins in these vessels, in this thesis the role of $\mathrm{NO}$ was studied. It was shown that $\mathrm{NO}$ is more important in protecting against prolonged thromboembolism in venules than in arterioles (Chapter 3). The observed effects on embolization in venules cannot be explained by differences in wall shear rate. It was argued that a lower bioavailability of NO in arterioles is a possible explanation, which may be due to the scavenging effect of superoxides.

An interesting additional finding of the study presented in Chapter 3 was that NO synthase inhibition abolished the difference in duration of embolization between arterioles and venules. Thus, the more important functional role of $\mathrm{NO}$ in venules, as compared to arterioles, provides a possible explanation for the difference in thromboembolic reaction normally found between the two vessel types.

At a site of wall injury antithrombotic endothelium-derived mediators (eg, $\mathrm{PGI}_{2}$ and $\mathrm{NO}$ ) are probably produced simultaneously and activated platelets are likely to be exposed to a combination of both. This combination may exert a more pronounced antithrombotic effect than 
expected on the basis of their individual antithrombotic effects, because in vitro studies have shown that $\mathrm{PGI}_{2}$ and $\mathrm{NO}$ released by cultured endothelial cells can act synergistically in the inhibition of platelet aggregation. Because it is unknown whether such a synergistic interaction is also effective in vivo and whether this interaction, if any, differs between vessel types, this question was dealt with in Chapter 4 of this thesis. Combined actions of $\mathrm{NO}$ and prostaglandins inhibit embolization in a synergistic manner in arterioles. There was no such synergistie effect in venules. In addition, it was found that $\mathrm{NO}$ and prostglandins play an important role in counteracting wall shear rate-enhanced platelet activation in arterioles. In venules other as yet unidentified antithromboembolic substances are likely to oppose wall-shear rate enhanced platelet activation.

Taken together, in arterioles the antithromboembolic effect of endogenous $\mathrm{NO}$ alone is negligible, but its effect is pronounced in the presence of endogenous prostaglandins, provided that sufficient NO is produced to activate the arachidonic acid/prostaglandin pathway. An additional possible element is that, unlike in venules, the balance between antithromboembolic and prothromboembolic properties of the wall is more towards identified prothromboembolic factors $\left(\mathrm{TX}_{2}\right.$ ) and possibly as yet unidentified prothromboembolic factors (eg, tissue factor or ADP) in arterioles. The exclusive presence of rolling leukocytes in venules, but not in arterioles, may offer an alternative explanation for the difference in thromboembolism between the two vessel types. either through a direct interaction between leukocytes and platelets or indirectly through involvement of vascular cells.

Hypercholesterolemia is an important risk factor for atherosclerosis, which affects the arterial system and may ultimately lead to ischemia and infarction. Most of these disorders result from thromboembolic processes at the site of the lesion. The vascular lesion plays an important role in these processes, but the role of hypercholesterolemia, as such, in thromboembolic events is less clear. Besides, the mediators involved in hypercholesterolemia-related thromboembolic events are, as yet, not well known. In our study described in Chapter $\mathbf{5}$ evidence was provided for a pronounced stimulating effect of diet-induced hypercholesterolemia on in vivo thrombus formation and subsequent thromboembolization in arterioles, but not in venules. In arterioles the effects of hypercholesterolemia on embolization, but not on thrombus formation, can be completely reversed by activating $\mathrm{NO}$ synthesis with $\mathrm{L}$-arginine. Effects of increased plasma cholenterol on thromboembolism in arterioles may be explained by a loss of NO/prostaglandin synergism. 
In the second part of this thesis we focused on mechanisms of NO synthase (NOS) activation and production of vascular NO in the macrocirculatory system.

Graft failure is one of the major causes of recurrent angina after coronary artery bypass grafting. Endothelial NO inhibits smooth muscle cell proliferation, reducing the chance of vascular intimal thickening which is an important cause of late coronary vein graft occlusion. In the study presented in Chapter 6 we investigated whether the superior long-term patency of the internal mammary artery in human coronary bypass grafting compared with that of the saphenous vein could be explained by different levels of NO production. The baseline endogenous NO appeared to be $50 \%$ higher in internal mammary artery than in saphenous vein. Previously, it was shown that vascular endothelial growth factor (VEGF) and the VEGF-receptors KDR (Flk-1) and Flt-1 are expressed in both internal mammary artery and saphenous vein and that VEGFreceptor density was higher in internal mammary artery than in saphenous vein. Therefore, we also investigated the influence of VEGF on NO release in both internal mammary artery and saphenous vein. VEGF augmented NO production by approximately $50 \%$ in saphenous vein and $100 \%$ in internal mammary artery. Based on this study it was concluded that VEGF augments endothelial constitutive NOS-dependent NO release to a greater extent in internal mammary artery than in saphenous vein. Differences in NO production between internal mammary artery and saphenous vein are not caused by a higher vascular expression of NOS. The previously reported higher VEGF-receptor density in internal mammary artery than in saphenous vein may explain the higher VEGF-stimulated NO production in internal mammary artery. These findings may help to explain the long-term superiority of internal mammary artery versus saphenous vein as a conduit for coronary artery bypass.

Because in many cardiovascular diseases the capacity of the endogenous L-arginine/NO system is decreased, an obvious therapeutic measure would be the pharmacological stimulation of this system. One of the third-generation $\beta$-blockers, nebivolol, has been shown to cause vasodilation, which is potentially mediated by increased NO production. In Chapter $\mathbf{7}$ a study is presented to explore whether nebivolol indeed induces vascular NO production and to obtain insight into the mechanism underlying this enhanced NO production, if any. In vivo metabolized nebivolol, but not nebivolol itself, indeed increased NO production from isolated mouse aorta. This phenomenon was dependent on the presence of endothelium and involved endothelial $\beta 2$ adrenoceptor ligation with a subsequent rise in endothelial free intracellular $\mathrm{Ca}^{2+}\left(\left[\mathrm{Ca}^{2+}\right]_{\mathrm{i}}\right)$ and endothelial NOS-dependent NO production. In addition, it was shown that selective pharmacological stimulation of vascular $\beta 2$-receptors resulted in an augmentation of $\mathrm{NO}$ release similar to that of metabolized nebivolol. In line with these results the unique presence of $\beta 2$-adrenoceptors, but not of $\beta 1$-adrenoceptors, on vascular endothelial cells was demonstrated. Endothelial NO production stimulated by endothelial $\beta$-adrenergic receptor ligation may well be an important 
mechanism in normal vaseular human physiology. Therefore, endothelial $\beta$-adrenoceptor mediated increase of endothelial NO production might become an additional therapeutic target in disorders associated with "endothelial dysfunction" and with preserved $\beta$-receptor mediated NO-dependent vasodilation.

The obtained insights into production and function of NO enhance our understanding of the complex multifactorial origin of thromboembolic processes and intimal thickening in the arterial and venous system. Furthermore, the present thesis provides strong experimental evidence for a large heterogeneity in function between arterioles and venules as well as between arteries and veins. The data presented in this thesis indicate that enhancing endothelial NO production protects against dietary cholesterol-induced thromboembolism, which is a well-know complication in atherosclerosis. Selective $\beta 2$-adrenergic receptor- or VEGF-mediated increase of endothelial NO production might become an additional therapeutic target in disorders associated with "endothelial dysfunction". 



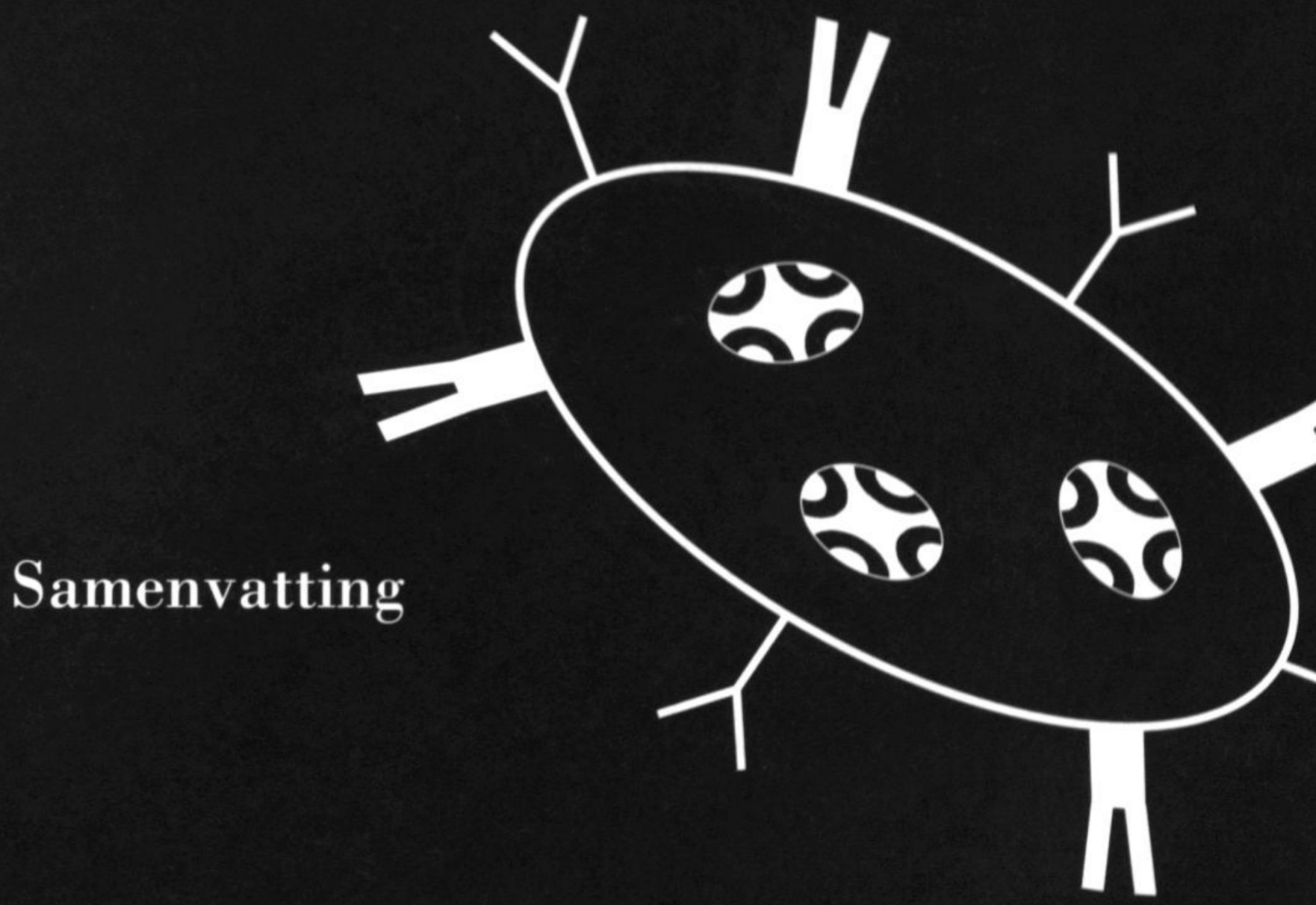


Door endotheel geproduceerd stikstof oxide (NO) speelt een belangrijke rol bij een groot aantal processen die bijdragen aan de normale anatomie en functie van bloedvaten. In veel cardiovasculaire ziekten is de biologische beschikbaarheid van NO verminderd. Dit kan bijdragen aan intima proliferatie, vasoconstrictie en trombusvorming en het kan leiden tot verminderde doorgankelijkheid van bloedvaten en uiteindelijk tot ischemie, infarct (bijvoorbeeld hartinfarct of herseninfaret) en sterfte. In dit proefschrift wordt aangetoond dat er grote verschillen bestaan tussen het arteriële en veneuze systeem met betrekking tot mechanismen van productie en antitrombo-embolische functie van endotheliaal NO. Na een algemene inleiding (Hoofdstuk 1) en een overzicht van de literatuur over productie en functies van NO (Hoofdstuk 2), volgt een beschrijving van de experimentele studies (Hoofdstukken 3-7) en een discussie van de bevindingen (Hoofdstuk 8).

Interacties tussen bloed en een beschadigde vaatwand resulteren in de vorming van een trombus, mogelijk gevolgd door embolisatie. Antitrombogene en trombogene eigenschappen van endotheel spelen tijdens dergelijke interacties een belangrijke rol. De betrokkenheid van endotheel bij trombotische processen wordt veelal in vitro onderzocht, aan cellen die geïsoleerd zijn uit grote bloedvaten. De condities waarin geïsoleerde endotheelcellen zich in vitro bevinden zijn echter niet in overeenstemming met hun natuurlijke omgeving, hetgeen het functioneren van deze cellen zeker beïnvloedt. Bovendien is, zowel in vitro als in vivo, aangetoond dat antitrombogene eigenschappen van endotheel niet in alle bloedvaten gelijk zijn, zodat het van belang is om functies van endotheel in verschillende bloedvaten met elkaar te vergelijken. Het onderzoek in dit proefschrift heeft zich gericht op de antitrombogene eigenschappen van endotheel in vivo in twee typen bloedvaten, te weten arteriolen en venulen. De nadruk lag daarbij op de productie en de rol van NO en van antitrombogene prostaglandines tijdens een trombo-embolische reactie. Zowel NO als deze prostaglandines zijn antitrombogene substanties afkomstig uit endotheel.

In het onderzoek werd steeds gebruik gemaakt van een in ons laboratorium ontwikkeld proefdiermodel. In het mesenterium van het geanestheseerde konijn werd de wand van arteriolen en venulen zeer lokaal beschadigd met een glazen micropipet. Op deze wijze werd in alle bloedvaten de onmiddellijke vorming van een trombus geïnduceerd, die de bloeding stopte. De trombus groeide daarna meestal aan in stroomafwaartse richting, totdat het nieuw gevormde, stroomafwaartse stuk emboliseerde; dit embolisatieproces herhaalde zich gedurende bepaalde tijd. Het stabiele, niet emboliserende deel van de trombus bleef steeds op zijn plaats en veranderde niet of nauwelijks in grootte. Deze trombo-embolische reactie werd met behulp van intravitaal microscopie bestudeerd en gekwantificeerd; ook de lokale en systemische hemodynamische condities werden gemeten. 
Uit eerder onderzoek was reeds bekend dat de trombo-embolische reactie in arteriolen en venulen versehillend is: de duur van embolisatie (dat wil zeggen, de tijd verstreken vanaf beschadiging van de vaatwand tot het afbreken van de laatste embolus) is twee tot acht maal langer in arteriolen dan in venulen. Direet voorafgaand aan dit project werd een studie verricht naar de "overall" rol van prostaglandines tijdens een trombo-embolische reactie. Met behulp van een hoge dosering van de eyclo-oxygenase-remmer aspirine werd de vorming van zowel het trombogene tromboxaan $A_{2}$ (TX $A_{2}$ ) als van de antitrombogene prostaglandines uit de vaatwand, zoals het prostacyeline $\left(\mathrm{PGI}_{2}\right)$, geremd. Dit bleek de embolisatie in arteriolen significant te verlengen, terwijl geen effeet werd gevonden in venulen. Vervolgens werd onderscheid gemaakt tussen de bijdrage van de antitrombogene prostaglandines en $\mathrm{TX}_{2}$ : de werking van $\mathrm{TX}_{2}$ kon selectief uitgeschakeld worden met behulp van sulotroban, een selectieve $\mathrm{TX}_{2}$-receptor blokker bij konijnen. Sulotroban bleek de embolisatie in arteriolen significant te remmen, terwijl in venulen geen effect werd gevonden. Net als aspirine had ook sulotroban geen effect op de trombusvorming en op de hemodynamische condities. Deze resultaten geven aan dat TX $\mathrm{A}_{2}$ een grotere rol speelt tijdens het trombo-embolische proces in arteriolen dan in venulen. Dit duidt erop dat niet alleen TXA $_{2}$ geproduceerd door bloedplaatjes een rol speelt; de bijdrage van het uit bloedplaatjes afkomstige $\mathrm{TXA}_{2}$ zou in arteriolen en venulen gelijk moeten zijn gezien de overeenkomstige grootte van trombus en emboli in beide typen vaten (eerder onderzoek). Ook cellen in de vaatwand zijn in staat TX $\mathrm{A}_{2}$ te produceren; blijkbaar wordt er meer TX $\mathrm{A}_{2}$ geproduceerd door arteriolaire dan door venulaire vaatwandcellen. Tezamen kan uit de aspirine- en sulotroban-data geconcludeerd worden dat zowel plaatjes-inhiberende als plaatjes-stimulerende prostaglandines in arteriolen een grotere rol spelen in de plaatjes-vaatwand interacties na een vaatwand-beschadiging dan in venulen. Dit duidt op een functioneel verschil tussen arteriolair en venulair endotheel in vivo; beschadigd/gestimuleerd endotheel in arteriolen lijkt meer prostaglandines te produceren dan venulair endotheel.

Gebaseerd op deze bevindingen, veronderstelden we dat functionele verschillen in antien protrombotische eigenschappen van de vaatwand het verschil in trombo-embolische reactie tussen deze microvaten zou kunnen verklaren. Omdat het verschil in embolisatie tussen arteriolen en venulen niet kan worden verklaard door de verschillende rol van prostaglandines in deze microvaten, werd in dit proefschrift de rol van $N O$ bestudeerd. Met behulp van $\mathrm{L}_{-} \mathrm{NA}\left(N^{\mathrm{C}}-\mathrm{nitro}^{-}\right.$ L-arginine, een NO synthase [NOS] remmer) werd gevonden dat endogeen NO beschermt tegen langdurige embolisatie in venulen (Hoofdstuk 3). In arteriolen had remming van NOS geen effeet op embolisatie. Het venulaire effect wordt niet veroorzaakt door veranderende hemodynamische condities omdat zowel in de venulen als in de arteriolen NOS remming geen invloed had op de hemodynamische parameters. Een grotere mate van beschikbaarheid van het geproduceerde NO in venulen lijkt een waarschijnlijke verklaring, gezien het feit dat er aanwijzingen zijn dat in het 
mesenterium (van de rat) meer zuurstof radicalen geproduceerd worden in arteriolen dan in venulen; zuurstof radicalen inactiveren NO en verminderen dus de "bioavailability" van het NO.

Een interessante bijkomende bevinding van deze studie is dat remming van NOS het verschil in embolisatieduur tussen arteriolen en venulen doet verdwijnen. Mogelijk vormt de meer belangrijke belangrijke rol van $\mathrm{NO}$ in venulen, vergeleken met arteriolen, een verklaring voor het verschil in trombo-embolische reactie tussen de twee vaattypen.

Ter plaatse van een vaatwand-beschadiging worden antitrombotische endotheliale substanties, zoals $\mathrm{PGI}_{2}$ en NO, waarschijnlijk gelijktijdig geproduceerd; geactiveerde bloedplaatjes worden dan blootgesteld aan een combinatie van beide. Deze combinatie heeft mogelijk een groter antitrombotisch effect dan wat is te verwachten op basis van hun individuele antitrombotische effecten. In vitro studies hebben namelijk aangetoond dat een combinatie van endotheliaal $\mathrm{PGI}_{2}$ en NO op synergistische wijze de aggregatie van bloedplaatjes remt. Omdat onbekend is of zo'n synergistische interactie ook in vivo werkzaam is en of deze interactie, indien aanwezig, verschilt tussen arteriolen en venulen, werd dit bestudeerd in het onderzoek beschreven in Hoofdstuk 4 van dit proefschrift. Middels gecombineerde remming van de productie van prostaglandines (met behulp van een hoge dosis aspirine) en het NO (met behulp van L-NA) werd onderzocht of er in vivo sprake is van een synergistisch, antitrombogeen effect van beide tijdens een trombo-embolische reactie, wederom in arteriolen en venulen. Deze gecombineerde remming van prostaglandine- en NO-productie resulteerde in arteriolen in een dramatische verlenging van de embolisatieperiode, een effect dat duidelijk groter was dan de som van de effecten van aspirine en L-NA afzonderlijk. In venulen, daarentegen, was het effect van de combinatie niet groter dan het effect van L-NA alleen. Dit duidt erop dat de combinatie van endogene prostaglandines en NO een synergistisch, antitrombogeen effect heeft in arteriolen, maar niet in venulen. Uit de literatuur blijkt dat $\mathrm{NO}$ in vitro in staat is cyclo-oxygenase-activiteit te stimuleren; wanneer dit een concentratie-afhankelijk effect zou zijn dat ook in vivo werkzaam is, dan zou dit onze bevindingen kunnen verklaren. Een andere opvallende bevinding in deze studie was dat er in arteriolen van de konijnen warin zowel prostaglandine- als NO-productie geremd werd, sprake was van een positieve relatie tussen de lokale gereduceerde snelheid, hetgeen een maat is voor de locale afschuifsnelheid of "wall shear rate", en de mate van embolisatie. Dit was niet het geval in de arteriolen van de overige groepen, en ook niet in venulen. Dit betekent dat, onder normale omstandigheden, in arteriolen het trombogene effect van de afschuifsnelheid onderdrukt wordt door het synergistische, antitrombogene effect van endogene prostaglandines en NO. In venulen zijn blijkbaar nog andere antitrombogene substanties werkzaam.

Samenvattend is in arteriolen het antitrombo-embolische effect van endogeen NO alléén verwaarloosbaar. Daarentegen is het effect van $\mathrm{NO}$ zeer uitgesproken in de aanwezigheid van endogene prostaglandines, op voorwaarde dat voldoende NO wordt geproduceerd om de 
arachidonzuur/prostaglandine cascade te activeren. Een bijkomend element is dat, anders dan in venulen, in arteriolen de balans tussen antitrombo-embolische en protrombo-embolische eigenschappen van de vaatwand meer in protrombo-embolische richting neigt. De exclusieve aanwezigheid van rollende leukocyten in venulen, maar niet in arteriolen, kan een alternatieve verklaring bieden voor het verschil in trombo-embolisehe reactie tussen de twee vaattypen, ofwel door een directe interactie tussen leukocyten en bloedplaatjes danwel indirect door betrokkenheid van vaatwandcellen.

Hypercholesterolemische patiënten en dieren hebben een verhoogd risico op atherosclerose, een aandoening van het arteriële systeem, welke uiteindelijk kan leiden tot ischemie en infarcering. Meestal wordt dit veroorzaakt door trombo-embolische processen ter hoogte van de vaatwandlaesie. Deze vaatwandlaesie speelt een belangrijke rol in deze processen, maar de rol van hypercholesterolemie, op zich, in trombo-embolische processen is minder duidelijk. Daarnaast zijn de mediatoren die bij trombo-embolische processen in hypercholesterolemie een rol spelen, tot op heden, niet goed bekend. Eerder onderzoek heeft aangetoond dat chronische hypercholesterolemie bij konijnen leidt tot afgenomen endogene NO-productie in zowel arteriën als venen. Gebruik makend van ons eigen model hebben wij onderzocht wat de consequentie van hypercholesterolemie is voor de trombo-embolische reactie in arteriolen en venulen, en welke rol NO hierbij speelt (Hoofdstuk 5). Konijnen kregen gedurende de twee weken voorafgaand aan de experimenten voedsel met een relatief hoog cholesterol-gehalte $(0.4 \%)$, wat leidde tot een significant verhoogde cholesterol-spiegel in het bloed; met name de LDL ("low-density lipoprotein")-concentratie was toegenomen ten opzichte van normaal. Dit veroorzaakte een zeer significante verlenging van de embolisatie-periode in arteriolen, terwijl in de venulen geen effect werd gevonden. Bovendien werd in de arteriolen de trombus groter. Blijkbaar heeft hypercholesterolemie in arteriolen een bloedplaatjes-stimulerend effect tijdens zowel de -primaire-fase van trombusvorming als de -secundaire- embolisatiefase. Superfusie van het mesenterium van de hypercholesterolemische konijnen met een overmaat aan L-arginine, het substraat voor endogene NO-productie, bracht de arteriolaire embolisatie, maar niet de trombusgrootte terug naar controle-niveau; wederom werd geen effect gevonden in de venulen. Hypercholesterolemie had geen effect op lokale hemodynamische condities in beide typen bloedvaten.

Uit de literatuur is bekend dat hypercholesterolemie gepaard kan gaan met verhoogde vasculaire productie van zuurstof radicalen, welke vervolgens NO kunnen inactiveren. De resultaten van onze studie suggereren dat dit effect zich met name voordoet in arteriolen en niet in venulen. Dit zou kunnen verklaren waarom de trombo-embolische reactie in venulen niet verandert onder invloed van hypercholesterolemie. In arteriolen heeft een afname van de NO-beschikbaarheid alléén geen significant effect op de reactie (zie Hoofdstuk 3). Daarom moet de hypercholesterolemie nog andere trombogene effecten op de arteriolaire vaatwand hebben. Aangezien 
het arteriolaire effect van de verhoogde cholesterol-spiegel veel lijkt op dat van gecombineerde remming van NO- èn prostaglandine-productie, zou het zo kunnen zijn dat ook de productie en/of de functie van antitrombogene prostaglandines geremd is in deze vaten.

In het tweede deel van dit proefschrift hebben we ons gericht op mechanismen van NOS-activatie en productie van vasculair $\mathrm{NO}$ in het macrocirculatoire systeem.

De bevindingen in Hoofdtuk 3 hebben geleid tot het opstarten van een nieuw stuk onderzoek. Dit extra onderzoek was gericht op A-V verschillen op het gebied van NO-productie in de humane situatie. Het betrof een onderzoek naar de productie van NO en de aanwezigheid en lokalisatie van NO-producerende enzymen ("endothelial cell" [ec]-NOS en "inducible" [i]-NOS) in de wand van humane bloedvaten die gebruikt worden als omleidingsvaten tijdens coronaire bypass chirurgie (arterieel: arteria mammaria interna; veneus: vena saphena). Gebruik van arteria mammaria interna blijkt in de klinische praktijk succesvoller te zijn dan gebruik van vena saphena; een verschil in NO-productie en/of activiteit zou hieraan kunnen bijdragen. Endotheliaal NO remt proliferatie van gladde spiercellen, welke dan mogelijk het proces van intima verdikking inhibeert; intima proliferatie is een belangrijke oorzaak van late bypass occlusie. In Hoofdstuk 6 onderzochten we of de superieure "patency" van de arteria mammaria interna in humane coronaire bypass chirurgie vergeleken met die van de vena saphena kan worden verklaard door een verschil in NO-productie. Dit onderzoek wees uit dat de basale NO-productie in humane arteria mammaria interna segmenten $50 \%$ hoger was dan in humane SV segmenten. Vervolgens onderzochten we de invloed van VEGF op NO-productie in zowel arteria mammaria interna als vena saphena. VEGF verhoogde NO-productie ongeveer $50 \%$ in vena saphena en $100 \%$ in arteria mammaria. Gebaseerd op deze studie werd geconcludeerd dat endotheliaal constitutief NOS-afhankelijke NO-productie meer verhoogd wordt door VEGF in arteria mammaria interna dan in vena saphena. Verschillen in NO-productie tussen arteria mammaria interna en vena saphena worden niet veroorzaakt door een hogere vasculaire expressie van ec-NOS of iNOS; ec-NOS is in gelijke mate aanwezig in de endotheelcel-laag van arteria mammaria interna en vena saphena, terwijl in geen van beide vaten sprake is van i-NOS expressie. De eerder beschreven hogere VEGF-receptor densiteit $(K D R(F l k-1)$ en $F l t-1)$ in arteria mammaria interna dan in vena saphena kan de hogere VEGF-gestimuleerde NO-productie in deze arteriën verklaren. Samengevat blijkt uit deze resultaten dat hetzij de activiteit van het ec-NOS, hetzij de biologische beschikbaarheid van het geproduceerde NO verschilt tussen de twee typen bloedvaten, en dat dit verschil waarschijnlijk bijdraagt aan het verschil in succes bij gebruik van deze vaten tijdens coronaire bypass chirurgie. 
In veel cardiovasculaire ziekten is de capaciteit van het endogene L-arginine/NO systeem verminderd. Een voor de hand liggend doel van therapie lijkt dus dit systeem farmacologisch te stimuleren. Van één van de derde-generatie $\beta$-blokkers, nebivolol, is aangetoond dat het vasodilatatie veroorzaakt, welke mogelijk wordt gemedieerd door verhoogde NO-productie. In Hoofdstuk 7 wordt onderzocht of nebivolol inderdaad vasculaire NO-productie stimuleert. In vivo gemetaboliseerd nebivolol, maar niet nebivolol zelf, verhoogde inderdaad de NO-productie in de geisoleerde aorta van de muis. Vervolgens werd getracht inzicht te verwerven in het onderliggende mechanisme. Het fenomeen bleek afhankelijk van de aanwezigheid van endotheel. Endotheliaal $\beta 2$-adrenoceptor binding bleek erbij betrokken te zijn, met een daarop volgende stijging in endotheliaal vrij intracellulair $\mathrm{Ca}^{2+}$ en tevens ec-NOS-afhankelijke NO-productie. Tevens werd aangetoond dat selectieve farmacologische stimulatie van vasculaire $\beta 2$-receptoren met salbutamol resulteerde in een verhoging van NO-productie vergelijkbaar met die van gemetaboliseerd nebivolol. In overeenstemming met deze resultaten werd de aanwezigheid van endotheliale $\beta 2$-adrenoceptoren aangetoond; $\beta 1$-adrenoceptoren waren niet aanwezig op vasculair endotheel. Endotheliale NO-productie, gestimuleerd door endotheliale $\beta$-adrenerge receptor binding, zou goed een belangrijk mechanisme in de normale vasculaire fysiologie kunnen zijn. Daarom zou endotheliale $\beta$-adrenoceptor gemedieerde verhoging van endotheliale NO-productie zeer goed een additioneel therapeutisch doel kunnen vormen bij ziekten geassocieerd met "endotheliale dysfunctie", waarbij $\beta$-receptor gemedieerde NO-afhankelijke vasodilatatie behouden is gebleven.

Samenvattend kan worden gesteld dat de antitrombogene eigenschappen van endotheel zeer verschillend blijken te zijn in het arteriële en veneuze systeem. In arteriolen blijkt de afzonderlijke antitrombogene rol van prostaglandines uit het endotheel groter te zijn dan die van het endotheliale NO; het gezamenlijke effeet blijkt echter de som van beide effecten afzonderlijk duidelijk te overtreffen: er lijkt sprake te zijn van potentiëring van het antitrombogene prostaglandine-effect door NO. In venulen is dit niet het geval; hier is de antitrombogene rol van NO veruit het belangrijkst. Dit verschil in antitrombogene eigenschappen van endotheel blijkt ook zijn consequenties te hebben in pathologische condities, zoals hypercholesterolemie: de effecten hiervan zijn duidelijk groter in arteriolen dan in venulen. Het verhogen van de endotheliale NO-productie beschermt tegen de hypercholesterolemie-geïnduceerde trombo-embolische reactie, welke een bekende complicatie bij atheroselerose is. Al met al wijzen de functionele studies in dit proefschrift uit dat het van het grootste belang is, ook vanuit klinisch oogpunt, om (anti)trombogene eigenschappen van endotheel ook in vivo te onderzoeken, om zodoende inzicht te verwerven in de hoge mate van heterogeniteit die er in dit opzicht bestaat. Tussen grote, humane arteriën en venen blijken ook verschillen te bestaan in mate van NO-productie en/of -beschikbaarheid; een 
dergelijk verschil kan medeverantwoordelijk zijn voor verschillen in succes-kans wanneer dergelijke vaten worden gebruikt voor coronaire bypass chirurgie. Selectieve $\beta 2$-adrenerge receptorof VEGF-gemedieerde verhoging van endotheliale NO-productie zou goed een additioneel therapeutisch doel kunnen worden in ziekten geassocieerd met "endotheliale dysfunctie". 


\section{Abbreviations}

5-HT 5-hydroxytryptamine; serotonin

12-HETE 12-hydroxyeicosatetraenoic acid

12-HPETE 12-hydroperoxyeicosatetraenoic acid

13-HODE 13-hydroxyoctadecadienoic acid

15-HPAA 15-hydroperoxy arachidonic acid

$\left[\mathrm{Ca}^{2+}\right]_{\mathrm{i}} \quad$ intracellular $\mathrm{Ca}^{2+}$ concentration

[NO] NO concentration

ACE angiotensin-converting enzyme

ADMA asymmetrical dimethylarginine

ADP adenosine diphosphate

AMP adenosine 3',5'-monophosphate

ANOVA analysis of variance

ARG arginine

ASA

acetylsalicylic acid; aspirin

ATP adenosine triphosphate

$\mathrm{BH}_{4} \quad$ tetrahydrobiopterin

bpm beats per minute

BSA bovine serum albumin

c

cyclic

CBB

Coomassie Brilliant Blue

CON control

COX cyclooxygenase

DAB 3,3'-diaminobenzide

ec endothelial cell

EDRF endothelium-derived relaxing factor

EDTA ethylene diamine tetraacetic acid

EDHF endothelium-derived hyperpolarizing factor

EPT production time of embolus

ET-1 endothelin-1

FAD flavin adenine dinucleotide

FMN flavin mononucleotide

Fing fibrinogen

f factor $\mathrm{V}$

GMP guanosine 3',5'-monophosphate 


\begin{tabular}{|c|c|}
\hline GSH-Px & glutathione peroxidase \\
\hline GSNO & $S$-nitrosoglutathione \\
\hline GTP & magnesium guanosine 5'-triphosphate \\
\hline $\mathrm{HC}$ & high cholesterol \\
\hline HDL & high-density lipoprotein \\
\hline HMG-CoA & 3-hydroxy-3-methylglutaryl coenzyme A \\
\hline $\mathrm{H}_{2} \mathrm{O}_{2}$ & hydrogen peroxide \\
\hline HR & heart rate \\
\hline i & inducible \\
\hline IBT & initial bleeding time \\
\hline IL-1 & interleukin-1 \\
\hline im & intramuscular \\
\hline $\mathrm{IP}_{3}$ & inositol-triphosphate \\
\hline iv & intravenous \\
\hline L-NA & $N^{G}$-nitro-L-arginine \\
\hline L-NAME & $N^{\mathrm{G}}$-nitro-L-arginine methyl ester \\
\hline L-NMMA & $N^{G}$-monomethyl-1-arginine \\
\hline LDL & low-density lipoprotein \\
\hline LPS & lipopolysaccharide \\
\hline MAP & mean arterial blood pressure \\
\hline MEPT & median embolus production time \\
\hline MMP & matrix metalloproteinase \\
\hline MRBCV & mean red blood cell velocity \\
\hline $\mathbf{n}$ & neural \\
\hline NADPH & nicotinamide adenine dinucleotide phosphate \\
\hline NANC & nonadrenergic noncholinergic \\
\hline NC & normal chow \\
\hline NO & nitric oxide \\
\hline $\mathrm{NO}_{2}^{-}$ & nitrite \\
\hline $\mathrm{NO}_{3}^{-}$ & nitrate \\
\hline NOS & nitric oxide synthase \\
\hline $\mathrm{O}_{2}$ & superoxide anion \\
\hline $\mathrm{OH}$ & hydroxyl radical \\
\hline $\mathrm{ONOO}^{-}$ & peroxynitrite \\
\hline OR & occurrence of rebleedings \\
\hline ox & oxidized \\
\hline
\end{tabular}




\begin{tabular}{|c|c|}
\hline PAF & platelet-activating factor \\
\hline PAI-1 & plasminogen activator inhibitor type 1 \\
\hline PBS & phosphate-buffered saline \\
\hline PDGF & platelet-derived growth factor \\
\hline PF4 & platelet factor 4 \\
\hline PG & prostaglandin \\
\hline $\mathrm{PGI}_{2}$ & prostaglandin endoperoxide $\mathrm{I}_{2}$; prostacyelin \\
\hline PKC & protein kinase $\mathrm{C}$ \\
\hline PRMT & protein arginine $\mathbf{N}$-methyltransferase \\
\hline PS & phosphatidylserine \\
\hline ROS & reactive oxygen species \\
\hline rpm & rotations per minute \\
\hline RTH & relative thrombus height \\
\hline SA & surface area \\
\hline sGC & soluble guanylate cyclase \\
\hline SMC & smooth muscle cell \\
\hline SNP & sodium nitroprusside \\
\hline TAFI & thrombin activatable fibrinolysis inhibitor \\
\hline TBS & tris-HCI buffered saline \\
\hline TF & tissue factor; thromboplastin \\
\hline TFPI & tissue factor pathway inhibitor \\
\hline TM & thrombomodulin \\
\hline TNF $-\alpha$ & tumor necrosis factor- $\alpha$ \\
\hline t-PA & tissue-type plasminogen activator \\
\hline Tsp & thrombospondin \\
\hline TX & thromboxane \\
\hline U & reduced velocity; mean red blood cell velocity/vessel diameter \\
\hline $\mathbf{u}-\mathbf{P A}$ & urokinase-type plasminogen activator \\
\hline VASP & vasodilator-stimulated phosphoprotein \\
\hline VEGF & vascular endothelial growth factor \\
\hline$v W f$ & von Willebrand factor \\
\hline
\end{tabular}


"De dagen waarin wij enorm nieuwsgierig zijn geweest behoren tot onze gelukkigste dagen." Deze stelling 7 van dit proefschrift is geïnspireerd op mijn herinnering aan de jaren op het lab Microcirculatie. Mirjam, Geert Jan en Rob. Een beter promotieteam had ik me niet kunnen wensen. Mirjam, jij was er altijd als ik weer een stuk had geschreven. "Heel goed" was vaak je commentaar. Met oog voor detail was jij de ideale, betrokken copromotor. Met het voortschrijden van de jaren bleef Rob op geduldige, inspirerende en kundige wijze mijn onderzoek en opleiding tot onderzoeker steunen. Geert Jan, bij jou vond ik een enthousiast en gewillig oor voor weer een nieuw idee of project. Sabrina, wat was het heerlijk om met je samen te werken. Een ware "moeder Theresa" voor het lab Microcirculatie. Van Dick leerde ik het motto van de biofysicus: "meten is weten". Tijdens het zwangerschapsverlof van Mirjam kreeg het onderzoek een andere wending met Rien van der Zee, Eric van Breda en Pieter Doevendans. Van jullie heb ik veel geleerd en het was goed om met jullie samen te werken. Erik van Gorsel, jij was een enthousiaste en toegewijde student-assistent. Bedankt voor je hulp en veel succes met de laatste loodjes van je studie.

Verstoken van Nederlanders en genietend van de Engelse cultuur was ik aangenaam verrast bij de verwachtte komst van een Maastrichtse dokter. De duisternis was gevallen op die rustige lenteavond in Exeter (Engeland). Een snerpend geluid drong mijn kamer binnen in de zustersflat van het ziekenhuis. Heuveltje af trachtte een wat nerveus ogende man zich niet te laten inhalen door zijn iets te grote Samsonite koffer met aanlopende wieltjes. Hij keek zoekend om zich heen. Toen wist ik het zeker, dit moet de Nederlander zijn. "Harrie Kurvers?" vroeg ik. "Joah" antwoordde hij met een Limburgse tongval. Die week in Exeter (1991) zal ik niet snel vergeten. "Never a dull moment" is op jou zeer zeker van toepassing. Van jou hoorde ik over de mogelijkheid tot combineren van promotieonderzoek en coschappen. Het lab Microcirculatie was jouw aanrader. Tijdens mijn AIO-jaren heb ik genoten van jou en Leo Hofstra. Jullie humor met een scherp randje ("Je mag me best terug pakken hoor, anders is het niet leuk") wierp een ander licht op onderzoek doen. Je wervelende aanwezigheid was inspirerend en stimulerend.

Ellen Rouwet (lees "Pirouwette")! Inzichten zijn vaak voortschrijdend. Zo ook onze vriendschap. Haalde jij eerst lunch voor grote baas Harrie. Toen Harrie weg was en voor zichzelf begon was ik degene die zich liet verrassen met een lunch. Ik heb hele goede herinneringen aan onze (weekend)experimenten op het lab. Ik achter het gordijn en jij bij je couveuse druk met een kippenei. Lief en leed heb ik met je gedeeld. Het doet me goed te horen dat je nu zelfs de verschillende stromingen in popmuziek weet te benoemen en je nu de verdiende erkenning krijgt voor je onderzoek. Bedankt voor alles Ellen! Je wordt een goede chirurg en ik wens je heel veel geluk met je onderzoek en Andrei.

Roland Beuk, nadenkend over tijdsbesteding tijdens werkreis naar Nieuw-Zeeland: "En lukt het niet literatuur te downloaden van internet dan ga ik toch gewoon lekker zeilen." Je was

\section{Dankwoord}


een sfeerverhogende factor op het lab. "Koffie in de kleur van de broek" was jouw devies. Heel veel geluk met Helena en jullie zoon Ewout.

Selma Tromp. Kamergenoot en deelgenoot van haast overlappend onderzoek. Ik telde emboli en jij leukocyten. "Keep 'm rolling Selma!" Veel geluk en sucees in de Neurologie.

Ewout Eenhoorn en Peter Danse bij een partij tennis: "Nee, Martijn je kan wel willen dat die bal in is, maar uit is uit." Vergelijkbare discussies deden zich voor over "aan" en "uit". Maar ja we hadden het over tennis, "in dier voeghe". Heel veel geluk samen met Fleur en Marijke en hoop snel weer eens met jullie een balletje te gaan slaan of anderszins.

In mijn Maastrichtse jaren speelden vele anderen een belangrijke en vaak beslissende rol. Wat was het heerlijk dat mijn lieve zusje Lisanne hier studeerde. Ik genoot van onze etentjes en denk graag terug aan jouw interesse voor mijn onderzoek en andere beslommeringen. Bedankt Lisanne! Je hebt samen met Ivo je geluk gevonden en ik wens jullie heel veel succes en geluk.

Leden van Sogart Experiat (Maastrichtse studentenvereniging Tragos). Ondanks een Mallot vinger ( $t j a$, Economen blijven toch op de cent hè Roel) en dankzij vele boomklimacties is het dan eindelijk zo ver. Wie is de volgende SE-er? Het vuur zal blijven branden!

Xander Wehrens, de Griekse Salsa koning. In de Kadans, als huisgenoot op de Heerderweg en in de Copa Cabana in NYC hebben wij ons goed vermaakt. Wehrens kerel, zet 'm op! De wereld ligt aan je voeten.

En dan door hen, voor hen en met hen... papa en mama! Jullie liefde en aanhoudende interesse en stimulans heeft dit alles mogelijk gemaakt. Heel veel gezondheid en geluk samen!

"The ultimate goal in modern medicine should be not to add years to life, but life to years." Laat stelling 9 van dit proefsehrift jullie leiden door het leven. Ik wens jullie en iedereen die in mijn gedachte is heel veel succes en geluk. 


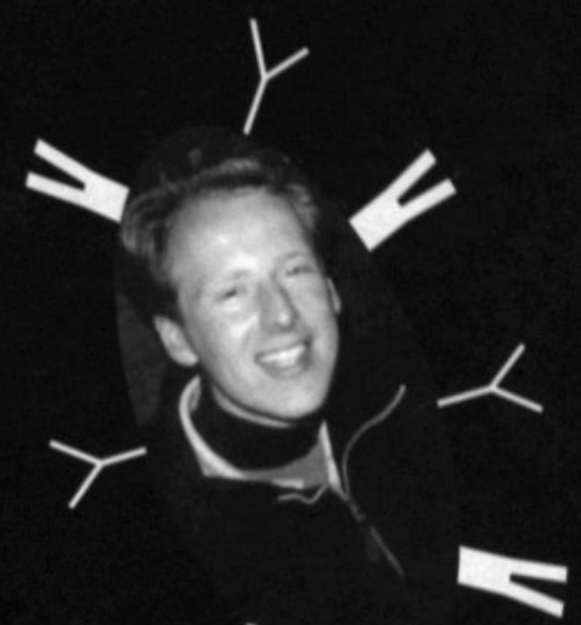

Curriculum vitae

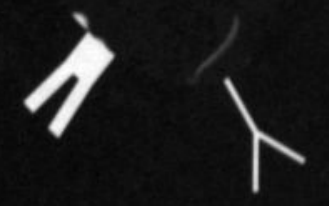


14 september 1970

1983-1989

1989-1993

1992

1992-1993

1993-1999

1999

2000-2001

2002

Curriculum vitae
Atheneum B, Mencia de Mendoza Lyceum, Breda

Doctoraal Geneeskunde, Universiteit Maastricht

Wetenschapsstage en Klinische stage Interne Geneeskunde, dept. of Internal Medicine, Exeter University, United Kingdom

Student-assistent, afdeling Cardiologie, Academisch Ziekenhuis Maastricht

A.I.O, vakgroep Fysiologie en Cardiovascular Research Institute Maastricht (C.A.R.I.M.), Faculteit der Geneeskunde, Universiteit Maastricht; coschappen

Artsexamen

Arts-assistent Cardiologie, Academisch Ziekenhuis Maastricht

Start opleiding Cardiologie, Leids Universitair Medisch Centrum; vooropleiding Interne Geneeskunde, Rijnland Ziekenhuis, Leiderdorp 
Publications

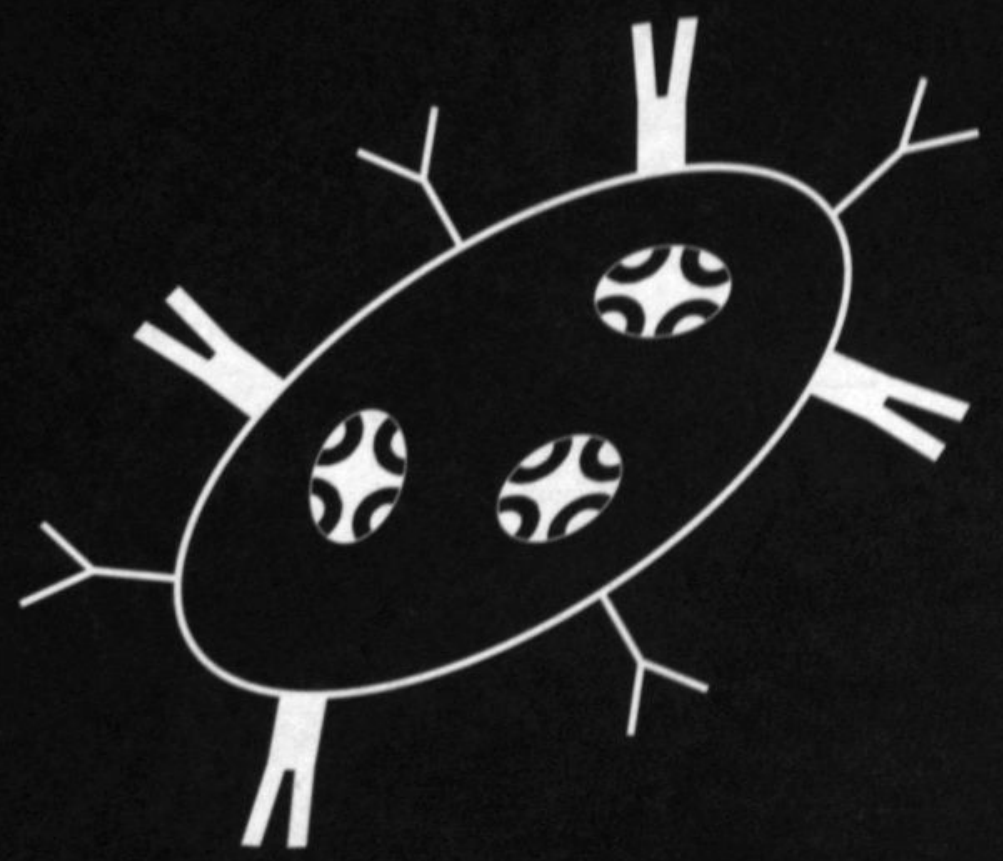


Taylor RS, Chidley K, Goodwin J, Broeders MAW, Kirby BJ. Accutracker II (version 30/23) ambulatory blood pressure monitor: clinical validation using the British Hypertension Society and Association for the Advancement of Medical Instrumentation standards. Journal of Hypertension. 1993;11(11):1275-1282.

Broeders MAW, Tangelder GJ, Slaaf DW, Reneman RS, oude Egbrink MGA. Endogenous nitric oxide protects against thromboembolism in venules but not in arterioles. Arteriosclerosis Thrombosis and Vascular Biology. 1998;18:139-145.

Broeders MAW, Doevendans PA, Bekkers BCAM, Bronsaer R, van Gorsel E, Heemskerk JWM, oude Egbrink MGA, van Breda E, Reneman RS, van der Zee R. Nebivolol: a third generation beta-blocker that augments vascular nitric oxide release. Endothelial $\beta 2$-adrenoceptor mediated nitric oxide production. Circulation. 2000;102(6):677-684.

Broeders MAW, Tangelder GJ, Slaaf DW, Reneman RS, oude Egbrink MGA. Endogenous nitric oxide and prostaglandins synergistically counteract thromboembolism in arterioles but not in venules. Arteriosclerosis Thrombosis and Vascular Biology. 2001; 21(1):163-169.

Broeders MAW, Doevendans PA, Maessen JG, van Gorsel E, oude Egbrink MGA, Daemen MJAP, Tangelder GJ, Reneman RS, van der Zee R. The human internal mammary artery releases more nitric oxide in response to vaseular endothelial growth factor (VEGF) than the human saphenous vein. Journal of Thoracic and Cardiovascular Surgery. 2001;122(2):305-309.

Broeders MAW, Tangelder GJ, Slaaf DW, Reneman RS, oude Egbrink MGA. Hypercholesterolemia enhances thromboembolism in arterioles but not in venules; complete reversal by L-arginine. Arteriosclerosis Thrombosis and Vascular Biology. 2002;220(4): 680-685.

oude Egbrink MGA, van Gestel MA, Broeders MAW, Slaaf DW, Reneman RS, Heemskerk JWM, Tangelder GJ. Platelet-vessel wall interactions in vivo: stimulation and inhibition. In: The Microcirculation and Vascular Biology. 22nd Meeting of the European Society for Microcirculation, edited by Tooke J, Shore A and Whatmore J. Monduzzi Editore, Bologna, 2002, pp 293-298.

Broeders MAW, Tangelder GJ, Reneman RS, oude Egbrink MGA. Endothelial nitric oxide as antithrombotic agent. Differences between the arterial and venous system. In preparation. 


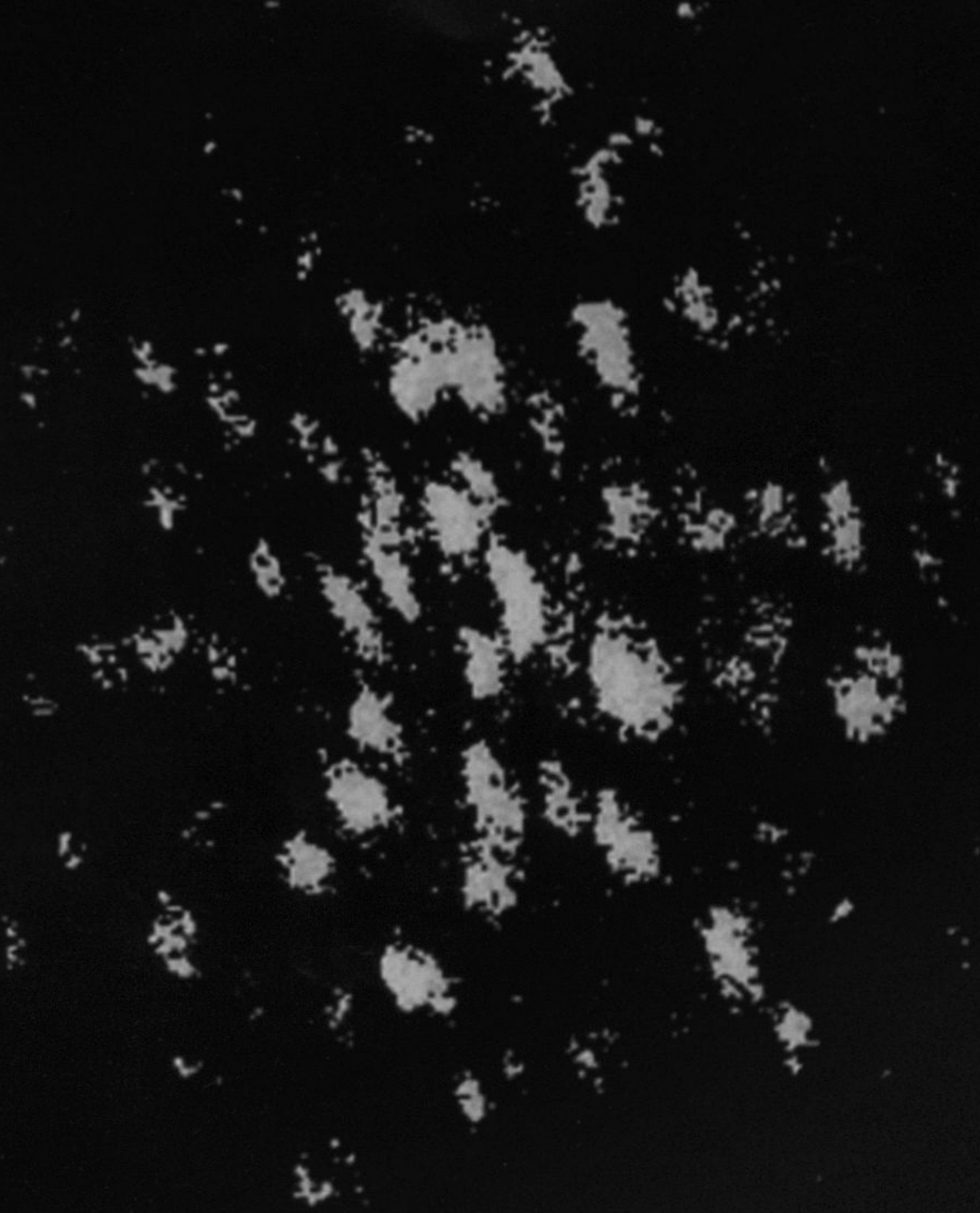


Production

\section{and}

Function

of

Endothelial

Nitric

$0 x i d e$

in

the

Arterial

and

Venous

System 